University of Louisville

ThinkIR: The University of Louisville's Institutional Repository

8-2012

\title{
A holistic examination of the impact of child maltreatment on child behavioral outcomes : a longitudinal multilevel analysis.
}

April L. Murphy

University of Louisville

Follow this and additional works at: https://ir.library.louisville.edu/etd

\section{Recommended Citation}

Murphy, April L., "A holistic examination of the impact of child maltreatment on child behavioral outcomes : a longitudinal multilevel analysis." (2012). Electronic Theses and Dissertations. Paper 1029.

https://doi.org/10.18297/etd/1029

This Doctoral Dissertation is brought to you for free and open access by ThinkIR: The University of Louisville's Institutional Repository. It has been accepted for inclusion in Electronic Theses and Dissertations by an authorized administrator of ThinkIR: The University of Louisville's Institutional Repository. This title appears here courtesy of the author, who has retained all other copyrights. For more information, please contact thinkir@louisville.edu. 


\title{
A HOLISTIC EXAMINATION OF THE IMPACT OF CHILD MALTREATMENT ON CHILD BEHAVIORAL OUTCOMES: A LONGITUDINAL MULTILEVEL
}

\section{ANALYSIS}

\section{By}

April L. Murphy

B.S., University of Louisville, 2003

MSW, Florida State University, 2007

\author{
A Dissertation \\ Submitted to the Faculty of the \\ Raymond A. Kent School of Social Work of the University of Louisville \\ in Partial Fulfillment of the Requirements \\ for the degree of
}

Doctor of Philosophy

\author{
Kent School of Social Work \\ University of Louisville \\ Louisville, Kentucky
}

August 2012 
Copyright 2012 by April L. Murphy

All rights reserved 


\section{By}

April L. Murphy

B.S., University of Louisville, 2003

MSW, Florida State University, 2007

A Dissertation Approved on

July 18,2012

by the following Dissertation Committee:

\begin{tabular}{c}
\hline Annatjie C. Faul, PhD, Chair \\
\hline Anita Barbee, $\mathrm{PhD}$ \\
\hline Crystal C. Collins-Camargo, PhD \\
\hline Pamela A. Yankelelov, PhD \\
Chris Flaherty/PhD
\end{tabular}




\section{DEDICATION}

This dissertation is dedicated to my parents,

Mike and Linda Murphy.

Dad, I just wish you could have

been here to share in this achievement. 


\section{ACKNOWLEDGEMENTS}

I would like to thank my dissertation committee for their support and commitment to reading this dissertation over and over again to ensure that the most proficient product was created. Each one of them provided a different set of expertise that helped this dissertation become what is presented in the following pages. It was an honor and a privilege to work with these extraordinary individuals. I will be forever grateful and will never forget the hours they put in to help me grow as a social worker, a researcher, a teacher, and a person.

There are not enough words to express the gratitude Dr. Annatjie Faul, my chair and mentor, deserves. Since my first week in the doctoral program at the Kent School of Social Work, I knew that I wanted to work with this extraordinarily intelligent individual. It did not take her long to take me under her wing and challenge me to be better than I even thought was possible. Her confidence in my ability and her constant cheering me on when I wanted to give up made this dissertation possible. While there are many individuals who are intelligent and committed to students, not all of them do so with humility and selflessness. Dr. Faul has willed me through the doctoral program and through the dissertation process and has been the cornerstone upon which I will finish. Dr. Faul is the type of person that will have a ripple effect on everyone that she encounters and the numerous students that she has and will continue to mentor. 
Dr. Crystal Collins-Camargo has also been a champion in my corner, offering support, advice, and guidance throughout my journey in the doctoral program. She has graciously allowed me to work with her since I started the doctoral program. Her experience in and passion for child welfare has been an inspiration. Dr. Collins-Camargo has a keen sense of child welfare policy and has been an invaluable asset to my growth as a social worker and scholar.

Dr. Anita Barbee's expertise in child welfare has proven to be an instrumental asset to this dissertation. Dr. Barbee has had decades of experience practicing in child welfare. Her guidance and feedback, especially in the Theory section of this dissertation, was extremely helpful and appreciated.

Dr. Pam Yankeelov has offered invaluable support throughout my doctoral studies, particularly in the teaching arena. Dr. Yankeelov is a statistical genius and a hilarious individual. She has offered her wisdom, both professionally and personally. I have thoroughly enjoyed working with Dr. Yankeelov over the course of my doctoral studies and through this dissertation adventure.

I have not had the opportunity to get to know Dr. Chris Flaherty like I have the other dissertation committee members. However, he has spent hours reviewing and offering feedback in order to help the finished product be the best that it could be. In the few conversations that I have had with Dr. Flaherty, it is apparent that he has a passion for child welfare and an amazing sense of humor. I can only hope to work with him in the future and continue to gain from his wisdom. 
Outside of the fabulous five that made up my dissertation committee, there were countless other faculty and staff who have helped me reach this pivotal point in my career. Dr. Seana Golder has always had an open door when I needed to talk or process anything, whether academic or personally. She has passed on wisdom related to academia and given me guidance and support along the way. Dr. Golder has also helped me be a better teacher in the classroom, which hopefully will reach a number of future social workers. Dr. Riaan van Zyl is probably one of the most intelligent men that I have ever met, but is yet so humble. He has spent a number of hours helping me complete a project outside of this dissertation. Dr. van Zyl challenged me and encouraged me to think and reassured me that it was ok to express my ideas. Norma Kyriss has been both an encouragement and a comic relief in the most stressful situations. She is a wonderful woman and I will never forget the random conversations we had on those Friday mornings during ARDA. Without Debra Evans, I would have never been able to do those wonderful presentations throughout my doctoral studies. She has always been willing to hook up whatever technology I needed, even if I forgot and she had to do it last minute. She has an incredible sense of humor and always makes people laugh. I also want to acknowledge three (3) doctoral students who have provided support and encouragement along the way: Shawnise Miller, Laneshia McCord, and Regardt "Reggie" Ferreira. I wish you all the best as you finish up your dissertations! My colleagues at work, Dr. Jeff Beaty, Dana Patrick, and Jennifer Scharfenberger, have been an enormous support during this journey. When I 
was afraid of taking a position as I was finishing up my dissertation, they assured me that they would give me the time I needed to make that happen. They lived up to that promise and without the time at work to finish this up and attend meetings, this day would not have happened in July. I am grateful to work with a group of great individuals.

I would not have been able to complete this dissertation without work put in by the individuals who originally collected all of the data utilized in this dissertation. The team was comprised of individuals at the Research Triangle Institute (RTI), the University of North Carolina at Chapel Hill (UNC), Caliber Associates (Caliber), the University of California at Berkeley (UCB), and the Child and Adolescent Services Research Center at San Diego Children's Hospital. Thank you for your dedication and countless hours it had to have taken to put together such a comprehensive database.

Last, but not least, my family has been the rock upon which I base my successful completion of this dissertation. My dad, before he passed away almost six years ago, always told me that I could do whatever I wanted. I like to think that he is looking down on me smiling, knowing that I could not have done this without his stubbornness that he definitely passed on to me. My mom, who had to deal with my craziness almost daily, has been an invaluable support. While her words of encouragement were not always welcomed by me when I was upset, they lifted me up and gave me the strength and the will to finish. I love you so much and I just wish that I could give you all that you deserve. You are the strongest woman I know and the most gracious. Thank you so much for 
those weekend movies and hilarious evenings. To my sister, Shelly Wyman, thank you for being the first one in the family to go to college. You were an inspiration to me and I always looked up to you (and now I can't deny it because it's in print). You are a bright woman who has raised amazing children who I am proud to call my nieces and nephew. Speaking of them, Braden, Brevin, and Brenna, I hope you have the courage to be what you want to be and go after your dreams. You are all bright, athletic children that I know are going to accomplish great things in this world and leave it a better place for your own children one day. Braden, you have courage and integrity unmatched by any 16 year old boy that I have ever met. I am so proud of you and love you like the son I will never have. To my partner, Misty, thank you for putting up with me leaving every weekend to get this finished and providing the support needed to accomplish my dream. I am not sure what gives you the strength to get through every day with me with a smile on your face, but I thank you. 


\begin{abstract}
A HOLISTIC EXAMINATION OF THE IMPACT OF

CHILD MALTREATMENT ON CHILD BEHAVIORAL OUTCOMES:
\end{abstract}

A LONGITUDINAL MULTILEVEL ANALYSIS

April L. Murphy

July 18,2012

Child maltreatment touches almost 700,000 children annually. The effects of child maltreatment range from micro-level consequences, such as behavior problems and mental health issues, to mezzo-level consequences, such as increased child welfare worker caseloads and overcrowding residential facilities, to macro-level consequences, such as increased costs and policy implications. Data from the National Survey of Child and Adolescent Well-Being (NSCAW) were analyzed to examine the factors that impact child behavior in children who have been reported to child protective services (CPS) as a result of child maltreatment. The model investigated the influence of child, caregiver, and environmental factors on child behavior problems over six years among a nationally representative sample of children age 2-18.

Methods: A longitudinal multivariate multilevel model was estimated utilizing MLwiN with a three-level nested structure. The model examined individual differences in 4,997 child behavior problems over six years, testing 
both time-variant and time-invariant predictors measured during four time periods.

Results: Following the estimation of six multivariate multilevel models, results indicated several statistically significant predictors at the child level (i.e., gender, race, age, social skills, maltreatment type, exposure to violence, physical and cognitive health), caregiver level (i.e., age, education, marital status, number of children in the home, number of changes in caregivers, permanent caregiver, physical health, domestic violence, social support, and perception of neighborhood), and environmental-level (i.e., percentage of single parents, access to social services, percentage of white population) on at least one of the dependent variables. Additionally, interaction effects were tested and a few proved to be statistically significant predictors of child behavior problems as well.

Conclusions: Children differ in terms of how they respond to maltreatment and other life events or situations. It is imperative that interventions be individualized to target specific issues and reduce specific behavior problems. Results indicated that improving child social skills and increasing caregiver social support may be key in reducing child behavior problems. Both practice and policy implications are discussed as well as recommendations for future research. 
TABLE OF CONTENTS

PAGE

DEDICATION

ACKNOWLEDGEMENTS $\ldots \ldots \ldots$

ABSTRACT

LIST OF TABLES

LIST OF FIGURES $\ldots$

CHAPTER I: Introduction to the Problem .............................................................

Problem Description

Child Maltreatment Defined

Child Maltreatment as a Social Problem …………….............................. 4

Risk Factors for Child Maltreatment

Consequences of Child Maltreatment

Summary

CHAPTER II: Literature Review

Psychosocial Development Theory ………………………………………….. 52

The Stages Defined

An Application of Erikson's Theory

Psychosocial Development Theory and Child Maltreatment...........60

Attachment Theory

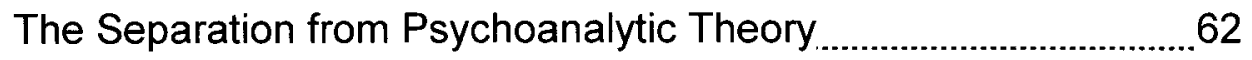

Bowlby's Attachment Theory ..............................................................6 63 
Mary Ainsworth and Attachment Styles

Attachment Theory and Child Maltreatment _.................................... 70

Ecological Systems Theory

Development from Bronfenbrenner's perspective .............................. 76

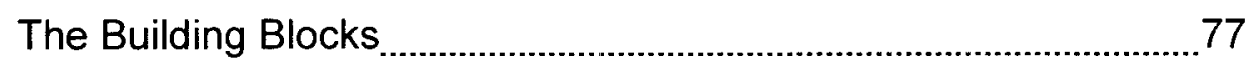

The Model Described ....................................................................... 78

Ecological Systems Theory and Child Maltreatment _......................... 82

Proposed Conceptual Model

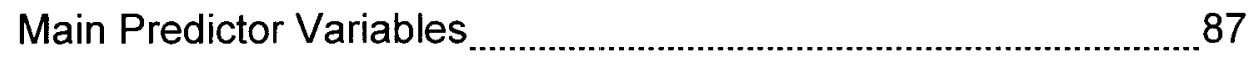

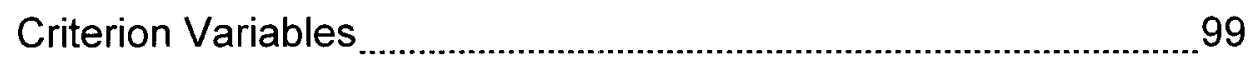

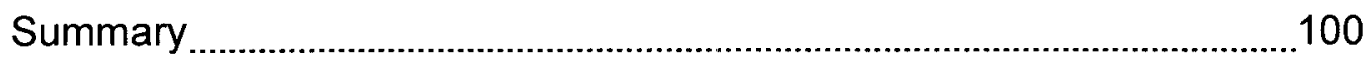

CHAPTER III: Methodology

Research Goal and Hypotheses

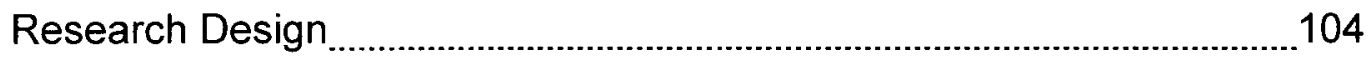

Data Source

Sampling

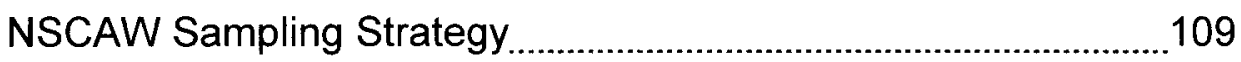

Study Sampling Strategy

Power

Operationalization of Variables ...................................................................... 115

Main Predictor Variables ..................................................................... 115

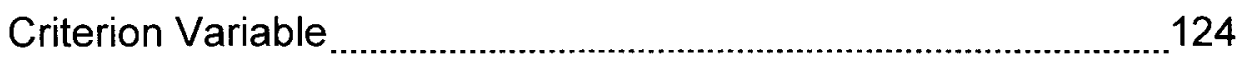

Analysis Plan $\ldots \ldots \ldots \ldots$ 


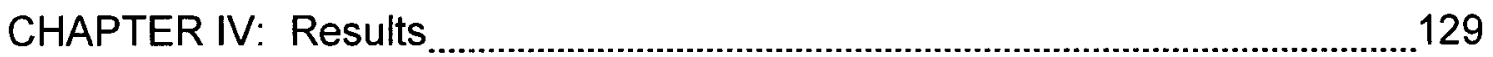

Data Preparation and Preliminary Analysis _............................................... 129

Retrieving and Merging Data

Creating the Person-Period Data File ...............................................130

Data Screening

Collinearity Diagnostics …….............................................................. 133

Description of the Sample

Child-level Predictors _............................................................................. 134

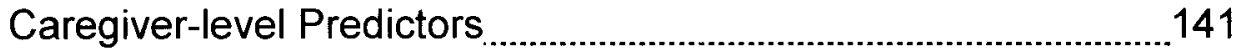

Environmental-level Predictors .............................................................150

Criterion Variables ............................................................................. 151

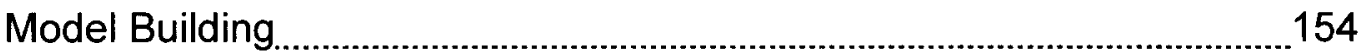

Assessing the Need for the Multilevel Model .................................... 154

Unconditional Model

Unconditional Growth Model................................................................ 172

Conditional Growth Model

Summary

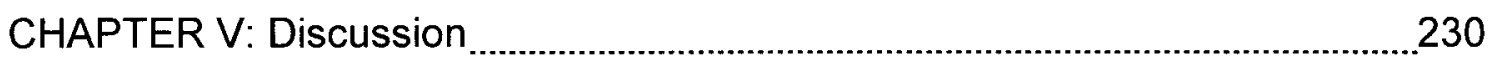

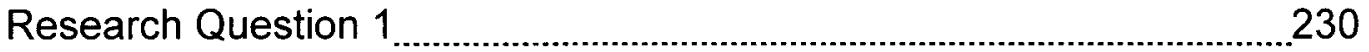

Research Question 2

Child-level Significant Predictors _.......................................................232

Caregiver-level Significant Predictors _................................................. 237

Environmental-level Significant Predictors _.......................................241 
Significant Interaction Effects.

Implications

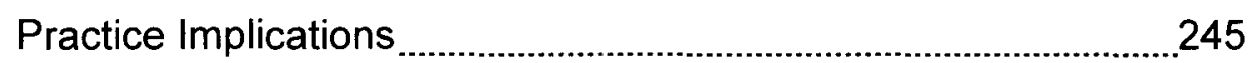

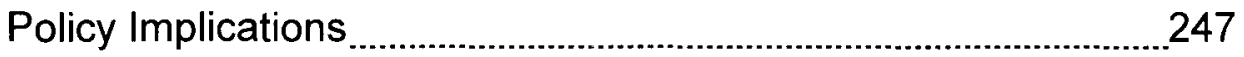

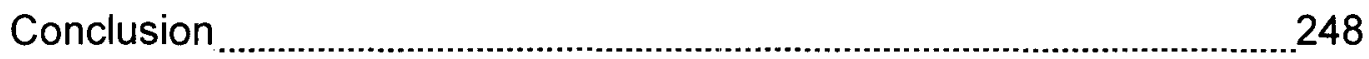

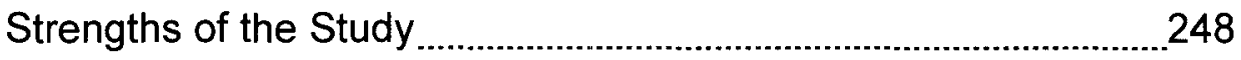

Limitations of the Study ......................................................................249

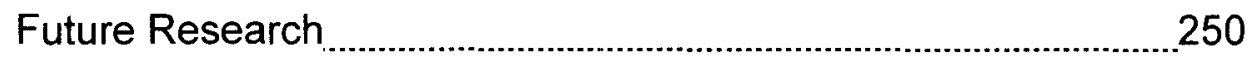

Summary

REFERENCES

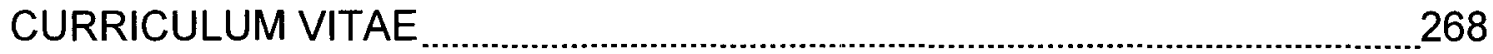




\section{LIST OF TABLES}

TABLE

PAGE

1. Summary of Child Risk Factors for Child Maltreatment by Type 10

2. Summary of Parent/Caregiver Risk Factors for Child Maltreatment by

Type 21

3. Summary of Family Risk Factors for Child Maltreatment by Type. 27

4. Summary of Environmental Risk Factors for Child Maltreatment by Type 33

5. Hypothetical Life Course Using Psychosocial Development Theory 58

6. Timeline of NSCAW data collection (taken from manual) 110

7. The Eight Within-PSU Sampling Domains for the NSCAW CPS Sample (taken from manual)

8. Main Predictor Variables (Level-1, Level-2, Level-3) 116

9. Criterion Variables (Level-1)

10. Missingness on Dependent Variables by Wave.

11. Sample Size per Wave with Complete Data on the Dependent Variables ..134

12. Child-level Demographic Characteristics 135

13. Child-level Development Predictors 136

14. Child-level Maltreatment Predictors

15. Child-level Health Predictors 140

16. Caregiver-level Demographic Characteristics

17. Caregiver-level Family Structure Predictors. 145 
18. Caregiver-level Other Factors Predictors

19. Environmental-level Predictors

20. Internalizing, Externalizing, and Total T-Scores by Category.

21. Summary Statistics for Criterion Variables

22. Unconditional Model 168

23. Unconditional Growth Model

24. Conditional Growth Model with Child Main Effects Only.

25. Conditional Growth Model with Child and Caregiver Main Effects

26. Conditional Growth Model with Child, Caregiver, and Environmental Main Effects

27. Conditional Growth Model with Child, Caregiver, and Environmental Main Effects and Interaction Effects

28. Summary table of Significant Predictors of Child Behavior Problems 227 


\section{LIST OF FIGURES}

FIGURE PAGE

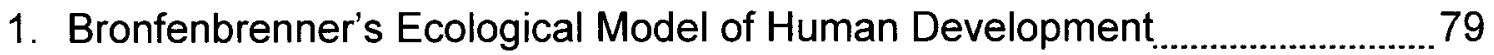

2. Proposed conceptual model

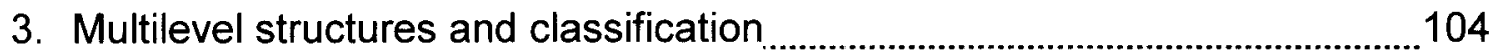

4. Flowchart of sampling process

5. Collected growth trajectories for all children in sample

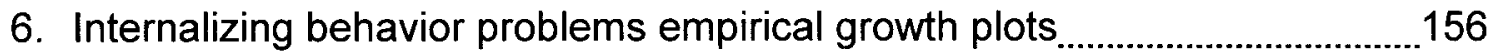

7. Externalizing behavior problems empirical growth plots

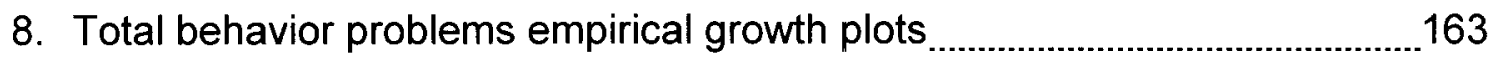

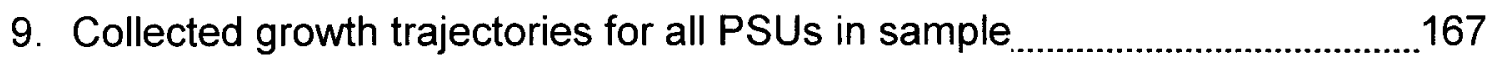

10. Ranked residuals for PSUs, unconditional model ............................................171

11. Ranked residuals for children/caregivers, unconditional model .....................172

12. Child behavior problems over time ..................................................................... 176

13. Child behavior problems over time with child main effects ............................181

14. Child behavior problems over time with child and caregiver main effects.... 187

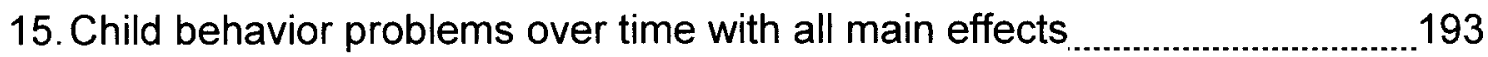

16. Child behavior problems over time with all main and interaction effects ..... 199

17. Child gender main effect on child behavior problems

18. Child race/ethnicity main effect on child behavior problems _..........................201

19. Child age main effect on child behavior problems ..........................................202 
20. Child social skills main effect on child behavior problems 203

21. Child maltreatment main effect on child behavior problems 204

22. Child exposure to violence main effect on child behavior problems 205

23. Child physical disability main effect on child behavior problems 206

24. Child physical health effect on child behavior problems 207

25. Child cognitive disability main effect on child behavior problems 208

26. Child cognitive health main effect on child behavior problems. 209

27. Caregiver age main effect on child behavior problems 210

28. Caregiver education main effect on child behavior problems 211

29. Caregiver marital status main effect on child behavior problems. 212

30. Number of children in household main effect on child behavior problems...213

31. Number of changes in caregiver main effect on child behavior problems $\ldots .214$

32. Permanent caregiver main effect on child behavior problems 215

33. Caregiver physical health main effect on child behavior problems 216

34. Caregiver domestic violence main effect on child behavior problems 217

35. Caregiver social support main effect on child behavior problems 218 36. Caregiver perception of neighborhood main effect on child behavior problems 219

37. PSU percentage of white people main effect on child behavior problems ...220

38. PSU percentage of single parents main effect on child behavior problems 221

39. PSU access to social services per capita main effect on child behavior problems 222 
40. Interaction effect of PSU percentage of single parents and maltreatment type on child externalizing behavior problems.

41. Interaction effect of PSU access to health services per capita and maltreatment type on child externalizing behavior problems

42. Interaction effect of PSU access to health services per capita and PSU percentage of Caucasians on child internalizing behavior problems 225

43. Interaction effect of PSU access to health services per capita and PSU percentage of Caucasians on child externalizing behavior problems 226

44. Interaction effect of PSU access to health services per capita and PSU percentage of Caucasians on child total behavior problems 226 


\section{CHAPTER I: INTRODUCTION TO THE PROBLEM}

Safety and security don't just happen, they are the result of collective consensus and public investment. We owe our children, the most vulnerable citizens in our society, a life free of violence and fear. - Nelson Mandela

Over 690,000 children were known to be maltreated and over 1,600 died as a result of maltreatment in 2009 , with a majority ( $80.8 \%$ ) of those deaths occurring before the age of 4 (U.S. Department of Health and Human Services, 2010). While reported estimates are beginning to decline, the rate of mortality continues to increase. Given that children are the future and a defenseless population, it is imperative that individuals step up to protect their innocence and their lives. In order to protect our children and minimize the behavioral problems that subsequently result from maltreatment, it is imperative that risk factors for both maltreatment and negative behavior be identified. Identification of risk factors for child maltreatment will allow for primary and preventative interventions to be developed while the identification of risk factor for child behavior problems resulting from maltreatment will allow for secondary interventions to be developed. The development of these secondary interventions will minimize the detrimental and potentially lifelong consequences of child maltreatment.

Admittedly, child maltreatment is an area that has been explored for decades. However, an examination of empirical evidence demonstrates there is 
an existing gap. Most of the past and current research examines child maltreatment from one perspective or dimension. Research highlights either child factors or family factors or environmental factors that put them more at risk for maltreatment and subsequently, child behavior problems. Some research even examines the impact of child behavior problems as a result of child maltreatment over time. However, no known model currently exists that examines child maltreatment and its impact on child behavior problems holistically. This dissertation will address the current gap by taking a multilevel approach to examining the impact of child maltreatment on behavior outcomes by answering two (2) research questions:

(1) Do the behavioral trajectories for children reported to child protective services (CPS) as a result of child maltreatment change differently over time?

(2) What are the most important child factors, caregiver factors, and environmental factors that predict the level of internalizing, externalizing, and total behavioral problems experienced by children reported to CPS as a result of child maltreatment over a period of six (6) years?

Using a nationally representative sample of children, who have been followed over a five (5) to six (6) year period and who have either had a substantiated case of maltreatment or have been reported to Child Protective Services (CPS) but do not have a substantiated case of maltreatment, allows for an increased understanding of the factors that predict child behavior problems. 
Additionally, by using a multilevel approach to assess this problem, both child welfare policy and practice decisions may be impacted as a result of more precise estimates. This dissertation examines child maltreatment across multiple time periods on multiple levels for multiple children; thereby bridging the gap in the child maltreatment literature.

This introductory chapter reviews the evolution of child maltreatment from a family issue to a social problem and discusses both the individual and societal impact of child maltreatment. Due to the impact child maltreatment has on child behavior problems, this introductory chapter provides a foundational discussion of the risk factors of child maltreatment. Additionally, it provides a discussion of current policy implications, including an examination of President Barack Obama's Strengthening Communities initiative. Finally, it argues for continued research and focus on community or environmental factors that contribute to and exacerbate the impact of child maltreatment.

\section{Problem Description}

\section{Child Maltreatment Defined}

Child maltreatment is a complex and prevalent problem impacting children and families across the United States and throughout the world. It takes on numerous forms, including physical abuse, psychological abuse, sexual abuse, and neglect. In the literature, the definition of child maltreatment is ambiguous. It is important, for the purposes of this dissertation, to clarify what "child maltreatment" means. In this dissertation, the vague term "child maltreatment" means any abuse or neglect suffered by a child. Unless specifically noted as 
physical abuse, sexual abuse, neglect or any other type of maltreatment, child maltreatment is used to describe any abuse or neglect of a child.

In 2009, 693,174 children were counted as "unique" victims of child maltreatment in the United States, with "unique" meaning that the child was reported sometime throughout the year as being maltreated. This definition is different from previous years in which "duplicates" were counted, which meant that children were counted each time they experienced some form of maltreatment during the year. More specifically, 543,035 (78.3\%) children experienced neglect, 123,599 (17.8\%) physical abuse, $65,964(9.5 \%)$ sexual abuse, and $52,534(7.6 \%)$ endured psychological or emotional maltreatment. (U.S. Department of Health and Human Services, 2010). While this number has declined over the last few years, the mortality rate of children who have been maltreated continues to increase from $1,413(1.94 \%)$ in 2005 to $1,676(2.34 \%)$ in 2009. Of those children who have died, a majority $(80.8 \%)$ were under the age of 4 and $35.8 \%$ died as a result of neglect alone (U.S. Department of Health and Human Services, 2010).

\section{Child Maltreatment as a Social Problem}

Child maltreatment has an extensive history in the United States spanning from the $19^{\text {th }}$ century. In 1874 , child maltreatment began to have a face. Mary Ellen Connolly (Wilson) was discovered by one concerned citizen, Etta Wheeler, who witnessed her stature and demeanor and felt compelled to help her. Petitioning what is known today as the American Humane Association for assistance; eventually Mary Ellen was permitted to testify against her abusers 
and was removed from their care. This was the beginning of the child protection movement (Watkins, 1990). However, child maltreatment was still largely considered a family problem. It was not until almost a century later that this mindset was changed. In the 1960s, Henry Kempe and colleagues (1962) could no longer ignore the hundreds of children who were being brought into the hospital with injuries inflicted at the hands of their caregivers. The publication of The Battered-Child Syndrome opened the eyes of medical professionals and child maltreatment started to be seen as a social problem (Kempe, et al., 1962).

The publicity from Kempe and colleagues' article led to the establishment of child abuse laws. By 1970, all 50 states implemented mandated child abuse reporting laws (Cicchetti \& Carlson, 1989). However, the legislation implemented at this time focused primarily on physical child abuse and negated child neglect. It was not until the Child Abuse and Prevention Act (CAPTA) was passed in 1974 that child neglect received nationwide attention (Cicchetti \& Carlson, 1989). Since then, several pieces of legislation, such as the Adoption Assistance and Child Welfare Act of 1980, the Adoption and Safe Families Act (ASFA) in 1997 and the Fostering Connections Act of 2008, have affirmed that child maltreatment is a social problem that deserves examination and intervention. Each of these major pieces of legislation will be discussed in turn.

CAPTA included a provision that expanded upon the "typical" abuse that was previously defined in law. It defines child abuse or neglect as "any recent act or failure to act... which results in death, serious physical or emotional harm, sexual abuse or exploitation or any act or failure to act which presents an 
imminent risk of serious harm" (42 U.S.C. $§ 5106 \mathrm{~g}(2))$. It is clearly explicit within the federal legislation that there are four (4) primary categories of child maltreatment: physical abuse, emotional or psychological abuse, sexual abuse, and neglect. However, since CAPTA allows states to independently define each of these subtypes of child maltreatment, it is difficult to formulate a comprehensive definition that encapsulates maltreatment across all 50 states. Therefore, child maltreatment is often viewed as any act of commission or omission that results in harm to a child, which researchers generally leave up to those individuals making substantiation decisions (Hutchison, 1990).

After CAPTA was passed, individuals were required to report any suspected case of child maltreatment. As a result, CPS workers began investigating and removing children from their homes. This resulted in a surge of children residing in foster care. The government had to do something to reduce the number of children entering foster care. The answer was the Adoption Assistance and Child Welfare Act of 1980 . This legislation offered financial incentives to keep families intact and reduce the number of children in foster care (Meyers, 2006). Additionally, CPS workers were required to develop a permanency plan for children within 18 months (P.L. 96-272). It was no longer acceptable for children to remain in long-term foster care without some type of plan to find them a permanent home.

Eventually, opponents of the Adoption Assistance and Child Welfare Act of 1980 were heard. Too many children were being reunited only to experience another case of maltreatment. Children were dying as a result of the current 
legislation, so once again there was a shift in child welfare legislation. President Bill Clinton passed the Adoption and Safe Families Act (ASFA) in 1997 in order to place child safety at the forefront (P.L. 105-89). While family preservation was still the optimal goal for children, this was no longer achieved at the expense of child safety and well-being. In addition to permanency planning, now CPS workers were required to include safety planning. There was also emphasis placed on timeliness of decisions regarding whether the child would return home or parental rights terminated. This would allow for both permanency and safety to be achieved with the safety and well-being of the child of paramount importance (Meyers, 2006).

Still, there were lingering issues in child welfare policy. Research in child welfare began to show that children who aged out of the foster care system had worse outcomes and illuminated the importance of family connections outside of the parental figures (Farruggia, Greenberger, Chen, \& Heckhausen, 2006; Ryan, Hernandez, \& Heiz, 2007; Scannapieco, Connell-Carrick, \& Painter, 2007). In 2008, President George W. Bush responded by signing the Fostering Connections to Success and Increasing Adoptions Act into law (P.L. 110-351). This legislation aimed at increasing relative placement and providing or extending education and healthcare benefits to children in foster care until the age of 21 (P.L. 110-351).

\section{Risk Factors for Child Maltreatment}

There are a number of risk factors documented in the literature regarding child maltreatment. According to the Child Welfare Information Gateway (n.d.), 
which is a site maintained by the U.S. Department of Health and Human Services, Administration for Children and Families, Children's Bureau, risk factors for child maltreatment may fall into four (4) main categories: child factors, parent or caregiver factors, family factors, and environmental factors. Note that risk factors vary depending upon the type of maltreatment experienced. Therefore, distinctions are made in the following sections between specific types of abuse and general maltreatment. It is important to identify the risk factors currently identified in the literature for each type of maltreatment; however, this is just a cursory overview of current research.

Child factors. There are two dominant child factors that make him or her more susceptible to maltreatment. These include the child's age and level of development. Younger children (birth to 1 year of age) continue to experience the highest rate of victimization at 20.6 per 1,000 children in the population (U.S. Department of Health and Human Services, 2010). Additionally, younger children experience a higher risk of the recurrence of maltreatment (Drake, Johnson-Reid, \& Sapokaite, 2006). Inherently, younger children require more care and attention due to their inability to care for themselves. Due to their inability to care for themselves, caregivers may experience higher levels of stress that could potentially result in the maltreatment of the child. In turn, this may also be exacerbated in cases of teenage pregnancy, single parenthood, mental illness of the caregiver, poverty, or a number of other essential factors.

Developmental factors, including the child's physical, mental, emotional, and social development, are also important risk factors to consider when 
examining child maltreatment. Children with disabilities are 3.76 times more likely to experience neglect, 3.79 times more likely to be physically abused, 3.14 times more likely to be sexually abused, and 3.88 times more likely to be emotionally abused (Sullivan \& Knutson, 2000). Additionally, 63\% of children with disabilities experience multiple forms of maltreatment and a majority $(71 \%)$ also experience multiple episodes of maltreatment (Sullivan \& Knutson, 2000). This is consistent with Drake and colleagues' (2006) report that children with reported mental health or substance abuse issues are almost twice as likely to experience a recurrence of maltreatment and $50 \%$ more likely if they are eligible for Special Education Services as a result of an emotional disturbance.

The type of disability a child has may also impact child maltreatment. Sullivan and Knutson (2000) developed a relative risk matrix comparing the risk of maltreatment by type of disability. Comparing visual impairment, hearing impairment, speech/language problems, mental retardation, learning disability, behavioral disorders, health impairment, autism, and physical disability, they found that children with behavioral disorders have the highest risk of maltreatment. More specifically, children with behavioral disorders are 7.3 times more likely to be physically abused, 7.0 times more likely to experience emotional abuse, 6.7 times more likely to be neglected, and 5.5 times more likely to be sexually abused (Sullivan \& Knutson, 2000). However, this study was not longitudinal in nature. This creates a problem in terms of determining whether the disability pre-dated the maltreatment incident. 
Children with disabilities are inherently more difficult to care for, creating a higher risk for child maltreatment. In 2009, 53,514 (11.1\%) children who were maltreated had a reported disability (U.S. Department of Health and Human Services, 2010). Some children with physical disabilities may never be able to walk or feed themselves, resulting in the caregiver having to spend a lot of time and money caring for that one child thereby increasing both caregiver stress and financial burden. Additionally, children with mental and emotional problems may aggressively act out or turn to self-destructive behaviors that may result in the caregiver having to protect themselves or their child, which may be viewed as maltreatment by someone outside of the situation.

Child factors appear straightforward; however, when coupled with caregiver, family, and environmental factors, it becomes much more complex. Child factors, such as age and development, have an impact on caregiver stress and subsequent behavior. Therefore, child factors must be examined in conjunction with other factors. Table 1 below provides a summary of the child factors discussed in this section.

\section{Table 1}

Summary of Child Risk Factors for Child Maltreatment by Type

\begin{tabular}{ll}
\hline & Child Age Risk Factor \\
\hline $\begin{array}{c}\text { Physical/Sexual/ } \\
\text { Emotional/Neglect }\end{array}$ & \multicolumn{1}{c}{ General } \\
\hline & $\begin{array}{l}\text { Younger children (birth to age 1) experience } \\
\text { the highest rate of victimization (20.6 per 1,000 } \\
\text { children in population) (U.S. Department of }\end{array}$ \\
& Health and Human Services, 2010) \\
& $\begin{array}{l}\text { Younger children have higher risk of } \\
\text { maltreatment recurrence (Drake, Johnson- } \\
\text { Reid, \& Sapokaite, 2006) }\end{array}$ \\
\hline
\end{tabular}




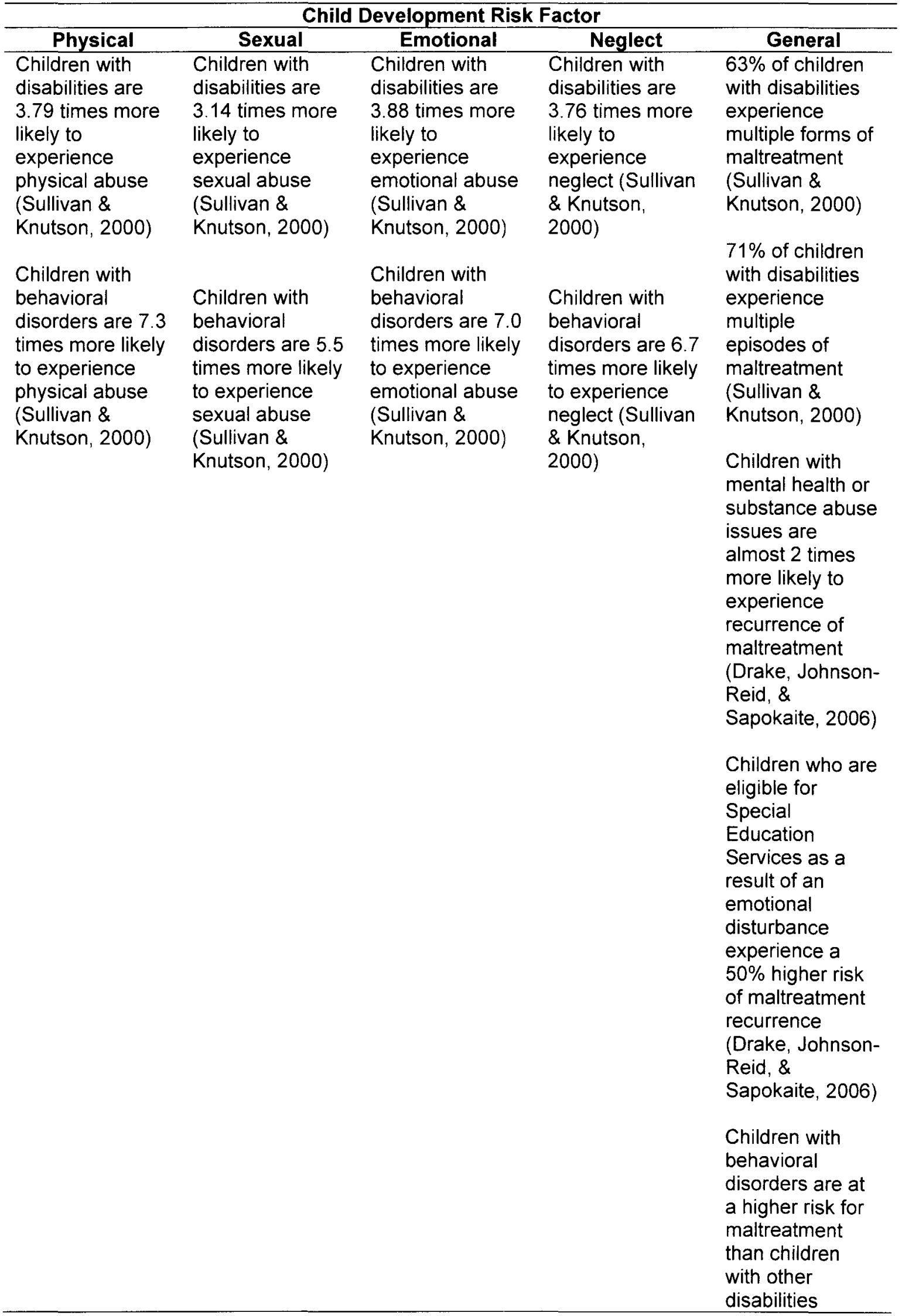


Parent/caregiver factors. Child maltreatment is prevalent among children with a parent or primary caregiver who has a mental health condition (Walsh, MacMillan, \& Jamieson, 2002; Francis \& Wolfe, 2008). In a retrospective study, Walsh and colleagues (2002) asked participants to recall their childhood experiences and determine if they had experienced physical or sexual abuse as a child using the Child Maltreatment History Self-Report (CMHSR) questionnaire. Additionally, they were asked to speculate as to whether their mother and/or father exhibited any mental health symptoms of Major Depressive Disorder, Mania, Schizophrenia, and/or Antisocial Disorder using a modified version of the NIMH ECA surveys. They reported that caregivers who had a mental health disorder demonstrated an increased risk of maltreating their children. Furthermore, while Depression, Mania, and Schizophrenia were similar across both physical and sexual abuse, antisocial behavior was more likely to result in physical abuse $(O R=6.1)$ than sexual abuse $(O R=4.7)$. Additionally, when both parents exhibited mental health problems, there was an increased risk of maltreatment (Walsh, MacMillan, \& Jamieson, 2002). Francis and Wolfe (2008) focused primarily on the paternal role in families and the maltreatment of children. They found that physically abusive fathers were more likely to exhibit certain mental health diagnoses as measured by the Brief Symptom Inventory (BSI) scale. More specifically, more than six (6) times as many physically abusive fathers fell in the clinically significant range on the Paranoia and Somatization subscales of the BSI and five (5) times as many physically abusive 
fathers fell in the clinically significant range on the Depression subscale of the BSI than non-abusive fathers (Francis \& Wolfe, 2008).

While these studies demonstrate an increased likelihood to maltreat if the caregiver exhibits characteristics associated with a psychiatric disorder or general mental health condition, there are both methodological limitations and confounding factors that have not been considered. From a methodological perspective, Walsh and colleagues (2002) relied solely on the memory of adults as they reflected back upon their childhood. Retrospective studies, in and of themselves, have limitations related to recollection and bias. It is difficult to accurately remember behaviors and surrounding characteristics experienced as a child, especially in cases of traumatic events such as child maltreatment. Additionally, confounding factors such as the level of social support, treatment availability, and adherence to taking prescribed medications may influence the impact of mental health on child maltreatment.

Having a personal history of maltreatment as a child has also been shown to be a risk factor for child maltreatment (Zuravin, McMillen, DePanfilis, \& RisleyCurtiss, 1996; Cunningham, 2003; Goldman, Salus, Wolcott, \& Kennedy, 2003; Narang \& Contreras, 2005; Francis \& Wolfe, 2008). Goldman and colleagues (2003), in a review of the literature, note that approximately one-third of caregivers who were victims of child maltreatment perpetuate the cycle of maltreatment on their own children. While history of maltreatment is examined here as a parental risk factor, note that it may also be considered a consequence or outcome of child maltreatment. 
Cunningham (2003) reported that caregivers who were hit when they were teens were 1.92 times more likely to admit to physically abusing their own children. When examining fathers, in particular, researchers found that physically abusive fathers were more likely to have experienced maltreatment as a child when compared to non-maltreating fathers (Francis \& Wolfe, 2008).

Additionally, there is some evidence that type or severity of abuse has an impact on whether caregivers continue or discontinue the cycle of abuse with their own children. Some research indicates that mothers who were victims of unwanted sexual intercourse were 2.3 times more likely to perpetuate the cycle of maltreatment rather than breaking it, while individuals who were molested (no penetration) were equally likely to continue the cycle of maltreatment as mothers who were not molested (Zuravin, et al., 1996).

These studies, however, do not address the two-thirds of caregivers who were maltreated as children who did break the cycle of maltreatment. Thus, a discussion examining these caregivers is necessary. Several researchers note that there are additional factors that must be considered in addition to history of maltreatment (Zuravin, et al., 1996; Cunningham, 2003; Narang \& Contreras, 2005). While there is a moderate correlation (0.34) between physical abuse history and the potential to physically abuse a child, as measured by the Child Abuse Potential Inventory (CAP), other factors, such as the level of dissociation and the level of family support, must be considered (Narang \& Contreras, 2005). Using the Dissociative Experiences Scale II (DES II) and the Family Environmental Scale (FES), Narang and Contreras (2005) reported that there is 
also a strong correlation (0.46) between Dissociation and Physical Abuse Potential and this relationship is further mediated by having high levels of family support. In other words, higher levels of dissociation are associated with more physical abuse, but this association is attenuated by family support. Zuravin and colleagues (1996) found similar results in a sample of low-income (AFDC recipients) mothers, noting that individuals who were able to experience supportive relationships with adults, despite their abuse, decreased their probability of continuing the cycle of maltreatment. Another factor to consider, in addition to history of experienced maltreatment, is history of witnessed violence. When interparental violence occurred in the home and was witnessed by the caregivers, caregivers who were hit as teens were just as likely to maltreat their children as those who were not hit as teens (Cunningham, 2003).

There were also some methodological concerns raised with the Cunningham (2003) study, in particular. In this study, both child maltreatment and interparental violence were measured using the Conflicts Tactics Scale (CTS) and therefore, do not include only substantiated cases of maltreatment. Actually, the study does not specify whether any of the cases were substantiated, which could result in erroneous conclusions based upon the fact that individuals have differing definitions of what constitutes child maltreatment. For example, one child may see a caregiver using a belt during a spanking as "being hit with an object" while another child views this as normal and appropriate discipline. With the above cited evidence, this raises concerns as to whether being maltreated as a child is a predictor of becoming a perpetrator of maltreatment or 
if violence in general may perhaps be the better predictor. If, in fact, violence is the dominant predictor, this would lead to more of an environmental argument surrounding living in violent communities. Poverty must also be examined in conjunction with caregiver maltreatment history. Poverty is a stressor that sometimes leads to increased stress, which in turn may lead to increased levels of family violence.

Parental substance abuse has also been cited as a risk factor for child maltreatment (Kelleher, Chaffin, Hollenberg, \& Fischer, 1994; Jaudes, Ekwo, \& VanVoorhis, 1995). Kelleher and colleagues (1994) reported that, after controlling for mental health disorders (depression, antisocial personality disorder) and environmental factors (social support), parents with substance abusing behaviors were 2.7 times more likely to report physically abusive behaviors and 4.2 times more likely to report neglectful behaviors. Additionally, parents who abused substances during their pregnancy are also more likely to subsequently maltreat their children (Jaudes, Ekwo, \& VanVoorhis, 1995). In fact, Jaudes and colleagues (1995) reported that $65.8 \%$ of children exposed to substances while in the womb were later found to have substantiated cases of child maltreatment, with a majority $(72.6 \%)$ of those cases being the result of neglect.

With substance abuse being a contributing factor to child maltreatment, it is of importance to note that $11.9 \%$ of children in the United States lived with at least one parent who abused substances from 2002 to 2007 (SAMHSA, 2009). This results in over 8 million children at risk for maltreatment based on the 
current literature citing substance abuse as a risk factor for child maltreatment. Furthermore, the U.S. Department of Health and Human Services (1999) report that children who are maltreated by substance abusing parents have worse outcomes and remain in out-of-home care for longer periods of time.

However, there are several confounding factors that have not been accounted for in the above-mentioned studies, such as poverty, mental health, and other life events. Substance abuse is generally a symptom of some greater issue; therefore, it is also important to examine the "why" of substance abuse, such as mental illness, mental retardation, past history of maltreatment, the prevalence of daily stressors coupled with poor coping skills, and major life events, rather than just substance abuse itself. These confounding factors impact both child maltreatment reports and substantiation of child maltreatment reports. While Kelleher and colleagues (1994) controlled for mental health issues and social support, they did not account for poverty either in the family or the environment. This eliminates the potential relationship between poverty and substance abuse and, consequently, child maltreatment. Poverty may, very well, be the reason for abusing substances. Poverty, stress, mental health problems, access to bars, and check-to-cash establishments, which are prevalent in poverty-stricken communities, may both facilitate and impact substance abuse and must be included in child maltreatment research.

Some scholars have suggested that becoming a parent as a teenager is a risk factor for child maltreatment (Drake, Johnson-Reid, \& Sapokaite, 2006). Drake and colleagues (2006) found that there was a higher rate of recurrence of 
maltreatment if the caregiver was under the age of 19 at the time of the birth of the first child $(65.1 \%$ vs. $61.4 \% ; p<0.05)$.

However, there are some scholars that argue that parental age is not the sole factor to consider when examining child maltreatment (Buchholz \& KornBursztyn, 1993; Flanagan, Coll, Andreozzi, \& Riggs, 1995). They call into question whether studies that cite parental age as a factor of child maltreatment are ignoring other factors related to becoming a teenage parent, such as poverty, lower levels of education, as well as other environmental factors. Parents have numerous factors to deal with upon giving birth to a child, including the financial costs and time constraints associated with raising a child. These costs are exacerbated when a parent is also a teen. In addition to the financial costs and time constraints, teenage parents also may face stress associated with being a single parent as well as potential social isolation due to the stigma often associated with teenage pregnancy and parenthood.

Additionally, teenage parents may not have fully developed cognitively. Current brain development research indicates that adolescence is a critical period of refinement for connections within the brain (Bava, Thayer, Jacobus, Ward, Jernigan, \& Tapert, 2010), which could potentially be negatively impacted by stress (McCormick \& Matthews, 2010). This could result in an inability to empathize or respond appropriately to the needs of the child. In fact, DePaul and Guibert (2008) found that neglectful caregivers were more likely to exhibit deficits related to expressing empathy. Additionally, focusing primarily on the paternal role in families, Francis and Wolfe (2008) reported that physically abusive fathers 
were more likely to see themselves as less empathetic and less able to see things from their child's perspective than non-abusive fathers. Therefore, all of these factors should be simultaneously considered, in addition to parental age, in order to gain a more accurate picture of the impact of parental age on child maltreatment.

There is also a relationship between caregiver educational attainment and child maltreatment. Research indicates that individuals with lower levels of education have an increased risk of maltreating their children (Currenton, McWey, \& Bolen, 2009; Berger, 2004) and experience a higher recurrence of maltreatment (Drake, Johnson-Reid, \& Sapokaite, 2006). Additionally, when comparing physically abusive fathers to non-abusive fathers, Francis and Wolfe (2008) reported that fathers who were physically abusive tended to have lower levels of educational attainment. Furthermore, Merritt (2009) examined education as it relates to the potential to abuse a child, as measured by the Child Abuse Potential Inventory (CAP). She found that being a high school graduate significantly reduced an individual's potential to abuse his or her child. Additionally, Merritt (2009) reported that education was significantly negatively correlated with individual CAP scores $(-0.29)$ and neighborhood maltreatment rates $(-0.17)$. However, there are several confounding factors that contribute to lower levels of educational attainment that warrant discussion. Individuals with lower levels of education tend to find employment in lower paying occupations, which may place them at or below the poverty line. Additionally, factors such as mental retardation and/or low IQ generally reach lower levels of educational 
attainment. Lastly, mental health issues, such as substance abuse and mental illness also place individuals at risk for lower levels of educational attainment. Therefore, it is imperative that all of these factors be included and controlled for when discussing child maltreatment.

As alluded to in the above paragraph, low levels of income and/or poverty has also been shown to be a contributing factor to child maltreatment. With regard to physical child abuse, fathers with lower levels of income were more likely to abuse their child when compared to non-abusive fathers (Francis \& Wolfe, 2008). Income is also negatively correlated with individual CAP scores (0.29) and neighborhood maltreatment rates (-0.04) (Merritt, 2009). Additionally, very poor families, defined as those who are unable to meet their basic needs, are more likely to have a child involved in the child welfare system than non-poor families who may be receiving assistance but are able to provide for basic needs ( $28 \%$ vs. $18 \%$ ) (Barth, Wildfire, \& Green, 2006 ). Furthermore, very poor families are more likely to be involved in other situations that are risk factors for maltreatment, such as domestic violence, recent arrest, serious mental health issue, some type of cognitive or physical impairment, and substance use or abuse (Barth, Wildfire, \& Green, 2006). However, while poverty is a well-cited risk factor for child maltreatment, the dynamics of poverty still need examination. Factors such as limited access to the better schools, neighborhood factors such as crime, child rearing practices, mental health, stress related factors, and poverty are all interrelated. While difficult, it is important to disentangle poverty from other confounding factors in order to discover which are the dominant 
factors and where intervention and prevention measures may have optimal impact.

In sum, there are a plethora of caregiver risk factors for maltreatment. However, many are interrelated and need closer examination in order to tease out the most crucial factors. Table 2 below summarizes the findings discussed in this section on parent/caregiver risk factors.

\section{Table 2}

Summary of Parent/Caregiver Risk Factors for Child Maltreatment by Type

\begin{tabular}{ccc}
\hline & Mental Health Risk Factor & \\
\hline Physical & Sexual & $\begin{array}{c}\text { Emotional/ } \\
\text { Neglect/ } \\
\text { General }\end{array}$
\end{tabular}

Caregivers with anti-social behavior are more likely to result in physical abuse (OR $=6.1)$ than sexual abuse $(\mathrm{OR}=4.7$ ) (Walsh, MacMillan, \& Jamieson, 2002)

When both parents have mental health problems, there is an increased risk of sexual

When both parents have mental health problems, maltreatment of the there is an increased risk of physical maltreatment (Walsh, MacMillan, \& Jamieson, 2002) child (Waish, MacMillan, \& Jamieson, 2002)

Physically abusive fathers are six (6) times more likely to fall in the clinically significant range on Paranoia and Somatization subscales of BSI (Francis $\&$ Wolfe, 2008)

Physically abusive fathers are five (5) times more likely to fall in the clinically significant range on Depression subscale of BSI (Francis \& Wolfe, 2008)

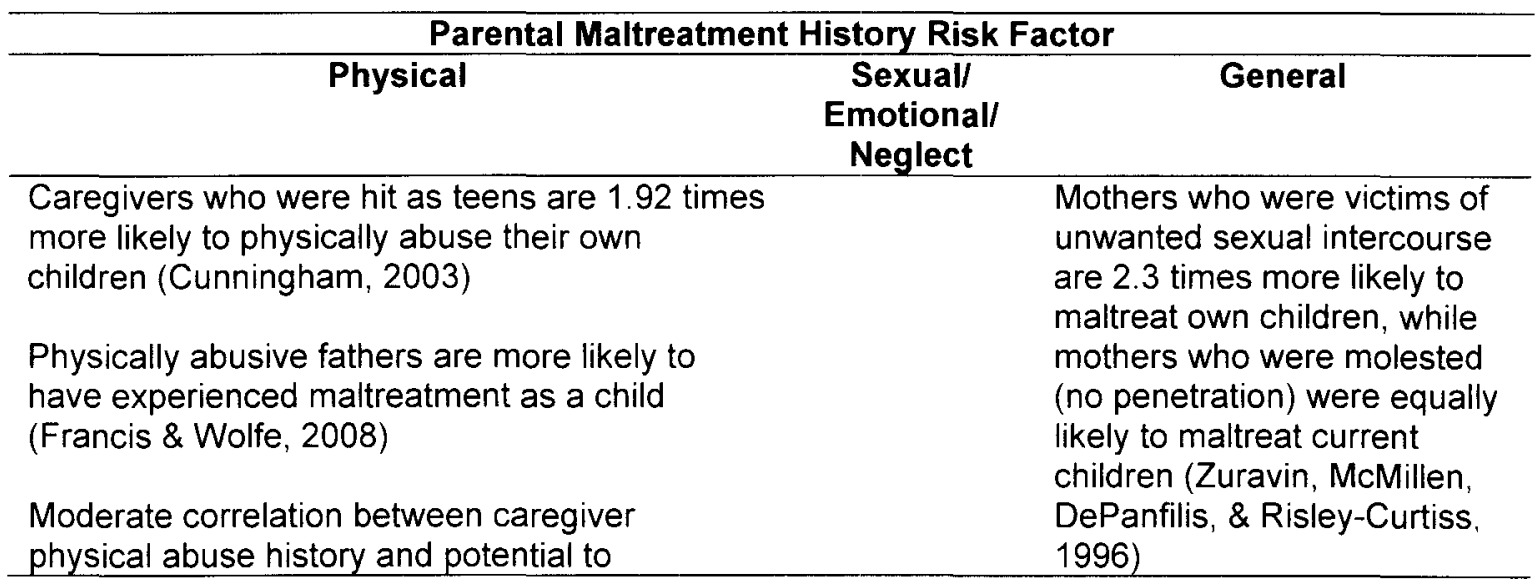


physically abuse their own child (0.34) (Narang

\& Contreras, 2005)

\begin{tabular}{|c|c|c|c|}
\hline \multicolumn{4}{|c|}{ Substance Abuse } \\
\hline Physical & $\begin{array}{c}\text { Sexual/ } \\
\text { Emotional }\end{array}$ & Neglect & General \\
\hline $\begin{array}{l}\text { Caregivers with } \\
\text { substance abusing } \\
\text { behaviors are } 2.7 \\
\text { times more likely to } \\
\text { report physically } \\
\text { abusive behaviors } \\
\text { (Kelleher, Chaffin, } \\
\text { Hollenberg, \& } \\
\text { Fischer, 1994) }\end{array}$ & & $\begin{array}{l}\text { Caregivers with substance abusing } \\
\text { behaviors are } 4.2 \text { times more likely } \\
\text { to report neglectful behaviors } \\
\text { (Kelleher, Chaffin, Hollenberg, \& } \\
\text { Fischer, 1994) } \\
72.6 \% \text { of children exposed to } \\
\text { substances while in the womb } \\
\text { were subsequently neglected after } \\
\text { birth (Jaudes, Ekwo, \& } \\
\text { VanVoorhis, 1995) }\end{array}$ & $\begin{array}{l}65.8 \% \text { of children } \\
\text { exposed to substances } \\
\text { while in the womb were } \\
\text { later found to have } \\
\text { substantiated cases of } \\
\text { child maltreatment } \\
\text { (Jaudes, Ekwo, \& } \\
\text { VanVoorhis, 1995) }\end{array}$ \\
\hline \multicolumn{4}{|c|}{ Teenage Parent Risk factor } \\
\hline $\begin{array}{l}\text { Physical/Sexual/ } \\
\text { Emotional/Neglect }\end{array}$ & & General & \\
\hline
\end{tabular}

Higher recurrence of maltreatment $(65.1 \%$ vs. $61.4 \%)$ is associated with being under the age of 19 when first child is born (Drake, Johnson-Reid, \& Sapokaite, 2006)

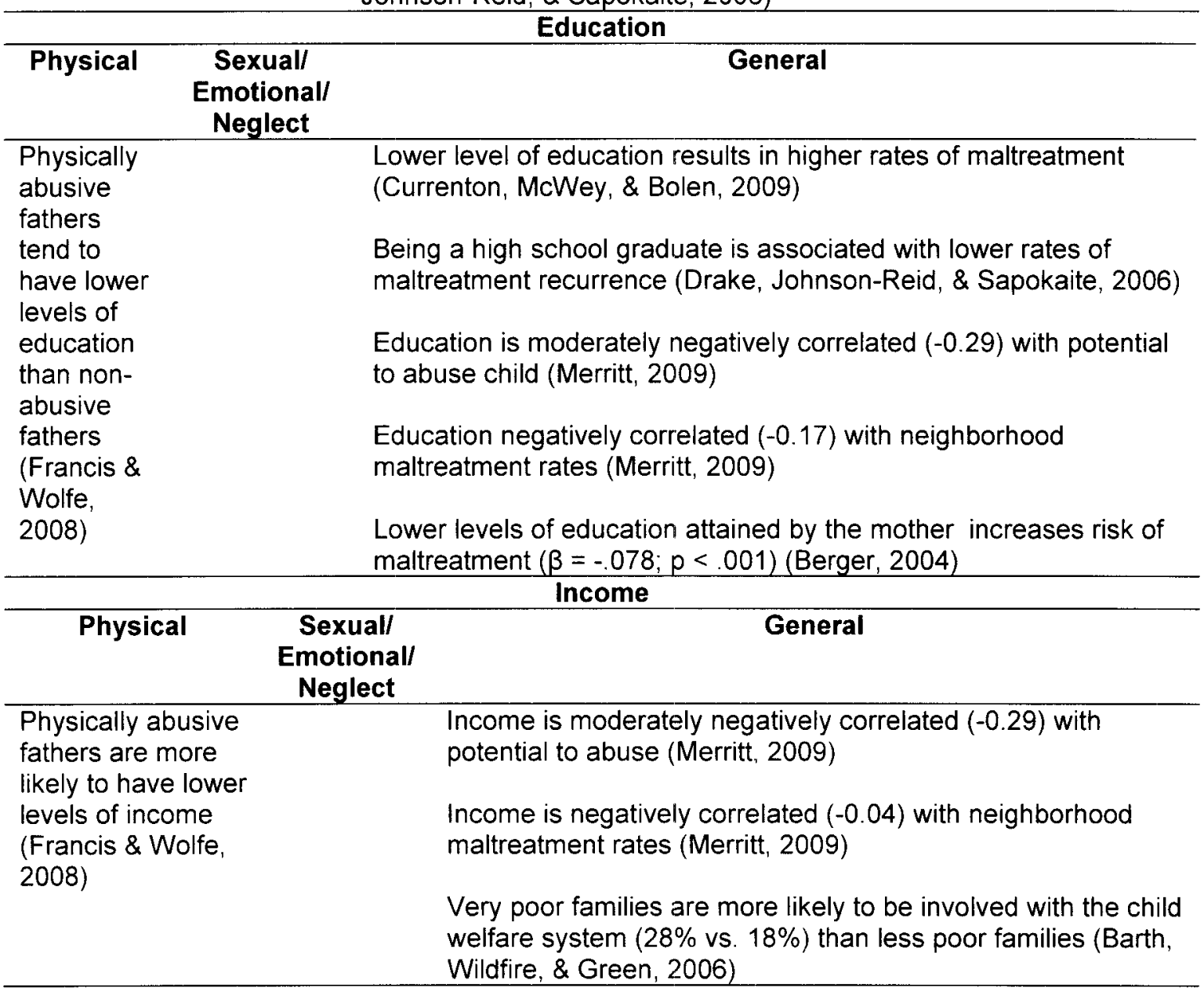


Family factors. It is also important to consider family factors when examining child maltreatment. These include factors that disrupt or impede the family system, such as family structure, domestic violence, and stressful life events. Situations that families have to endure impact family behavior and, consequently, may result in the maltreatment of children. Therefore, in order to accurately understand child maltreatment, it is important to examine the role familial circumstances play in child maltreatment.

The structure of the family may result in the risk of child maltreatment. Family structure includes factors such as the number of children in a household and the marital status of the caregivers, including single parenthood. As the number of children in the household increases, the more likely children will experience the recurrence of maltreatment (Drake, Johnson-Reid, \& Sapokaite, 2006; Berger, 2004). This may be a result of the increased financial responsibility of additional children, which ultimately may increase the level of stress experienced by the caregivers. Drake and colleagues (2006) reported that $57.7 \%$ of families with 1 or 2 children experienced a re-report of child maltreatment, while $65 \%$ of families with 3 to 5 children and $76.8 \%$ of families with 6 or more children experienced a re-report of child maltreatment.

Marital status is also a key family structure factor that may contribute to the maltreatment of children. Research indicates that there is a negative moderate correlation $(-0.23)$ between being married and an individual's potential to maltreat his or her child (Merritt, 2009). This coincides with Berger' (2004) report that single mothers who reside with a partner may be at a higher risk of 
maltreating their children $(\beta=0.114 ; p<.05)$ than single mothers residing alone with their children $(\beta=-0.237 ; p<.001)$. Similarly, Wilson and Daly (2005) showed that stepchildren were more likely to be maltreated, sometimes fatally. However, older stepchildren have a decreased risk of experiencing maltreatment. In 1976, American stepchildren between the ages of 0 and 2 were 6.9 times more likely to be maltreated than biological children, while American stepchildren between the ages of 14 and 17 were only 2.2 times more likely to be maltreated than biological children (Wilson \& Daly, 2005). Examining this same issue seven (7) years later in Canada showed a similar trend. Canadian stepchildren between the ages of 0 and 4 were 40.1 times more likely to experience maltreatment than biological children, whereas Canadian stepchildren between the ages of 11 and 17 were only 9.8 times more likely to experience maltreatment than biological children (Wilson \& Daly, 2005).

Living in homes where domestic violence occurs may also put a child at an increased risk of being maltreated. It causes great concern that, on average, $35.2 \%(216,490)$ of children under the age of 12 lived in households where there was confirmed intimate partner violence between 2001 and 2005 (Catalano, 2007). Furthermore, 126,697 (18.3\%) of maltreated children had a caregiver who was involved in a domestic violence situation in 2009 (U.S. Department of Health and Human Services, 2010). Compared to families without evidence of domestic violence, those experiencing domestic violence were 3.38 times more likely to have confirmed cases of physical abuse, 2.2 times more likely to have confirmed cases of psychological abuse, and 2.18 times more likely to have 
confirmed cases of neglect (McGuigan \& Pratt, 2001). Using the Conflict Tactic Scale (CTS), Hartley (2004) classified fathers into one of two groups based on the severity of domestic violence in the household: less severe domestic violence and more severe domestic violence. Those in the more severe domestic violence group had one (1) of six (6) of the following factors present in their situation: (a) threatened victim with a knife, gun, or other weapon; (b) kicked, bit, or hit victim with fist; (c) tried to or did hit victim with something; (d) choked or strangled victim; (e) beat the victim up; and/or (f) used a knife, gun, or other weapon against victim. Ultimately, she found that $63.9 \%$ of children in the more severe domestic violence group experienced maltreatment in the form of lack of supervision compared to only $32 \%$ of those residing in less severe domestic violence families (Hartley, 2004). Surprisingly, Hartley (2004) also found that only $27.8 \%$ of children in the severe domestic violence group experienced physical abuse compared to $56 \%$ living in less severe domestic violence families. As Hartley (2004) notes, this finding is contradictory to most research that indicates there is a higher risk of physical maltreatment in families experiencing domestic violence. This contradictory finding may be the result of the way in which Hartley differentiated the two groups of domestic violence families or the relatively small sample sizes making up the less severe $(n=25)$ and the more severe $(n=36)$ domestic violence families. While it is clear that domestic violence present in the household may be a risk factor for child maltreatment, it is important to examine domestic violence in conjunction with other family and environmental factors. Factors such as the inability to meet 
basic needs, stress, and societal attitudes toward violence may be confounding factors and, therefore, must also be examined.

Having high levels of stress in a family has also been cited as a risk factor for child maltreatment. Using the Parenting Stress Index (PSI), Francis and Wolfe (2008) reported that physically abusive fathers scored significantly higher on each subscale (Parental Distress, Parent-Child Dysfunctional Interaction, and Difficult Child) as well as the Total Parenting Stress Scale. Furthermore, Currenton and colleagues (2009), comparing maltreating and non-maltreating caregivers also using the PSI, found that the maltreating group was beyond the $95^{\text {th }}$ percentile for level of dysfunctional interactions with their child and only maltreating families exhibited scores signifying that they were in need of clinical intervention on the Difficult Child subscale of the PSI. Examining specific stressful life events, Merritt (2009) reported that an individual's potential to abuse his or her child, using the Child Abuse Potential (CAP) Scale, was significantly negatively correlated $(-0.12)$ with full-time employment. In other words, caregivers who are unemployed have a higher risk of potentially maltreating their child.

Stress, however, is often the result of some event occurring in an individual's life in which they perceive that cannot handle. It is important to determine why some of these individuals maltreat their children while others do not maltreat their children. Evidence suggests that both social support and higher levels of education may serve as moderators to stress in families (Koeske \& Koeske, 1990; Budd, Holdsworth, \& HoganBruen, 2006). Thus, by increasing 
families' accessibility to external supports, such as child care and neighborhood community centers, the incidence of child maltreatment may decrease.

Additionally, by providing parents, especially young parents, with parenting classes and encouraging higher levels of educational attainment, fewer children may experience child abuse and neglect. In sum, it is important to not only provide services to counter parental stress but also to account for other exogenous factors that may lead to increased stress, and subsequently child maltreatment, in predictive models in order to detangle the interconnectedness of these factors.

\section{Table 3}

Summary of Family Risk Factors for Child Maltreatment by Type

\section{Family Structure Risk Factor}

\begin{tabular}{|c|c|c|c|}
\hline $\begin{array}{l}\text { Physical/Sexuall } \\
\text { Emotional/Neglect }\end{array}$ & \multicolumn{3}{|c|}{ General } \\
\hline & \multicolumn{3}{|c|}{$\begin{array}{l}57.7 \% \text { of families with } 1-2 \text { children experience a re-report of child } \\
\text { maltreatment compared to } 65 \% \text { of families with } 3-5 \text { children and } 76.8 \% \text { of } \\
\text { families with } 6 \text { or more children (Drake, Johnson-Reid, \& Sapokaite, 2006) }\end{array}$} \\
\hline & \multicolumn{3}{|c|}{$\begin{array}{l}\text { The more children in a household, the more risk of child maltreatment }(\beta= \\
0.103 ; p<.001)\end{array}$} \\
\hline & \multicolumn{3}{|c|}{$\begin{array}{l}\text { Being married is moderately negatively correlated }(-0.23) \text { with individual } \\
\text { child abuse potential (CAP) scores (Merritt, 2009) }\end{array}$} \\
\hline & \multicolumn{3}{|c|}{$\begin{array}{l}\text { Single mothers residing with a partner are at a higher risk of maltreating } \\
\text { their child }(\beta=0.114 ; p<.05) \text { (Berger, 2004) }\end{array}$} \\
\hline & \multicolumn{3}{|c|}{$\begin{array}{l}\text { Stepchildren are more likely to be maltreated and killed; however, this } \\
\text { decreases with the child's age (Wilson \& Daly, 2005) }\end{array}$} \\
\hline \multicolumn{4}{|c|}{ Domestic Violence Risk Factor } \\
\hline Physical & Emotional & Neglect & General \\
\hline $\begin{array}{l}\text { Families with } \\
\text { domestic violence } \\
\text { are } 3.38 \text { times } \\
\text { more likely to } \\
\text { physically maltreat } \\
\text { their children } \\
\text { (McGuigan \& Pratt, } \\
\text { 2001) }\end{array}$ & $\begin{array}{l}\text { Families with } \\
\text { domestic violence } \\
\text { are } 2.2 \text { times more } \\
\text { likely to emotionally } \\
\text { or psychologically } \\
\text { maltreat their } \\
\text { children (McGuigan } \\
\text { \& Pratt, 2001) }\end{array}$ & $\begin{array}{l}\text { Families with } \\
\text { domestic violence } \\
\text { are } 2.18 \text { times } \\
\text { more likely to } \\
\text { neglect their } \\
\text { children } \\
\text { (McGuigan \& } \\
\text { Pratt, 2001) }\end{array}$ & $\begin{array}{l}18 \% \text { of maltreated } \\
\text { children had } \\
\text { caregivers who were } \\
\text { involved in domestic } \\
\text { violence situations } \\
\text { (U.S. Department of } \\
\text { Health and Human } \\
\text { Services, } 2010 \text { ) }\end{array}$ \\
\hline
\end{tabular}




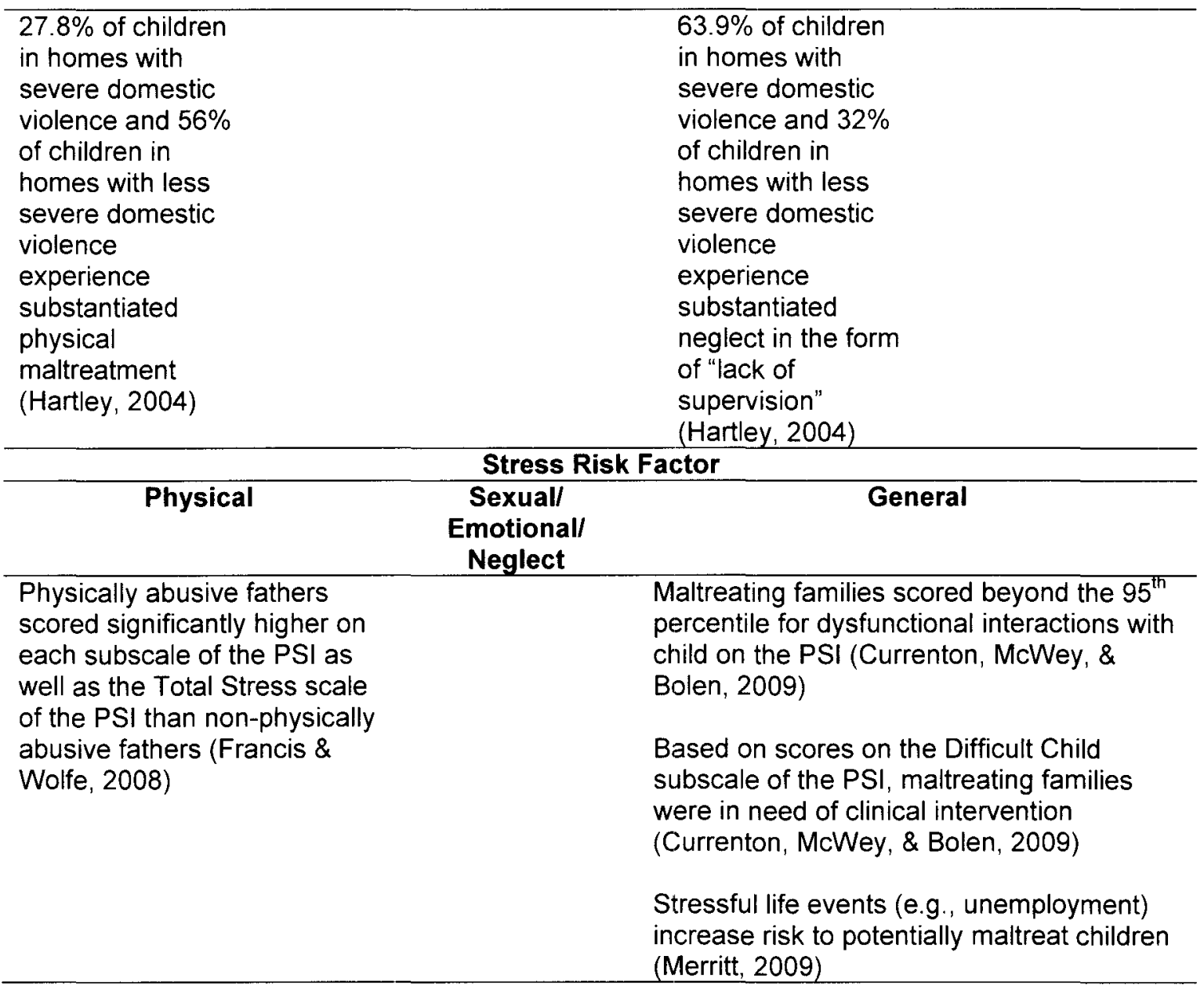

Environmental factors. There are a number of environmental factors that have been shown to be predictors of child maltreatment, with neighborhood poverty and unemployment being the most cited (Drake \& Pandey, 1996;

Freisthler, 2004; Drake, Johnson-Reid, \& Sapokaite, 2006; Merritt, 2009).

However, there are several other environmental factors that contribute to child maltreatment, such as lack of social support, alcohol availability, crime, and child care burden that will be discussed in this section. Of importance, here, is to be aware that families and children do not exist in a vacuum. They interact with and are a part of the communities in which they live. Therefore, it is imperative to 
examine the impact the environment has on their behavior, including child maltreatment.

Drake and Pandey (1996) examined a combination of specific neighborhood factors, including property value, high school dropout percentage, percentage of 2-parent homes, income, and poverty rates within neighborhoods, and their relationship to child maltreatment. They found that these neighborhood factors explained $75.2 \%$ of the variance of neglect reports $\left(R^{2}=0.752, F=\right.$ $76.645), 62.4 \%$ of the variance of physical abuse reports $\left(R^{2}=0.624, F=\right.$ $42.057)$, and $50.3 \%$ of the variance of sexual abuse reports $\left(R^{2}=0.503, F=\right.$ 25.585) (Drake \& Pandey, 1996). However, it is important to keep in mind that all of these factors are interrelated. From a macro or systems perspective, there is a clear relationship between neighborhood poverty and all of the other aforementioned factors. Thus, it is important to examine a comprehensive model of child maltreatment that includes all of these factors, in conjunction with child and parental factors, in order to gain an accurate picture of child maltreatment.

Neighborhood poverty is the most commonly cited predictor of child maltreatment. Drake and Pandey (1996) noted that poverty rates within a neighborhood is positively associated with sexual abuse reports $(\beta=0.441, p<$ $.01)$, physical abuse reports $(\beta=0.257, p<.05)$, and neglect reports $(\beta=0.430$, $p<.001$ ). In regards to the recurrence of child maltreatment, Drake and colleagues (2006) showed that lower rates of child maltreatment re-reports were associated with higher levels of median household income (over $\$ 20,000$ per year) within a neighborhood. Furthermore, Merritt (2009) examined 
impoverishment in neighborhoods, which was measured by family headship, poverty rate, unemployment rate, vacant housing, population loss, and the percentage of African Americans residing within a community, and found a significant positive correlation between impoverishment and both an individual's potential to abuse his or her child (0.13) and neighborhood maltreatment rates (0.16)

It is important to understand that poverty is interrelated with unemployment and minority status. Therefore, it is no surprise that Freisthler (2004) found that as neighborhood unemployment rates and the percentage of impoverished families living within a neighborhood increased, child maltreatment also increased. However, it is also important to consider the fact that poor families are also more likely to be reported for suspected child maltreatment (Gelles, 2005). This could result in potential bias toward individuals living in poorer communities, with doctors and law enforcement being more aware of the potential for maltreatment among low socioeconomic status families, resulting in families from these neighborhoods being more at risk of a substantiated maltreatment case.

Social support and/or social isolation are also important factors to consider when examining child maltreatment. The lack of social support, from both family and friends, is a contributing factor of child maltreatment (Merritt, 2009). Family support is highly negatively correlated $(-0.41)$ with individual CAP scores, while support from friends is moderately negatively correlated $(-0.33)$ with individual CAP scores (Merritt, 2009). These results indicate that higher levels of social 
support leads to decreased potential to maltreat a child. While Merritt (2009) did not discuss specific behaviors or gestures of social support, conceptually it makes sense that higher levels of support reduce an individual's potential to maltreat his or her child. If an individual has more resources, such as family or friends to talk to or share child rearing, then he or she has more options when stressful situations related to raising the child occur. In fact, Merritt (2009) also found a moderate positive correlation ( 0.31$)$ between child care burden, measured by the ratio of children to adults, ratio of males to females, and the percentage of elderly within a community, and neighborhood rates of child maltreatment as well as higher CAP scores among those in high child care burden areas. Therefore, having an increased level of social support can greatly reduce the stress associated with raising a child. This could be achieved by building trustworthy social networks within communities that could relieve parental stress and child care burden and, subsequently, could be a step toward reducing child maltreatment.

The prevalence of crime and violence within a neighborhood is also a risk factor for child maltreatment (Child Welfare Information Gateway, n.d.). Closely related to crime and neighborhood violence is the availability of alcohol and other substances within a community (Lipton \& Gruenwald, 2002) and population density or population mobility (Freisthler, 2004). It has already been discussed that, on an individual level, substance abuse is a risk factor for child maltreatment. Therefore, the availability of alcohol and other substances within close proximity may also contribute to child maltreatment. In fact, Freisthler 
(2004) reported that the number of bars per 1,000 residents in a community is positively related to maltreatment rates.

Families in fear due to high crime tend to move out of these neighborhoods, if they have the resources, in an attempt to protect their families. This increases neighborhood mobility, which may clearly be associated with neighborhood crime rates. Freisthler (2004) showed that child maltreatment rates were positively associated with the population per square mile. This, there is a higher prevalence of child maltreatment in overcrowded neighborhoods. However, Freisthler (2004) also reported that changes in overall neighborhood population negatively impacts child maltreatment. This indicates that as the population increases within a neighborhood, child maltreatment rates tend to decrease, which appears to be in contradiction with the previous statement. However, the population per square mile is vastly different than the population within a census block. Therefore, this finding becomes more clear. Child maltreatment decreases as the population within a neighborhood increases, while child maltreatment increases as the number of individuals living within a small area increases (e.g. apartments or projects versus single family homes). There are many reasons why there may be fluctuations in neighborhood mobility. If people are moving into an area, this may be indicative of an improving neighborhood. However, if several individuals are housed together, this may be indicative of a poorer neighborhood.

Following the line of reasoning above, Drake and colleagues (2006) examined the proportion of families that have moved within the last five years 
within a neighborhood and reported that higher re-reports of child maltreatment are associated with a higher number of families moving. Additionally, Merritt, 2009) looked at instability within neighborhoods, measured by movement, tenure under 10 years, and recent movement. She found that instability was significantly negatively correlated $(-0.12)$ with neighborhood maltreatment rates. Ultimately, movement is generally indicative of other issues that may be present in that community and must be considered when examining child maltreatment holistically.

\section{Table 4}

Summary of Environmental Risk Factors for Child Maltreatment by Type

\begin{tabular}{|c|c|c|c|c|}
\hline \multicolumn{5}{|c|}{ Neighborhood Poverty/Property Value Risk Factor } \\
\hline Physical & Sexual & Emotional & Neglect & General \\
\hline $\begin{array}{l}\text { Percentage of } \\
\text { families in poverty } \\
(\beta=.257, p<.05) \\
\text { positively related } \\
\text { to reports of } \\
\text { physical } \\
\text { maltreatment } \\
\text { (Drake \& Pandey, } \\
1996)\end{array}$ & $\begin{array}{l}\text { Percentage of } \\
\text { families in poverty } \\
(\beta=.441, p<.01) \\
\text { positively related } \\
\text { to reports of } \\
\text { sexual } \\
\text { maltreatment } \\
\text { (Drake \& Pandey, } \\
1996)\end{array}$ & & $\begin{array}{l}\text { Percentage of } \\
\text { families in } \\
\text { poverty }(\beta=.430, \\
p<.001) \\
\text { positively related } \\
\text { to reports of } \\
\text { neglect (Drake \& } \\
\text { Pandey, 1996) }\end{array}$ & $\begin{array}{l}\text { Neighborhood } \\
\text { impoverishment is } \\
\text { negatively } \\
\text { correlated with child } \\
\text { abuse potential } \\
(0.13) \text { and } \\
\text { neighborhood } \\
\text { maltreatment rates } \\
(0.16) \text { (Merritt, } \\
2009)\end{array}$ \\
\hline $\begin{array}{l}\text { Property value ( } \beta \\
=-.146, p<.05 \text { ) is } \\
\text { related to physical } \\
\text { maltreatment } \\
\text { reports (Drake \& } \\
\text { Pandey, } 1996 \text { ) }\end{array}$ & $\begin{array}{l}\text { Property value ( } \beta \\
=-.175, p<.05 \text { ) is } \\
\text { related to sexual } \\
\text { maltreatment } \\
\text { reports (Drake \& } \\
\text { Pandey, } 1996 \text { ) }\end{array}$ & & & $\begin{array}{l}\text { Negative correlation } \\
\text { between income } \\
\text { and child } \\
\text { maltreatment } \\
\text { (Drake, Johnson- } \\
\text { Reid, \& Sapokaite, } \\
2006 \text { ) }\end{array}$ \\
\hline \multicolumn{5}{|c|}{ Neighborhood 2-parent Home Risk Factor } \\
\hline \multicolumn{2}{|c|}{ Physical } & $\begin{array}{r}\text { Sexual/Emoti } \\
\text { /General }\end{array}$ & & Veglect \\
\hline \multicolumn{2}{|c|}{$\begin{array}{l}\text { Percentage of } 2 \text {-parent homes }(\beta=- \\
423, p<.05) \text { is related to reports of } \\
\text { physical maltreatment (Drake } \& \\
\text { Pandey, } 1996)\end{array}$} & & \multicolumn{2}{|c|}{$\begin{array}{l}\text { Percentage of } 2 \text {-parent families }(\beta \\
=.263, p<.05) \text { is related to reports } \\
\text { of neglect (Drake \& Pandey, } 1996 \text { ) }\end{array}$} \\
\hline
\end{tabular}

Neighborhood Education Risk Factor Physical/Sexual/Emotional/General Neglect

Drop-out rates $(\beta=-.162, p<.05)$ are related to neglect reports (Drake \& Pandey, 1996) 


\begin{tabular}{|c|c|}
\hline \multicolumn{2}{|c|}{ Neighborhood Social Support/lsolation Risk Factor } \\
\hline $\begin{array}{l}\text { Physical/Sexual/ } \\
\text { Emotional/Neglect }\end{array}$ & General \\
\hline & $\begin{array}{l}\text { Family support is highly negatively correlated } \\
(-0.41) \text { with individual child abuse potential } \\
\text { (CAP) scores (Merritt, 2009) }\end{array}$ \\
\hline & $\begin{array}{l}\text { Friend support is moderately negatively }(-0.33) \\
\text { with individual child abuse potential (CAP) } \\
\text { scores (Merritt, 2009) }\end{array}$ \\
\hline \multicolumn{2}{|c|}{ Neighborhood Child Care Burden Risk Factor } \\
\hline $\begin{array}{l}\text { Physical/Sexual/ } \\
\text { Emotional/Neglect }\end{array}$ & General \\
\hline & $\begin{array}{l}\text { Moderate positive correlation (0.31) between } \\
\text { child care burden and individual child abuse } \\
\text { potential (CAP) scores (Merritt, 2009) }\end{array}$ \\
\hline \multicolumn{2}{|c|}{ Neighborhood Alcohol Availability Risk Factor } \\
\hline $\begin{array}{l}\text { Physical/Sexual/ } \\
\text { Emotional/Neglect }\end{array}$ & General \\
\hline & $\begin{array}{l}\text { Bars per } 1,000 \text { population is positively related (b } \\
=0.7331 ; \mathrm{p}<0.01) \text { to child maltreatment } \\
\text { (Freisthler, 2004) }\end{array}$ \\
\hline \multicolumn{2}{|c|}{ Neighborhood Population Mobility/Density/Change Risk Factor } \\
\hline $\begin{array}{l}\text { Physical/Sexual/ } \\
\text { Emotional/Neglect }\end{array}$ & General \\
\hline & $\begin{array}{l}\text { Child maltreatment is positively related }(b= \\
0.0022 ; p<0.001) \text { to population per square mile } \\
\text { (Freisthler, 2004) }\end{array}$ \\
\hline & $\begin{array}{l}\text { Higher mobility is associated with a higher } \\
\text { recurrence ( } 64 \% \text { vs. } 61.3 \% ; p<0.001) \text { of child } \\
\text { maltreatment (Drake, Johnson-Reid, \& } \\
\text { Sapokaite, } 2006)\end{array}$ \\
\hline & $\begin{array}{l}\text { Neighborhood instability is negatively correlated } \\
(-0.12) \text { with neighborhood maltreatment rates } \\
\text { (Merritt, 2009) }\end{array}$ \\
\hline
\end{tabular}

\section{Consequences of Child Maltreatment}

Child maltreatment has extensive consequences spanning from individuallevel problems to societal-level concerns. On an individual level, being the victim of child maltreatment has been shown to result in problems such as delayed development, poor academic performance, delinquency and legal involvement, mental health problems, harmful sexual behaviors (e.g., rape or promiscuity), and other negative acting-out behaviors. Societal problems include exorbitant costs 
for foster care and other services, such as child welfare services, mental health services, and legal services. The remainder of this section will first examine the individual impact of child maltreatment and conclude with the societal impact of child maltreatment.

Micro-level consequences. Micro-level consequences include those consequences that impact individuals on an individual-level, such as behavioral problems, academic performance, and cognitive functioning. Before discussing each of these consequences, it is important to note that the impact of child maltreatment may differ depending upon the type and severity of maltreatment experienced by the child. Therefore, it is important to categorize maltreatment by type and/or severity in order to accurately determine the impact of maltreatment. Models that do not account for this difference may be misleading.

Pears and colleagues (2008) used Latent Profile Analysis in order to separate cases of maltreatment into four (4) groups (Neglect/Emotional Maltreatment; Sexual Abuse/Emotional Maltreatment/Neglect; Physical Abuse/Emotional Maltreatment/Neglect; Sexual Abuse/Physical Abuse/Emotional Maltreatment/Neglect) prior to comparing outcomes (cognitive functioning, internalizing behaviors, and externalizing behaviors). These groups differ in terms of severity of maltreatment. Compared to the first group (Neglect/Emotional Maltreatment), the second group adds only Sexual Abuse, the third group adds only Physical Abuse, and the fourth group adds both Physical and Sexual Abuse. Outcomes were composite measures taken from various validated scales where scores were first standardized and then 
averaged. For example, the cognitive functioning composite was derived from the Wechsler Preschool and Primary Scales of Intelligence-Revised, the NEPSY: A Developmental Neuropsychological Assessment, and the Preschool Language Scale-Third Edition; the internalizing problems composite was derived from the Oppositional Defiant Disorder and Conduct Disorder scale of the Early Childhood Inventory, the Aggressive Behaviors, Delinquent Behaviors, and Social Problems scales of the Child Behavior Checklist; the externalizing problems composite was derived from the Generalized Anxiety, Separation Anxiety, PTSD, and Social Phobia scales of the Early Childhood Inventory and the Anxious/Withdrawn scale of the Child Behavior Checklist.

Ultimately, Pears and colleagues (2008) found that children in the Sexual Abuse/Physical Abuse/Emotional Maltreatment/Neglect group (i.e., the most severe group) had a much lower mean score $(-0.72)$ on cognitive functioning than the Sexual Abuse/Emotional Maltreatment/Neglect (i.e., the second group) group (0.24). Thus, just the addition of the physical abuse resulted in significantly lower mean scores on cognitive functioning. This could be a result of the additional trauma caused by the physical abuse, such as head injuries and missed days of school due to visible signs of physical abuse. However, as with the study above, there was not any measure of cognitive functioning prior to the maltreatment incident. Therefore, it is difficult to attribute lower cognitive functioning to maltreatment without obtaining baseline scores prior to the maltreatment occurrence. 
In terms of externalizing problems, the Sexual Abuse/Physical Abuse/Emotional Maltreatment/Neglect group (i.e., the most severe group) had a much higher mean score $(0.75)$ than the Neglect/Emotional Maltreatment (i.e., the least severe group) group (0.09). Therefore, adding the combination of both physical and sexual abuse resulted in higher externalizing behaviors (Pears, Kim, \& Fisher, 2008). This could be a result of the self-destructive behaviors that are common in sexual abuse victims and aggression that is often seen by children who have been physically abused.

Lastly, the Sexual Abuse/Emotional Maltreatment/Neglect group (i.e., the second group) had the highest mean score (0.38) on internalizing problems while the Neglect/Emotional Maltreatment (i.e., the least severe group) group had the lowest mean score (0.01) on internalizing problems. Thus, here it is the addition of only Sexual Abuse that resulted in higher levels of internalizing behaviors (Pears, Kim, \& Fisher, 2008). This could be a result of depression and feelings of helplessness and guilt that generally arise in children who have been sexually abused. Ultimately, the results of this study give evidence to the fact that severity and type of maltreatment impact individual-level consequences of child maltreatment.

Emotional and behavioral consequences. Root and colleagues (2008) found that maltreated children, when compared to non-maltreated children, had significantly higher scores on both the externalizing and internalizing problems scale of the CBCL. Similarly, Shaffer and colleagues (2008) reported that $74 \%$ of their sample met diagnostic criteria for a clinical disorder and found that 
individuals who were maltreated as a child exhibited the most emotional and behavioral problems in adolescence.

There is a substantial amount of literature that supports the fact that child maltreatment negatively impacts the mental health (internalizing behaviors) and increases in acting-out behaviors (externalizing problems) of children who are maltreated. Furthermore, it is important to note that the impact of child maltreatment on the mental health of children is not discriminatory when it comes to race. Kaslow and Thompson (2008) examined several mental health conditions using three different validated scales (Child Behavior Checklist (CBCL), Youth Self Report (YSR), and Trauma Symptom Checklist for Children (TSCC)) among low socioeconomic status African American children. In this case, the CBCL and the YSR are similar measures with the exception being that the $C B C L$ is a parent self-report instrument while the $Y S R$ is a child self-report instrument. They found that in nine (9) out of ten (10) of the dependent variables (the internalizing and externalizing scales of the $\mathrm{CBCL}$, the internalizing and externalizing scales of the YSR, and the anxiety, depression, PTSD, disassociation, and sexual concerns scales of the TSCC), child maltreatment impacted the child's level of distress. The only scale that did not show any statistical significance was the anger scale of the TSCC (Kaslow \& Thompson, 2008). This may be due to the sample obtained in this study. Maltreatment was measured using the Childhood Trauma Questionnaire (CTQ), which is used to assess the presence of maltreatment. Consequently, not all children included in 
this sample were maltreated, which may have had an impact on the anger subscale of the TSCC.

While Kaslow and Thompson (2008) may not have found a relationship between anger issues and child maltreatment, Shaffer and colleagues (2009) found that increased aggression in middle childhood was associated with emotional neglect, emotional abuse, and social withdrawal in middle childhood and lower socioemotional competence in early adolescence. However, once they included gender and simultaneous physical and sexual abuse, the relationship between anger and emotional abuse dissolved. In fact, the only remaining statistically significant relationship was the impact that emotional abuse had on social withdrawal for boys only (Shaffer, Yates, \& Egeland, 2009). Therefore, anger was no longer significant once they accounted for gender and type or severity of maltreatment, which may have also been the issue in the Kaslow and Thompson (2008) study mentioned above.

The risk of criminal behavior also increases when a child experiences maltreatment (Root, et al., 2008). Root and colleagues (2008) compared maltreated and non-maltreated children and fire setting behaviors. They found that maltreated children were more likely to be frequently involved with fire, more resourceful in regards to sources and targets of fire, as well as using family stressors and anger as a motivator for setting fires (Root, et al., 2008). Using the $\mathrm{CBCL}$ to determine if child externalizing and/or child internalizing behaviors mediated the impact of maltreatment on the aforementioned fire setting behaviors, Root and colleagues (2008) noted that externalizing and internalizing 
problems only mediated frequency and resourcefulness of involvement with fire, while only externalizing problems mediated an individual's recidivism in regards to fire setting. As Root and colleagues (2008) discuss, this may be a result of a lack of knowledge regarding appropriate ways to express anger. Perhaps interventions aimed at developing appropriate coping skills, increasing parenting skills, or fostering emotional identification and awareness may reduce criminal behavior, such as fire setting, for those children who are maltreated.

Substance abusers, especially those that get involved with illegal substances as a child, generally have more difficulty maintaining employment, exhibit higher truancy rates from school, and have substance abuse issues as adults. Coupled with child maltreatment, the impact could be exacerbated. Defining binge drinking as consuming five (5) or more alcoholic beverages in a row at least two (2) to three (3) times per month in the past year, Shin and colleagues (2009) reported that children who had experienced neglect were 1.24 times more likely to binge drink, children who had experienced only physical abuse were 1.34 times more likely to engage in binge drinking, those who were victims of only sexual abuse were 2.26 times more likely to demonstrate binge drinking behavior, those who suffered both neglect and physical abuse were 1.33 times more likely to binge drink, and those children who had endured neglect, physical and sexual abuse were 1.79 times more likely to engage in binge drinking (Shin, Edwards, \& Heeren, 2009). However, when children were grouped as being maltreated versus not maltreated, there was no relationship between maltreatment and adolescent binge drinking. It was not until the co- 
occurrence of multiple categories of maltreatment was introduced that all demonstrated a significant relationship with adolescent binge drinking (Shin, Edwards, \& Heeren, 2009). This suggests that multiple categories of maltreatment, including both type and severity, be included in order to reveal all significant relationships.

Academic consequences. Child maltreatment also impacts a child's academic achievement in school. Coohey and colleagues (2011) examined both math and reading levels of children who experienced maltreatment at three points in time. Ultimately, they found that while chronic maltreatment did not impact reading levels directly, it did impact math scores $(p<0.001)$. More specifically, at Wave 1 , children who experienced chronic maltreatment scored 13.33 points lower on math scores, 5.93 points lower on math scores at Wave 2 , and 8.29 points lower on math scores at Wave 3 (Coohey, Renner, Hua, Zhang, \& Whitney, 2011).

Similarly, Fantuzzo and colleagues (2011) found that maltreatment impacted a number of subject areas using the TerraNova, Second Edition scale which measures reading, language, math and science levels. However, they accounted for timing (pre-post kindergarten) and type of maltreatment (substantiated physical abuse, substantiated neglect, unsubstantiated reports). While there was no statistically significant relationship between subject areas and physical abuse and either pre- or post-kindergarten substantiated physical abuse, there were statistically significant relationships for substantiated neglect and unsubstantiated reports (Fantuzzo, Perlman, \& Dobbins, 2011). More 
specifically, children who experienced pre-kindergarten neglect had an odds ratio of 1.31 in Reading $(p<0.05), 1.42$ in Language $(p<0.05)$, and 1.35 in Science $(p<0.05)$, but no statistically significant relationship in Math. Post-kindergarten neglect only demonstrated a statistically significant relationship on Science scores $(O R=1.41 ; p<0.001)$. Pre-kindergarten unsubstantiated reports of maltreatment demonstrated a statistically significant relationship on Reading (OR $=1.23 ; p<0.05)$, Math $(O R=1.34 ; p<0.001)$, Language $(O R=1.32 ; p<0.001)$, and Science $(O R=1.27 ; p<0.001)$ scores. Post-kindergarten unsubstantiated reports of maltreatment demonstrated a statistically significant relationship on Reading $(O R=1.50 ; p<0.05)$ and Language $(O R=1.79 ; p<0.01)$ scores only (Fantuzzo, Perlman, \& Dobbins, 2011). These results indicate that early maltreatment may have a more detrimental impact on academic performance than maltreatment that occurs later in development.

These studies indicate that there is an impact on academic performance for children who experience maltreatment. Furthermore, these studies highlight the importance of taking both type of maltreatment and developmental period at time of maltreatment into consideration when examining the impact of child maltreatment on child academic performance. There are multiple explanations as to why academic achievement may be impacted by child maltreatment, ranging from absenteeism to trauma suffered in the brain due to maltreatment.

Biological consequences. While there are many biological components that could be discussed in this section, the primary focus here will be on brain development. Child maltreatment may impact different areas of the brain that 
lead to long-lasting effects on child behavior and growth. What differentiates the impact on the brain from other consequences, such as behavioral and emotional consequences, is that damage to the brain is often irreparable.

Prior to a discussion of the impact of child maltreatment on brain development, it is important to give an overview of brain regions that may be impacted by child maltreatment. First, it is important to note that the level of gray matter in the brain is vital. Decreases in gray matter lead to inhibited functioning. Common areas of the brain that are often discussed are the hippocampus, the amygdala, the anterior cingulate cortex (ACC), the prefrontal cortex, and the adrenal cortex. The hippocampus is primarily responsible for short-term memory, long-term memory, and spatial navigation (Manns \& Eichenbaum, 2006). The primary function of the amygdala is facial recognition and an individual's ability to recognize emotions (Adolphs, 2002). The ACC primarily deals with rational cognitive functioning, such as processing conflict, planning, organizing, and implementing actions or behaviors (Weston, 2012). The prefrontal cortex functions as a regulator of emotional behavior (van Harmelen, van Toi, van der Wee, Veltman, Aleman, Spinhoven, van Buchem, Zitman, Penninx, \& Elzinga, 2010). The hypothalamic-pituitary-adrenal (HPA) axis is located in the adrenal cortex and is responsible for providing a feedback loops to regulate the release of hormones, such as cortisol (Miller, Chen, \& Zhou, 2007).

Now that an overview of brain functions have been given, it is appropriate to review current literature that outlines the potential impact on the brain for children who have experienced maltreatment. Thomaes and colleagues (2010) 
showed that there was a statistically significant relationship between child abuserelated complex PTSD and reduced gray matter volume in the right hippocampus region $\left(P_{\text {svc corrected }}=0.04\right)$ and the right dorsal $A C C\left(P_{\text {svc corrected }}=0.02\right)$. These results suggest that children with PTSD as a result of child maltreatment have reduced capacity to remember and rationally think through decisions.

Current research also indicates that the prefrontal cortex is also impacted by child maltreatment. Van Harmelen and colleagues (2010) examined individuals who experienced emotional maltreatment as a child and reported that there was a $7.2 \%$ reduction in the volume of the left dorsal medial prefrontal cortex. However, there were no statistically significant reductions in the hippocampus region or the amygdala (van Harmelen, et al., 2010). This suggests that children who experience emotional maltreatment during childhood have a decreased capacity to regulate emotional behavior. This could potentially result in risky behaviors and impulsivity.

There is also an impact on the release of hormones related to stress. The hypothalamic-pituitary-adrenal (HPA) axis is activated during stressful life events, such as child maltreatment. In fact, Carpenter and colleagues (2011) showed that there was a reduced level of cortisol released for women who experienced physical abuse in childhood when compared to women who did not experience physical abuse as a child. If not regulated properly or addressed, excess cortisol may result in both physical and mental health related issues (Carpenter, Shattuck, Tyrka, Geracioti, \& Price, 2011; Miller, Chen, \& Zhou, 2007). 
Mezzo-level consequences. Mezzo-level consequences include those issues related to agencies and administrators, including the services available for children who experience maltreatment. One of the major issues that child protection agencies and frontline workers have to face is overload and overcrowding. In a survey of child protection services administrators, it was reported that when caseloads increase there is a change in screening practices (Jones, Finkelhor, \& Kopiec, 2001; Wells, Downing, \& Fluke, 1991). This may result in cases not being accepted for investigated that perhaps should be investigated, which impacts the substantiation of cases. Substantiation of child maltreatment cases has been declining since the mid-1990s and there is much debate as to the reasons for this decline. Some suggest that increased caseloads and reduced resources are the cause (Finkelhor \& Jones, 2004; Jones \& Finkelhor, 2001; Jones, Finkelhor, \& Kopiec, 2001; Wells, Downing, \& Fluke, 1991), while others suggest that there has been an actual decline in child maltreatment (Almeida, Cohen, Subramanian, \& Molnar, 2008). Therefore, this is an issue that still does not have a clear and definitive answer. However, it still must be investigated and considered when examining consequences of child maltreatment.

Also, with cuts in Medicaid, there is also an impact on the services being provided to children who may be exposed to child maltreatment. As shown throughout the beginning of this section, many of the children who have substantiated cases of maltreatment come from poor families. Whether this is a result of discriminatory reporting practices is a trivial point in this section. 
However, what is important is that these children are the ones that rely on Medicaid and Passport to cover mental health issues. With these funds being cut and more stringent policies for community-based agencies to follow with regard to accepting these clients, it follows that many children will go without needed services.

Other service providers and mandated reporters also face consequences with regard to child maltreatment. Doctors and nurses are required to report to child protective services any case which they suspect may involve child maltreatment. However, as Hickey and Lyckholm (2004) point out, it is difficult to make a decision because of the struggle between parental autonomy and protecting the general welfare of the child. This becomes an ethical issue that mandated reporters have to struggle with on a daily basis. However, this is complicated even more by not having the same laws across states, including the fact that 33 states within the United States have laws protecting parents when a child dies as a result of not receiving timely and appropriate medical care (Hickey \& Lyckholm, 2004).

Macro-level consequences. Macro-level consequences of child maltreatment include both monetary (e.g., costs) and non-monetary factors (e.g., social policy). Both fiscal and non-fiscal factors impact society as a whole and must be considered in order to address and attempt to reduce child maltreatment. Each of these factors will be discussed in turn.

Monetary factors. Past research indicated that the estimated future loss to productivity as a result of child maltreatment ranges from between $\$ 658$ million 
and $\$ 1.3$ billion annually (Daro, 1988). More recently, this number has increased to over $\$ 33$ billion annually in 2007 (Wang \& Holton, 2007). However, future loss to productivity is not the only societal cost of child maltreatment. Total cost of child maltreatment in 2007 was over $\$ 103$ billion, accounting for costs associated with the victim. Other costs, such as treatment, associated with the perpetrator or other family members were not included in this figure (Wang \& Holton, 2007).

Wang and Holton (2007) broke down the $\$ 103$ billion figure into both direct and indirect costs associated with child maltreatment. Direct costs consisted of those costs that were a result of the immediate needs of the child, such as hospitalization, mental health services, child welfare services, and law enforcement. Indirect costs included long-term secondary effects, such as special education, juvenile delinquency, mental health and health care services, adult criminal justice services, and lost productivity to society. Based on their analysis, over $\$ 33$ billion were a result of direct costs, while more than two times that amount ( $\$ 70.6$ billion) were associated with indirect costs. More specifically, the individual costs were as follows: hospitalization ( $\$ 6.6$ billion), mental health ( $\$ 1.1$ billion), child welfare services ( $\$ 25.4$ billion), law enforcement $(\$ 33.3$ million), special education ( $\$ 2.4$ billion), juvenile delinquency ( $\$ 7.2$ billion), mental health and health care services ( $\$ 67.8$ million), adult criminal justice services ( $\$ 28.0$ billion) and lost productivity to society ( $\$ 33.0$ billion) (Wang \& Holton, 2007).

Non-monetary factors. Non-monetary macro factors primarily include definitional issues and policy implications related to child maltreatment. From a 
definitional perspective, what constitutes child maltreatment differs by state due to the fact that States determine their own laws regarding child maltreatment (U.S. Department of Health and Human Services, 2009). Until there is a consensus on what constitutes child maltreatment, including the subtypes of child maltreatment, there cannot be accurate measures of child maltreatment.

Furthermore, as alluded to in the beginning of this chapter, child welfare policy has continued to swing on a pendulum since the first identified case of child maltreatment. Politicians and citizens alike have struggled with defining child maltreatment and the states' role in protecting the child versus upholding parental autonomy. This has been reflected in the movement from immediate removal to family preservation to community intervention. As more and more individuals are beginning to realize that change cannot be solely achieved on the individual level, community intervention is becoming paramount. This is evident in President Obama's Strengthening Communities initiative, which has led to the Strengthening Families and Communities initiative to eradicate child maltreatment by the Children's Bureau (U.S. Department of Health and Human Services, 2011).

The Strengthening Families and Communities resource guide was developed in response to President Obama's Strengthening Communities initiative. The resource guide aims to assist communities in prevention measures to protect children from child maltreatment. It is based on five (5) identified protective factors (e.g., nurturing and attachment, knowledge of parenting and of child and youth development, parental resilience, social connections, and 
concrete supports for parents) that have been discussed throughout this first chapter. This resource guide is the culmination of decades of research and policy changes in the United States on child maltreatment. It includes information related to how to work with families to build on the five (5) aforementioned protective factors, how to engage communities in order to tap into resources and build community awareness, how to protect children from maltreatment including reporting of child maltreatment, resources for parents and practitioners, and tip sheets for parents that are written from a strengths-based perspective (U.S. Department of Health and Human Services, 2011). This is the foundation of child maltreatment prevention today and another step in the right direction for the prevention of child maltreatment in the United States.

\section{Summary}

Based on the above problem statement, one aspect is blatantly clear: there is a plethora of research on child maltreatment; however, the research is not comprehensive across different types of maltreatment. A majority of the literature included in this study focuses on child maltreatment in general. However, there are clear distinctions of child maltreatment between the different types of child maltreatment. How a child manifests the impact of physical abuse may be very different than how that child would manifest the impact of sexual abuse. Furthermore, child maltreatment does not only have immediate consequences, there are long-lasting effects of being maltreated as a child. If these children can be identified and appropriate interventions implemented, the impact of maltreatment may be minimized. This demonstrates why it is so 
important that these differences be accounted for and established in the literature.

Children and families do not exist in a vacuum. There are a number of factors outside an individual that influence who they become. A child grows up within a family who grew up within different families where values and child rearing approaches may be different. For example, a caregiver who grew up being maltreated as a child may continue that behavior when he or she has his or her own children or they may decide to end the cycle and make decisions in complete contradiction to the way he or she was taught and instead teach resilience to their children. Every family is influenced, either positively or negatively, by the environment in which they live and the relationships in which they surround themselves. A family living in a high crime area may have rules that seem strict to a suburban family, but are necessary in order to protect their children. A family that resides in the south, for example, is so much different than a family that lives in the north. A family living five (5) blocks away from the World Trade Center on September 11, 2001 is likely to be far different than a family living 5,000 miles away from the World Trade Center. The environment has an impact on everyone, including those children who have experienced child maltreatment.

Social work, as a profession, has known for years the impact that systems have on individuals. However, the models that have been analyzed are mostly individual-level models. Despite individuals like Urie Bronfenbrenner in Developmental Psychology and Carel and Alex Gitterman in Social Work 
outlining ecological and life models in the mid to late 1970s, researchers continued to model their problems as individual-level problems. This was due, partly, to the fact that such models required advanced statistical techniques that were very complex. However, now that software programs have been developed that allow such computation to be completed in seconds, it is time that social work moves in that direction (Payne-Sturges, Sanders, Zenick, \& Wells, 2006).

The discussion above examining the risk factors and consequences of child maltreatment illuminates the need for a multilevel approach. It is evident that children who are maltreated are victims of a larger society, a large problem. They do not grow up in a vacuum. The lives that children live are influenced by their parents or primary caregiver as well as the environment in which they live. This is not an individual level problem and should not be examined or analyzed as if it was only a child level problem. This fact is beginning to be realized by politicians and service providers, although there is much more work to be done in the area of child maltreatment prevention. The Strengthening Families and Communities initiative is a step in the right direction. However, much more needs to be done in terms of developing a uniform definition of child maltreatment as well as having uniform policies among child protection services agencies across the United States. 


\section{CHAPTER II: LITERATURE REVIEW}

There can be no better measure of our governance than the way we treat our children, and no greater failing on our part than to allow them to be subjected to violence, abuse or exploitation. Jessica Lange

Cicchetti (1996) argues that in order to understand any "normal" behavior, one must examine individuals in "abnormal," or adverse, situations. In order to successfully guide this journey of discovery, one must use theories. Theories are the foundation for all good research. They provide a basis upon which problems are formed and predictors are selected. As for child maltreatment, there are numerous theories from which to choose. For this discussion, however, only three theories utilized in child welfare will be examined: (a) Erikson's Theory of Psychosocial Development; (b) Attachment Theory; and (c) Ecological Systems Theory.

\section{Psychosocial Development Theory}

One of the major proponents of Psychosocial Development Theory was

Erik Erikson. Erikson came out of a psychodynamic tradition but sought to revitalize the Freudian movement (Roazen, 1976). Later, Erikson was mentored by Freud's daughter, Anna Freud, and gained a great deal of respect for her as a scholar and as a person (Schlein, 1987). Erikson focused on the psychosocial development of children and examined the entire life course from birth to old age. 
As one could imagine, the relationship between Freudian thought and Erikson's Psychosocial Development Theory is evident upon examination of the eight (8) life cycles he defined: (a) basic trust vs. mistrust (birth to 18months); (b) autonomy vs. shame and doubt (18 months to 3 years old); (c) initiative vs. guilt ( 3 years old to 6 years old); (d) industry vs. inferiority ( 6 years old to 12 years old); (e) identity vs. role confusion (adolescence); (f) intimacy vs. isolation (young adulthood); (g) generativity vs. stagnation (maturity); and (h) ego integrity vs. despair (old age) (Erikson, 1993). Erikson strongly advocated that in order to be a well-adjusted adult, one must successfully deal with each conflict or crisis that occurs in each stage. For example, an individual who fails to develop a healthy identity in stage five (5) will struggle to maintain healthy relationships and intimacy in stage (6) (Erikson, 1993). While there are some criticisms that there is not a hierarchical relationship between stages, there are also proponents that have set out to empirically prove this hierarchical structure (Beyers \& SeiffgeKrenke, 2010). Utilizing a longitudinal study design of 93 students, Beyers and Seiffge-Krenke (2010) demonstrated that there was a direct relationship between identity (e.g., early ego development) at age 15 and intimacy at age 25 but no relationship between early intimacy and later identity.

\section{The Stages Defined}

The first stage in Erikson's Psychosocial Development Theory is basic trust vs. basic mistrust, which occurs from birth to 18 months. As infants, parents are the basis upon which children develop trust or mistrust (Erikson, 1993). For example, infants are completely dependent upon their parent or some adult 
caregiver for food, clothing, shelter, and general basic necessities. Therefore, one would assume that when an infant is hungry, the parent or other adult caregiver will provide that child with food. Over time, the infant begins to trust the parent or other adult caregiver, which results in the parent or adult caregiver being able to leave the room without scaring the infant. Trust has been developed. While Erikson placed much of this responsibility on the mother, stating that "the firm establishment of enduring patterns for the solution of the nuclear conflict of basic trust versus basic mistrust in mere existence is the first task of the ego, and thus first of all a task for maternal care" (Erikson, 1993, p. 249), scholars and practitioners now know that "who" provides the care and nurturing is not as relevant as ensuring that that "someone" provides that care and nurturing.

Following the first stage, children enter a stage known as autonomy vs. shame and doubt from 18 months to 3 years of age. Here the child becomes slightly more self-sufficient and begins to crave independence (Erikson, 1993). Thus, it is important to encourage this independence with words and actions of affirmation in order to foster autonomy. However, if this yearning for independence is answered with ridicule and scorn, one will foster shame and doubt in the child (Erikson, 1993). According to Erikson (1993):

This stage, therefore, becomes decisive for the ratio of love and hate, cooperation and willfulness, freedom of self-expression and its suppression. From a sense of self-control without loss of self-esteem comes a lasting sense of good will and pride; from a sense of loss of self- 
control and of foreign overcontrol comes a lasting propensity for doubt and shame. (p. 254).

In the third stage of psychosocial development, children ages 3 to 6 begin moving around freely, exploring their surroundings and developing relationships. Ultimately, if this behavior is encouraged, children will develop a sense of selfconfidence and be more likely to initiate relationships in the future. However, if this behavior is prohibited, children will be more likely to develop a sense of guilt as a result of their natural longing to explore and initiate relationships (Erikson, 1993).

From the ages of 6 to 12 , children enter into the industry vs. inferiority stage of psychosocial development. This is the time children begin entering the school system where mastery of subject content becomes important. The more successful a student is at mastering subject content, the more industrious the child will feel. However, if a student fails to master subject content, he or she will most likely acquire feels of inferiority (Erikson, 1993).

Stage 5 of Erikson's Psychosocial Development Theory is probably the most difficult for children as they are also entering adolescence. Adolescents are beginning to develop a sense of identity and find their place within society. If problems persist during this stage, children will progress into adolescence with no real sense of who they are as an individual. Uniqueness and forming and maintaining peer relationships become paramount (Beyers \& Seiffge-Krenke, 2010). Think about adolescence and the different peer groups that exist in high schools. There were "preps", "athletes", "grunge", "druggies", "nerds", and the list 
goes on infinitely. Where an individual chooses to belong becomes part of their identity. However, there are always those individuals that did not fit in one of those peer groups, as Erikson (1993) points out:

In most instances... it is the inability to settle on an occupational identity which disturbs individual young people. To keep themselves together they temporarily overidentify, to the point of apparent and complete loss of identity, with the heroes of cliques and crowds. (p. 262)

The inability to fit into a peer group can have a devastating impact on later psychosocial development. However, it may also result in bullying and increases in teen suicide, as this has become a major problem of the $21^{\text {st }}$ century.

Intimacy vs. isolation occurs in young adulthood, according to Erikson (1993), where love relationships are of primary importance. It is during this stage that individuals seek intimacy or closeness with another individual. However, if other stages have not been mastered, as discussed previously, this may be a difficult thing to attain. How can one have intimacy without trust or a sense of who they are as an individual? According to Erikson (1993), intimacy is "the capacity to commit himself to concrete affiliations and partnerships and to develop the ethical strength to abide by such commitments, even those that may call for significant sacrifices and compromises" (p. 263). Failure to attain intimacy in this stage results in isolation, which may eventually lead to "characterproblems," as defined in psychopathology (Erikson, 1993).

Erikson's seventh stage is known as generativity vs. stagnation, which occurs during maturity. During this stage, parenting and creating are important 
life events. Individuals who have a sense of generativity look to the future and seek to leave something better behind. These are the individuals who are actively engaged in community life and bring awareness to social problems.

Generativity, then, is primarily the concern in establishing and guiding the next generation, although there are individuals who, through misfortune or because of special and genuine gifts in other directions, do not apply this drive to their own offspring. And indeed, the concept generativity is meant to include such more popular synonyms as productivity and creativity (Erikson, 1993, p. 267)

On the other hand, stagnation refers to those individuals who are generally selfcentered and have no desire to give back to the world. They are generally isolated and lack productivity in their lives; they become stagnant (Erikson, 1993).

During old age, individuals enter the final psychosocial stage known as ego integrity vs. despair. The most important life event that occurs during this stage is reflection on one's own life. As an individual looks back over his or her life, he or she will either see a life they can be content with or one where there are many regrets.

Only in him who in some way has taken care of things and people and has adapted himself to the triumphs and disappointments adherent to being, the originator of others or the generator of products and ideas - only in him may gradually ripen the fruit of these seven stages. I know no better word for it than ego integrity. (Erikson, 1993, p. 268) 
According to Erikson (1993), the former will experience peace and joy and a sense of ego integrity, while the latter will experience despair. "Ego integrity, therefore, implies an emotional integration which permits participation by followership as well as acceptance of the responsibility of leadership" (Erikson, 1993, p. 269).

\section{An Application of Erikson's Theory}

Using Erikson's model, Table 5 below shows two hypothetical life trajectories: one child born into a loving and caring family where growth and development is fostered; one child born to an abusive and neglectful family where maltreatment is incorporated into daily activities. For illustrative purposes, the first child will be referred to as Jane, the second as Suzy. Please note that the following stories or life trajectories represent two (2) extremes of psychosocial development. There are many variations and outliers to every case and child maltreatment and development research must take into account all of the life trajectories in between these two (2) extremes.

\section{Table 5}

Hypothetical Life Course using Psychosocial Development Theory

\begin{tabular}{|c|c|}
\hline \multicolumn{2}{|c|}{ Trust vs. Mistrust } \\
\hline Jane & Suzy \\
\hline $\begin{array}{l}\text { Jane comes from a loving family where she is } \\
\text { fed, clothed, and protected. As a result, she } \\
\text { develops a sense of trust based on the } \\
\text { relationship formed with her parents. She is } \\
\text { taught that her parents are dependable and } \\
\text { predictable. }\end{array}$ & $\begin{array}{l}\text { Suzy is born into a family that does not want } \\
\text { her and consequently ignores her cries for food } \\
\text { and does not pay attention to her safety. Suzy } \\
\text { fails to develop a sense of trust as her basic } \\
\text { needs are not being met. She is taught that } \\
\text { people are not dependable and the world is } \\
\text { generally unpredictable. }\end{array}$ \\
\hline \multicolumn{2}{|c|}{ Autonomy vs. Shame and Doubt } \\
\hline $\begin{array}{l}\text { As Jane grows and begins to walk and become } \\
\text { toilet trained, she develops a healthy sense of } \\
\text { self. She begins to realize that she has some } \\
\text { control over herself and can exercise some } \\
\text { level of independence. }\end{array}$ & $\begin{array}{l}\text { Suzy's parents continue to ignore her basic } \\
\text { needs, so from the beginning, Suzy is behind in } \\
\text { learning basic motor skills. Suzy is ridiculed } \\
\text { and made fun of because she cannot do what } \\
\text { other children her age are doing and }\end{array}$ \\
\hline
\end{tabular}


consequently develops a sense of shame and doubts her ability to perform tasks.

Jane becomes more independent and begins to develop more self-confidence. Thus, she begins to initiate relationships with her peers and exhibit assertiveness.

\section{vs. Guilt}

Since Suzy, by this time, has developed a low self-esteem, she continues to doubt her ability to do well in school, make friends, and even begins to question her own likeability. She begins to feel like this is all her fault because she is too stupid to keep up with "normal" people, which results in extreme guilt.

\section{Industry vs. Inferiority}

Now that Jane has developed a social network and has established a healthy self-esteem, she begins to lead others and take control of situations. As a result, she has developed extraordinary problem-solving skills and has become popular in school.

Seeing that Suzy has developed a guilty personality, her father begins to take interest in her sexually. Knowing that Suzy will blame herself for the sexual abuse and be too afraid and ashamed to tell anyone, her father begins to beat her, molest her, and eventually have intercourse with her. Suzy begins to think she is invisible and develops a sense of inferiority.

\section{Identity vs. Role Confusion}

Popularity and a healthy self-esteem have helped Jane develop a good sense of who she is as a woman. She begins to find her place in the world and becomes more independent as she weighs her options to attend college.

Suzy is broken and defeated. She has no sense of who she is or what her role is in this world. She begins to question why she was born and beg for some type of answer. "Who am I?" "Why is this happening to me?" "What does the future hold for me... why do I go on?"

\section{Intimacy vs. Isolation}

As she weighs her options for secondary education, she falls in love with the quarterback of her high school football team. Since she learned how to trust and developed as a strong, independent woman, she was able to give her heart to him. They made plans to attend the same Ivy League University and get Not finding answers to her questions, Suzy begins to contemplate taking her own life. There is no reason for her to be in this world. She has been neglected, beaten, and sexually assaulted her whole life. She has nobody she can turn to. She is all alone. "I am nobody." married in the Fall.

\section{Generativity vs. Stagnation}

Life continues to go well for Jane. She married Jack in the Fall and they have a successful marriage with their first child on the way. She graduated Summa Cum Laude and is active in her community and career.

As her life comes to an end, Jane sits in her living room surrounded by her family and friends. She reflects back on her life and smiles. She has lived her life with a great deal of integrity and love. As she closes her eyes for the last time, she feels the tiny little fingers of her last grandchild wrap around her pinky. A tear falls from her eye... her journey has come to an end.
Rather than killing herself, Suzy discovers that drugs and alcohol are amazing ways to cope with her abuse. Living on the streets, she no longer has to feel the pain she has endured all her life.

\section{ntegrity vs. Despair}

Then, at the age of 45 , despite many attempts to resolve earlier mistakes in her life, Suzy realizes that she cannot do this anymore. Drugs and alcohol only mask the pain and it takes more and more to forget her past. As she reflects on her life, she comes to the conclusion that she is nobody. "The world won't miss me. I can just take these pills, drink this bourbon, and pull the trigger ... it will all finally be over." BANG! 
With Erikson's argument that future success in developmental stages is largely based on previous success in prior stages, it is clear that by the time Suzy reaches Stage 8 and begins reflecting on her life, there is no alternative but despair. Throughout her life course, she was unable to trust, develop a positive sense of self, or form meaningful and lasting relationships with others, resulting in a life full of regrets. Two little girls, born at the same time and place, ended up with two very different outcomes. Hypothetical stories like these happen every day in the United States. Where can policy makers and clinicians intervene? How can one person become a catalyst for change? It is imperative that we use theories, like Erikson's, to empirically determine the best course of action when faced with stories like Jane's and Suzy's.

\section{Psychosocial Development Theory and Child Maltreatment}

Child development is negatively impacted by child maltreatment. "Child maltreatment may represent the greatest failure of the environment to provide opportunities for normal development" (Cicchetti, 1996, p. 19). While true, it is difficult to determine the extent that child maltreatment hinders future development. Other confounding factors, such as family dysfunction, socioeconomic status, and societal norms, may sometimes disguise the developmental impact of maltreatment. Thus, it has been recommended that in order to accurately examine the developmental impact of child maltreatment, one must approach it from a life span perspective (Cicchetti, 1996). This would mean an increase in longitudinal studies that examine the impact of child maltreatment over an extended period of time. 
In order for this type of research to occur, one must first define maltreatment from a developmental perspective. In other words, one must take into account the age at which maltreatment occurs before the impact is assessed. Graham and colleagues (2010) did this by examining the chronicity of maltreatment based on Erikson's psychosocial development stages. They evaluated the effects of patterns of maltreatment across developmental stages. They evaluated the effects of patterns of maltreatment across developmental stages on child outcomes, such as peer relationships. Ultimately, they found that using a definition of maltreatment based on developmental stages was a better predictor of child peer relationships than using typical definitions based on the duration of maltreatment. Furthermore, findings indicated that using a developmental definition of child maltreatment was a more accurate predictor of aggressive peer relationships than a durational definition of maltreatment (Graham, English, Litrownik, Thompson, Briggs, \& Bangdiwala, 2010). Impact on development may also have differential outcomes based on the type of maltreatment experienced by the child. For example, Fergusson and colleagues (2008) found that children that experience sexual abuse involving "attempted or completed sexual penetration" were 2.4 times more likely to exhibit mental health disorders later in life, such that the impact of physical abuse appeared to be dissolved by other confounding factors, such as socioeconomic status. Conceptually, this makes sense due to the level of stigma and selfloathing that generally accompanies long lasting and devastating sexual abuse. Eventually these issues surface and require the individual to deal with them 
appropriately, but the damage to the individual's development has already occurred.

\section{Attachment Theory}

Attachment Theory is an important theory to consider when examining child maltreatment. As Holmes (1993) notes, "the remarkable feature of attachment bonds is their durability. The persistence of attachment in the face of maltreatment and severe punishment has enormous implications for child and adult psychopathology" (p. 72). The first major proponent of Attachment Theory was John Bowlby in the 1960s. Since Bowlby, several others, such as Mary Ainsworth, have expanded on and modified what is known today as Attachment Theory (Holmes, 1993). The remainder of this section will give an overview of Attachment Theory and present research related to child maltreatment using Attachment Theory.

\section{The Separation from Psychoanalytic Theory}

Attachment Theory was born out of Psychoanalytic Theory and Ethology. However, Bowlby began to become uncomfortable with some of the major tenets of these theories. For example, Freud strongly believed that a child's attachment to his or her mother was instinctual and sexual. Bowlby, however, argued that this was not the case and that a child's bond with his or her mother is largely psychological. As Bowlby began realizing some potential discrepancies in Psychoanalytic Theory, a study by Harlow was published showing that monkeys attached to a "fuzzy" monkey rather than a "wire" monkey that provided food. 
Hence, this began to support Bowlby's claim that there was more to attachment than food provision or instinct (Bowlby, 1973).

Another issue that Bowlby found with Psychoanalytic Theory was its complete disregard for environmental threats. "Bowlby criticizes psychoanalysts for their over-civilized view of man in which they discount environmental threat and emphasize instead the projection of 'internal' dangers (feelings of rage and hatred, for example) onto a neutral or benign environment" (Holmes, 1993, p. 65). Environmental threats, such as child predators, are and always have been a reality. Thus, children attach to their parents for protection.

Lastly, a third complaint that Bowlby had with Freud dealt with a linear trajectory of personality development proposed by Freud. According to Freud, every child goes through certain phases of personality development in a linear fashion. Additionally, this is the same for all children to the extent that it was almost pre-determined. Bowlby, on the other hand, argued that such a uniform linear trajectory does not exist because there are multiple developmental paths upon which an individual may take. Additionally, these paths are largely dependent upon the environment in which the child grows.

\section{Bowlby's Attachment Theory}

Bowlby's frustration with Freud's Psychoanalytic Theory paved the way for his own formulation of what is known today as Attachment Theory. According to Bowlby, the most influential individual in a child's life is his or her mother. He argues that physical, intellectual, behavioral and emotional damage is the result of maternal deprivation, or the withdrawal of something that was previously 
present, which ultimately results in the child's inability to form healthy and appropriate bonds with others (Bowlby, 1988). Based on this argument, Bowlby strongly opposes immediate separation after birth and institutional care for children (Bowlby, 1953).

Institution-raised children grow less well, and are retarded in their acquisition of language, and as they become older show evidence of impaired ability to form stable relationships - often tending to be superficially friendly but promiscuous (either metaphorically or literally) in their relationships. (Holmes, 1993, p. 39).

However, the impact of maternal separation may be time specific. Bowlby argued that delinquent character development is the direct result of prolonged maternal separation within the first five (5) years of life. Additionally, lack of maternal care may also produce intergenerational effects; however, these may be mediated or dissolved by social, economic and psychological interventions (Bowlby, 1940).

Both the state and quality of a child's attachment is encapsulated in the term "attachment" (Holmes, 1993). Thus, it does not just consider the duration of interaction with a caregiver, but also whether that relationship is positive and meaningful. According to Bowlby, attachments will either be secure or insecure, which is based on the quality rather than the duration of the relationship. However, the development of attachment styles is a continual process spanning the life cycle (Bowlby, 1998). While the ways in which attachment occurs may change, the underlying principles remain the same. 
Defining attachment. As previously mentioned, "attachment is an overall term which refers to the state and quality of an individual's attachments" (Holmes, 1993, p. 67). Individuals form attachments by their attachment behavior, which is "any form of behaviour that results in a person attaining or retaining proximity to some other differentiated and preferred individual" (Holmes, 1993, p. 68). In other words, attachment behavior encompasses those behaviors that children employ in order to keep their caregiver close and prevent separation. While in the early years this generally takes the form of acting out behaviors, such as crying or throwing a tantrum, in later years this begins to be more manipulative as the child becomes capable of logical thinking.

Attachment and attachment behaviour are based on an attachment behavioural system, a blueprint or model of the world in which the self and significant others and their interrelationship are represented and which encodes the particular pattern of attachment shown by an individual. (Holmes, 1993, p. 68).

There are three (3) key features of Attachment Theory: (a) proximity seeking to a preferred figure; (b) the secure base effect; and (c) separation protest (Weiss, 1982). Basically, a child will identify an individual, usually the mother or primary caregiver, to whom he or she will attach. Once this attachment is formed, the child will go to whatever lengths needed in order to remain in close contact with the identified individual. However, the space needed will depend on several factors, such as age, surroundings (e.g., safe, unsafe), and the length of time since the last separation (Weiss, 1982). For example, if 
the child has been separated from his or her mother or primary caregiver for the last eight hours, the child will be less likely to let the mother or primary caregiver out of sight once he or she arrives home. The secure base effect, a termed coined by Mary Ainsworth, deals with safety. A child who can see his or her mother is more willing to explore the surroundings and drift away from the mother. However, if that child begins to feel unsafe or the distance becomes too far, the child will run back to the mother, the secure base (Ainsworth, 1982). "Where no secure base exists, the individual... resorts to defensive manoeuvres... in order to minimize the pain of separation anxiety, and, if needs be, to manipulate support at the expense of truly reciprocal companionship" (Holmes, 1993, p. 71).

Lastly, separation protest refers to the actions taken to show that separation is not wanted. A young child removed (voluntarily or involuntarily) from his or her parent or primary caregiver is likely to resort to crying, screaming, and hitting in order to remain with that individual (Weiss, 1982). For example, a child who is left with a babysitter so his or her parent or primary caregiver can go out for the evening will often show negative behaviors before that individual is able to leave. However, this behavior may also persist once the parent or primary caregiver returns as a way to punish that individual for leaving him or her.

Developmental phases of attachment. As mentioned earlier in this section, attachment is a process that is developed over the course of a child's life. Attachment generally occurs in four (4) phases: (a) orientation; (b) pattern 
recognition; (c) set-goal attachment; and (d) formation of a reciprocal relationship. Orientation and pattern recognition take place between birth and six (6) months. During this phase, a child begins to recognize his or her mother and other close persons such as his or her father, sibling or siblings, and other caregivers (e.g., grandparents, day care teachers). Maternal responsiveness is extremely important during the orientation phase. If the mother fails to respond affectionately, the child may experience developmental issues later (Holmes, 1993). A pattern begins to form based on the facial recognition that occurs during the orientation phase. This is the onset of the second phase of attachment known as pattern recognition. During pattern recognition, the child begins to respond differently to the mother's or primary caregiver's voice and presence. This is the beginning of awareness and alertness that an infant goes through during the first stages of life (Holmes, 1993).

During the third phase, which occurs from six (6) months to three (3) years, set-goal attachment begins to take place. Set-goal attachment is the process a child utilizes "to keep 'close enough' to the mother: to use her as a secure base for exploration when environmental threat is at a minimum, and to exhibit separation protest or danger signaling when the need arises" (Holmes, 1993, p. 75). It is evident, therefore, that if the parent or primary caregiver is neglectful and does not appropriately respond to "danger signaling," for example, the child may begin to feel anxious or abandoned in a time of need.

The fourth and final phase of attachment development begins at the age of three (3) and continues throughout the life cycle. During this stage, the child 
begins to realize that he or she must share the mother or primary caregiver with other individuals as well as other obligations (e.g., work). This is the beginning of forming a reciprocal relationship. If properly developed, this provides the child with a healthy and appropriate foundation upon which to build future relationships (Holmes, 1993).

\section{Mary Ainsworth and Attachment Styles}

Mary Ainsworth built off of the foundation first set by Bowlby. Ainsworth and colleagues (1978) defined four (4) basic attachment styles: (a) secure attachment; (b) insecure-avoidant; (c) insecure-ambivalent (anxious-ambivalent); and (d) insecure-disorganized. These styles were named based on behavior exhibited by both the child and the caregiver once the researcher and caregiver left the child alone in a room. Ainsworth also noted that the child's behavior upon re-entry by the researcher and caregiver was largely influenced by the caregiver's response as well as the child's individual feelings about the separation.

Children classified as having a secure attachment had mothers that were very attentive to their children's signals and emotions, encouraged the child to explore the environment away from the mother's side, spoke calmly and assured them that they would return, and showed excitement when reunited with their child. Securely attached children showed minimal evidence of distress upon separation from their mother but quickly calmed down and upon reuniting, the child ran to the mother with joy and was then able to contently return to play (Ainsworth, Blehar, Waters, \& Wall, 1978). 
Mothers of insecure-avoidant children were very negative both about and toward their children. They did not encourage exploration of the environment, simply left the room without any reassurance to the child, and were not particularly happy to see their child upon their return. Insecure-avoidant children showed few signs of distress upon separation and ignored their mother, or went in the opposite direction, when reunited, especially on the second occasion when the stress is presumably greater. The children remained watchful of their mother and restrained in their play (Ainsworth, Blehar, Waters, \& Wall, 1978).

Mothers of insecure-ambivalent, or anxious-ambivalent, children were very anxious themselves, very self-focused on their own emotions and needs, clung to their children, did not focus on the child's emotional and/or cognitive needs, did not encourage exploration, forced the child to do what the mother wanted to do in terms of play and behavior, showed distress when they left their child and while happy to reunite with their child caused an ambivalent reaction in the children who hesitated before clinging to her for dear life upon reunion. These children generally have the hardest time with separation. Additionally, they often cannot be consoled once the period of separation has ended. They tend to be ambivalent, or wavering, in their feelings toward the mother upon reunion. At one point, they are seeking closeness and the next they are angry. This resembles a classic tug-of-war where, here, the child does not know whether to draw near to the mother or push her away (Ainsworth, Blehar, Waters, \& Wall, 1978). 
The most recent attachment style to be defined is the insecuredisorganized group. These children "show a diverse range of confused behaviours including 'freezing,' or stereotyped movements, when re-united with their parent" (Holmes, 1993, p. 105). This attachment style resembles, partially, a deer in headlights reaction. The child sees the mother but is confused about the proper reaction to have and subsequently decides not to have any reaction at all, but rather freeze. Here, the mother appears frightened, withdrawn, negative, confused, and demonstrated errors in affective communication. In addition to "freezing" behavior, the child was also observed rocking and exhibiting contradictory behaviors (e.g., approaching mother with back turned) (Main \& Solomon, 1986).

\section{Attachment Theory and Child Maltreatment}

While Attachment Theory focused primarily on the mother-child relationship, it is also important to consider other relationships, such as the father-child or grandparent-child relationship. The impact of these relationships, or attachments, is growing in the research literature, especially in light of the growing number of stay-at-home fathers as well as the increase in the number of grandparents as the primary caregivers for children. Additionally, environmental factors also need to be given much attention due to its potential impact on child development. However, regardless of which factors Attachment Theory focuses on, it is important to note that attachment not only impacts the individual, but also other involved in that individual's life (Payne, 1997) 
One risk factor of child maltreatment is previous parental history of maltreatment as a child. Attachment Theory appears to support, or at least partially explain, this idea of intergenerational maltreatment. Baumrind (1994) states that "the most frequent explanation of intergenerational transmission of maltreatment...comes from attachment theory" (p. 366). Basically, a child develops a model of parenting based upon the reality in which he or she lives and it is often difficult to change this model over time. However, there may be hope for these children, or future parents. If positive relationships are formed and maintained, either through love relationships or other familial bonds, the negative trajectory set out for these children may be changed (Baumrind, 1994). Thus, finding supportive environments outside the immediate home may in fact counter the negative consequences and alter the outcomes. Perhaps Bowlby was right when he argued that child development was not predestined, as Freud suggested.

Éithier and colleagues (1995) compared negligent mothers with nonnegligent mothers in terms of childhood adversity, parental stress, and depression from an Attachment Theory perspective. Utilizing a semi-structured interview to capture childhood adversity (separations from parent; non-availability of affection; psychological and physical abuse; sexual abuse), they found that it was not the frequency with which these events occurred in a caregiver's past, but rather the intensity with which they occurred. For example, the negligent group was the only group that experienced sexual abuse, either in terms of rape or prostitution. Additionally, negligent mothers were more likely to be removed from 
their home and placed in foster care, experience physical abuse, and experience abuse by a higher number of perpetrators. "The emotional intensity experienced following such an event was linked not only to the nature of the event but also to the context in which this event took place and to the consequences which it would have on the child's future affective relationships" (Éithier, Lacharité, \& Couture, 1995, p. 629). In other words, the trauma experienced as a child impacted the caregiver's development, which in turn impacted their ability to form healthy attachments with their child.

Also utilizing an Attachment Theory perspective, Aber and Allen (1987) examined the effects of maltreatment on a child's socioemotional development by comparing three (3) groups (children from maltreating families, AFDC families, and middle-class families) on two (2) factors (secure readiness to learn and outer directedness) that were derived following a factor analysis on the ten (10) original dependent variables. The ten (10) original dependent variables, and their measurement in parentheses, were as follows: dependency (Marble-in-the-Hole game), wariness (Marble-in-the-Hole game), interpersonal distance (Felt Board game), imitation (Sticker Game Imitation task), pictorial curiosity (assessed using 12 cardboard houses each with a pair of doors where 1 door is blank and the other is not), variability seeking (Box Maze), verbal attention seeking (measured during other activities by watching video tape and recording whether the child asked for something), approval seeking smiles (measured during other activities by watching video tape and recording whether the child sought a smile from the game participant), and cognitive maturity (Peabody Picture Vocabulary Test, 
Form $L$ ). The secure readiness to learn factor captured a child's willingness to explore when surrounded by adults who were unfamiliar. Thus, this factor was high in pictorial curiosity, variability seeking, and cognitive maturity and low in dependency. The outer directedness factor measured the child's ability to solve problems by using external cues rather than his or her own cognitive ability. Thus, this factor includes measures of verbal attention seeking, approval-seeking smiles, wariness, and imitation. Ultimately, Aber and Allen (1987) found that children from maltreating families scored significantly lower than the AFDC and middle-class families on the secure readiness factor. However, while children from maltreating families scored significantly higher than children from middleclass families on the outer readiness factor, there was no statistically significant difference between children from maltreating and AFDC families. Therefore, Aber and Allen (1987) concluded that:

Similar to the organization construct of security of attachment in infancy, secure readiness to learn in early childhood also appears to represent a dynamic balance between establishing safe, secure relationships with adults and feeling free enough to venture out to explore the world in a manner that is likely to promote maturation of cognitive competencies. ( $p$. 411)

These results indicate that children from maltreating families are less likely to venture out and explore their surrounding due to the lack of a secure base. Failure to explore and learn generally has lasting developmental consequences, 
as learning, emotional, and social development is often delayed or never properly formed in adulthood.

Examining attachment styles of children who have been physically and verbally maltreated, Reinert and Edwards (2009) examined the relationship between same-sex parent attachment (daughter-mother; son-father) and opposite-sex parent attachment (daughter-father; son-mother). They found "that verbal and physical childhood maltreatment generally adversely related to attachment dynamics, but...also found important sex differences" (Reinert \& Edwards, 2009, p. 593). Ultimately, the results seem to support Bowlby's assertion that the maternal attachment is paramount. Attachment with the mother, regardless of child's gender, overall demonstrated higher correlations with verbal and physical maltreatment ( $.15-.65$ vs. $.07-.48)$. Additionally, attachment with the same-sex parent demonstrated higher correlations on both anxious (.07- .60 vs. $.09-.40)$ and avoidant ( $.29-.65$ vs. $.15-.37)$ attachment for children who experienced both physical and verbal maltreatment. Reinert and Edwards (2009) conclude by saying that:

From an attachment theory perspective, the purpose of the attachment dynamics is for safety and security, and this, combined with sex identification with mother in young adulthood, may make females more likely than males to interpret their suffering abuse as a maternal failure to protect. (p. 595)

These are only a few of the hundreds of studies conducted surrounding the importance of Attachment Theory in understanding child maltreatment. While 
results may vary from study to study, there is a general consensus that having a positive attachment during childhood is paramount. Being able to rely on a caregiver to supply basic necessities as an infant, as well emotional and cognitive stimulation throughout the life cycle is important in child development, adjustment, and in forming healthy relationships later in life. These all stem from experiencing healthy and balanced attachments throughout the life course.

\section{Ecological Systems Theory}

"An ecological perspective is particularly well suited to issues like the consequences of child maltreatment that are dominated by the interplay of individual factors, social resources, cultural definition, and public policy" (Garbarino, 2005, p. 300). Ecological Systems Theory was developed by Urie Bronfenbrenner in the early 1970 s. Bronfenbrenner understood that individuals were affected by the surrounding environment. There is a definite interaction that occurs between a person and his or her environment that impacts behavior, but as of yet, it had not been modeled or generally accepted. Bronfenbrenner set out to not only conceptually model his idea, but also to empirically validate his theory. He argued that "the ecological environment is conceived as a set of nested structures, each inside the next, like a set of Russian dolls" (Bronfenbrenner, 1979, p. 3). As it relates to child maltreatment, it is clear that children are nested within families that are nested within environments (e.g., neighborhoods, counties, schools). Thus, a careful examination of Bronfenbrenner's Ecological Systems Theory is necessary. 


\section{Development from Bronfenbrenner's Perspective}

Before examining the systems in which an individual develops, it is important to define development from Bronfenbrenner's perspective. According to Bronfenbrenner, "development is defined as the person's evolving conception of the ecological environment and his relation to it, as well as the person's growing capacity to discover, sustain, or alter its properties" (Bronfenbrenner, 1979, p. 9). From this definition, one can see that an individual's perception of their environment can change over time; it is not static. Additionally, not only must one consider how an individual perceives his or her environment, but also how that individual interacts with his or her environment. Lastly, and maybe most importantly, is the idea that an individual has the potential to not only discern what makes up his or her environment, but also has the ability to change the environment.

Human development is the process through which the growing person acquires a more extended differentiated, and valid conception of the ecological environment, and becomes motivated and able to engage in activities that reveal the properties of, sustain, or restructure that environment at levels of similar or greater complexity in form and content. (Bronfenbrenner, 1979, p. 27)

Bronfenbrenner posited that individual human development is influenced by the individual's interaction with their environment. However, not only is the actual environment in which an individual lives important, but the individual's perception of their environment also impacts human development and behavior 
(Bronfenbrenner, 1979). For example, an individual may live in a community in which there is relatively little crime; however, if that individual perceives his or her community to be unsafe, his or her behavior is going to be a result of perception rather than reality, or empirical evidence. Similarly, actually residing in an unsafe neighborhood will also impact human development and behavior.

\section{The Building Blocks}

Bronfenbrenner focused on eight (8) components he felt formed the "building blocks" of one's environment: (a) molar activity; (b) dyads; (c) role; (d) setting; (e) social network; (f) institutions; (g) subculture; and (h) culture. "A molar activity is an ongoing behavior possessing a momentum of its own and perceived as having meaning or intent by the participants in the setting" (Bronfenbrenner, 1979, p. 45). Therefore, it is a dynamic process that continues over time and builds off of individual meaning or purpose. A dyad consists of two (2) individuals, usually a caregiver and a child in the context of child maltreatment. In regard to Bronfenbrenner's Ecological Systems Theory, he noted three types of dyads that exist in the environment: (a) an observational dyad; (b) a joint activity dyad; and (c) a primary dyad. An observational dyad exists in early childhood and can best be described as learning by watching. A joint activity dyad would include a "learning by doing" component and requires reciprocity, a balance of power, and affective relations. "A primary dyad is one that continues to exist phenomenologically for both participants even when they are not together" (Bronfenbrenner, 1979, p. 58). This would encompass relationships beyond the physical presence of individuals. 
"A role is a set of activities and relations expected of a person occupying a particular position in society, and of others in relation to that person" (Bronfenbrenner, 1979, p. 85). For example, as a mother, her expected role might be to take care of the children. Setting refers to an individual's environment and can influence other factors, such as roles and activities. Social networks include the dyad and at least one (1) other person, which may include spouses, relatives, friends, neighbors, or any other third party. However, Bronfenbrenner argued that if this third party (e.g., paramour, spouse) is absent or disruptive, it will negatively impact the child's development because the entire system will break down. Institutions refer to those places in which individuals may develop, such as group homes and nursing homes. A subculture includes the ideas and values of a specific group of individuals that may exist within a larger culture. It is important to note that different ideas and values are held within different cultures and it is therefore vital to study individuals in different cultural contexts. Bronfenbrenner argued that while within groups or cultures, systemic structures may be similar, between groups or cultures may in fact be very different.

\section{The Model Described}

In developing his Ecological Systems Theory, Bronfenbrenner posited nine (9) propositions and fifty (50) hypotheses. While it is beyond the scope of this dissertation to individually examine each of these, it is important to note that these propositions and hypotheses formed the foundation upon which he based his final theory consisting of four (4) structures: (a) the microsystem; (b) the 
mesosystem; (c) the exosystem; and (d) the macrosystem (Bronfenbrenner, 1979). Later, a fifth structure known as the chronosystem was added to Bronfenbrenner's final model. Each of these systems will be discussed in turn. A visual depiction of Bronfenbrenner's Ecological Systems Theory is depicted in Figure 1 below.

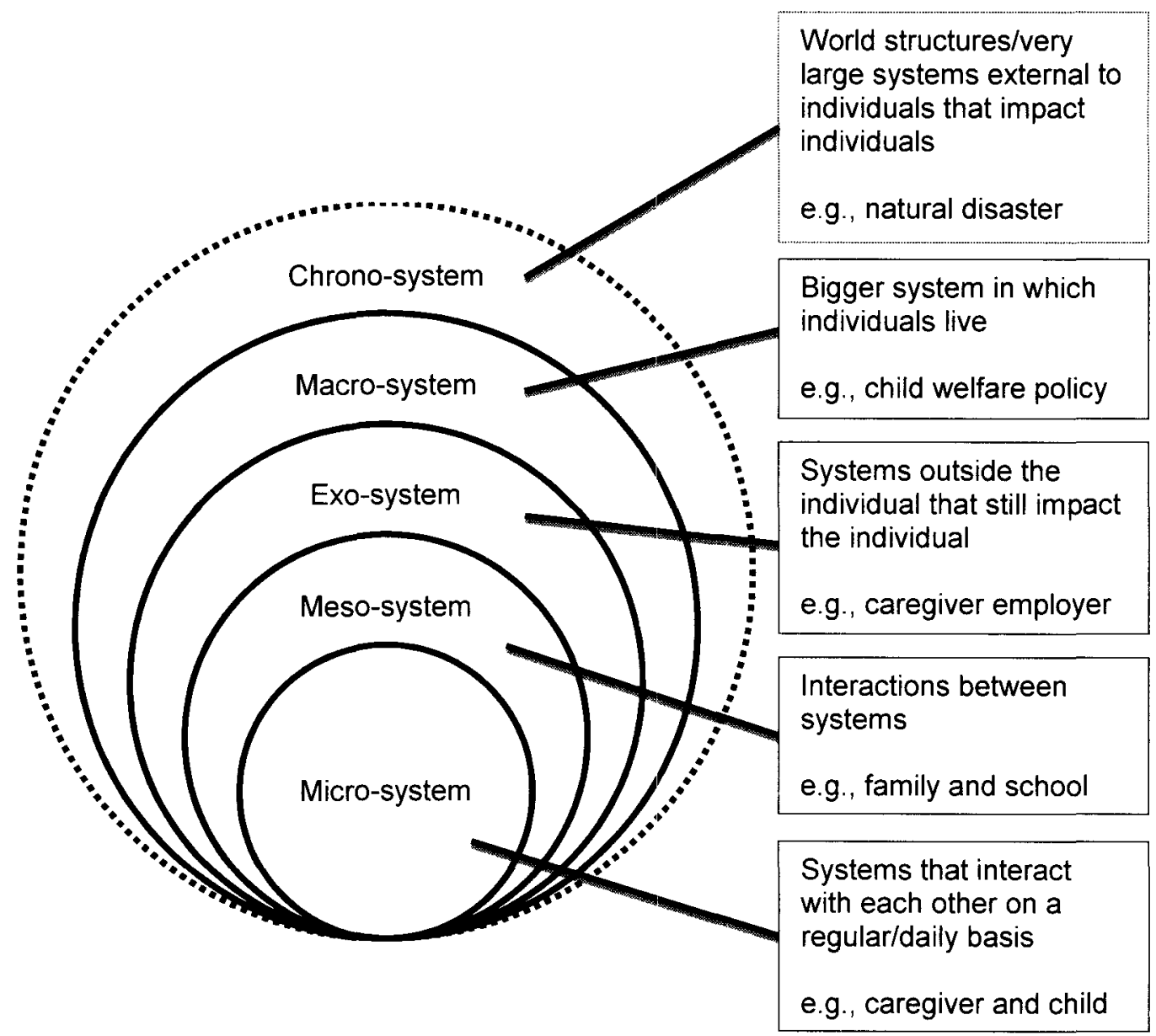

Figure 1. Bronfenbrenner's Ecological Model of Human Development.

"A microsystem is a pattern of activities, roles, and interpersonal relations experienced by the developing person in a given setting with particular physical and material characteristics" (Bronfenbrenner, 1979, p. 22). It is important to note, that according to Bronfenbrenner's theory, the microsystem includes more than just dyadic relationships between parent or caregiver and child. The 
microsystem consists of those systems that individuals interact with on a daily basis, such as friends, peer groups, school, and family. Important factors to consider here, within microsystems, would be parental or other adult response to maltreatment, such as attitudes toward maltreatment or child rearing practices, and general parental involvement with their children (Garbarino, 2005).

"A mesosystem comprises the interrelations among two or more settings in which the developing person actively participates (such as, for a child, the relations among home, school, and neighborhood peer group; for an adult, among family work, and social life)" (Bronfenbrenner, 1979, p. 25). With mesosystems, one must consider the interaction of the different settings explained within microsystems. In other words, mesosystems take into consideration the interaction of friends and church and family and school. "The stronger and more diverse the links between settings, the more powerful the influence of the mesosystem on the individual's development" (Garbarino, 2005, p. 303). Therefore, important consideration with mesosystems would be levels of social support and isolation from other social groups (Garbarino, 2005).

"An exosystem refers to one or more settings that do not involve the developing person as an active participant, but in which events occur that affect, or are affected by, what happens in the setting containing the developing person" (Bronfenbrenner, 1979, p. 25). Examples of exosystems would be local government or places of employment for primary caregivers. Clearly, local government policy or decisions will impact families and consequently child welfare. Take for example changes in child welfare policies within a local 
community agency. What happens when definitions of maltreatment become constricted or expanded? With places of employment, imagine a caregiver loses his or her job and then comes home and takes the loss of employment out on the family. This clearly impacts the individual without that individual being directly involved in that system. In other words, exosystems have indirect effects on children (Garbarino, 2005).

"The macrosystem refers to consistencies, in the form and content of lower-order systems (micro-, meso-, and exo-) that exist... at the level of the subculture or the culture as a whole, along with any belief systems or ideology underlying such consistencies" (Bronfenbrenner, 1979, p. 26). Important to note, here, is that Bronfenbrenner included public policy in the macrosystem and viewed public policy as the cornerstone upon which human development research should be based.

The meso- and exosystems are set within the broad ideological and institutional patterns of a particular culture or subculture. This is the macrosystem. It is the 'blueprint' for the ecology of human development. It reflects a shared assumption of 'how things should be done' and of 'human nature'. (Garbarino, 2005, p. 303)

The fifth system, developed much later by Bronfenbrenner, is referred to as a chronosystem.

A chronosystem encompasses change or consistency over time not only in the characteristics of the person but also of the environment in which that person lives (e.g., changes over the life course in family structure, 
socioeconomic status, employment, place of residence, or the degree of hecticness and ability in everyday life). (Bronfenbrenner, 1994, p. 40)

This would explain, to some degree, why neighborhood mobility, divorce, familial stress, presence of wars and natural disasters are risk factors for child maltreatment. The events that occur in the chronosystem create system-level chaos that trickles down to the individual family and individual levels. Therefore, these factors must be considered when examining child maltreatment from an ecological systems perspective.

\section{Ecological Systems Theory and Child Maltreatment}

In a discussion of the social context of child maltreatment, Baumrind (1994) examined familial related factors from an ecological perspective. More specifically, she addressed the economic and cultural factors that contribute to child maltreatment. Ultimately, Baumrind (1994) notes that there is an abundance of research linking poverty to maltreatment; however, there are some factors, such as family commitment and social support, that may mediate the occurrence of maltreatment. This is congruent with Bronfenbrenner's premise that positive support can reduce the developmental impact of child maltreatment on a micro-level. The second issue that Baumrind (1994) discussed was the impact that culture has on child maltreatment, which Bronfenbrenner addressed as a microsystems issue. Child maltreatment reports are generally made when individuals do not agree with the way a family raises their child. Baumrind (1994) argues that "departures from affluent Euro-American standards of good parenting are often regarded as 'maltreatment,' and implicitly as abuse" (p. 360). Open- 
mindedness is a requirement when faced with cultural practices that differ from the "standard" or "norm" of child rearing. Take for example, spanking. There has been continued debate over whether it is appropriate to spank a child or whether that could be considered maltreatment. While one family may consider it abusive to spank a child, another family may view it as necessary for protective reasons. However, issues such as female circumcision must be addressed even though they are culturally appropriate in some areas across the world, which lead Baumrind (1994) to state that "cultural pluralism mandates understanding, but not unconditional acceptance" (p. 362).

When one thinks of an ecological perspective of child maltreatment, one may immediately think of neighborhoods. Claudia Coulton and Jill Korbin are two of the most prominent scholars in this area. Coulton and colleagues (1995) examined substantiated and indicated maltreatment reports across 177 census tracks in Cleveland, Ohio. They found overwhelming evidence to suggest that structural factors contribute to child maltreatment rates. More specifically, first using a factor analysis to yield three (3) factors (impoverishment, child care burden, and instability), they used these factors to predict maltreatment. Impoverishment was measured by poverty rate, unemployment, vacant housing, population loss, percent of female-headed households, and percentage of African Americans residing within a census track. Child care burden was measured using the ratio of children to adults, ratio of males to females, and the percentage of elderly individuals residing within a census track. Lastly, instability was measured using the proportion of residents that had moved to or from a 
different location within the last five years, percentage of households who lived in their current home less than 10 years, and the percentage of households who lived in their current home less than 1 year. Ultimately, all three of these predictors (impoverishment, child care burden, and instability) were statistically significant predictors of child maltreatment, with impoverishment having the strongest effect $(\beta=0.56)$, followed by child care burden $(\beta=0.20)$, an interaction effect between impoverishment and child care burden $(\beta=-0.17)$, living adjacent to impoverished neighborhoods $(\beta=0.14)$, and instability $(\beta=$ $0.13)$.

In addition to examining the impact of impoverishment, child care burden, and instability on child maltreatment reports, Coulton and colleagues (1995) also examined the impact of these factors on drug trafficking, violent crime, juvenile delinquency, teen child bearing, and low birth rate. Results indicated that impoverishment and child care burden were statistically significant predictors of drug trafficking, violent crime, juvenile delinquency, teen child bearing, and low birth rate. Other important factors were instability with violent crime $(\beta=0.30 ; p$ $<.001)$ and teen child bearing $(\beta=0.22 ; p<.01)$; interaction of impoverishment and child care burden with violent crime $(\beta=-0.12 ; p<.01)$; and adjacency to impoverished neighborhoods with juvenile delinquency $(\beta=0.23 ; p<.001)$. Ultimately, Coulton and colleagues (1995) argues that these findings "are further support for the claim that community context is an important component of child maltreatment" (p. 1273). In other words, it is imperative to examine child maltreatment from an ecological systems perspective. 


\section{Proposed Conceptual Model}

Child maltreatment is a complex social problem that has long-term consequences for children, such as behavioral problems, disrupted social relationships, mental health problems, and difficulties succeeding in school. In addition to actual maltreatment, however, there are many other risk and protective factors that influence children's behavior, which will be discussed more fully below. These factors may be classified as child factors, caregiver factors, and external or environmental factors.

The proposed conceptual model that will be tested in this study incorporates the principles of psychosocial development theory, attachment theory, and ecological systems theory (see Figure 2). It focuses on the direct linkage of child factors (psychosocial development theory), caregiver factors (attachment theory), and external factors (ecological systems theory), and child behavioral outcomes. As shown in the figure, these factors are all interrelated, meaning that increases or decreases in any one of the predictor variables may lead to corresponding changes in other predictors, consequently resulting in changes in behavioral outcomes. 


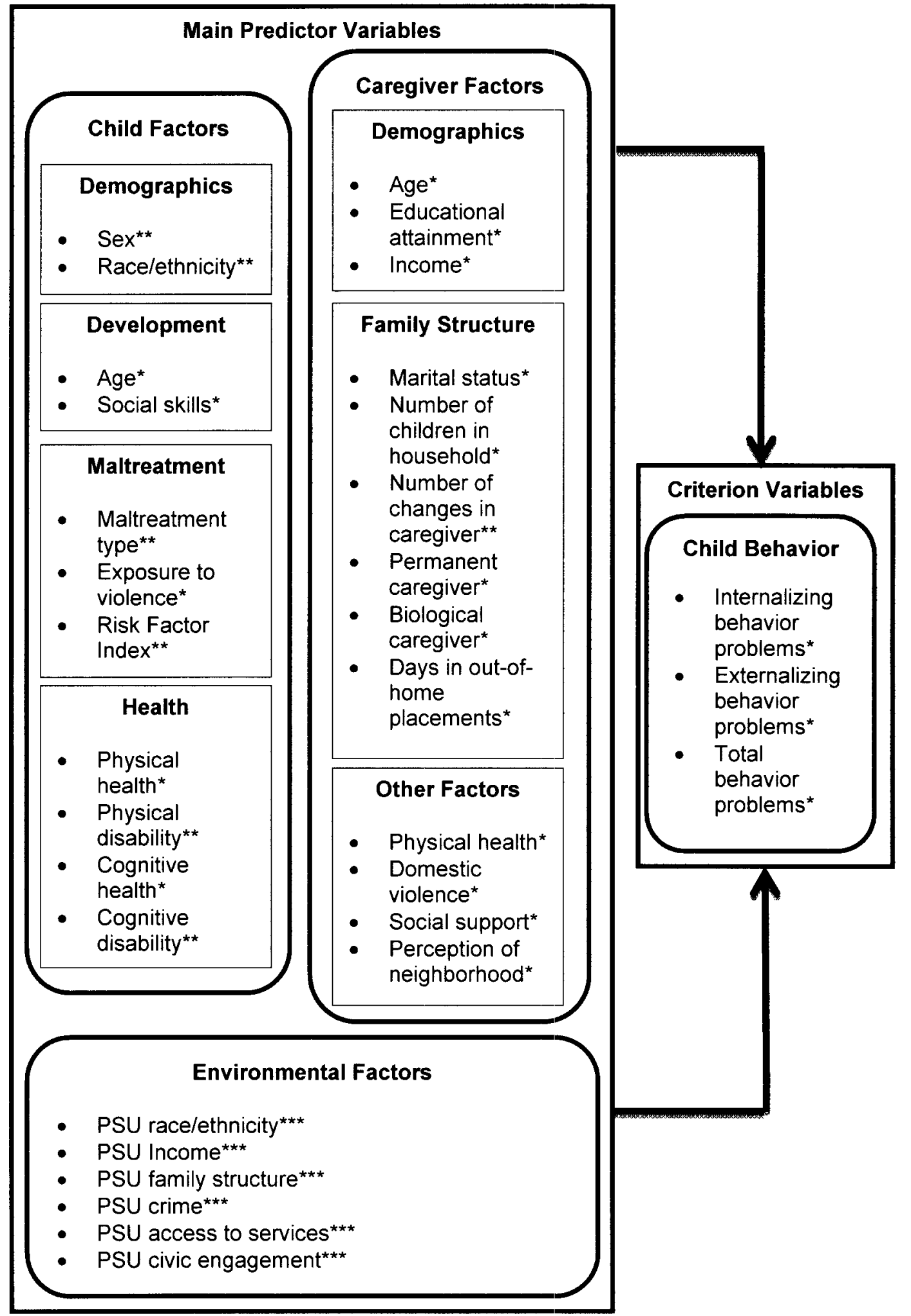

Key: * Level-1 (Time Variant); ${ }^{\star \star}$ Level-2 (Time Invariant); ${ }^{\star \star \star *}$ Level-3 (Environmental Factors)

Figure 2. Proposed conceptual model. 


\section{Main Predictor Variables}

Main predictor variables include child factors, caregiver factors, and external factors. These are measured both on level-1 and level-2, depending upon variability over time. These predictors are of most concern in this proposed model.

Child factors. Child factors include predictor variables related specifically to the child, such as demographics (e.g., child sex and child race/ethnicity), development (e.g., age and social skills), child maltreatment (e.g., type of maltreatment experienced, exposure to violence, and risk factor index), and health (e.g., physical health and cognitive health). These factors are related to psychosocial developmental theory and are, therefore, deemed appropriate and important predictors to include in the proposed model.

Child demographics. The sex of a child has an impact on his or her behavioral outcomes. Achenbach (1991) reported that boys tend to score higher on the externalizing problems scale, while girls tend to score higher on the internalizing problems scale. Rosenthal and Curiel (2006) also reported that gender played a statistically significant role in total child behavior problems (Female: $\beta=-0.192 ; p<.01$ ). In other words, males involved with the child welfare system scored significantly higher on the total behavior problems scale of the Child Behavior Checklist (CBCL). Additionally, utilizing latent growth modeling to evaluate child behavior, Edwards and colleagues (2006) reported that males exhibited higher levels of aggression. Males have also been cited as 
having higher levels of antisocial behavior than girls (Jaffee, Caspi, Moffitt, PoloTomás, \& Taylor, 2007).

Child race or ethnicity also plays a role in child behavioral outcomes. Examining children who were involved with the child welfare systems, Rosenthal and Curiel (2006) reported that Asian Americans $(\beta=-0.279 ; p<.05)$ scored significantly lower on the total behavioral problems scale. However, they found no significant effects for Native American or Hispanic children involved in the child welfare system. Stahmer and colleagues (2009) found that Hispanic children demonstrated fewer behavioral problems $(\beta=-5.91 ; p=.02)$, but no significant results for other races. This may be the result of cultural norms that exist within and differ between cultures (Rosenthal \& Curiel, 2006).

Child development. Age and social skills are included in the proposed model as child development predictors. For cases of substantiated child maltreatment, Proctor and colleagues (2010) examined behavioral trajectories from age 6 to 14. A 3-class solution (stable adjustment, mixed/decreasing adjustment, and increasing adjustment) was found for internalizing behavioral problems, while a 4-class solution (stable adjustment, mixed adjustment, increasing adjustment, and stable maladjustment) was found for externalizing behavioral problems. Early social competence predicted membership to the increasing adjustment group $(\mathrm{OR}=.96, \mathrm{p}<.05)$ for internalizing behavior problems. For externalizing behavior problems, early social competence $(O R=$ $97, p<.05)$ predicted membership to the stable maladjustment group (Proctor, Skriner, Roesch, \& Litrownik, 2010). 
Child maltreatment. Type of maltreatment is an important factor to consider. Research indicates that including subtypes and multiple categories of maltreatment has stronger predictive power than using basic classification schemes alone (Lau, Leeb, English, Graham, Briggs, Brody, \& Marshall, 2005). Additionally, greater effect sizes have been reported when using subtypes of neglect when examining child behavioral outcomes (Dubowitz, Pitts, \& Black, 2004). Other studies indicate that subtypes of maltreatment have differential effects on child behavioral outcomes. Examining subtypes of neglect (physical, psychological, environmental, and cumulative) and its impact on child behavior, Dubowitz and colleagues (2002) reported that only psychological neglect influenced both internalizing $(\beta=0.27 ; p=.002)$ and externalizing $\beta=0.23 ; p=$ .006) behavior problems at age 3 . Additionally, cumulative neglect impacted internalizing $(\beta=0.20 ; p=.02)$ behavior problems at age 3 , but not externalizing behaviors. Furthermore, examining subtypes of maltreatment (sexual abuse, physical abuse, failure to provide, lack of supervision, and emotional maltreatment) on child internalizing, externalizing, and total behavior problems, Litrownik and colleagues (2005) reported that sexual abuse predicted internalizing $(\beta=1.326 ; p<.05)$, externalizing $(\beta=1.726 ; p<.05)$, and total $(\beta=$ $1.751 ; p<.05)$ behavior problems, while physical abuse predicted only externalizing $(\beta=1.147 ; p<.05)$ behavior problems. Failure to provide, lack of supervision, and emotional abuse did not predict child behavior problems (Litrownik, Lau, English, Briggs, Newton, Romney, \& Dubowitz, 2005). On the other hand, Schneider and colleagues (2005) reported that emotional 
maltreatment (measured as safety and security, and self-esteem and autonomy) predicted both externalizing and total behavioral problems. More specifically, safety and security predicted externalizing $(\beta=3.62 ; p<.001)$ and total $(\beta=$ 2.46; $p<.05)$ behavior problems and self-esteem and autonomy predicted externalizing $(\beta=3.94 ; p<.01)$ and total $(\beta=3.70 ; p<.01)$ behavior problems. Using subscales of the Child Behavior Checklist ( $\mathrm{CBCL})$ to examine the impact of child physical abuse on child aggression and depression, Johnson and colleagues (2002), reported that physical abuse was a significant predictor of both aggression and depression. In sum, the impact of different types of maltreatment is ambiguous. For example, some research indicates that emotional maltreatment is a statistically significant predictor of child behavior, while other studies report the contrary. Therefore, it is important that subtypes of maltreatment be included in this study.

A child's exposure to violence may also impact his or her behavior. Johnson and colleagues (2002) examined the impact of child exposure to violence on child aggression and depression. They found that child report of witnessed violence was a significant predictor of both aggression and depression. Other studies on violence in the home noted that any form of violence in the home resulted in internalizing, externalizing, and total behavioral problems (English, Graham, Newton, Lewis, Thompson, Kotch, \& Weisbart, 2009).

Child health. Child health is comprised of both physical health and cognitive health. Both physical health as well as cognitive health is hypothesized 
to impact child behavioral problems. With regard to physical health, there are a number of childhood developmental disorders, diabetes, as well as other health issues that plague children. Kring and colleagues (2010) examined the impact of physical health on behavior for children with autism. They found that increased health problems resulted in greater behavioral problems.

For cases of substantiated child maltreatment, Proctor and colleagues (2010) examined behavioral trajectories from age 6 to 14. A 3-class solution (stable adjustment, mixed/decreasing adjustment, and increasing adjustment) was found for internalizing behavioral problems, while a 4-class solution (stable adjustment, mixed adjustment, increasing adjustment, and stable maladjustment) was found for externalizing behavioral problems. Early cognitive ability predicted membership to the increasing adjustment group $(O R=1.30, p<.01)$ for internalizing behavior problems and membership to the stable adjustment group $(O R=1.15, p<.05)$ for externalizing behavior problems (Proctor, Skriner, Roesch, \& Litrownik, 2010).

Caregiver factors. Caregiver factors are included based on attachment theory and have been cited as important predictors of child behavioral outcomes. Based on attachment theory, it is plausible that caregiver factors, such as demographics (e.g., age, educational attainment, and income), family structure (e.g., marital status, number of children in household, number of changes in caregiver, whether the caregiver is permanent and/or biological parent, and days in out-of-home placements), and other factors (e.g., physical health, domestic violence, social support, and perception of the neighborhood in which the family 
resides) influence child behavior. Therefore, the aforementioned factors are included in the proposed model.

Caregiver demographics. Caregiver age may have some impact on child behavior. Analyzing separately a fixed-effect ANOVA and an ordinary least squares (OLS) regression, Kalil and Dunifon (2007) showed that maternal age had no effect on child behavior problems when analyzing a fixed-effect ANOVA model, but the OLS results indicated a negative relationship between maternal age and child externalizing behaviors. This indicates that there is some ambiguity with regard to the effect of caregiver age on child behavior problems, but some evidence suggests that younger caregivers experience more externalizing behavior problems from their children. The level of education attained by the child's caregiver has an impact on child behavioral outcomes. Examining child reports, caregiver reports, and teacher reports of the impact of caregiver education on child behavior, only teacher reports showed a statistically significant effect on child total behavior problems $(\beta=-0.093, p<.01)$. This indicates that caregiver's with lower levels of education have children with higher levels of externalizing behavior problems, from the perspective of the child's teacher (Rosenthal \& Curiel, 2006).

Income has been considered an important factor to consider when examining child behavior. Rosenthal and Curiel (2006) reported a negative relationship between income and child total behavior problems $(\beta=-0.029, p<$ .01), indicating that as a caregiver's income decreases, child behavioral problems increase. Additionally, McLeod and Nonnemaker (2000) stated that 
families living in persistent poverty exhibited greater behavioral problems $(\beta=$ $0.300, p<.05$ ). In examining the impact of socioeconomic status (SES) on child attention, aggression, and delinquency, results indicate that boys from lower SES families exhibit higher levels of aggression and delinquency issues based on maternal reports; however, teacher reports also indicate that boys from low SES families also demonstrate attention problems (Barry, Dunlap, Cotton, Lochman, \& Wells, 2005).

Family structure. Marital status, number of children in the household, number of changes in caregiver, whether the caregiver is a permanent or biological caregiver, and the number of days in out-of-home placements all relate to family structure. Marital status has been shown to be an important predictor of child behavioral problems. Using path analysis, Hilton and Desrochers (2002) noted both a direct and indirect effect between marital status and child externalizing behaviors (direct path coefficient $=2.24$ ). Furthermore, they reported a combined total effect of -0.26 (direct effect $=-0.24$; indirect effect $=-$ 0.02). Additionally, Shaw and colleagues (1999) classified caregivers in four groups: (a) always two-parent, (b) to-be divorced, (c) already divorced, and (d) always single. The always two-parent families included those that consisted of biological parents who were married or living together with no occurrences of separation. The to-be divorced group consisted of parents who would divorce by the end of the study period. The already divorced group included parents who were divorced at the time of the study. The always single group consisted of single mothers. They found that children in the always single group 
demonstrated significantly higher scores than the always two-parent group in terms of both internalizing $(t=2.02, p<.05)$ and externalizing $(t=2.17, p<.05)$ behavioral problems (Shaw, Winslow, \& Flanagan, 1999). This may be a result of research discussed earlier in this dissertation that shows that the presence of paramours in the household contribute to child maltreatment (Wilson \& Daly, 2005).

A number of studies have shown that the number of siblings in a household as well as the number of individuals in a household effect child behavior and outcomes. Runyan and colleagues (1998) showed that children with fewer siblings in the household have impeded physical and behavioral development. Additionally, there is a negative impact on educational attainment for children who reside in households with a greater number of siblings (Coleman \& Hoffer, 1987).

Placement stability is also an important factor to consider when examining child behavioral problems. Lewis and colleagues (2007) examined three (3) groups of children: (a) those who had been adopted and experienced placement instability; (b) those who had been adopted and experienced one (1) stable placement; and (c) those who had never experienced a placement in foster care. Results indicated that those children who had experienced placement instability demonstrated lower inhibition and higher scores related to oppositional behavior (Lewis, Dozier, Ackerman, \& Sepulveda-Kozakowski, 2007). Additionally, as discussed above, placement stability as opposed to instability predicted membership to the stable adjustment group for both internalizing $(O R=1.44, p<$ 
$.05)$ and externalizing $(O R=1.47, p<.05)$ behavior problems (Proctor, Skriner, Roesch, \& Litrownik, 2010).

The number of out-of-home placements negatively impact child behavioral problems. For cases of substantiated child maltreatment, Proctor and colleagues (2010) examined behavioral trajectories from age 6 to 14. A 3-class solution (stable adjustment, mixed/decreasing adjustment, and increasing adjustment) was found for internalizing behavioral problems, while a 4-class solution (stable adjustment, mixed adjustment, increasing adjustment, and stable maladjustment) was found for externalizing behavioral problems. Placement stability predicted membership to the stable adjustment group for both internalizing $(O R=1.44, p<$ $.05)$ and externalizing $(\mathrm{OR}=1.47, \mathrm{p}<.05)$ behavior problems (Proctor, Skriner, Roesch, \& Litrownik, 2010).

Caregiver other factors. Caregiver other factors include caregiver health, negative factors, and protective factors. Caregiver health includes physical health. Caregivers with poor physical health may impact child behavior. Domestic violence, or the level of exposure to violence, has also been shown to significantly impact child behavioral outcomes. For children who had substantiated cases of child maltreatment, English and colleagues (2003) examined the impact of domestic violence on child total behavioral problems. While results indicated that there was not a direct effect between domestic violence and child behavior problems, there were indirect effects through caregiver verbal aggression toward child $(\beta=2.13, p<.001)$, family health and competence $(\beta=0.170, p=.006)$, and total number of CPS referrals $(\beta=0.643$, 
$p<.001)$. Another study reported that all forms of violence in the home (verbal aggression, minor violence, and severe violence) were indicative of child internalizing, externalizing, and total behavioral problems (English, et al., 2009).

Caregiver protective factors include social support and perception of neighborhood. While social support has been measured in different ways, there has been sufficient evidence to support that the level of social support perceived by the caregiver impacts child behavior. Examining the impact of social support, measured by the level of instrumental support and emotional support, on child depression/anxiety and aggression, results indicated that instrumental support modified the relationship between child maltreatment and child aggression (Saluja, Kotch, \& Lee, 2003). Runyan and colleagues (1998) examined caregiver social support and its impact on child behavior ("doing well" versus "not doing well"). They determined that one of the most important factors that determined whether a child was "doing well" was social support $(O R=1.69)$ (Runyan, Hunter, Socolar, Amaya-Jackson, English, Landsverk, Dubowitz, Browne, Bangdiwala, \& Matthew, 1998).

Perception of the caregiver's neighborhood also impacts child behavior. Putnam (2000) showed that when caregivers perceive their neighborhood as having a high level of social trust that there was a decrease in the number of delinquent acts committed by juveniles in that neighborhood. Positive perceptions of the neighborhood resulted in a higher probability that children would enroll in college as an adult (Furstenberg \& Hughes, 1995). On the other hand, negative perceptions of the neighborhood resulted in increased depression 
and violence for juveniles residing in that neighborhood (Stevenson, 1998; Johnson, 1999).

Environmental factors. Environmental factors, or external factors, include neighborhood or community factors that may attribute to child behavioral problems. Some of these factors include race/ethnicity, poverty rate, family structure, crime rate, access to services, and civic engagement. These predictors are drawn from ecological systems theory and are considered important factors to consider when examining child behavioral outcomes.

Race/ethnicity. Racial composition of a neighborhood may play a role in child behavioral outcomes. Research indicated that minorities are more likely to reside in poor neighborhoods (Kasarda, 1993; Quillian, 2003). Quillian (2003) notes that over a ten (10) year period, $60 \%$ of African Americans were exposed to a poor neighborhood for at least one (1) year while only $10 \%$ of Caucasians were exposed to a poor neighborhood for at least one (1) year. This indicates that there is a high concentration of minorities residing in poorer neighborhoods, which has been shown to impact child behavior (Hoffman, 2006)

Poverty rate. Neighborhood poverty may influence child behavior. Hoffman (2006) examined the effect neighborhood poverty has on child behavioral problems. He found that the percentage of families, within a specific zip code, below the poverty line was positively related to child behavior problems $(\beta=0.43, p<.01)$. Thus, children who reside in neighborhoods with a high concentration of poverty tend to exhibit more behavioral problems. 
Family structure. Family structure, namely the percentage of two-parent families or percentage of female-headed households, within a neighborhood significantly impacts children's behavior. Hoffman (2006) reported a positive relationship between the percentage of female-headed households in a given zip code and child behavior problems $(\beta=0.91, p<.01)$. Therefore, family structure is an important predictor to consider in this model, as single-headed households, particularly female-headed households, have been shown to negatively impact child behavior.

Crime rate. Neighborhood crime has an impact on child behavioral outcomes. In comparing resilient and non-resilient maltreated children, Jaffee and colleagues (2007) reported that living in high crime areas is less prevalent among resilient children than non-resilient children $(R R R=0.72, p<.01)$. Plybon and Kliewer (2001) examined three (3) types of neighborhoods: (a) low poverty-low crime; (b) high poverty-moderate crime; and (c) moderate povertyhigh crime. They found that the high poverty-moderate crime group had significantly higher externalizing behavior problems than the low poverty-low crime group (Plybon \& Kliewer). However, Plybon and Kliewer (2001) also reported that high levels of family cohesion (e.g., spending time together) moderated externalizing behavior problems for all three (3) groups. Therefore, higher behavioral problems are exhibited by children who reside in neighborhoods with a high percentage of crime.

Access to services. Access to community services (e.g., medical, mental health, social services, etc.) may impact child behavioral problems. 
Gutman and colleagues (2005) reported that caregivers who rated their neighborhood as having a high level of barriers to services was positively correlated to parent-adolescent conflict, adolescent depression and anxiety and negatively correlated with academic achievement. Thus, lack of access to services resulted in more conflict, depression, and anxiety and lower performance academically.

Civic engagement. Civic engagement is an important community factor to consider when examining the impact of child maltreatment on child behavioral outcomes. Research indicates that there is a positive relationship between the level of parental engagement in civic activities and his or her child's overall wellbeing (Garbarino \& Sherman, 1980; Sampson, Morenoff, \& Earls, 1999). Additionally, Putnam (2000) reported that parental engagement in the community also leads to fewer child behavioral incidents while in school. Lee (2008) reported that higher levels of community civic engagement are associated with lower community crime rates. As noted above, neighborhoods with high levels of crime often have children with higher levels of behavioral problems (Jaffee et al., 2007; Plybon \& Kliewer, 2001).

\section{Criterion Variables}

Child behavioral problems are the criterion variables proposed in this conceptual model. The Child Behavior Checklist (CBCL), developed by Thomas Achenbach (1991), is one of the most widely used and accepted measure of child internalizing, externalizing, and total behavior problems for children between the ages of 2 to 18 . Therefore, the $C B C L$ will be utilized to estimate a 
multilevel multivariate normal response model of child behavioral problems, accounting for internalizing, externalizing, and total behavior problems.

\section{Summary}

Psychosocial Development Theory, Attachment Theory, and Ecological Systems Theory are all intertwined. While Erikson's Psychosocial Development Theory provides a foundation upon which child maltreatment may be investigated, it may be better used in conjunction with other existing theories such as Attachment Theory and Ecological Systems Theory. Attachment is extremely important in the initial phases of development discussed by Erikson; however, Erikson only indirectly refers to attachment. Additionally, current research has shown that it does not matter, necessarily, where that love and support of positive relationships occur as long as they do occur for a child (Baumrind, 1994). This provides a case for including Ecological Systems Theory and the impact that both immediate relationships and distal relationships with systems on child maltreatment research.

The interconnectedness of these three (3) theories is also seen in their influence by Freud and the psychodynamic perspective. Thus, ego development and formation is an integral component of each of these theories (Bronfenbrenner, 1979; Erikson, 1993; Holmes, 1993; Payne, 1997). Secondly, these theories are based partially upon the individual's environmental perception, rather than an objective reality. "Environmental failure is not merely impressed on a passive organism but is experienced and given meaning by the afflicted individual" (Holmes, 1993, p. 37-38). 
Child maltreatment is a complex social problem requiring complex models. It is not enough to examine individual level effects of a multi-level problem. As the first two (2) chapters of this dissertation have outlined, child maltreatment is a multifaceted problem. Researchers must use more sophisticated models in order to not only improve predictive power, but also to more precisely differentiate cases. For example, many children who have been maltreated do not end up maltreating their own children. What makes them different? The only way to answer this question is by developing and analyzing "a complex model...to explain individual differences that takes into account the child, the parent and their appraisal, and the social environment" (Holmes, 1993, p. 51). Multilevel modeling provides us with the ability to develop such a complex model. 


\title{
CHAPTER III: METHODOLOGY
}

\author{
Essentially, all models are wrong, \\ but some are useful. George E.P. Box
}

\section{Research Goal and Hypotheses}

The purpose of this dissertation is to examine the impact of child maltreatment on child behavioral outcomes on multiple levels. As shown and demonstrated throughout the first two (2) chapters, much of the current research focuses on the impact of child maltreatment from an individual level, such as including only child-level predictors (e.g., age, mental health, etc.) or caregiverlevel factors (e.g., substance abuse, history of abuse as a child, etc.), or community-level factors (e.g., neighborhood poverty, neighborhood family structure). While this research has provided a foundation in child maltreatment research, by not accounting for the nested nature of child maltreatment, estimates may be inaccurate, which consequently results in erroneous conclusions that may impact child welfare policy and practice decisions (Moerbeek, 2004; Raudenbush \& Bryk, 2002). This study aims to bridge the aforementioned gap and address the potential impact on child welfare policy and practice decisions by investigating the impact of child factors, caregiver factors, and environmental factors over a period of six (6) years utilizing multivariate 
multilevel modeling. The goal of this dissertation is to answer the following research questions:

(1) Do the behavioral trajectories for children reported to child protective services (CPS) as a result of child maltreatment change differently over time?

(2) What are the most important child factors, caregiver factors, and environmental factors that predict the level of internalizing, externalizing, and total behavioral problems experienced by children reported to CPS as a result of child maltreatment over a period of six (6) years?

Based on the questions above, the following specific aims and hypotheses were formulated:

Specific Aim 1: To determine if behavioral trajectories for children reported to child protective services (CPS) as a result of child maltreatment change differently over time.

Hypothesis 1: Behavioral trajectories for children reported to CPS as a result of child maltreatment will change differently over time.

Specific Aim 2: To determine if differences and changes in certain child factors, caregiver factors, and environmental factors will have a differential effect on six (6) year internalizing, externalizing, and total behavioral problems change trajectories of children reported to CPS.

Hypothesis 2: Differences and changes in certain child factors, caregiver factors, and environmental factors within and between children reported to CPS 
will have a differential effect on six (6) year internalizing, externalizing, and total behavioral problems change trajectories.

\section{Research Design}

This dissertation is a secondary data analysis of existing data from the National Data Archive on Child Abuse and Neglect (NDACAN), National Survey of Child and Adolescent Well-Being (NSCAW). The design is a longitudinal panel study analyzing a three-level multilevel growth model. This model will investigate individual differences in behavioral problems (internalizing, externalizing, and total) over a period of approximately six (6) years. Observed differences in growth trajectories for maltreated children will be examined by analyzing multiple predictors, including child, caregiver, and environmental factors (See Figure 2).
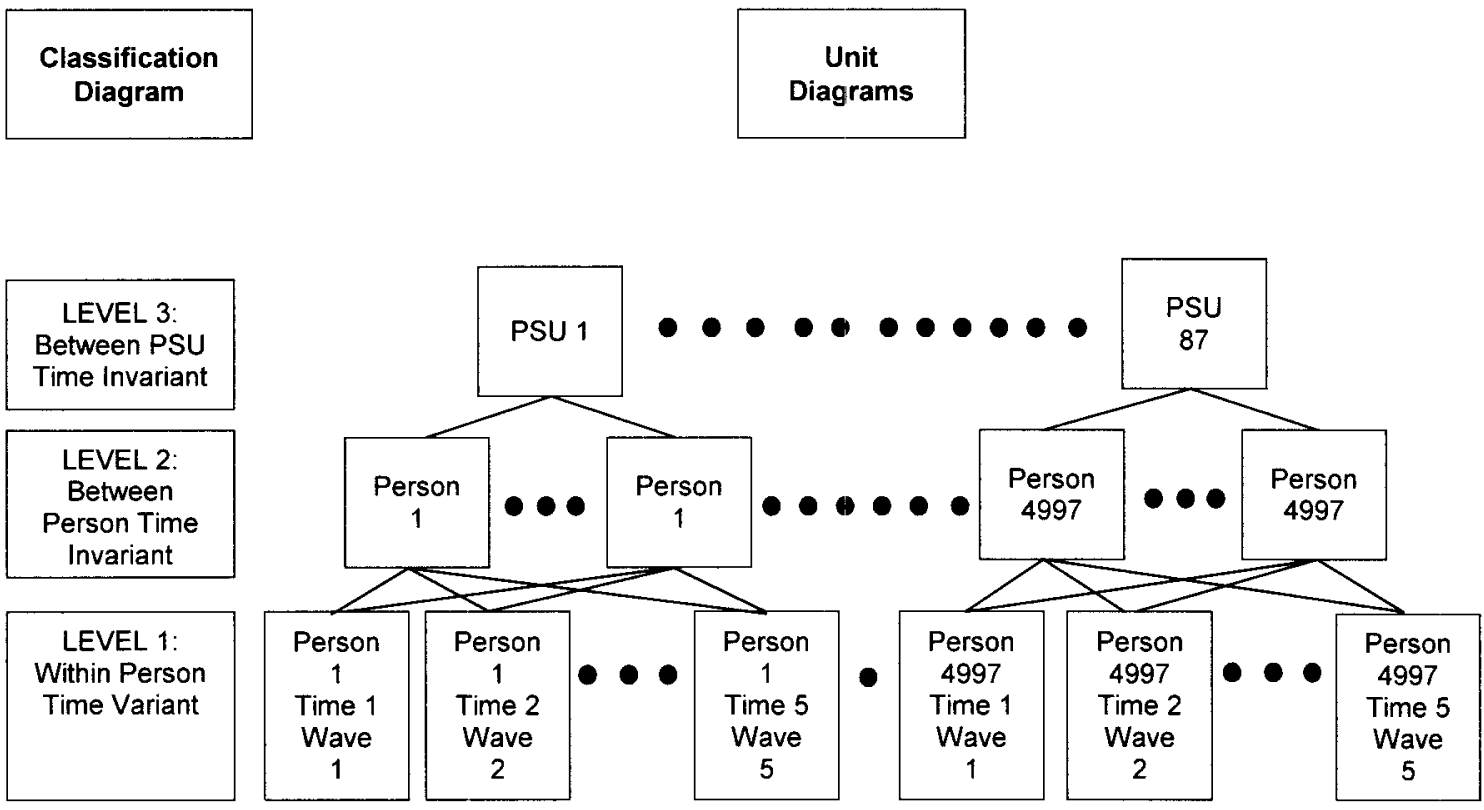

Figure 3. Multilevel structures and classification.

Since this study explores the long-term effects of maltreatment on child behavior by examining the dependent variable longitudinally, it exhibits a 
hierarchical structure as shown in Figure 3 . Therefore, hierarchical linear modeling (HLM) is the best statistical approach to utilize in this study. While many researchers have attempted to account for the nested nature of child maltreatment utilizing multiple regression and ANOVAs, these approaches are inadequate.

Utilizing a typical multiple regression to analyze change over time will likely result in smaller standard errors (Raudenbush \& Bryk, 2002). This is due to the fact that independence assumptions are violated. It is inaccurate to assume that an individual's response at baseline is independent from future responses on the same scale. Additionally, it is plausible to assume that children in the same geographical area will be impacted similarly, thus another clear violation of the independence assumption. In this study, the same children are administered the same instrument over time and are grouped within primary sampling units (PSUs). Thus, a standard multiple regression is inappropriate for this study.

Using ANOVAs when there are multiple groups (e.g., PSUs) requires the inclusion of numerous variables, which reduces statistical power. Additionally, ANOVAs do not handle missing data well, which again will reduce power due to having a smaller sample size. With ANOVAs, cases exhibiting any missingness are eliminated from the analyses. Conversely, it is possible to include all data in HLM analyses regardless of missingness on specific time periods, thereby increasing statistical power and reducing wasted information (Singer \& Willett, 2003). Lastly, random variability of group effects (e.g., PSU effects) are ignored when using ANOVAs. This may potentially result in making inaccurate 
interpretations (Luke, 2004). However, HLM accounts for these violations, which produces more precise estimates (Luke, 2004; Singer \& Willett, 2003; Raudenbush \& Bryk, 2002).

Now that a case for HLM has been made, it is important to discuss some criteria for longitudinal multilevel analysis. Three (3) factors must be considered in order to conduct an analysis of change: (a) the number of waves of data, (b) how time is measured, and (c) the level of measurement for the dependent variable. A prerequisite for a longitudinal study is that there are at least three (3) waves of data (Singer \& Willett, 2003). For the proposed study, there will be five (5) waves of data, which meets the requirements for a longitudinal analysis.

Second, time must be measured in some meaningful way to detect change over time (Singer \& Willett, 2003). For the purposes of this study, data was collected for the same children at five (5) waves at monthly intervals after the close of the CPS investigation (e.g., close of investigation, 12, 18, 36, and 59-96 months after the close of investigation). Lastly, the dependent variable must change systematically over time (Singer \& Willett, 2003). In this study, the dependent variables will change systematically over time. While this will be verified during preliminary analyses, it is assumed at this point that children who have experienced maltreatment will experience increased behavioral problems over time (Stahmer, Hurlburt, Horwitz, Landsverk, Zhang, \& Leslie, 2009). Therefore, all three (3) of the aforementioned criteria are met in order to successfully conduct a longitudinal multilevel analysis. 
This study has several strengths in its design. First, it utilizes a longitudinal growth model design that follows the same children over time for a period of six (6) years. This accounts for the natural maturation of children over time. Additionally, it includes a nationally representative sample from the United States and utilizes a two (2) step systematic random sampling procedure, which will be discussed in a later section on sampling. The research team also intentionally oversampled specific groups of maltreated children to ensure sufficient statistical power for interpreting results related to permanency, sexual abuse, and those receiving ongoing services. Lastly, this study includes data from multiple sources: children, caregivers, and child welfare workers as well as environmental factors. This assists with ensuring that the most holistic model possible is built and analyzed.

There are also limitations to the proposed study that must be considered. These limitations are related to measurement error and history. Measurement error takes on two forms: systematic error and random error. Systematic error is inevitably present when using standardized instruments (Meyers, Gamst, \& Guarino, 2006). However, the NSCAW research team was developed to ensure that the best instruments were used based on psychometric properties and applicability to the age of participants (Dowd, Kinsey, Wheeless, Thissen, Richardson, Suresh, Mierzwa, Biemer, Johnson, Lytle, Dolan, Hendershott, Smith, \& Day, 2008). Additionally, sensitive information solicited from participants was administered on a computer in order to reduce embarrassment of participants and increase accuracy of responses. Random error, on the other 
hand, is the result of participant mood or attitude, which may vary on any given day (Meyers, Gamst, \& Guarino, 2006). However, since the data included in this study is panel data collected over a period of approximately six (6) years, random error is less problematic. This is due to the fact that panel studies examine the same individuals over time, thus are deemed more powerful and accurate than either trend or cohort studies (Rubin \& Babbie, 2008). Another common threat to internal validity is history. These threats are related to other factors that occur outside of the study that may influence participant responses on given instruments (Rubin \& Babbie, 2008). For example, in this study, one of the outcome measures is Internalizing Behavior Problems. This is partly comprised of anxiety and depression subscales of the Child Behavior Checklist (CBCL). Thus, if a child suddenly experiences a death in the family, this may result in increased levels of Internalizing Behavior Problems. However, there is no way to differentiate the infinite number of potential factors that may contribute to differences of scores on the instruments in this study.

\section{Data Source}

This study proposes the use of data over a six (6) year time period from the National Survey of Child and Adolescent Well-Being (NSCAW), which is a national survey that follows the same children over time that have had some type of contact with the child welfare system between October 1999 and December 2000. The NSCAW was funded by the Department of Health and Human Services (DHHS), Administration on Children and Families (ACF). Furthermore, the data were collected by a collaborative research team including academic researchers, statisticians, and other experts. The team was comprised of 
individuals at the Research Triangle Institute (RTI), the University of North Carolina at Chapel Hill (UNC), Caliber Associates (Caliber), the University of California at Berkeley (UCB), and the Child and Adolescent Services Research Center at San Diego Children's Hospital. It was the first study that attempted to solicit information from individuals involved in the child welfare system rather than relying on secondary data collected by state agencies. Additionally, it sought to incorporate measures to examine the impact of maltreatment from an ecological perspective, which results in a dataset ideal for multilevel analysis (Dowd, et al., 2008).

\section{Sampling}

\section{NSCAW Sampling Strategy}

The NSCAW collected data from children, caregivers, teachers, and child welfare workers for children ages birth to fourteen (14) years of age at baseline who had some interaction with the child welfare system between October 1999 and December 2000 (see Table 6). The sample included both a child protection services (CPS) sample $(n=5,501)$ as well as a long term foster care (LTFC) sample $(n=727)$. For the purposes of this dissertation, only children in the CPS sample were included in this analysis. It was cletermined that the LTFC data was inappropriate to include in this study due to restrictions on data collected for the primary caregiver. In the LTFC sample, the biological caregiver information (e.g., caregiver history of maltreatment) was not included in the data. Therefore, including the LTFC data could potentially lead to misleading conclusions. Participants were followed for approximately six (6) years with assessments 
administered at five (5) points in time: (a) close of investigation; (b) 12 months after close of investigation (wave 2); (c) 18 months after close of investigation (wave 3); (d) 36 months after close of investigation (wave 4); and (e) 59-96 months after close of investigation (wave 5).

Table 6

Timeline of NSCAW Data Collection (taken from manual)

\begin{tabular}{lccccc}
\hline \multicolumn{1}{c}{ Wave } & $\mathbf{1}$ & $\mathbf{2}$ & $\mathbf{3}$ & $\mathbf{4}$ & $\mathbf{5}$ \\
\hline $\begin{array}{l}\text { Start and End Dates } \\
\text { Months after close of }\end{array}$ & $\begin{array}{c}11 / 15 / 99- \\
04 / 30 / 01\end{array}$ & $\begin{array}{c}10 / 01 / 00- \\
03 / 31 / 02\end{array}$ & $\begin{array}{c}04 / 01 / 01- \\
09 / 30 / 02\end{array}$ & $\begin{array}{c}08 / 01 / 02- \\
02 / 28 / 04\end{array}$ & $\begin{array}{c}09 / 05 / 05- \\
\text { investigation for CPS sample }\end{array}$ \\
$\begin{array}{l}\text { (LTFC) } \\
\text { Respondent }\end{array}$ & $2-6(12)$ & $12(24)$ & $18(30)$ & $36(48)$ & $59-97$ \\
$\quad$ Child & $\mathrm{X}$ & & & & \\
$\quad$ Current Caregiver & $\mathrm{X}$ & $\mathrm{X}$ & $\mathrm{X}$ & $\mathrm{X}$ & $\mathrm{X}$ \\
$\quad$ Investigator/Services & $\mathrm{X}$ & $\mathrm{X}$ & $\mathrm{X}$ & $\mathrm{X}$ & $\mathrm{X}$ \\
Caseworker & $\mathrm{X}$ & & $\mathrm{X}$ & $\mathrm{X}$ & $\mathrm{X}$ \\
$\quad$ Teacher & & & & & $\mathrm{X}$ \\
\hline
\end{tabular}

The research team also utilized advanced statistical procedures, twostage stratified sampling, to define primary sampling units (PSUs). PSUs were generally defined as geographic areas served by one (1) CPS agency. Therefore, PSUs could be made up of more than one (1) county depending on the size of the geographic area and CPS caseload. In the first stage, the research team divided the United States into nine (9) sampling areas based on child welfare caseloads. The first eight (8) areas are comprised of the eight (8) states with the largest child welfare caseloads while the final area was comprised of the remaining thirty-eight (38) states and Washington, D.C. From these nine (9) sampling areas, the research team then randomly selected PSUs to include in the research study utilizing a probability-proportionate-to-size (PPS) procedure 
aimed to give areas with larger caseloads a higher probability of being selected.

From the PSUs, counties were then selected based on size. Only counties that were large enough to justify at least one caseworker (at least 60-67 cases per year) were selected for inclusion in the sample. Lastly, a within-PSU sample was then obtained using eight (8) sampling domains based on age, whether the participant had received services, and type of maltreatment (see Table 7). Table 7

The Eight Within-PSU Sampling Domains for the NSCAW CPS Sample (taken from manual)

\begin{tabular}{|c|c|}
\hline Domain & Description \\
\hline 1 & Infants (age < 1 year old) who were not receiving CPS agency funded services. \\
\hline 2 & Children age 1 to 14 years old who were not receiving CPS agency funded services. \\
\hline 3 & $\begin{array}{l}\text { Infants (age }<1 \text { year old) who were receiving CPS agency funded services and } \\
\text { were no in out of home care. }\end{array}$ \\
\hline 4 & $\begin{array}{l}\text { Children age } 1 \text { to } 14 \text { years old who were receiving CPS agency funded services, } \\
\text { were not in out of home care, and were investigated for allegations of sexual abuse. }\end{array}$ \\
\hline 5 & $\begin{array}{l}\text { Children age } 1 \text { to } 14 \text { years old who were receiving CPS agency funded services, } \\
\text { were not in out of home care and were investigated for allegations of other abuse or } \\
\text { neglect. }\end{array}$ \\
\hline 6 & $\begin{array}{l}\text { Infants (age }<1 \text { year old) who were receiving CPS agency funded services and } \\
\text { were in out of home care. }\end{array}$ \\
\hline 7 & $\begin{array}{l}\text { Children age } 1 \text { to } 14 \text { years old who were receiving CPS agency funded services, } \\
\text { were in out of home care, and were investigated for allegations of sexual abuse. }\end{array}$ \\
\hline 8 & $\begin{array}{l}\text { Children age } 1 \text { to } 14 \text { years old who were receiving CPS agency funded services, } \\
\text { were in out of home care, and were investigated for allegations of other abuse or } \\
\text { neglect. }\end{array}$ \\
\hline
\end{tabular}

The research team also employed rigorous inclusion criteria to ensure minimal intrusion on the children and families included in this study and to minimize duplication of cases. Once the child was selected in one frame, they were then deleted from subsequent cases so they would not be randomly 
selected a second time. Additionally, if there were multiple children in the household with allegations of maltreatment that were selected in the sample, siblings were then deleted and not included in sampling frame. Lastly, children who were also perpetrators of maltreatment were also eliminated from the sampling frame. Once the research team completed all of the aforementioned steps, they utilized simple random sampling to comprise the final sample.

\section{Study Sampling Strategy}

The sample for this study was obtained from the NSCAW CPS database who met two (2) criteria: (a) must have participated in the NSCAW study and (b) caregiver must have completed the $\mathrm{CBCL}$ for the child for at least one (1) wave. In order for the $\mathrm{CBCL}$ to be completed by the caregiver, the child must have been between the ages of 2 to 18 .

Following this initial sampling procedure, data were investigated for missingness on the child, caregiver, and environmental-level predictors. If missing values could not be replaced, these time-specific cases were eliminated from the final sample. Based on the aforementioned parameters, a final sample of 4,997 children and caregivers were included in the study. A visual depiction of the sampling process is shown in Figure 4. 


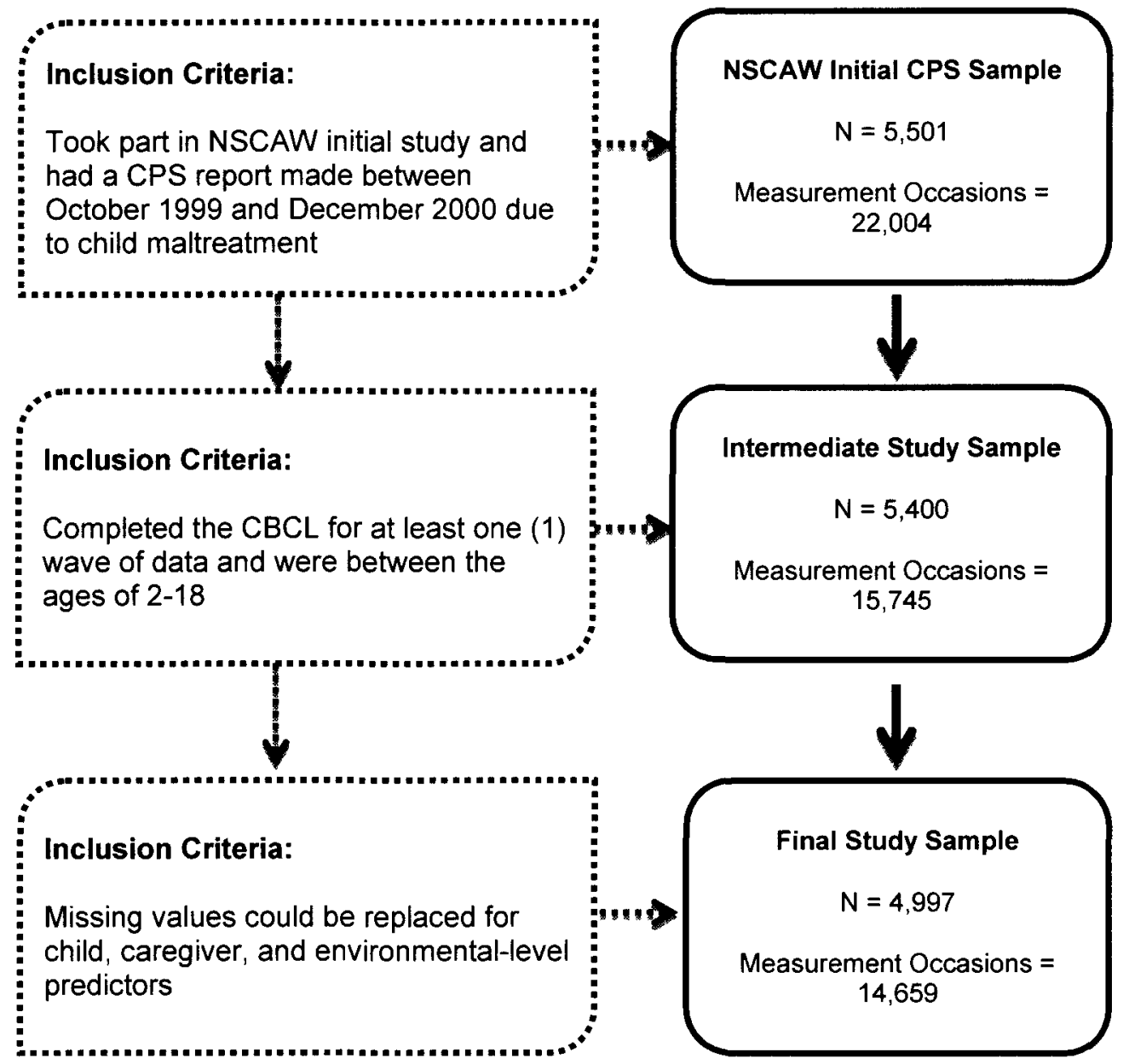

Figure 4. Flowchart of sampling process.

\section{Power}

Power refers to a researcher's ability to support their hypotheses and claim that an effect does in fact exist in the population (Snijders \& Bosker, 1999). In general, power is derived from the effect size in a given population, sample size, significance level, and study design. In multilevel models, determining power is more complex. In addition to power being a function of the aforementioned factors, it is also important to consider the intraclass correlation as well as the number of groups and the number of cases per group, which 
differs for fixed and random effects (Cohen, Cohen, West, \& Aiken, 2003). Thus, in multilevel models, power must be addressed on all levels (Snijders, 2005). In this study, power for level-1 depends upon the number of observations included in this study. Level-2 power is dependent upon the number of individuals included in the study, while the number of primary sampling units (PSUs) included in this study determines power for level 3 .

In multilevel models, sample size refers to the number of units at each level (Kreft \& de Leeuw, 1998; Snijders, 2005). Simulation studies have suggested that while large samples are required for multilevel models, the number of individuals is more important than the number of measurement occasions (Kreft \& de Leeuw, 1998) and as many units as possible is desired on the highest level (Snijders, 2005). Kreft and de Leeuw (1998) have suggested that at least 20 units are required on the highest level in order to detect crosslevel interactions. In this study, there were 4,997 children and caregivers (level2) nested in 87 PSUs (level-3) across 14,659 measurement occasions (level-1), suggesting sufficient power in terms of sample size.

Significance levels for this study were set at .05 , as is the convention. Additionally, the model sought to detect at least a medium effect size $(0.4)$ and at least $80 \%$ power. Based on the sample size, this should be achieved. Lastly, the intraclass correlation, which is an indication of the dependence of errors and provides justification for using hierarchical linear modeling (HLM), must be set (Tabachnick \& Fidell, 2007). According to Hedges and Hedberg (2007), appropriate intraclass correlations are determined by values reported from 
cluster-randomized experiments or sample surveys that have utilized a clustersampling design. The convention is to set the intraclass correlation at a minimum size of .05 . This small size is recommended for health and mental health research (Spybrook, Raudenbush, Liu, Congdon, \& Martinez, 2008).

\section{Operationalization of Variables}

The proposed conceptual model depicted in Figure 2 includes independent variables that serve as either time variant (within person) or time invariant (between person/PSU) predictor variables that were selected based on a review of the literature. The dependent variables, internalizing behavioral problems, externalizing behavioral problems, and total behavioral problems, were all time variant (within person).

\section{Main Predictor Variables}

Main predictor variables will be measured on all three (3) levels: time variant child and caregiver factors (level-1), time invariant child and caregiver factors (level-2), and time invariant environmental factors (level-3). Each of the included predictor variables have been selected based on evidence presented in the development of the conceptual framework. Table 8 shows which predictor variables were included in this proposed study, level of measurement, how they were operationalized, and psychometric information if standardized instruments were used. 
Table 8

Main Predictor Variables (Level-1, Level-2, Level-3)

\begin{tabular}{|c|c|c|}
\hline Variable & Operationalization & $\begin{array}{c}\text { Values used in } \\
\text { analysis }\end{array}$ \\
\hline \multicolumn{3}{|c|}{ CHILD FACTORS } \\
\hline Sex (level-2) & Is the child male or female? & $\begin{array}{l}\text { Child sex was } \\
\text { coded as follows: } \\
\begin{array}{l}1=\text { male (ref cat) } \\
2=\text { female }\end{array}\end{array}$ \\
\hline $\begin{array}{l}\text { Race/ethnicity } \\
\text { (level-2) }\end{array}$ & $\begin{array}{l}\text { What is the child's race/ethnicity? } \\
\text { Combined two (2) variables: } \\
\text { (a) Child Hispanic coded as follows: } 1=\text { yes, } 2=\text { no; } \\
\text { and } \\
\text { (b) Child race coded as follows: } 1=\text { Native } \\
\text { Indian/Alaskan, } 2=\text { Black, } 3=\text { White, } 4=\text { Other }\end{array}$ & $\begin{array}{l}\text { Child } \\
\text { race/ethnicity was } \\
\text { recoded as } \\
\text { follows: } \\
1=\text { Black/Non- } \\
\text { Hispanic } \\
2=\text { White/Non- } \\
\text { Hispanic } \\
3= \\
\text { Hispanic/Native } \\
\text { Indian/Alaskan/ } \\
\text { Other (ref cat) }\end{array}$ \\
\hline Age (level-1) & What is the child's age? & $\begin{array}{l}\text { Continuous } \\
\text { variable ranging } \\
\text { from } 2-18\end{array}$ \\
\hline $\begin{array}{l}\begin{array}{l}\text { Social skills } \\
\text { (level-1) }\end{array} \\
\text { Social Skills } \\
\text { Rating System } \\
\text { (SSRS) } \\
\text { (Gresham \& } \\
\text { Elliot, 1990) } \\
\text { Internal } \\
\text { consistency } \\
\quad \text { Cronbach's } \alpha \\
\quad=0.73-0.95 \\
\text { Construct Validity } \\
\quad \text { with CBCL- } \\
\text { correlates.58 } \\
\text { with the } \\
\text { social skills } \\
\text { scale. }\end{array}$ & $\begin{array}{l}\text { Social skills standard-preschool } \\
\text { Social skills standard-elementary } \\
\text { Social skills standard score-secondary }\end{array}$ & $\begin{array}{l}\text { Three variables } \\
\text { (preschool, } \\
\text { elementary, and } \\
\text { secondary) were } \\
\text { combined to form } \\
\text { one variable } \\
\text { encompassing } \\
\text { child social skills, } \\
\text { which is a } \\
\text { continuous } \\
\text { variable } \\
\text { Higher scores are } \\
\text { indicative of } \\
\text { higher level of } \\
\text { social skills }\end{array}$ \\
\hline
\end{tabular}


Internal consistency for NSCAW

- Preschoolers $-\alpha=.90$

- Elementaryage children $-\alpha=.87$

- Secondaryage children $-\alpha=.90$

\section{Maltreatment} type (level-2)

\section{Exposure to violence (level-1)}

Violence

Exposure Scale for Children

(VEX-R) (Shahinfar, Fox, \& Leavitt, 2000)

2 domains: Witness or victim of violence at school, home, neighborhood, or on TV

Internal
Most severe type of maltreatment?

This variable was 1 = physical maltreatment, $2=$ sexual maltreatment, $3=$ emotional maltreatment, $4=$ physical neglect, did not provide, $5=$ neglect, no supervision, $6=$ abandonment, $7=$ moral/egal maltreatment, $8=$ educational maltreatment, $9=$ exploitation, $10=$ other

Was the maltreated substantiated?

$1=$ yes, 2 = no

recoded as

follows:

$0=$ not substantiated $1=$ physical maltreatment 2 = sexual maltreatment (ref cat)
$3=$ other (combined emotional, abandonment, moral/egal, education, exploitation, and other)

$4=$ neglect (combined both physical neglect and neglect)

Look at the following cards and answer the question using the following guide: $1=$ never; $2=0$ ne time; $3=a$ few times; $4=$ lots of times.

If so, have you seen this happen in the last month? $1=y e s ; 2=n o$

Did you also see it happen before that? 1=yes, 2=no

Mild/severe violence total exposure

Higher scores are indicative of greater exposure to violence

Have you seen this happen with the people you live with now? $1=y e s, 2=$ no

How many times

Have you seen an adult yell at another person in a home you lived in?

Has an adult yelled at you in a home you lived in? Have you seen an adult throw something at another person in a home you lived in? Has an adult thrown something at you in a home you 


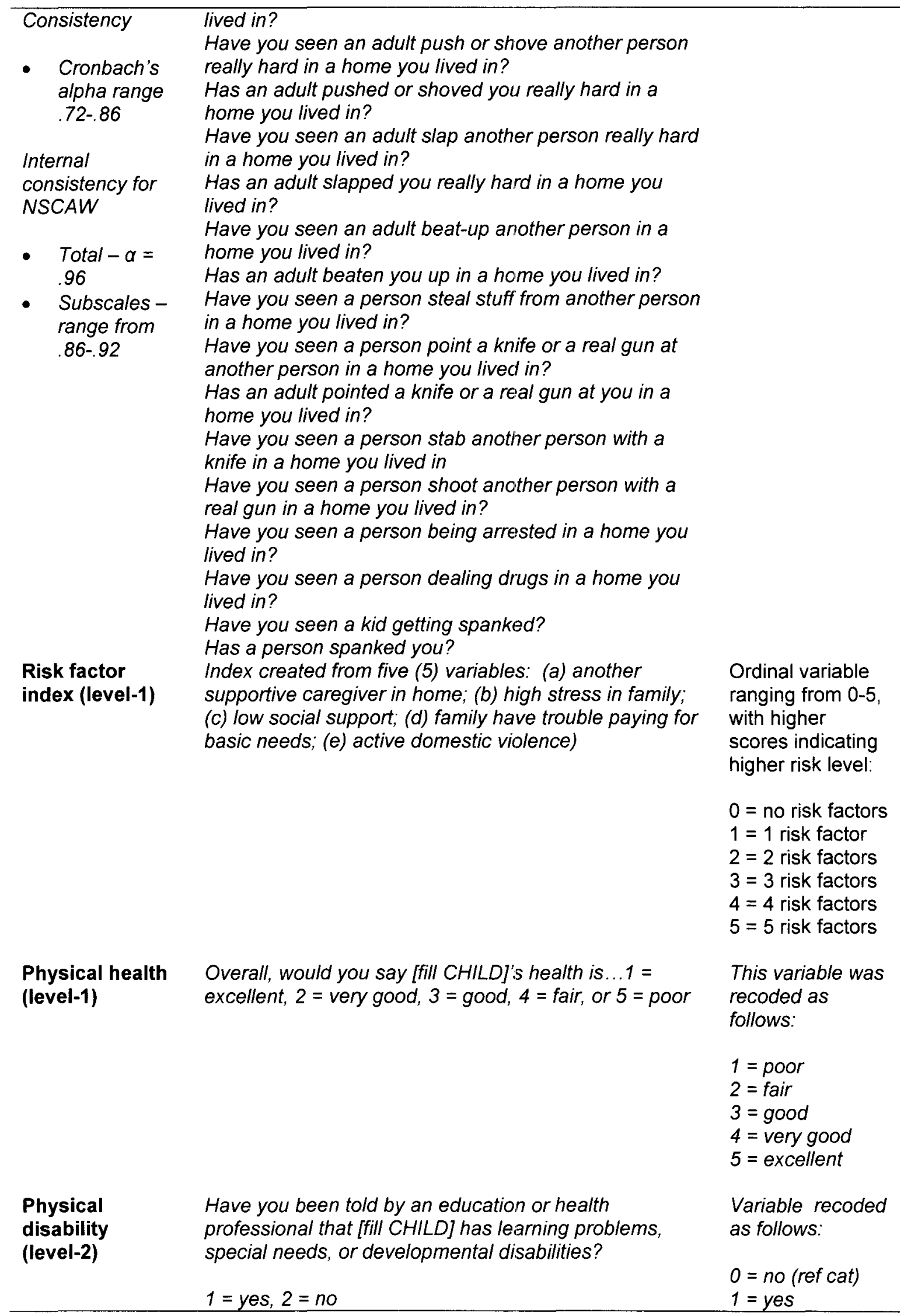




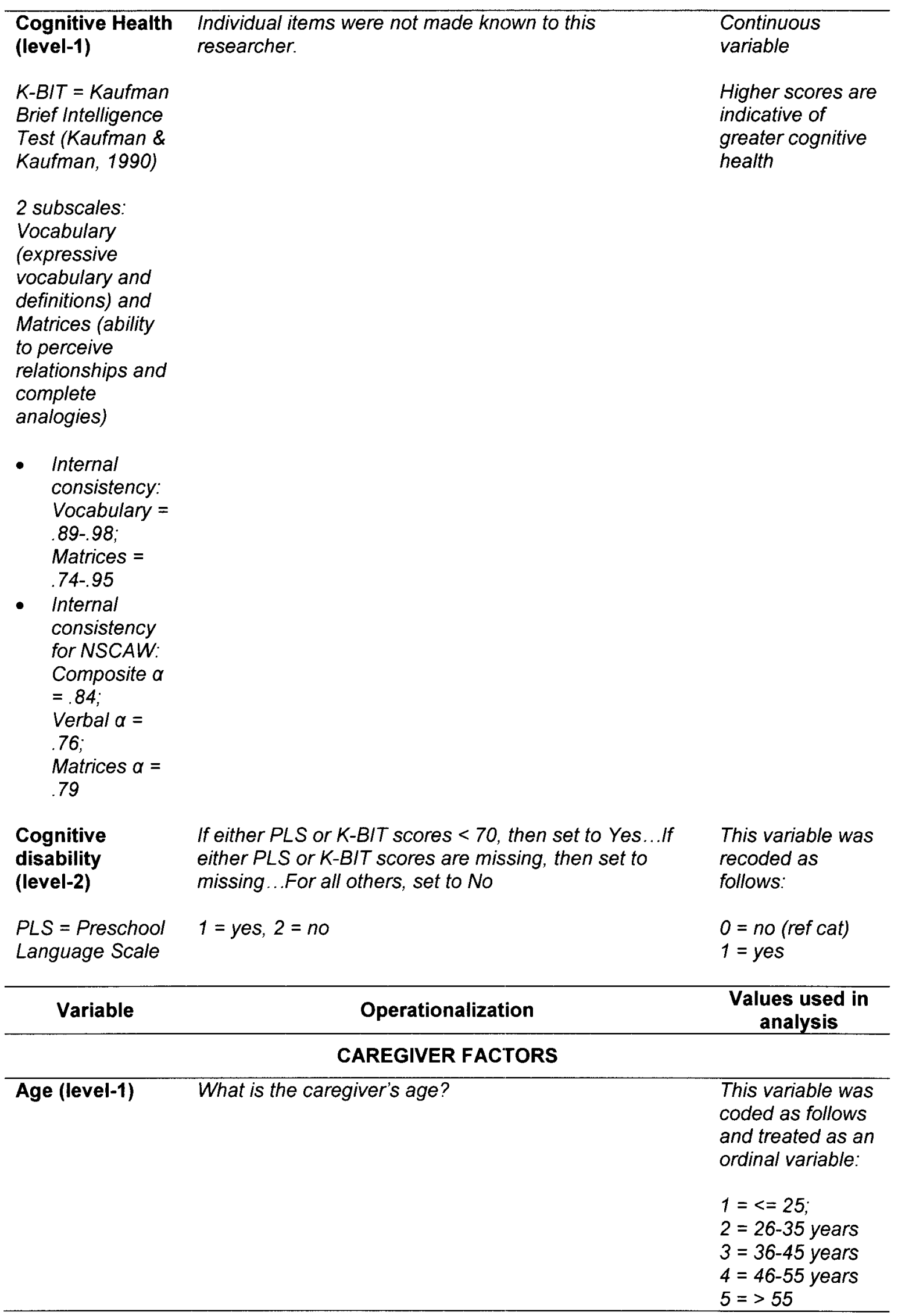




$\begin{aligned} & \text { Educational } \\ & \text { attainment } \\ & \text { (level-1) }\end{aligned}$
$\begin{aligned} & \text { What is the caregiver's level of education? } \\ & \text { (a) Highest degree coded as follows: } 1=\text { none, } 2= \\ & \text { high school equivalent, high school diploma, or } \\ & \text { vocational diploma, } 3=\text { associate's degree, } R N \\ & \text { diploma, } 4=\text { bachelor's degree, } 5=\text { master's } \\ & \text { degree, } 6=\text { other } \\ & \text { (b) Highest grade completed coded as follows: } 1= \\ & 8^{\text {th }} \text { grade or less, } 2=9^{\text {th }}-11^{\text {th }} \text { grade, } 3=12^{\text {th }} \\ & \text { grade or GED, } 4=\text { vocational/technical, } 5=\text { any } \\ & \text { college }\end{aligned}$

Income (level-1) What is the caregiver's annual income?
Number of children in household (level-1)
How many children live in the household?

\section{Marital Status}

Now I have a few more questions about you. Are you currently... 1=married, 2=separated, 3=divorced, 4=widowed, or $5=$ Have you never been married?
This variable was recoded as follows:

$$
\begin{aligned}
& 1=\text { less than } 12^{\text {th }} \\
& \text { grade } \\
& 2=\text { high school } \\
& \text { diploma or } \\
& \text { equivalent } \\
& 3=\text { some college } \\
& \text { (ref cat) } \\
& 4=\text { don't know } \\
& \text { education level }
\end{aligned}
$$

Income was coded as follows and treated as an ordinal variable:

$$
\begin{aligned}
& 1=\$ 0-\$ 9,999 \\
& 2=\$ 10,000- \\
& \$ 19,999 \\
& 3=\$ 20,000- \\
& \$ 29,999 \\
& 4=\$ 30,000- \\
& \$ 39,999 \\
& 5=\$ 40,000 \text { and } \\
& \text { greater }
\end{aligned}
$$

Marital status was recoded as follows:

$$
\begin{aligned}
& 1=\text { married (ref } \\
& \text { cat) } \\
& 2=\text { separated/ } \\
& \text { divorced/ } \\
& \text { widowed } \\
& 3=\text { never married }
\end{aligned}
$$

This variable is coded as follows and treated as an ordinal variable:

$$
\begin{aligned}
& 1=1 \text { child } \\
& 2=2 \text { children } \\
& 3=3 \text { childre } n \\
& 4=4 \text { childre } \\
& 5=>=5 \text { children }
\end{aligned}
$$

\footnotetext{
Number of

Did the caregiver remain the same between waves? changes in caregiver (level- $0=$ no, $1=$ yes
}

Aggregate continuous variable ranging from 0 (no changes in 


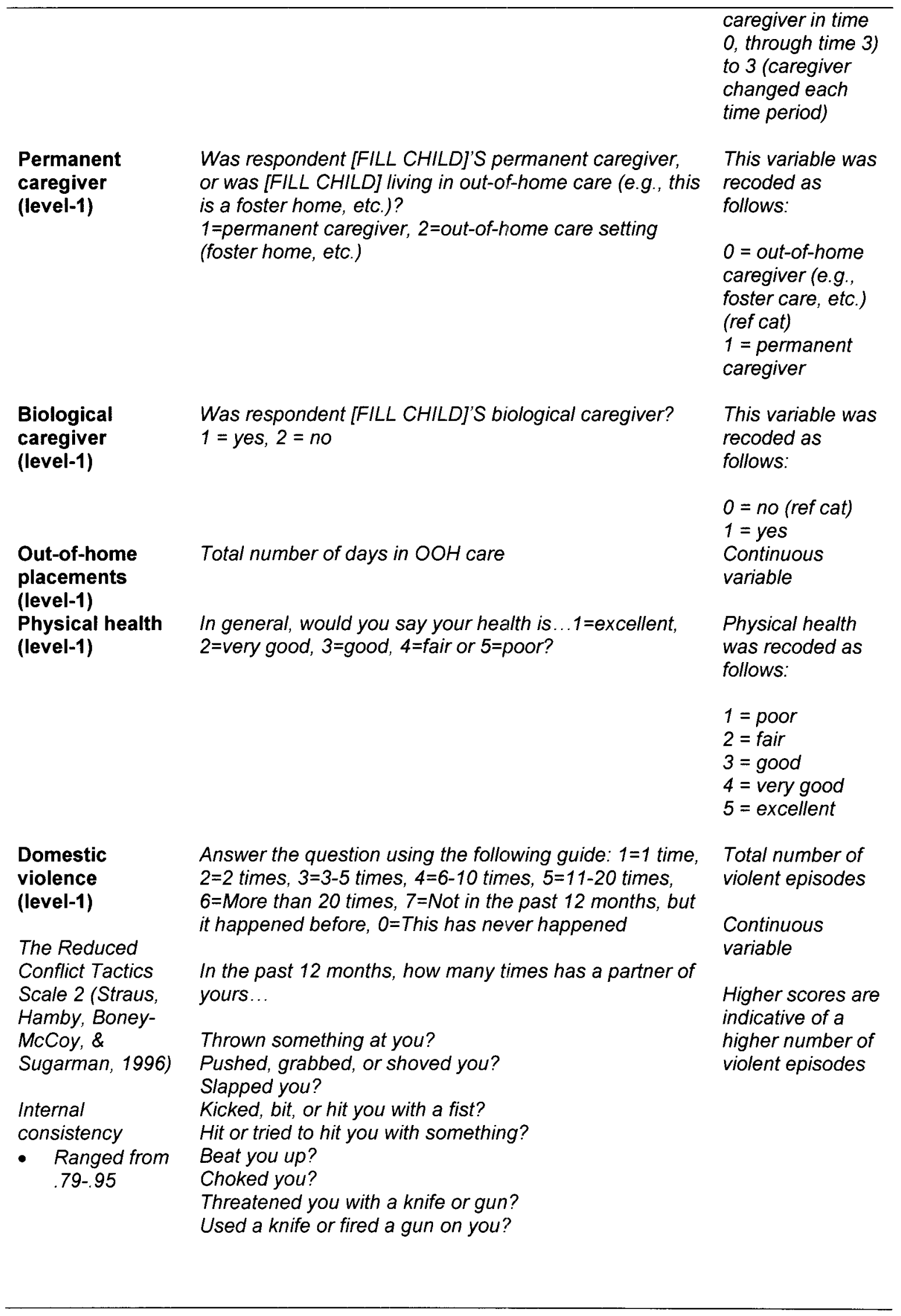




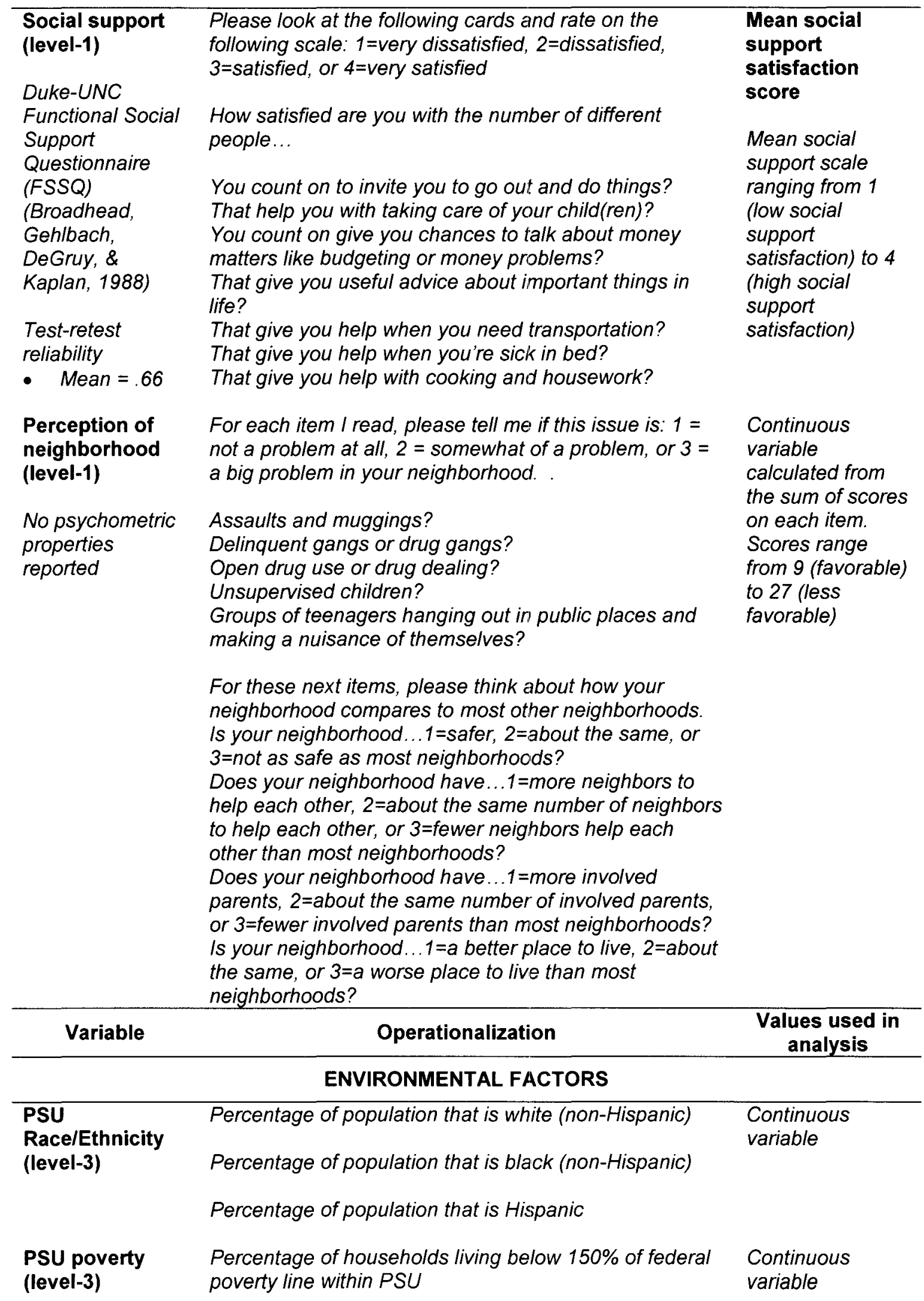




\begin{tabular}{|c|c|c|}
\hline $\begin{array}{l}\text { PSU child } \\
\text { poverty (level-3) }\end{array}$ & Percentage of children living in poverty within PSU & $\begin{array}{l}\text { Continuous } \\
\text { variable }\end{array}$ \\
\hline $\begin{array}{l}\text { PSU family } \\
\text { structure (level- } \\
\text { 3) }\end{array}$ & $\begin{array}{l}\text { Percentage of households with single parents within } \\
\text { PSU }\end{array}$ & $\begin{array}{l}\text { Continuous } \\
\text { variable }\end{array}$ \\
\hline $\begin{array}{l}\text { PSU number of } \\
\text { juvenile arrests } \\
\text { (level-3) }\end{array}$ & $\begin{array}{l}\text { Percentage of children (age 0-17) in juvenile corrections } \\
\text { within PSU }\end{array}$ & $\begin{array}{l}\text { Continuous } \\
\text { variable }\end{array}$ \\
\hline $\begin{array}{l}\text { PSU access to } \\
\text { health services } \\
\text { (level-3) }\end{array}$ & $\begin{array}{l}\text { Composite variable created from the following: } \\
\text { - Number of doctors per capita } \\
\text { - Number of child psychiatrists per capita } \\
\text { - Number of general psychiatrists per capita } \\
\text { - Number of psychologists per capita } \\
\text { - Number of social workers per capita } \\
\text { - Number of Community Mental Health Centers per } \\
\text { - Nupita } \\
\text { - } \\
\text { - Numbita }\end{array}$ & $\begin{array}{l}\text { Continuous } \\
\text { variable created } \\
\text { from summing the } \\
\text { following } \\
\text { variables: (a) } \\
\text { number of } \\
\text { doctors per } \\
\text { capita, (b) } \\
\text { number of child } \\
\text { psychiatrists per } \\
\text { capita, (c) } \\
\text { number of } \\
\text { general } \\
\text { psychiatrists per } \\
\text { capita, (d) } \\
\text { number of } \\
\text { psychologists per } \\
\text { capita, (e) } \\
\text { number of social } \\
\text { workers per } \\
\text { capita, (f) number } \\
\text { of Community } \\
\text { Mental Health } \\
\text { Centers per } \\
\text { capita, ( }(\text { ) } \\
\text { number of } \\
\text { Federally } \\
\text { Qualified Health } \\
\text { Centers per } \\
\text { capita, and (h) } \\
\text { number of HMOs } \\
\text { per capita. }\end{array}$ \\
\hline $\begin{array}{l}\text { PSU access to } \\
\text { social services } \\
\text { (level-3) }\end{array}$ & $\begin{array}{l}\text { Composite variable created from the following: } \\
\text { - Number of civic organizations per capita } \\
\text { - Number of social assistance establishments per } \\
\text { capita }\end{array}$ & $\begin{array}{l}\text { Continuous } \\
\text { variable created } \\
\text { from summing the } \\
\text { following } \\
\text { variables: (a) } \\
\text { number of civic } \\
\text { organizations per } \\
\text { capita and (b) } \\
\text { number of social } \\
\text { assistance } \\
\text { establishments } \\
\text { per capita }\end{array}$ \\
\hline
\end{tabular}




\begin{tabular}{lll}
\hline $\begin{array}{l}\text { PSU civic } \\
\text { engagement } \\
\text { (level-3) }\end{array}$ & $\begin{array}{l}\text { Percentage of population over the age of } 18 \text { who voted } \\
\text { in the year 2000. }\end{array}$ & $\begin{array}{l}\text { Continuous } \\
\text { variable }\end{array}$ \\
\hline
\end{tabular}

\section{Criterion Variables}

The three (3) criterion variables (internalizing behavioral problems, externalizing behavioral problems, total behavioral problems) were all measured on level-1 (time variant) utilizing the Child Behavior Checklist (CBCL). The $\mathrm{CBCL}$ is one of the most widely used standardized instruments used to evaluate child behavior. Developed by Thomas Achenbach, it measures child competence (activities, social, and academic) as well as behavioral and emotional problems as reported by an adult, usually a parent or caregiver. In order for the CBCL to be completed, the child must be between the ages of 2 to 18 . For this study, only the 118 items assessing behavioral and emotional problems are utilized. The items on the $\mathrm{CBCL}$ are measured on a 3-point scale ranging from 0 (not true) to 3 (very true). Thus, higher scores are indicative of greater behavioral and/or emotional problems (Achenbach, 1991).

The CBCL is comprised of nine (9) subscales: (a) Aggressive Behavior, (b) Anxious/Depressed, (c) Attention Problems, (d) Delinquent Behavior, (e) Social Problems, (f) Somatic Complaints, (g) Thought Problems, (i) Withdrawn, and (j) Sex Problems. Three (3) of these subscales (Withdrawn, Somatic Complaints, Anxious/Depressed) were combined to form the Internalizing Problems Scale, while two (2) of the subscales (Delinquent Behavior, Aggressive Behavior) were combined to make up the Externalizing Problems Scale. Scores are converted to T-Scores and standardized with cut-off values indicating 
whether a child is exhibiting normal, borderline, or clinically significant behaviors (Achenbach, 1991). Table 9 describes the psychometric properties for the CBCL.

Table 9

Criterion Variables (Level-1)

\begin{tabular}{|c|c|c|}
\hline Variable & Operationalization & $\begin{array}{l}\text { Values used in } \\
\text { Analysis }\end{array}$ \\
\hline \multicolumn{3}{|c|}{ INTERNALIZING BEHAVIORAL PROBLEMS } \\
\hline $\begin{array}{l}\text { Internalizing behavioral } \\
\text { problems (level-1) }\end{array}$ & $\begin{array}{l}32 \text { items from the Child } \\
\text { Behavior Checklist (CBCL) }\end{array}$ & $\begin{array}{l}\text { T-scores can range from 0- } \\
100, \text { with higher scores } \\
\text { indicative of greater }\end{array}$ \\
\hline $\begin{array}{l}\text { Child Behavior Checklist } \\
\text { (Achenbach, 1991) }\end{array}$ & $\begin{array}{l}\text { Comprised of withdrawn, } \\
\text { somatic complaints, and } \\
\text { anxious/deressed subscales }\end{array}$ & $\begin{array}{l}\text { internalizing behavioral } \\
\text { problems. }\end{array}$ \\
\hline Test-retest reliability $=0.93$ & of $\mathrm{CBCL}$ & $\begin{array}{l}\text { T-scores less than } 60 \text { are } \\
\text { considered "normal", between } \\
60 \text { and } 63 \text { are considered } \\
\text { "borderline", and T-scores } \\
\text { greater than } 63 \text { are considered } \\
\text { "clinical". }\end{array}$ \\
\hline \multicolumn{3}{|c|}{ EXTERNALIZING BEHAVIORAL PROBLEMS } \\
\hline $\begin{array}{l}\text { Externalizing behavioral } \\
\text { problems (level-1) }\end{array}$ & $\begin{array}{l}33 \text { items from the Child } \\
\text { Behavior Checklist (CBCL) }\end{array}$ & $\begin{array}{l}\text { T-scores can range from } 0- \\
100, \text { with higher scores } \\
\text { indicative of greater }\end{array}$ \\
\hline $\begin{array}{l}\text { Child Behavior Checklist } \\
\text { (Achenbach, 1991) }\end{array}$ & $\begin{array}{l}\text { Comprised of aggressive } \\
\text { behavior and delinquent } \\
\text { behavior subscales of the }\end{array}$ & $\begin{array}{l}\text { internalizing behavioral } \\
\text { problems. }\end{array}$ \\
\hline Test-retest reliability $=0.89$ & $\mathrm{CBCL}$ & $\begin{array}{l}\text { T-scores less than } 60 \text { are } \\
\text { considered "normal", between } \\
60 \text { and } 63 \text { are considered } \\
\text { "borderline", and T-scores } \\
\text { greater than } 63 \text { are considered } \\
\text { "clinical". }\end{array}$ \\
\hline \multicolumn{3}{|c|}{ TOTAL BEHAVIORAL PROBLEMS } \\
\hline $\begin{array}{l}\text { Total behavioral problems } \\
\text { (level-1) }\end{array}$ & $\begin{array}{l}118 \text { items from the Child } \\
\text { Behavior Checklist (CBCL) }\end{array}$ & $\begin{array}{l}\text { T-scores can range from } 0- \\
100, \text { with higher scores } \\
\text { indicative of greater }\end{array}$ \\
\hline $\begin{array}{l}\text { Child Behavior Checklist } \\
\text { (Achenbach, 1991) }\end{array}$ & $\begin{array}{l}\text { Comprised of withdrawn, } \\
\text { somatic complaints, } \\
\text { anxious/depressed, social }\end{array}$ & $\begin{array}{l}\text { internalizing behavioral } \\
\text { problems. }\end{array}$ \\
\hline Test-retest reliability $=0.93$ & $\begin{array}{l}\text { problems, thought problems, } \\
\text { attention problems, delinquent } \\
\text { behavior, aggressive behavior, } \\
\text { and sex problems subscales } \\
\text { of the CBCL }\end{array}$ & $\begin{array}{l}\text { T-scores less than } 60 \text { are } \\
\text { considered "normal", between } \\
60 \text { and } 63 \text { are considered } \\
\text { "borderline", and T-scores } \\
\text { greater than } 63 \text { are considered } \\
\text { "clinical". }\end{array}$ \\
\hline
\end{tabular}




\section{Analysis Plan}

Multilevel modeling, or hierarchical linear modeling (HLM), is the most appropriate analysis for this type of study. HLM allows for both the identification of patterns within and between individuals, as well as for testing potential interactions between predictors and time. The model fit will be accomplished via a two-stage estimation process first utilizing Iterative Generalized Least Squares (IGLS) followed by Markov Chain Monte Carol (MCMC) estimation. These estimation techniques are a form of Maximum Likelihood (ML) estimation, which is appropriate for this study because (a) the sample size is large enough; (b) the sample comes from a well-defined population; and (c) feedback loops are possible, although not tested in this analysis (Singer \& Willett, 2003).

The National Survey of Child and Adolescent Well-Being (NSCAW) data will be obtained from the National Data Archive on Child Abuse and Neglect (NDACAN) in eleven (11) separate Statistical Package for the Social Sciences (SPSS) files. These files will be mined for selected variables relevant to this proposed study and then merged based on a child identification variable. The data will then be organized and sorted into level-3 (PSU), level-2 (time invariant between person), and level-1 (time variant within person) data. MLwiN version 2.25 (Rasbash, Browne, Healy, Cameron, \& Charlton, 2010) will then be utilized to estimate a multilevel multivariate normal response longitudinal hierarchical linear model, accounting for each of the dependent variables (internalizing behavioral problems, externalizing behavioral problems, and total behavioral problems). Additionally, since a multivariate model is estimated, MLwiN adds an 
additional level that becomes a response variable level. Therefore, actually a 4level model with be estimated with level-1 being the response indicator, level-2 becoming the time variant within person level, level-3 becoming the time invariant between person level, and level-4 becoming the time invariant PSU level.

Preliminary analyses will investigate the structure of each variable on each level to ensure sufficient variability for HLM analyses. Additionally, plots will be created in order to observe intercepts and slopes in order to determine whether the intercepts and slopes should be random or fixed. Then, bivariate analyses will be conducted in order to investigate correlations between variables and test for multicollinearity. Variables, if any, that do exhibit multicollinearity will be removed from the model based on the correlation with the dependent variable. Lastly, outliers will be removed from the analysis and the distribution of each variable will be inspected in order to meet the assumptions of multilevel analyses. The assumptions made are that the independent variables are independent from one another (e.g., not highly correlated) and the error terms are distributed with a mean of zero and a standard deviation equal to $\sigma_{\varepsilon}^{2}$.

After the preliminary analysis, the analytic models for the dependent variable will be developed in four (4) steps, using HLM. Keep in mind that there will be three separate dependent variables being estimated simultaneously. First, as alluded to earlier, a visual inspection of the empirical growth plots for a sample of individuals will be examined. Second, the unconditional means model will be estimated using the following equation for internalizing behavior as an example: $Y_{i \mathrm{jkl}}=\beta_{0 \mathrm{jkl}}+f_{0}+f_{1}+v_{0}+v_{1}+u_{0}+u_{1}$. The equations were similar for 
the externalizing and total behavior problems, with the only difference being the subscript on the beta values and error terms. The unconditional means model describes the average child behavior problems across individuals and neighborhoods and time. Third, the unconditional growth model, which depicts mean child behavior changes over time across individuals and neighborhoods, will be estimated by the following equation for internalizing behavior problems: $Y_{i j k l}=\beta_{0 j \mathrm{kl}}+\beta_{1 \mathrm{kl}}\left(T I M E_{\mathrm{jkk}}\right)+f_{0}+f_{1}+v_{0}+v_{1}+u_{0}+u_{1}$. The equations were similar for the externalizing and total behavior problems, with the only difference being the subscript on the beta values and error terms. Lastly, predictors will be entered in order to explain the change in the dependent variable. This is represented by the following equation for internalizing behavior problems: $Y_{i j k l}=\beta_{0 j \mathrm{kl}}+\beta_{1 \mathrm{kl}}\left(\mathrm{TIME}_{\mathrm{ijk}}\right)+$ $\sum \beta_{i j k l}+\sum \beta_{j k l}+\sum \beta_{k l}+f_{0}+f_{1}+v_{0}+v_{1}+u_{0}+u_{1}$. The equations were similar for the externalizing and total behavior problems, with the only difference being the subscript on the beta values and error terms. Each model will first be estimated using IGLS estimation followed by a separate MCMC estimation due to the desire to compare models. Predictor variables that do not contribute to the model fit will be excluded from the final model in order to have the most parsimonious model possible. 


\title{
CHAPTER IV: RESULTS
}

\author{
Analysis does not set out to make pathological reactions impossible, \\ but to give the patient's ego freedom to decide one way or another. -Sigmund Freud
}

The aim of this study was to develop a better understanding of the impact of child maltreatment on behavioral outcomes. Specifically, the goal was to identify the importance of child, family, and environmental factors in relationship to child internalizing, externalizing, and total behavioral problems over time. Findings related to the following research questions will be described in this chapter: a) Do the behavioral trajectories for children reported to child protective services (CPS) as a result of child maltreatment change differently over time? and (b) What are the most important child factors, caregiver factors, and environmental factors that predict the level of internalizing, externalizing, and total behavioral problems experienced by children reported to CPS as a result of child maltreatment over a period of six (6) years? This chapter will explain data preparation activities and preliminary analyses, describe the study sample, detail the model building process, and present the results.

\section{Data Preparation and Preliminary Analysis}

\section{Retrieving and Merging Data}

The first step in the data preparation process was to obtain the dataset from the National Data Archive on Child Abuse and Neglect (NDACAN) at 
Cornell University. This dataset was obtained following an extensive review of security and privacy measures taken to ensure that the data would be stored safely and securely. Once the data were received, it was mined for appropriate variables related to this dissertation. Ultimately, over 40,000 variables in 11 separate files were reduced to less than 50 variables. The five (5) data files with the CPS sample discussed above were then merged together to form the working data set.

\section{Creating the Person-Period Data File}

Multilevel analysis requires that the data be structured in a long file format (Singer \& Willett, 2003). This means that the horizontal layout which has separate columns for each repeated measure of a variable must be restructured to a person-period data file. This results in a vertical layout with multiple rows for each measurement occasion. The person-period data file had four (4) kinds of variables: a) unit identifiers for PSUs, households, and measurement occasions; b) a time indicator with values ranging from one (1) to four (4) indicating the four measurement occasions; c) the criterion variable measured on four (4) occasions; and d) predictor variables.

\section{Data Screening}

Dependent variables. The first step taken in the data screening process was to examine the level of missingness across the five (5) waves. Immediately, it was evident that wave 2 data could not be utilized in the data file as it did not include data on the dependent variable. This reduced the sample to four (4) time periods, which was comprised of wave 1 , wave 3 , wave 4 , and wave 5 variables. 
Secondly, the three (3) dependent variables were inspected for missingness. All measurement occasions with missingness on the dependent variables (internalizing, externalizing, total behavior problems) were deleted from the final data file.

Table 10 below shows missingness on the dependent variables by wave. As demonstrated in Table 10 below, a majority (69.50\%) of the children and caregiver had at least three (3) or four (4) waves of completed data. A majority of the missingness on the dependent variable was due to the fact that the $\mathrm{CBCL}$ could not be administered until the child was at least two (2) years of age and could not be administered after the child reached the age of 18 . However, if the caregivers completed the $\mathrm{CBCL}$ at any point during the study, they were included in the sample.

Table 10

Missingness on Dependent Variables by Wave

\begin{tabular}{cc}
\hline $\begin{array}{c}\text { Number of } \\
\text { completed waves } \\
\text { of data }\end{array}$ & $\mathbf{N}(\%)$ \\
\hline 1 & $392(7.84)$ \\
2 & $1132(22.65)$ \\
3 & $1889(37.80)$ \\
4 & $1584(31.70)$ \\
\hline
\end{tabular}

Lastly, the dependent variables were inspected for normality assumptions.

Skewness and kurtosis analyses indicated that all three (3) dependent variables were normally distributed.

Child-related predictors. Initially, there were ten (10) child-related predictor variables included in the proposed model. However, after examination of missingness, some of these variables (e.g., child educational status, number 
of maltreatment incidents) needed to be removed from the initial proposed model due to extreme missingness. For those variables that remained in the originally proposed model and demonstrated an acceptable level of missingness, values were replaced using individual mean substitution and/or overall mean substitution. With regard to normality assumptions, each of the continuous variables were inspected for skewness and kurtosis. Initial analyses indicated that all child-related predictors were normally distributed.

Caregiver-related predictors. Initially, there were seventeen (17) caregiver-related predictor variables included in the proposed model. The caregiver-related predictors proved more difficult in determining the decisionmaking process with regard to missingness. This difficulty was present due to the fact that the caregiver could change between waves and there was no accurate way to determine the value of the missing value. Therefore, some of these variables (e.g., caregiver race/ethnicity, employment status, number of household members, depression, substance abuse, caregiver history of maltreatment, caregiver number of arrests, attachment, and emotional/cognitive stimulation) needed to be removed from the initial proposed model due to either extreme missingness or unusable data. When possible, missing values for categorical variables were replaced with the previous or subsequent value if the caregiver did not change from one time period to the next. For continuous variables, if the value could not be determined based on examining previous or subsequent time period data and it was deemed an appropriate level of missingness to replace the missing values, those values were replaced utilizing 
mean substitution. As a final step, caregiver-related predictors were examined to determine if they met normality assumptions. Based on skewness and kurtosis analysis, it was determined that the included variables met normality assumptions.

PSU-related variables. The PSU-related variables included in this analysis were collected by the NSCAW research team based on 1990 U.S. Census data and included in the data files initially received (Dowd et al, 2008). First, the PSU needed to be identified since the unrestricted NSCAW data file did not contain information identifying the PSU of each child. This was created by summing three variables (percentage of African Americans, per capita income, and total number of households) in order to group children together in a geographic area. Once this was calculated, each value was assigned an arbitrary number designating the child's PSU. There were a total of 87 PSU's included in the final data file. Second, these variables needed to be inspected for missingness. There was no missingness for any of these included variables. PSU-related predictors were examined for distribution. Access to social services exhibited high skewness values and was therefore trimmed. Utilizing the trimmed mean adequately took care of the skewness and all variables now met normality assumptions.

\section{Collinearity Diagnostics}

It is important to check included variables for collinearity prior to running any analysis. Tabachnick and Fidell (2001) have recommended that any two (2) variables with a correlation of 0.70 or higher be evaluated based on theory and 
importance and one (1) of the two (2) variables either be omitted or a composite score created. There were no variables that exhibited high collinearity in the model.

\section{Description of Sample}

The final sample included 14,659 measurement occasions (Level-1) for 4,997 children and their caregivers (Level-2) nested within 87 PSUs (Level-3) across four (4) time periods. Descriptive statistics are presented below for childlevel predictors, caregiver-level predictors and environmental-level predictors. Since the sample size is different for each wave after handling missing cases, Table 11 exhibits the final overall sample size per wave as well as the final sample size for maltreated and non-substantiated cases of maltreatment per wave.

\section{Table 11}

Sample Size per Wave with Complete Data on the Dependent Variables

\begin{tabular}{cccc}
\hline Wave & Overall $\boldsymbol{n}$ & Maltreated $\boldsymbol{n}$ & Non-substantiated $\boldsymbol{n}$ \\
\hline 1 & 3,462 & 1,979 & 1,483 \\
2 & 3,738 & 2,138 & 1,600 \\
3 & 4,309 & 2,551 & 1,758 \\
4 & 3,150 & 1,871 & 1,279 \\
\hline
\end{tabular}

\section{Child-level Predictors}

Child-level predictors are divided up into demographics, development, maltreatment, and health. The descriptive statistics for each of these sections are presented separately below.

Demographics. Child-level demographic predictors included gender and race/ethnicity. Table 12 below presents a summary of demographic characteristics for the overall sample, maltreated children, and non-substantiated 
cases of child maltreatment. The sample is evenly split between males and females; however there is a higher percentage of White/non-Hispanics than any other race/ethnicity specified in the sample. This sample is similar to national statistics, which report that $48.5 \%$ of reports are for males and $51.2 \%$ are for females (U.S. Department of Health and Human Services, 2011). With regard to race, the White/non-Hispanic ( $44.3 \%$ vs. $44.8 \%$ ) sample is similar to national statistics; however, there appears to be a slight oversampling of Black/nonHispanic (31.5\% vs. $21.9 \%)$ and Native Indian/Alaskan ( $4.7 \%$ vs. $1.1 \%)$ and a slight under sampling of Hispanics (16.9\% vs. $21.4 \%$ ). Based on the chi-square statistic, there was no statistically significant difference between the maltreated and non-substantiated group with regard to gender; however, there was a statistically significant difference with regard to race $\left(X^{2}=0.069, p<0.001\right)$, showing a significantly larger amount of African Americans in the maltreated group compared to the non-substantiated group.

Table 12

Child-level Demographic Characteristics

\begin{tabular}{lccc}
\hline Characteristic & $\begin{array}{c}\text { Overall } \\
\mathbf{f ( \% )}\end{array}$ & $\begin{array}{c}\text { Maltreated } \\
\mathbf{f ( \% )}\end{array}$ & $\begin{array}{c}\text { Non-substantiated } \\
\mathbf{f}(\%)\end{array}$ \\
\hline $\begin{array}{l}\text { Gender } \\
\text { Male }\end{array}$ & $2,477(49.6)$ & $1,426(48.5)$ & $1,051(51.0)$ \\
$\quad$ Female & $2,520(50.4)$ & $1,512(51.5)$ & $1,008(49.0)$ \\
Race/ethnicity & & & \\
$\quad$ White/non-Hispanic & $2,214(44.3)$ & $1,256(42.8)$ & $958(46.5)$ \\
Black/non-Hispanic & $1,575(31.5)$ & $1,005(34.2)$ & $570(27.7)$ \\
Hispanic & $846(16.9)$ & $477(16.2)$ & $369(17.9)$ \\
Native Indian/Alaskan & $233(4.7)$ & $127(4.3)$ & $106(5.1)$ \\
Other & $129(2.6)$ & $73(2.5)$ & $56(2.7)$ \\
\hline
\end{tabular}

Development. Child-level development predictors included age and social skills. Table 13 below presents a summary of development predictors for 
the overall sample, maltreated children, and non-substantiated cases of child maltreatment across the four (4) time periods.

Table 13

Child-level Development Predictors

\begin{tabular}{|c|c|c|c|c|c|c|}
\hline \multirow{2}{*}{ Predictor } & \multicolumn{2}{|c|}{ Overall } & \multicolumn{2}{|c|}{ Maltreated } & \multicolumn{2}{|c|}{ Non-Substantiated } \\
\hline & $M(S D)$ & Range & $M(S D)$ & Range & $M(S D)$ & Ranqe \\
\hline \multicolumn{7}{|l|}{ Age } \\
\hline Time 1 & $8.05(3.84)$ & $2-16$ & $8.14(3.87)$ & $2-16$ & $7.93(3.80)$ & $2-15$ \\
\hline Time 2 & $7.90(4.55)$ & $2-16$ & $8.04(4.59)$ & $2-16$ & $7.71(4.50)$ & $2-16$ \\
\hline Time 3 & $8.25(4.80)$ & $2-18$ & $8.10(4.87)$ & $2-18$ & $8.47(4.68)$ & $2-18$ \\
\hline Time 4 & $9.71(4.13)$ & $4-18$ & $9.56(4.19)$ & $4-18$ & $9.93(4.03)$ & $5-18$ \\
\hline \multicolumn{7}{|l|}{ Social Skills } \\
\hline Time 1 & $89.49(15.6)$ & $42-130$ & $89.13(15.6)$ & $42-130$ & $89.97(15.9)$ & $44-130$ \\
\hline Time 2 & $90.56(15.7)$ & $40-130$ & $90.09(15.5)$ & $40-130$ & $91.18(15.8)$ & $40.5-130$ \\
\hline Time 3 & 91.28 (16.1) & $40-130$ & 91.05 (16.1) & $42-130$ & 91.61 (16.1) & $40-130$ \\
\hline Time 4 & $94.16(16.0)$ & $41-130$ & $94.03(16.1)$ & $42-130$ & $94.35(15.9)$ & $41-130$ \\
\hline
\end{tabular}

Based on the data presented above, there is no difference between the maltreated and non-substantiated group with respect to age in time 1. However, children in the maltreated group are significantly older in time $2(t=-2.201, p=$ $0.028)$ and significantly younger in time $3(t=2.520, p=0.012)$ and time $4(t=$ $2.503, \mathrm{p} 0.012$ ). With respect to social skills, children in the maltreated group are similar to children in the non-substantiated group in time 1, time 3 , and time 4 . However, children in the maltreated group scored significantly lower with regard to social skills in time $2(t=2.102, p=0.036)$.

Maltreatment. Child-level maltreatment predictors included type of maltreatment, exposure to violence, and risk. Table 14 below presents a summary of maltreatment predictors for the overall sample, maltreated children, and non-substantiated cases of child maltreatment across the four (4) time periods, when applicable. "Neglect" in the table below is made up of both 
physical neglect, did not provide and neglect, no supervision. The "other maltreatment" category is comprised of emotional maltreatment, abandonment, moral/legal maltreatment, educational maltreatment, exploitation, and any other form of maltreatment not accounted for by the physical maltreatment, sexual maltreatment, or neglect categories.

Table 14

Child-level Maltreatment Predictors

\begin{tabular}{|c|c|c|c|c|c|c|c|c|c|}
\hline \multirow[b]{2}{*}{ Predictor } & \multicolumn{3}{|c|}{ Overall } & \multicolumn{3}{|c|}{ Maltreated } & \multicolumn{3}{|c|}{ Non-substantiated } \\
\hline & $\begin{array}{c}f \\
(\%)\end{array}$ & $\underset{(\mathrm{SD})}{M}$ & Range & $\begin{array}{c}f \\
(\%)\end{array}$ & $\underset{(\mathrm{SD})}{M}$ & Range & $\begin{array}{c}f \\
(\%)\end{array}$ & $\underset{(S D)}{M}$ & Range \\
\hline \multicolumn{10}{|l|}{ Maltreatment } \\
\hline \multicolumn{10}{|l|}{ Type } \\
\hline $\begin{array}{l}\text { Not } \\
\text { Substantiated }\end{array}$ & $\begin{array}{l}2,059 \\
(41.2)\end{array}$ & & & $\begin{array}{c}0 \\
(0.0)\end{array}$ & & & $\begin{array}{c}2,059 \\
(100.0)\end{array}$ & & \\
\hline Physical & $\begin{array}{c}597 \\
(11.9)\end{array}$ & & & $\begin{array}{l}597 \\
(20.3)\end{array}$ & & & & & \\
\hline Sexual & $\begin{array}{c}367 \\
(7.3)\end{array}$ & & & $\begin{array}{c}367 \\
(12.5)\end{array}$ & & & & & \\
\hline Neglect & $\begin{array}{l}1,436 \\
(28.7)\end{array}$ & & & $\begin{array}{l}1,436 \\
(48.9)\end{array}$ & & & & & \\
\hline Other & $\begin{array}{c}538 \\
(10.8)\end{array}$ & & & $\begin{array}{c}538 \\
(18.3)\end{array}$ & & & & & \\
\hline \multicolumn{10}{|l|}{$\begin{array}{l}\text { Exposure to } \\
\text { violence }\end{array}$} \\
\hline Time 1 & & $\begin{array}{c}5.56 \\
(3.86)\end{array}$ & $0-19$ & & $\begin{array}{c}5.63 \\
(3.93)\end{array}$ & $0-19$ & & $\begin{array}{c}5.47 \\
(3.76)\end{array}$ & $0-19$ \\
\hline Time 2 & & $\begin{array}{c}5.23 \\
(3.79)\end{array}$ & $0-19$ & & $\begin{array}{c}5.26 \\
(3.89)\end{array}$ & $0-19$ & & $\begin{array}{c}5.19 \\
(3.65)\end{array}$ & $0-19$ \\
\hline Time 3 & & $\begin{array}{c}5.00 \\
(3.90)\end{array}$ & $0-19$ & & $\begin{array}{c}5.00 \\
(3.90)\end{array}$ & $0-19$ & & $\begin{array}{c}5.02 \\
(3.88)\end{array}$ & $0-19$ \\
\hline Time 4 & & $\begin{array}{c}4.94 \\
(3.68)\end{array}$ & $0-19$ & & $\begin{array}{c}4.97 \\
(3.70)\end{array}$ & $0-19$ & & $\begin{array}{c}4.88 \\
(3.66)\end{array}$ & $0-19$ \\
\hline $\begin{array}{l}\text { Risk Factor } \\
\text { Index }\end{array}$ & & $\begin{array}{c}2.04 \\
(1.42)\end{array}$ & $0-5$ & & $\begin{array}{c}2.37 \\
(1.38)\end{array}$ & $0-5$ & & $\begin{array}{c}1.58 \\
(1.36)\end{array}$ & $0-5$ \\
\hline
\end{tabular}

Based on the data presented above, it appears that there was an over sampling of sexual maltreatment $(12.5 \%$ vs. $9.2 \%)$ and physical abuse $(20.3 \%$ vs. $17.6 \%)$ and an under sampling of neglect $(48.9 \%$ vs. $78.3 \%)$ based on 2010 national statistics (U.S. Department of Health and Human Services, 2011). 
However, national statistics report multiple types of maltreatment whereas the sample included in this study reports only the most severe type of maltreatment experienced by the child. Exposure to violence decreases over time, which is surprising due to the nature of the data but there is not a statistically significant difference in these scores between the maltreated and non-substantiated group. It could be possible that exposure to violence decreases over time as a result of children being placed in out-of-home care in a less violent environment. Also, as would be expected, the mean risk factor index is significantly higher for those children and caregivers in the maltreated $(M=2.37)$ group than for those in the non-substantiated $(M=1.58)$ group $(t=-20.054, p<0.001)$.

Health. Child-level health predictors included both physical and cognitive health. There are two (2) variables measuring each of these variables. The presence of a physical disability as well as caregiver reported physical health of the child measure physical health while the presence of a cognitive disability and scores on the Kaufman Brief Intelligence Test (K-BIT) are utilized to measure cognitive health. Table 15 below presents a summary of health-related predictors for the overall sample, maltreated children, and non-substantiated cases of child maltreatment. As indicated in the table below, there is an oversampling of both children with physical disabilities ( $8.0 \%$ vs. $0.8 \%)$ and children with cognitive disabilities $(22.9 \%$ vs. $2.1 \%)$ when compared with 2010 statistics (U.S. Department of Health and Human Services, 2011). There is not, however, a statistically significant difference in the percentage of children with physical disabilities and cognitive disabilities in the maltreated group when 
compared with those in the non-substantiated group. With regard to child general health status, the median health status was "very good" across all groups and all time periods. Children in the maltreated group had similar scores on the K-BIT compared to children in the non-substantiated group. 
Table 15

Child-level Health Predictors

\begin{tabular}{|c|c|c|c|c|c|c|c|c|c|}
\hline \multirow[b]{2}{*}{ Predictor } & \multicolumn{3}{|c|}{ Overall } & \multicolumn{3}{|c|}{ Maltreated } & \multicolumn{3}{|c|}{ Non-substantiated } \\
\hline & $\begin{array}{c}f \\
(\%)\end{array}$ & $\begin{array}{c}M \\
\text { (SD) }\end{array}$ & Range & $\begin{array}{c}f \\
(\%)\end{array}$ & $\begin{array}{c}M \\
\text { (SD) }\end{array}$ & Range & $\begin{array}{c}f \\
(\%)\end{array}$ & $\begin{array}{c}M \\
\text { (SD) }\end{array}$ & Range \\
\hline \multicolumn{10}{|c|}{ Physical Health } \\
\hline \multicolumn{10}{|c|}{ Physical Disability } \\
\hline Yes & $\begin{array}{c}402 \\
(8.0)\end{array}$ & & & $\begin{array}{c}248 \\
(8.4)\end{array}$ & & & $\begin{array}{c}154 \\
(7.5)\end{array}$ & & \\
\hline No & $\begin{array}{l}4,595 \\
(92.0)\end{array}$ & & & $\begin{array}{l}2,690 \\
(91.6)\end{array}$ & & & $\begin{array}{l}1,905 \\
(92.5)\end{array}$ & & \\
\hline \multicolumn{10}{|l|}{ General Health* } \\
\hline Time 1 & & 4.0 & $1-5$ & & 4.0 & $1-5$ & & 4.0 & $1-5$ \\
\hline Time 2 & & 4.0 & $1-5$ & & 4.0 & $1-5$ & & 4.0 & $1-5$ \\
\hline Time 3 & & 4.0 & $1-5$ & & 4.0 & $1-5$ & & 4.0 & $1-5$ \\
\hline Time 4 & & 4.0 & $1-5$ & & 4.0 & $1-5$ & & 4.0 & $1-5$ \\
\hline \multirow{2}{*}{\multicolumn{10}{|c|}{$\begin{array}{l}\text { Cognitive Health } \\
\text { Cognitive Disability }\end{array}$}} \\
\hline & & & & & & & & & \\
\hline Yes & $\begin{array}{l}1,146 \\
(22.9)\end{array}$ & & & $\begin{array}{c}675 \\
(23.0)\end{array}$ & & & $\begin{array}{c}471 \\
(22.9)\end{array}$ & & \\
\hline No & $\begin{array}{l}3,851 \\
(77.1)\end{array}$ & & & $\begin{array}{l}2,263 \\
(77.0)\end{array}$ & & & $\begin{array}{l}1,588 \\
(77.1)\end{array}$ & & \\
\hline \multicolumn{10}{|l|}{ K-BIT Scores } \\
\hline Time 1 & & $\begin{array}{c}93.49 \\
(15.26)\end{array}$ & $40-158$ & & $\begin{array}{c}93.37 \\
(15.13)\end{array}$ & $40-158$ & & $\begin{array}{c}93.66 \\
(15.43)\end{array}$ & $40-155$ \\
\hline Time 2 & & $\begin{array}{c}94.03 \\
(14.87)\end{array}$ & $40-160$ & & $\begin{array}{c}93.97 \\
(14.69)\end{array}$ & $40-153$ & & $\begin{array}{c}94.10 \\
(15.11)\end{array}$ & $40-160$ \\
\hline Time 3 & & $\begin{array}{c}93.29 \\
(14.74)\end{array}$ & $40-141$ & & $\begin{array}{c}93.32 \\
(14.37)\end{array}$ & $40-141$ & & $\begin{array}{c}93.24 \\
(15.26)\end{array}$ & $40-138$ \\
\hline Time 4 & & $\begin{array}{c}92.18 \\
(14.84)\end{array}$ & $40-141$ & & $\begin{array}{c}92.11 \\
(14.49)\end{array}$ & $40-141$ & & $\begin{array}{c}92.29 \\
(15.35)\end{array}$ & $40-137$ \\
\hline
\end{tabular}

* indicates median rather than mean reported 


\section{Caregiver-level Predictors}

Caregiver-level predictors are divided up into demographics, family structure, health, negative factors, and protective factors. The descriptive statistics for each of these sections are presented separately below.

Demographics. Caregiver-level demographic predictors included age, educational attainment, and income. Table 16 below presents a summary of demographic characteristics for the overall sample, caregivers with maltreated children, and caregivers with non-substantiated cases of child maltreatment. While these values would normally not vary over time periods, they are treated as time-variant characteristics in this sample due to the fact that the caregiver may change from one time period to the next. With regard to caregiver age, there is a statistically significant difference between the maltreated and nonsubstantiated group at time $1\left(X^{2}=51.28, p<0.001\right)$, time $2\left(X^{2}=40.35, p<\right.$ $0.001)$, time $3\left(X^{2}=38.03, p<0.001\right)$, and time $4\left(X^{2}=23.781, p<0.001\right)$. There is a lower percentage of younger caregivers (i.e., less than $25,26-35$ ) and a higher percentage of older caregivers (i.e., $46-55$, over 55 ) in the maltreated group compared to the non-substantiated group across all four (4) time periods. In terms of caregiver education, there was not a statistically significant difference between the maltreated and non-substantiated groups. There was, however, a statistically significant difference between caregiver income at time $1\left(X^{2}=14.80\right.$, $p=0.005)$, time $2\left(X^{2}=18.79, p<0.001\right)$, and time $3\left(X^{2}=12.20, p=0.016\right)$ but not at time 4. There are a greater percentage of caregivers with higher levels of income (i.e., $\$ 30,000-\$ 39,999$ group and $\$ 40,000$ or more group) in the 
maltreated group compared to the non-substantiated group for time 1 through time 3. This may be due to children being removed from abusive homes and placed with other family members or placed into a foster home.

Table 16

Caregiver-level Demographic Characteristics

\begin{tabular}{|c|c|c|c|}
\hline Characteristic & $\frac{\text { Overall }}{f(\%)}$ & $\frac{\text { Maltreated }}{f(\%)}$ & $\frac{\text { Non-substantiated }}{\mathrm{f}(\%)}$ \\
\hline \multicolumn{4}{|l|}{ Age } \\
\hline \multicolumn{4}{|l|}{ Time 1} \\
\hline$<25$ & $509(14.7)$ & $266(13.4)$ & $243(16.4)$ \\
\hline $26-35$ & $1,380(39.9)$ & $760(38.4)$ & $620(41.8)$ \\
\hline $36-45$ & $963(27.8)$ & $526(26.6)$ & $437(29.5)$ \\
\hline $46-55$ & $394(11.4)$ & $273(13.8)$ & $121(8.2)$ \\
\hline$>55$ & $216(6.2)$ & $154(7.8)$ & $62(4.2)$ \\
\hline \multicolumn{4}{|l|}{ Time 2} \\
\hline$<25$ & $629(16.8)$ & $312(14.6)$ & $317(19.8)$ \\
\hline $26-35$ & $1,373(36.7)$ & $763(35.7)$ & $610(38.1)$ \\
\hline $36-45$ & $1,054(28.2)$ & $611(28.6)$ & $443(27.7)$ \\
\hline $46-55$ & $458(12.3)$ & $298(13.9)$ & $160(10.0)$ \\
\hline$>55$ & $224(6.0)$ & $154(7.2)$ & $70(4.4)$ \\
\hline \multicolumn{4}{|l|}{ Time 3} \\
\hline$<25$ & $614(14.2)$ & $324(12.7)$ & $290(16.5)$ \\
\hline $26-35$ & $1,504(34.9)$ & $877(34.4)$ & $627(35.7)$ \\
\hline $36-45$ & $1,318(30.6)$ & $760(29.8)$ & $558(31.7)$ \\
\hline $46-55$ & $580(13.5)$ & $388(15.2)$ & $192(10.9)$ \\
\hline$>55$ & $293(6.8)$ & $202(7.9)$ & $91(5.2)$ \\
\hline \multicolumn{4}{|l|}{ Time 4} \\
\hline$<25$ & $236(7.5)$ & $131(7.0)$ & $105(8.2)$ \\
\hline $26-35$ & $1,094(34.7)$ & $619(33.1)$ & $475(37.1)$ \\
\hline $36-45$ & $972(30.9)$ & $570(30.5)$ & $402(31.4)$ \\
\hline $46-55$ & $540(17.1)$ & $332(17.7)$ & $208(16.3)$ \\
\hline$>55$ & $308(9.8)$ & $219(11.7)$ & $89(7.0)$ \\
\hline \multicolumn{4}{|l|}{ Educational Attainment } \\
\hline \multicolumn{4}{|l|}{ Time 1} \\
\hline Less than $12^{\text {th }}$ grade & $1,190(34.4)$ & $526(35.5)$ & $664(33.6)$ \\
\hline Diploma or equivalent & $813(23.5)$ & $326(22.0)$ & $487(24.6)$ \\
\hline Some College & $971(28.0)$ & $409(27.6)$ & $562(28.4)$ \\
\hline Don't know & $488(14.1)$ & $222(15.0)$ & $266(13.4)$ \\
\hline \multicolumn{4}{|l|}{ Time 2} \\
\hline Less than $12^{\text {th }}$ grade & $1,262(33.8)$ & $700(32.7)$ & $562(35.1)$ \\
\hline Diploma or equivalent & $921(24.6)$ & $548(25.6)$ & $373(18.1)$ \\
\hline Some College & $992(26.5)$ & $561(26.2)$ & $431(26.9)$ \\
\hline Don't know & $563(15.1)$ & $329(15.4)$ & $234(14.6)$ \\
\hline \multicolumn{4}{|l|}{ Time 3} \\
\hline Less than $12^{\text {th }}$ grade & $1,494(34.7)$ & $861(33.8)$ & $633(36.0)$ \\
\hline Diploma or equivalent & $974(22.6)$ & $587(23.0)$ & $387(22.0)$ \\
\hline Some College & $1,232(28.6)$ & $734(28.8)$ & $498(28.3)$ \\
\hline Don't know & $609(14.1)$ & $369(14.5)$ & $240(13.7)$ \\
\hline
\end{tabular}




$\begin{array}{cccc}\text { Time } 4 & & \\ \text { Less than } 12^{\text {th }} \text { grade } & 1,017(32.3) & 601(32.1) & 416(32.5) \\ \text { Diploma or equivalent } & 747(23.7) & 447(23.9) & 300(23.5) \\ \text { Some College } & 954(30.3) & 578(30.9) & 376(29.4) \\ \text { Don't know } & 437(13.7) & 245(13.1) & 187(14.6) \\ \begin{array}{c}\text { Income } \\ \text { Time } 1\end{array} & & & \\ \$ 0-\$ 9,999 & 664(19.2) & 355(17.9) & 309(20.8) \\ \$ 10,000-\$ 19,999 & 934(27.0) & 510(25.8) & 424(28.6) \\ \$ 20,000-\$ 29,999 & 885(25.6) & 513(25.9) & 372(25.1) \\ \$ 30,000-\$ 39,999 & 362(10.5) & 214(10.8) & 148(10.0) \\ \$ 40,000+ & 617(17.8) & 387(19.6) & 230(15.5) \\ \text { Time } 2 & & & \\ \$ 0-\$ 9,999 & 679(18.2) & 372(17.4) & 307(19.2) \\ \$ 10,000-\$ 19,999 & 1,079(28.9) & 571(26.7) & 508(31.8) \\ \$ 20,000-\$ 29,999 & 795(21.3) & 473(22.1) & 322(20.1) \\ \$ 30,000-\$ 39,999 & 436(11.7) & 259(12.1) & 177(11.1) \\ \$ 40,000+ & 749(20.0) & 463(21.7) & 286(17.9) \\ \text { Time } 3 & & & \\ \$ 0-\$ 9,999 & 758(17.6) & 431(16.9) & 327(18.6) \\ \$ 10,000-\$ 19,999 & 1,156(26.8) & 666(26.1) & 490(27.9) \\ \$ 20,000-\$ 29,999 & 902(20.9) & 524(20.5) & 378(21.5) \\ \$ 30,000-\$ 39,999 & 516(12.0) & 306(12.0) & 210(11.9) \\ \$ 40,000+ & 977(22.7) & 624(24.5) & 353(20.1) \\ \text { Time } 4 & & & \\ \$ 0-\$ 9,999 & 411(13.0) & 244(13.0) & 167(13.1) \\ \$ 10,000-\$ 19,999 & 811(25.7) & 474(25.3) & 337(26.3) \\ \$ 20,000-\$ 29,999 & 671(21.3) & 388(20.7) & 283(22.1) \\ \$ 30,000-\$ 39,999 & 382(12.1) & 222(11.9) & 160(12.5) \\ \$ 40,000+ & 875(27.8) & 543(29.0) & 332(26.0) \\ & & & \end{array}$

Family structure. Caregiver-level family structure predictors included marital status, number of children in the household, number of changes in caregiver, whether the caregiver was a permanent or a biological parent, and the number of out-of-home placements. Table 17 below presents a summary of family structure predictors for the overall sample, caregivers with maltreated children, and caregivers with non-substantiated cases of child maltreatment. There was a statistically significant difference between the maltreated and nonsubstantiated group with regard to caregiver marital status in time $1\left(X^{2}=8.27, p\right.$ $=0.016$ ), but not in the subsequent time periods. In time 1, there was a higher percentage of married caregivers in the maltreated group compared to the non- 
substantiated group. With regard to the number of children in the household, there was a statistically significant difference between the maltreated and nonsubstantiated group in time $1\left(X^{2}=15.52, p=0.004\right)$ and time $3\left(X^{2}=11.38, p=\right.$ 0.023 ) but not in time 2 or time 4 . In time 1 , there was a higher percentage of households with five (5) or more children in the maltreated group compared to the non-substantiated group. In time 3 , there was a higher percentage of households with four (4) or more children in the maltreated group compared to the non-substantiated group. Additionally, there were higher percentages of caregivers with children in the non-substantiated group reporting that they were the permanent caregivers at time $1\left(X^{2}=216.53, p<0.001\right)$, time $2\left(X^{2}=124.00\right.$, $p<0.001)$, and time $3\left(X^{2}=44.23, p<0.001\right)$ but not at time 4 . There were also higher percentages of caregivers with children in the non-substantiated group reporting that they were the biological caregiver at time $1\left(X^{2}=143.45, p<\right.$ $0.001)$, time $2\left(X^{2}=105.15, p<0.001\right)$, time $3\left(X^{2}=123.44, p<0.001\right)$, and time $4\left(X^{2}=78.69, p<0.001\right)$. Furthermore, children in the maltreated group had a higher number of changes in caregivers $(t=-6.164, p<0.001)$ and spent a longer amount of time in out-of-home care $(t=-12.785, p<0.001)$. 
Table 17

Caregiver-level Family Structure Predictors

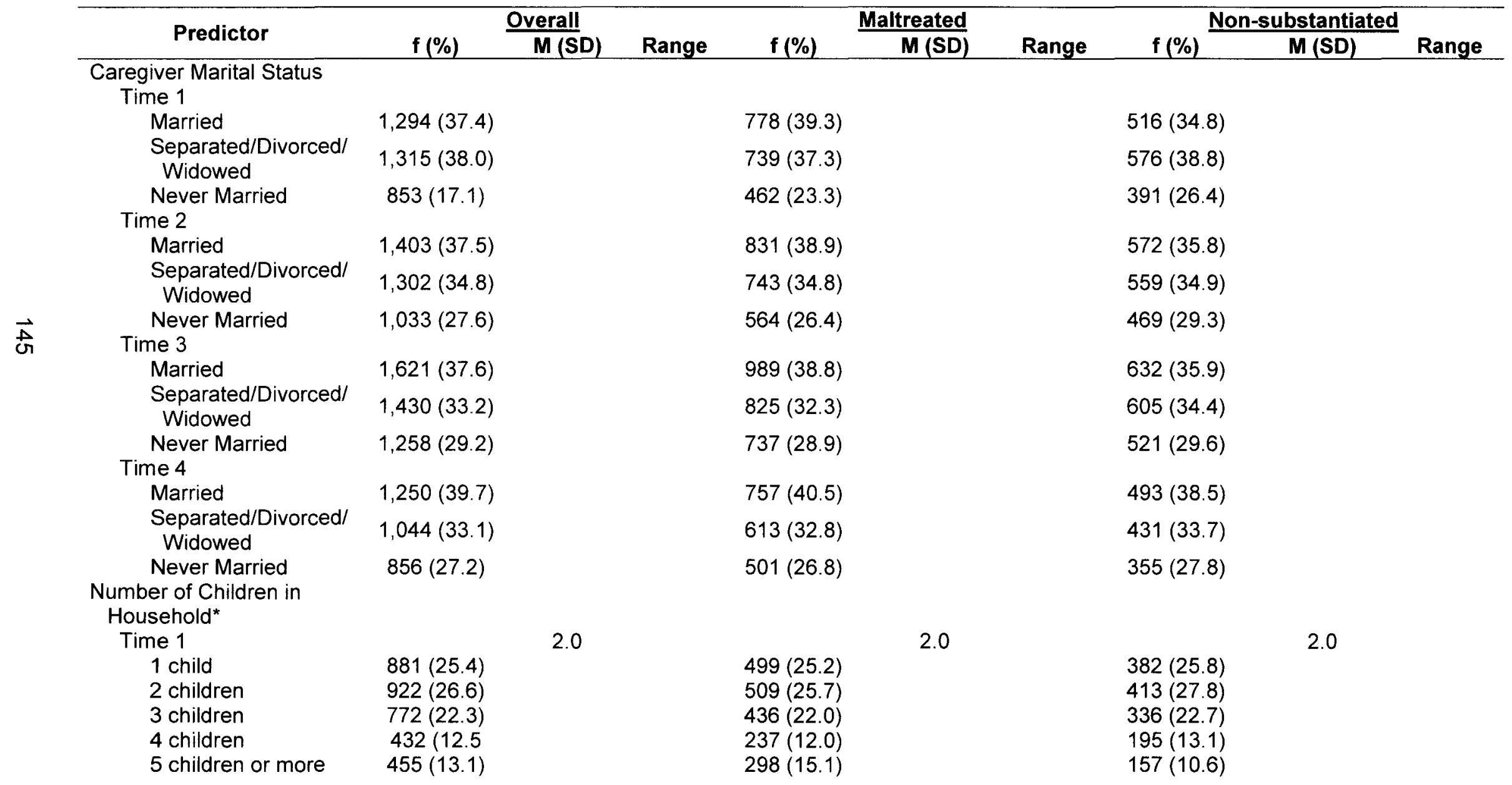




\begin{tabular}{|c|c|c|}
\hline & Time 2 & \\
\hline & 1 child & $991(26.5)$ \\
\hline & 2 children & $996(26.6)$ \\
\hline & 3 children & $861(23.0)$ \\
\hline & 4 children & $470(12.6)$ \\
\hline & 5 children or more & $420(11.2)$ \\
\hline & Time 3 & \\
\hline & 1 child & $1,127(26.2)$ \\
\hline & 2 children & $1,143(26.5)$ \\
\hline & 3 children & $961(22.3)$ \\
\hline & 4 children & $554(12.9)$ \\
\hline & 5 children or more & $524(12.2)$ \\
\hline & Time 4 & \\
\hline & 1 child & $803(25.5)$ \\
\hline & 2 children & $861(27.3)$ \\
\hline & 3 children & $700(22.2)$ \\
\hline & 4 children & $428(13.6)$ \\
\hline & 5 children or more & $358(11.4)$ \\
\hline & Permanent Caregiver & \\
\hline & Time 1 & \\
\hline & Yes & $2,668(77.1)$ \\
\hline & No & $794(22.9)$ \\
\hline & Time 2 & \\
\hline & Yes & $2,936(78.5)$ \\
\hline & No & $802(21.5)$ \\
\hline & Time 3 & \\
\hline & Yes & $3,613(83.8)$ \\
\hline & No & $696(16.2)$ \\
\hline & Time 4 & \\
\hline & Yes & $2,955(93.8)$ \\
\hline & No & $195(6.2)$ \\
\hline & Biological Caregiver & \\
\hline & Time 1 & \\
\hline & Yes & $2,237(64.6)$ \\
\hline & No & $1,225(35.4)$ \\
\hline & Time 2 & \\
\hline & Yes & $2,400(64.2)$ \\
\hline
\end{tabular}

2.0

560 (26.2)

577 (27.0)

$468(21.9)$

$278(13.0)$

255 (11.9)

2.0

661 (25.9)

654 (25.6)

$558(21.9)$

335 (13.1)

$343(13.4)$

2.0

479 (25.6)

498 (26.6)

406 (21.7)

$258(13.8)$

$230(12.3)$

$1,345(68.0)$

$634(32.0)$

1,541 (72.1)

597 (27.9)

$2,060(80.8)$

491 (19.2)

1,744 (93.2)

$127(6.8)$

$1,112(56.2)$

867 (43.8)

$1,224(57.2)$
2.0

431 (26.9)

$419(26.2)$

393 (24.6)

$192(12.0)$

$165(10.3)$

2.0

466 (26.5)

$489(27.8)$

$403(22.9)$

$219(12.5)$

$181(10.3)$

2.0

324 (25.3)

363 (28.4)

294 (23.0)

$170(13.3)$

$128(10.0)$

$1,323(89.2)$

$160(10.8)$

$1,395(87.2)$

205 (12.8)

$1,553(88.3)$

205 (11.7)

$1,211(94.7)$

$68(5.3)$

$1,125(75.9)$

$358(24.1)$

$1,176(73.5)$ 


\begin{tabular}{|c|c|c|c|c|c|c|c|c|c|}
\hline $\begin{array}{c}\text { No } \\
\text { Time } 3\end{array}$ & $1,338(35.8)$ & & & $914(42.8)$ & & & $424(26.5)$ & & \\
\hline Yes & $2,664(61.8)$ & & & $1,403(55.0)$ & & & $1,261(71.7)$ & & \\
\hline No & $1,645(38.2)$ & & & $1,148(45.0)$ & & & $497(28.3)$ & & \\
\hline Time 4 & & & & & & & & & \\
\hline Yes & $1,841(58.4)$ & & & $973(52.0)$ & & & $868(67.9)$ & & \\
\hline No & $1,309(41.6)$ & & & $898(48.0)$ & & & $411(32.1)$ & & \\
\hline $\begin{array}{l}\text { Number of Changes in } \\
\text { Caregiver }\end{array}$ & 4,997 & $\begin{array}{c}0.42 \\
(0.68)\end{array}$ & $0-3$ & 2.938 & $0.47(0.70)$ & $0-3$ & 2,059 & $0.35(0.64)$ & $0-3$ \\
\hline $\begin{array}{l}\text { Number of Days in Out-of- } \\
\text { Home Placements }\end{array}$ & 4,997 & $\begin{array}{c}289.26 \\
(493.42)\end{array}$ & $0-2,194$ & 2,938 & $\begin{array}{c}362.78 \\
(526.35)\end{array}$ & $0-2,872$ & 2,059 & $\begin{array}{c}184.36 \\
(420.62) \\
\end{array}$ & $0-2,914$ \\
\hline
\end{tabular}


Other caregiver factors. Due to a large number of variables that had to be eliminated due to extreme missingness, caregiver health, negative factors and protective factors were combined to make an "other caregiver factors" predictor group. Within this group, caregiver-level other factors included health, domestic violence, social support, and perception of neighborhood. Table 18 below presents a summary of caregiver protective factors predictors for the overall sample, caregivers with maltreated children, and caregivers with nonsubstantiated cases of child maltreatment. Caregiver general health stayed consisted at "good" across all four (4) time periods and across both the maltreated and non-substantiated group. Social support scores are pretty similar between the maltreated and non-substantiated group over time, with a significantly lower score in time 3 for the maltreated group $(t=-2.509, p=0.012)$. This is contrary to what would be expected for social support based on the literature, which reports that caregivers with lower levels of social support are at a higher risk of maltreating their children. With regard to domestic violence, caregivers with children in the maltreated group scored significantly higher than those caregivers with children in the non-substantiated group in time $1(\mathrm{t}=$ 2.593, $p=0.010$ ), but were relatively similar for time 2 through time 4 . This is also contradictory for domestic violence where it would be expected that domestic violence scores would be higher for caregivers with children in the maltreatment group across all time periods rather than just the first time period. However, this may be due to children being removed from violent homes where domestic violence is present and placed in out-of-home care during subsequent 
time periods. Lastly, caregivers with children in the maltreated group scored significantly lower with regard to perception of neighborhood than caregivers with children in the non-substantiated group for time $2(t=1.991, p=0.047)$ and time $4(t=2.579)$. However, there was not a statistically significant difference between the maltreated and non-substantiated group with regard to perception of neighborhood for time 1 or time 3 . This indicates that caregivers with children in the maltreated group had a more negative perception of their neighborhood than caregivers with children in the non-substantiated group during time periods 2 and 4.

Table 18

Caregiver-level Other Factors Predictors

\begin{tabular}{|c|c|c|c|c|c|c|}
\hline \multirow[t]{2}{*}{ Predictor } & \multicolumn{2}{|c|}{ Overall } & \multicolumn{2}{|c|}{ Maltreated } & \multicolumn{2}{|c|}{ Non-Substantiated } \\
\hline & $M(S \bar{D})$ & Range & $M(\mathrm{SD})$ & Range & $\overline{M(S D)}$ & Range \\
\hline \multicolumn{7}{|l|}{ Caregiver Health* } \\
\hline \multicolumn{7}{|l|}{ General Health* } \\
\hline Time 1 & 3.0 & $1-5$ & 3.0 & $1-5$ & 3.0 & $1-5$ \\
\hline Time 2 & 3.0 & $1-5$ & 3.0 & $1-5$ & 3.0 & $1-5$ \\
\hline Time 3 & 3.0 & $1-5$ & 3.0 & $1-5$ & 3.0 & $1-5$ \\
\hline Time 4 & 3.0 & $1-5$ & 3.0 & $1-5$ & 3.0 & $1-5$ \\
\hline \multicolumn{7}{|c|}{ Caregiver Negative Factors } \\
\hline \multicolumn{7}{|c|}{ Domestic Violence } \\
\hline Time 1 & $\begin{array}{c}4.54 \\
(14.16)\end{array}$ & $0-225$ & $\begin{array}{c}5.08 \\
(14.54)\end{array}$ & $0-225$ & $\begin{array}{c}3.81 \\
(13.62)\end{array}$ & $0-180$ \\
\hline Time 2 & $\begin{array}{c}2.49 \\
(10.37)\end{array}$ & $0-200$ & $\begin{array}{c}2.42 \\
(10.07)\end{array}$ & $0-200$ & $\begin{array}{c}2.58 \\
(10.76)\end{array}$ & $0-175$ \\
\hline Time 3 & $\begin{array}{c}2.09 \\
(10.32)\end{array}$ & $0-204$ & $\begin{array}{c}1.98 \\
(9.63)\end{array}$ & $0-177$ & $\begin{array}{c}2.25 \\
(11.26)\end{array}$ & $0-204$ \\
\hline Time 4 & $\begin{array}{l}1.37 \\
(8.05)\end{array}$ & $0-175$ & $\begin{array}{l}1.29 \\
(8.38)\end{array}$ & $0-175$ & $\begin{array}{c}1.48 \\
(7.56)\end{array}$ & $0-164$ \\
\hline \multicolumn{7}{|c|}{$\begin{array}{l}\text { Caregiver Protective Factors } \\
\text { Social Support }\end{array}$} \\
\hline Time 1 & $\begin{array}{c}3.37 \\
(0.50)\end{array}$ & $1-4$ & $\begin{array}{c}3.36 \\
(0.47)\end{array}$ & $1-4$ & $\begin{array}{c}3.38 \\
(0.53)\end{array}$ & $1-4$ \\
\hline Time 2 & $\begin{array}{c}3.24 \\
(0.57)\end{array}$ & $1-4$ & $\begin{array}{c}3.24 \\
(0.54)\end{array}$ & $1-4$ & $\begin{array}{c}3.23 \\
(0.61)\end{array}$ & $1-4$ \\
\hline Time 3 & $\begin{array}{c}3.29 \\
(0.56)\end{array}$ & $1-4$ & $\begin{array}{c}3.31 \\
(0.53)\end{array}$ & $1-4$ & $\begin{array}{c}3.26 \\
(0.59)\end{array}$ & $1-4$ \\
\hline Time 4 & $\begin{array}{c}3.33 \\
(0.59)\end{array}$ & $1-4$ & $\begin{array}{c}3.33 \\
(0.58)\end{array}$ & $1-4$ & $\begin{array}{c}3.32 \\
(0.61)\end{array}$ & $1-4$ \\
\hline
\end{tabular}




\begin{tabular}{ccccccc}
\hline Perception of Neighborhood & 13.42 & $3-27$ & 13.30 & $3-27$ & 13.58 & $5-27$ \\
Time 1 & $(4.18)$ & & $(4.24)$ & & $(4.09)$ & \\
& 13.31 & $5-27$ & 13.20 & $6-27$ & 13.46 & $5-27$ \\
Time 2 & $(3.95)$ & & $(3.98)$ & & $(3.89)$ & \\
& 13.44 & $2-27$ & 13.35 & $2-27$ & 13.56 & $5-27$ \\
Time 3 & $(4.07)$ & & $(4.05)$ & & $(4.09)$ & \\
& 13.03 & $1-27$ & 13.15 & $4-27$ & 13.53 & $1-27$ \\
Time 4 & $(4.04)$ & & $(3.98)$ & & $(4.10)$ & \\
& & &
\end{tabular}

* indicates median rather than mean reported

Environmental-level Predictors

Environmental-level predictors are measured by PSU income, PSU family structure, PSU number of juvenile arrests, PSU access to services, and PSU civic engagement. The descriptive statistics for the overall sample, maltreated children, and non-substantiated cases of child maltreatment are presented in Table 18 below. Based on the data presented in Table 19, there was not a statistically significant difference between the maltreated and non-substantiated group for any of the environmental-level predictors shown below.

Table 19

Environmental-level Predictors

\begin{tabular}{|c|c|c|c|c|c|c|}
\hline \multirow{2}{*}{ Predictor } & \multicolumn{2}{|c|}{ Overall } & \multicolumn{2}{|c|}{ Maltreated } & \multicolumn{2}{|c|}{ Non-Substantiated } \\
\hline & M (SD) & Range & $M(S D)$ & Range & $M(S D)$ & Range \\
\hline \multicolumn{7}{|l|}{ PSU Race/Ethnicity } \\
\hline White & $\begin{array}{c}69.25 \\
(20.79)\end{array}$ & $\begin{array}{l}14.58- \\
98.93\end{array}$ & $\begin{array}{l}69.30 \\
(21.11)\end{array}$ & $\begin{array}{l}14.58- \\
98.93\end{array}$ & $\begin{array}{c}69.20 \\
(20.55)\end{array}$ & $\begin{array}{l}27.66- \\
98.93\end{array}$ \\
\hline $\begin{array}{l}\text { African } \\
\text { American }\end{array}$ & $\begin{array}{c}14.10 \\
(14.60)\end{array}$ & $\begin{array}{l}0.15- \\
60.00\end{array}$ & $\begin{array}{c}14.13 \\
(14.39)\end{array}$ & $\begin{array}{l}0.15- \\
60.00\end{array}$ & $\begin{array}{c}14.06 \\
(14.94)\end{array}$ & $\begin{array}{l}0.15- \\
60.00\end{array}$ \\
\hline Hispanic & $\begin{array}{c}5.09 \\
(6.72)\end{array}$ & $\begin{array}{l}0.15- \\
34.41\end{array}$ & $\begin{array}{l}5.05 \\
(6.60)\end{array}$ & $\begin{array}{l}0.15- \\
34.41\end{array}$ & $\begin{array}{c}5.13 \\
(6.91)\end{array}$ & $\begin{array}{l}0.15- \\
34.41\end{array}$ \\
\hline \multicolumn{7}{|l|}{ PSU Income } \\
\hline $\begin{array}{l}\text { Per Capita } \\
\text { Income }\end{array}$ & $\begin{array}{c}\$ 20,457.88 \\
(4,092.98)\end{array}$ & $\begin{array}{l}\$ 13,136- \\
\$ 32,795\end{array}$ & $\begin{array}{l}\$ 20,411.25 \\
(4,058.10)\end{array}$ & $\begin{array}{l}\$ 13,136- \\
\$ 32,795\end{array}$ & $\begin{array}{c}\$ 20,513.45 \\
(4,161.61)\end{array}$ & $\begin{array}{l}\$ 13,136- \\
\$ 32,795\end{array}$ \\
\hline $\begin{array}{l}\text { Households in } \\
\text { Poverty }\end{array}$ & $\begin{array}{l}21.47 \\
(6.70)\end{array}$ & $\begin{array}{l}6.42- \\
40.01\end{array}$ & $\begin{array}{l}21.52 \\
(6.93)\end{array}$ & $\begin{array}{l}6.42- \\
40.01\end{array}$ & $\begin{array}{l}21.40 \\
(6.46)\end{array}$ & $\begin{array}{l}6.42- \\
40.01\end{array}$ \\
\hline $\begin{array}{l}\text { Children in } \\
\text { Poverty }\end{array}$ & $\begin{array}{l}16.82 \\
(5.83)\end{array}$ & $\begin{array}{l}3.27- \\
34.40\end{array}$ & $\begin{array}{l}16.85 \\
(6.01)\end{array}$ & $\begin{array}{l}3.27- \\
34.40\end{array}$ & $\begin{array}{l}16.78 \\
(5.65)\end{array}$ & $\begin{array}{l}3.27- \\
29.62\end{array}$ \\
\hline \multicolumn{5}{|l|}{ PSU Family } & & \\
\hline $\begin{array}{c}\text { Single-parent } \\
\text { Households }\end{array}$ & $\begin{array}{l}11.29 \\
(3.02)\end{array}$ & $\begin{array}{l}5.41- \\
25.69\end{array}$ & $\begin{array}{l}11.35 \\
(3.18)\end{array}$ & $\begin{array}{l}5.41- \\
25.69\end{array}$ & $\begin{array}{l}11.22 \\
(2.84)\end{array}$ & $\begin{array}{l}5.41- \\
20.52\end{array}$ \\
\hline
\end{tabular}




\begin{tabular}{lcccccc} 
PSU Crime & & & & & & \\
$\quad$ Juvenile Arrests & 0.16 & $0.00-$ & 0.16 & $0.00-$ & 0.15 & $0.00-$ \\
PSU Access to & $(0.19)$ & 1.03 & $(0.20)$ & 1.03 & $(0.18)$ & 0.69 \\
Services & & & & & & \\
$\quad$ Health Services & 0.48 & $0.04-$ & 0.48 & $0.04-$ & 0.47 & $0.04-$ \\
& $(0.25)$ & 1.23 & $(0.25)$ & 1.23 & $(0.25)$ & 1.23 \\
$\quad$ Social Services & 0.16 & $0.06-$ & 0.16 & $0.06-$ & 0.16 & $0.06-$ \\
PSU Civic & $(0.06)$ & 0.34 & $(0.06)$ & 0.34 & $(0.06)$ & 0.34 \\
Engagement & & & & & & \\
$\quad$ Percent Voted & 49.99 & $32.32-$ & 49.88 & $32.32-$ & 50.13 & $37.17-$ \\
$\quad$ 2000 & $(7.93)$ & 76.63 & $(8.08)$ & 76.63 & $(7.81)$ & 76.63 \\
\hline
\end{tabular}

\section{Criterion Variables}

There are three (3) criterion variables measured in this study: (a)

internalizing behavior problems; (b) externalizing behavior problems; and (c) total behavior problems. Based on Achenbach's (1991) criteria, T-scores could range between 0 and 100 , with scores less than 60 considered "normal," scores between 60-63 considered "borderline," and scores greater than 63 considered "clinical." Table 20 shows the overall number and percentage of children in each of these categories. 
Table 20

Internalizing, Externalizing, and Total T-Scores by Category

\begin{tabular}{|c|c|c|c|c|c|c|c|c|c|}
\hline Time & \multicolumn{3}{|c|}{ Overall } & \multicolumn{3}{|c|}{ Maltreated } & \multicolumn{3}{|c|}{ Non-Substantiated } \\
\hline \multicolumn{10}{|c|}{ Internalizing Behavior Problems } \\
\hline 1 & $2,219(64.1)$ & $378(10.9)$ & $865(25.0)$ & $1,258(63.6)$ & $223(11.2)$ & $498(25.2)$ & $961(64.8)$ & $155(10.5)$ & $367(24.7)$ \\
\hline 3 & $3,020(70.1)$ & $462(10.7)$ & $827(19.2)$ & $1,766(69.2)$ & $282(11.1)$ & $503(19.7)$ & $1,254(71.3)$ & $180(10.3)$ & $324(18.4)$ \\
\hline 4 & $2,415(76.7)$ & $275(8.7)$ & $460(14.6)$ & $1,451(77.5)$ & $168(9.0)$ & $252(13.5)$ & $964(75.4)$ & $107(8.4)$ & $208(16.2)$ \\
\hline \multicolumn{10}{|c|}{ Externalizing Behavior Problems } \\
\hline 1 & $1,916(55.3)$ & $421(12.2)$ & $1,125(32.5)$ & $1,080(54.6)$ & $234(11.8)$ & $665(33.6)$ & $836(56.4)$ & $187(12.6)$ & $460(31.0)$ \\
\hline 4 & $2,062(65.5)$ & $325(10.3)$ & $763(24.2)$ & $1,230(65.7)$ & $192(10.3)$ & $449(24.0)$ & $832(65.0)$ & $133(10.4)$ & $314(24.6)$ \\
\hline \multicolumn{10}{|c|}{ Total Behavior Problems } \\
\hline 1 & $1,880(54.3)$ & $337(9.7)$ & $1,245(36.0)$ & $1,050(53.1)$ & $204(10.3)$ & $725(36.6)$ & $830(56.0)$ & $133(9.0)$ & $520(35.0)$ \\
\hline 2 & $2,241(60.0)$ & $395(10.5)$ & $1,102(29.5)$ & $1,258(58.8)$ & $236(11.1)$ & $644(30.1)$ & $983(61.5)$ & $159(9.9)$ & $458(28.6)$ \\
\hline 3 & $2,691(62.4)$ & $439(10.2)$ & $1,179(27.4)$ & $1,581(62.0)$ & $249(9.8)$ & $721(28.2)$ & $1,110(63.1)$ & $190(10.8)$ & $458(26.1)$ \\
\hline 4 & $2,023(64.2)$ & $325(10.3)$ & $802(25.5)$ & $1,225(65.5)$ & $168(9.0)$ & $478(25.5)$ & $798(62.4)$ & $157(12.3)$ & $324(25.3)$ \\
\hline
\end{tabular}


As shown in Table 20 above, a majority (e.g., $50 \%$ or higher) of the children in the sample were categorized as "normal" regardless of time, type or maltreatment status.

The descriptive statistics, presented as standardized T-scores, for the overall sample, maltreated children, and non-substantiated cases of child maltreatment are presented in Table 21 below. Based on the data presented in Table 21, it appears as if the scores on all three (3) criterion variables decrease over time. It is interesting to note that all of the mean scores are in the "normal" range. There are not any statistically significant differences between the maltreated and non-substantiated group with regard to scores on any of the behavior scales, with the exception of internalizing behavior scores at time $1(\mathrm{t}=$ $-1.995, p=0.046)$. At time 1, the maltreated group reported higher average score than those in the non-substantiated group.

Table 21

Summary Statistics for Criterion Variables

\begin{tabular}{|c|c|c|c|c|c|c|}
\hline \multirow{2}{*}{ Predictor } & \multicolumn{2}{|c|}{ Overall } & \multicolumn{2}{|c|}{ Maltreated } & \multicolumn{2}{|c|}{ Non-Substantiated } \\
\hline & $M(S D)$ & Range & $M(\overline{\mathrm{SD}})$ & Range & $\overline{M(S D)}$ & Range \\
\hline \multicolumn{7}{|c|}{$\begin{array}{l}\text { Internalizing Behavior } \\
\text { Problems }\end{array}$} \\
\hline Time 1 & $\begin{array}{c}55.52 \\
(11.61)\end{array}$ & $30-97$ & $\begin{array}{c}55.86 \\
(11.52)\end{array}$ & $30-97$ & $\begin{array}{r}55.06 \\
(11.73)\end{array}$ & $30-93$ \\
\hline Time 2 & $\begin{array}{c}53.85 \\
(11.32)\end{array}$ & $30-92$ & $\begin{array}{c}54.16 \\
(11.31)\end{array}$ & $30-87$ & $\begin{array}{c}53.43 \\
(11.32)\end{array}$ & $30-92$ \\
\hline Time 3 & $\begin{array}{c}53.29 \\
(11.22)\end{array}$ & $30-94$ & $\begin{array}{c}53.45 \\
(11.17)\end{array}$ & $30-94$ & $\begin{array}{l}53.07 \\
(11.30)\end{array}$ & $30-93$ \\
\hline Time 4 & $\begin{array}{c}51.31 \\
(11.17)\end{array}$ & $31-88$ & $\begin{array}{c}51.17 \\
(11.00)\end{array}$ & $31-88$ & $\begin{array}{l}51.50 \\
(11.42)\end{array}$ & $31-87$ \\
\hline \multicolumn{7}{|c|}{$\begin{array}{l}\text { Externalizing Behavior } \\
\text { Problems }\end{array}$} \\
\hline Time 1 & $\begin{array}{c}57.76 \\
(12.14)\end{array}$ & $30-95$ & $\begin{array}{c}57.98 \\
(12.27)\end{array}$ & $30-94$ & $\begin{array}{l}57.47 \\
(11.96)\end{array}$ & $30-95$ \\
\hline Time 2 & $\begin{array}{c}56.37 \\
(11.78)\end{array}$ & $30-95$ & $\begin{array}{c}56.62 \\
(11.69)\end{array}$ & $30-95$ & $\begin{array}{c}56.04 \\
(11.88)\end{array}$ & $30-91$ \\
\hline Time 3 & $\begin{array}{c}55.57 \\
(11.73)\end{array}$ & $30-99$ & $\begin{array}{c}55.64 \\
(11.62)\end{array}$ & $30-99$ & $\begin{array}{l}55.46 \\
(11.89)\end{array}$ & $30-96$ \\
\hline
\end{tabular}




\begin{tabular}{ccccccc} 
Time 4 & 55.06 & $30-89$ & 55.01 & $30-89$ & 55.13 & $30-86$ \\
$\begin{array}{c}\text { Total Behavior } \\
\text { Problems }\end{array}$ & $(11.48)$ & & $(11.41)$ & & $(11.59)$ & \\
Time 1 & & & & & & \\
& 58.23 & $23-94$ & 58.53 & $23-94$ & 57.82 & $23-91$ \\
Time 2 & $(12.23)$ & & $(12.21)$ & & $(12.25)$ & \\
& 56.35 & $23-91$ & 56.65 & $24-91$ & 55.96 & $23-91$ \\
Time 3 & $(12.04)$ & & $(11.95)$ & & $(12.15)$ & $23-94$ \\
& 55.60 & $23-94$ & 55.75 & $23-92$ & 55.40 & $23-94$ \\
Time 4 & $(12.10)$ & & $(11.97)$ & & $(12.30)$ & $23-88$ \\
\hline
\end{tabular}

\section{Model Building}

\section{Assessing the Need for the Multilevel Model}

The first research question asked in this dissertation was "Do the behavioral trajectories for children reported to child protective services (CPS) as a result of child maltreatment change differently over time?" The corresponding hypothesis was that the behavioral trajectories for children reported to child protective services (CPS) as a result of child maltreatment would change differently over time. This question can initially be answered by examining the empirical growth plots, both for children over time and PSUs over time. Figure 5 shows the empirical growth plots for internalizing, externalizing, and total behavior problems over time for all children in the sample. It is clearly visible that children start at different points and change differently over time. For example, it appears that some of the slopes are relatively flat while others are fairly steep. 


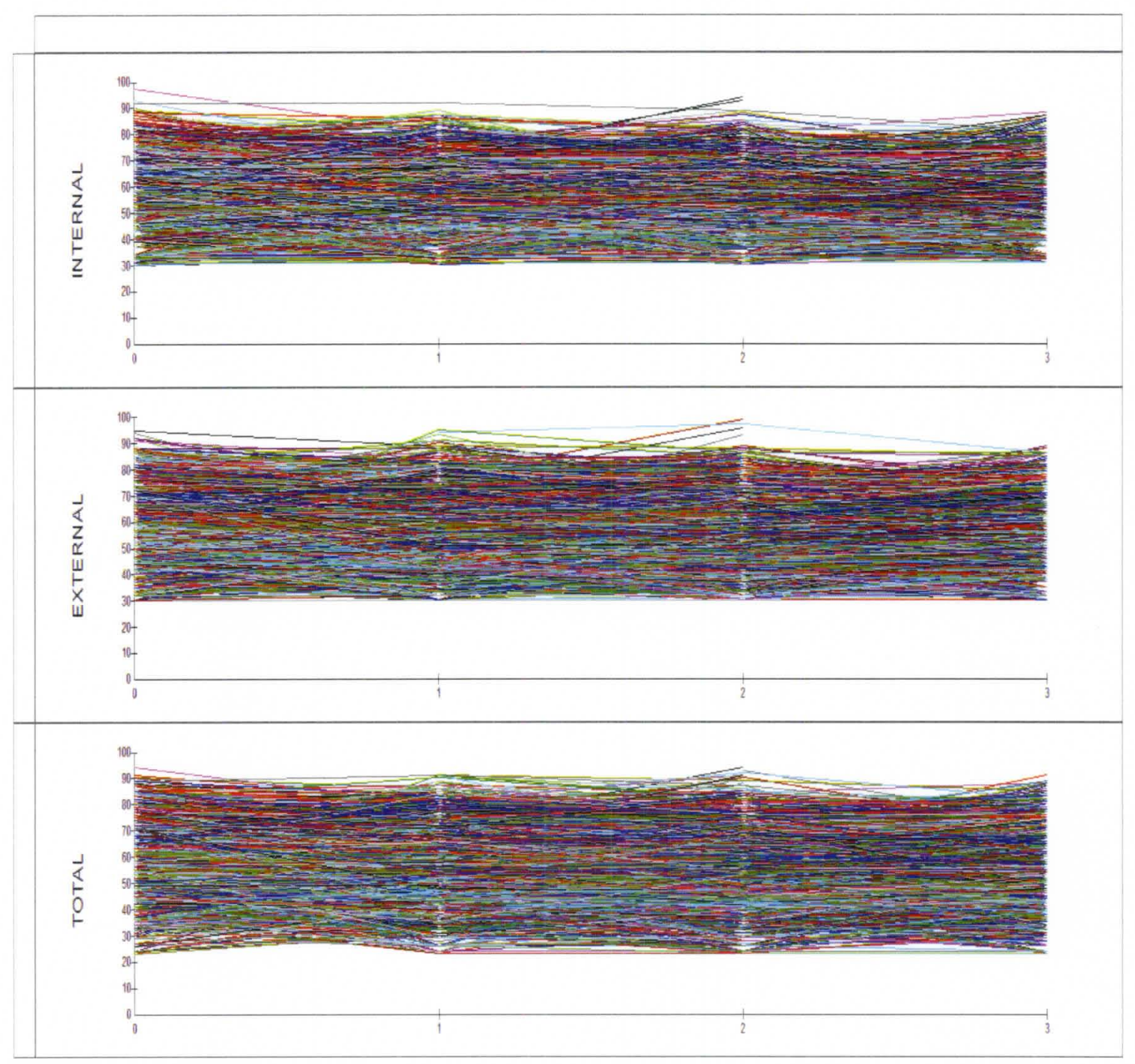

Figure 5. Collected growth trajectories for all children in sample.

Another way to determine whether children change differently over time is to visually inspect the growth trajectories for a sample of cases (Singer \& Willett, 2003). A random sample of twenty (20) cases was selected for visual inspection of the growth trajectories for each of the criterion variables. Figure 6 depicts the growth trajectories for internalizing behavior problems. As demonstrated in Figure 6 , it is evident that these individuals start at different points and change differently over time. Some trajectories increase and decrease over time (e.g., 
200110) while others remain relatively flat over time (e.g., 200888). Other trajectories start relatively flat and then decrease after time 2 (e.g., 203306) or increase until time 2 and then become relatively flat (e.g., 200135).
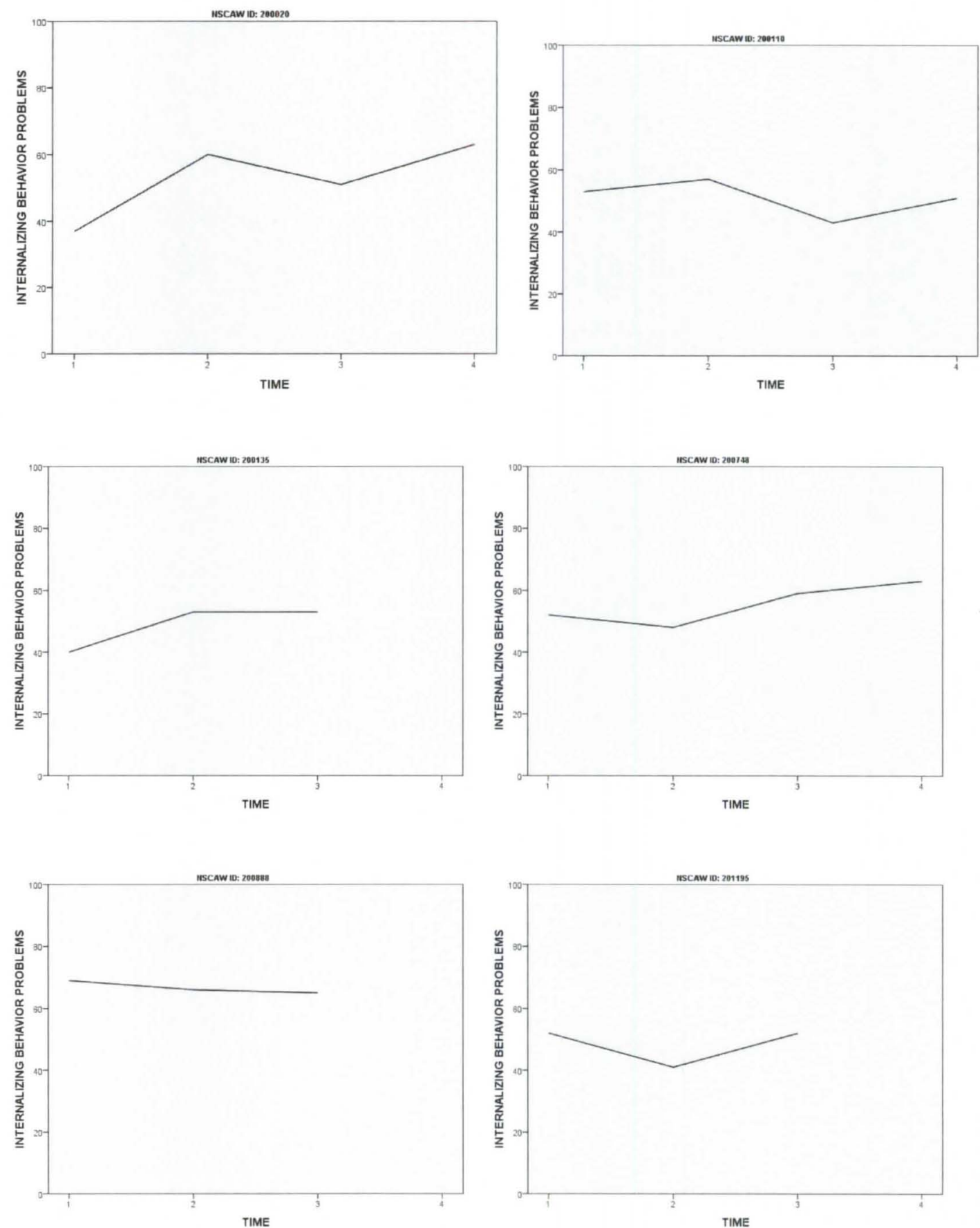

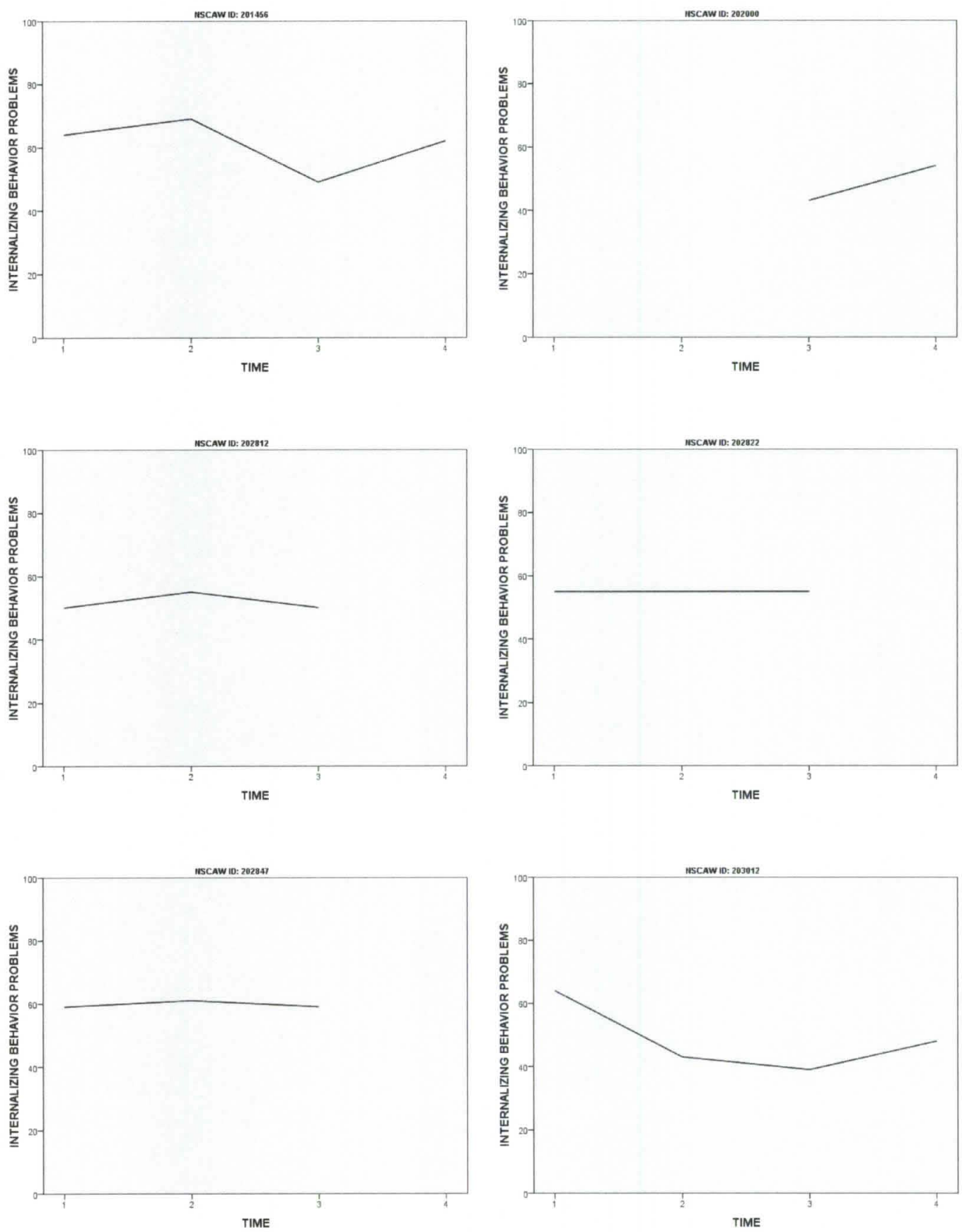

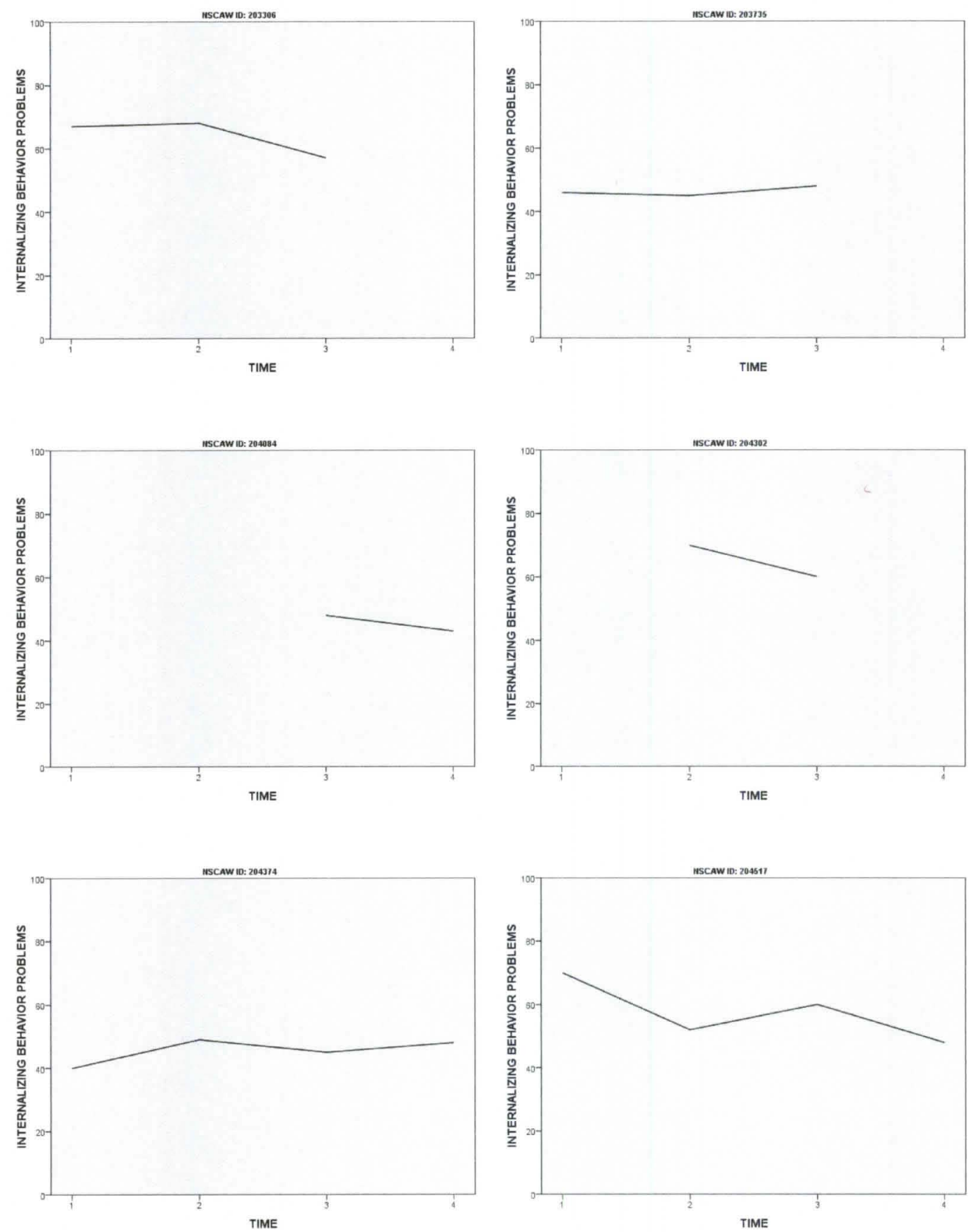

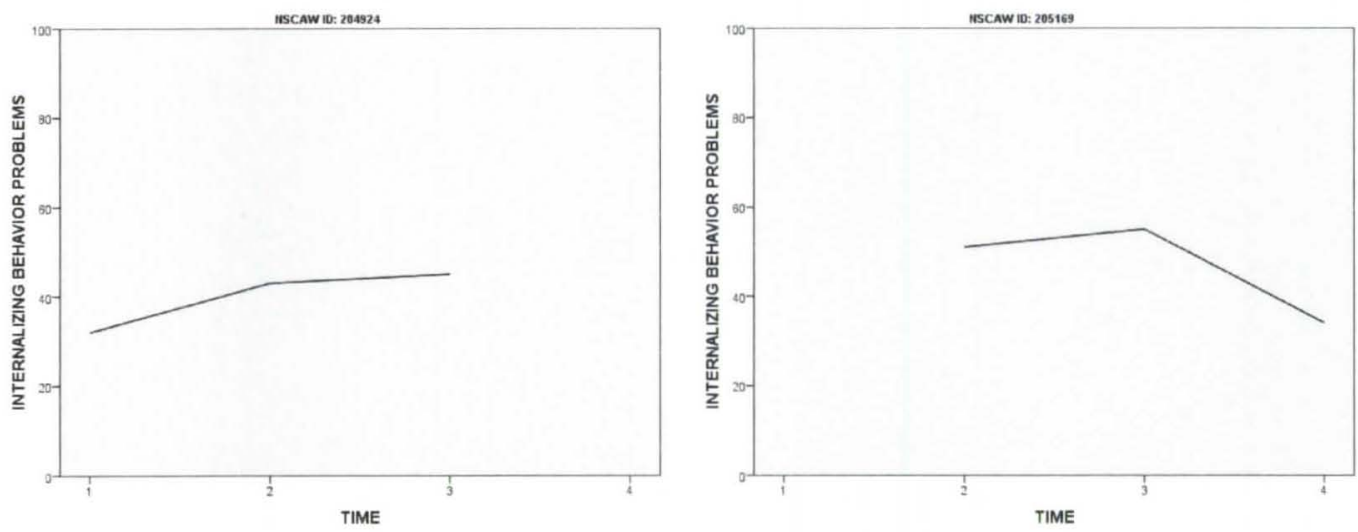

Figure 6. Internalizing behavior problems empirical growth plots.

Figure 7 below depicts the growth trajectories for externalizing behavior problems. As with the trajectories for internalizing behavior problems, the trajectories below similarly demonstrate that individuals start at different levels and change differently over time. Some individuals increase and decrease over time (e.g., 201349), while others only increase (e.g., 200944) or only decrease (e.g., 205013).
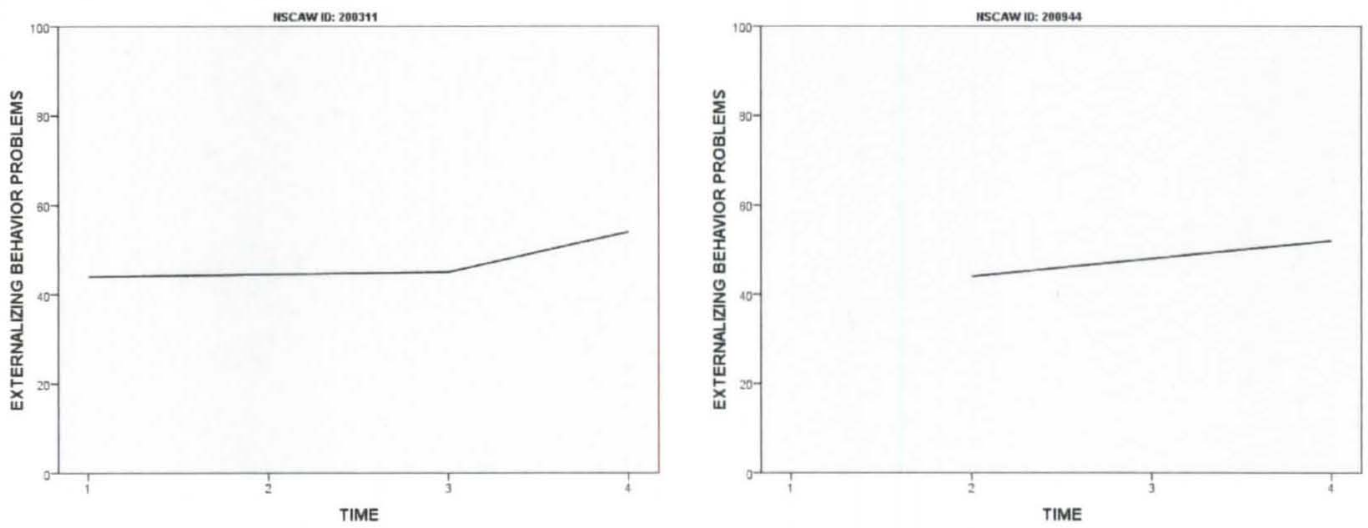

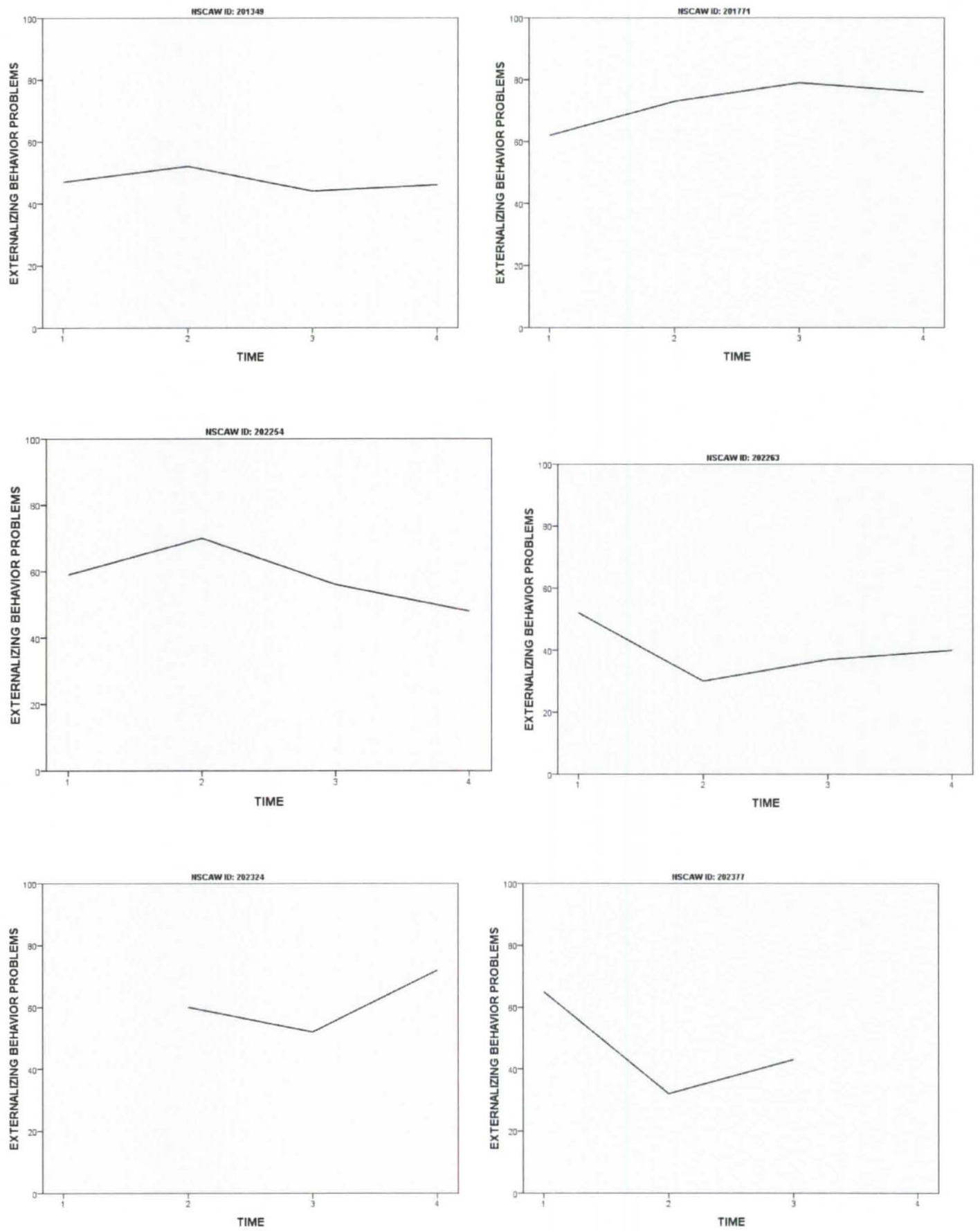

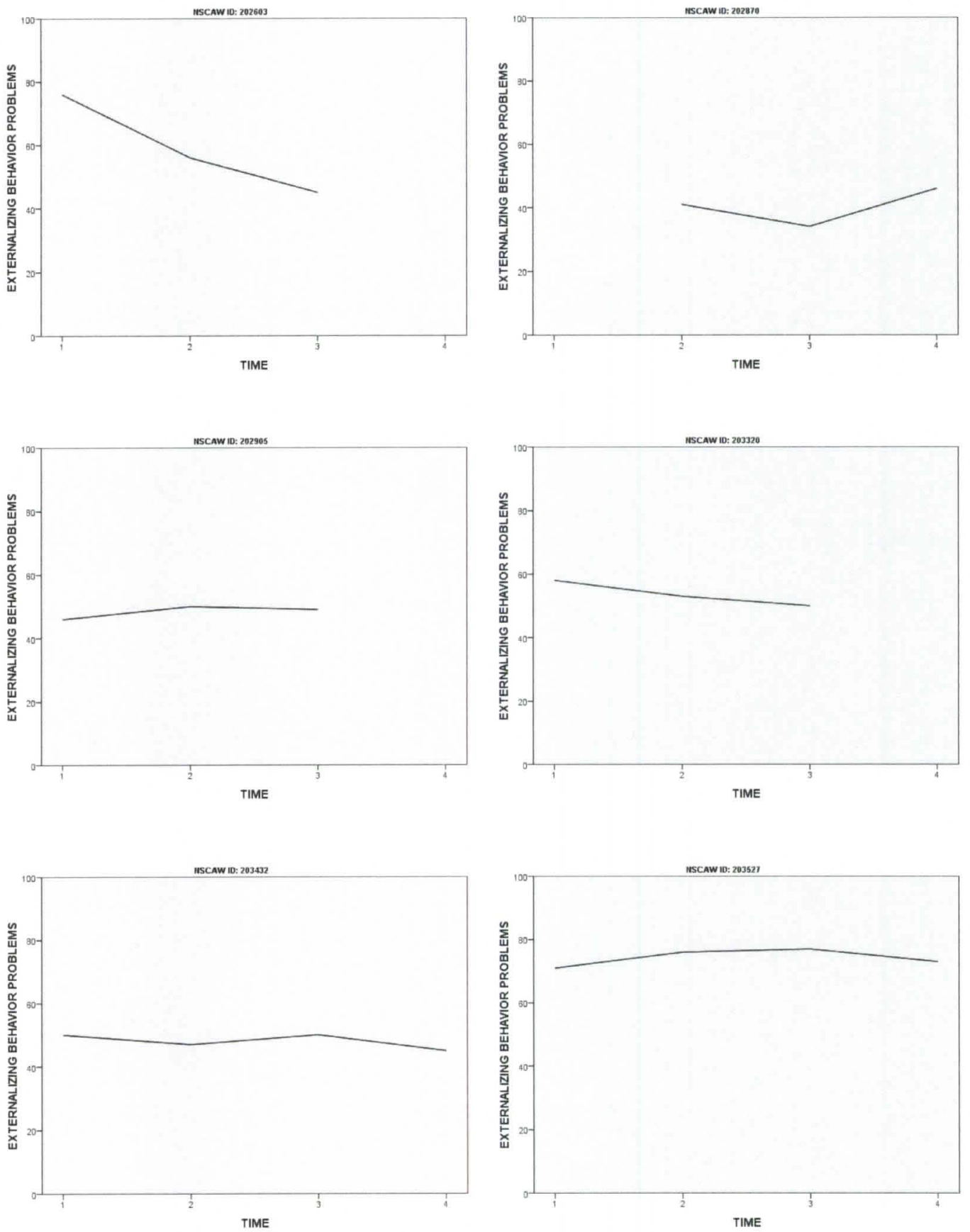

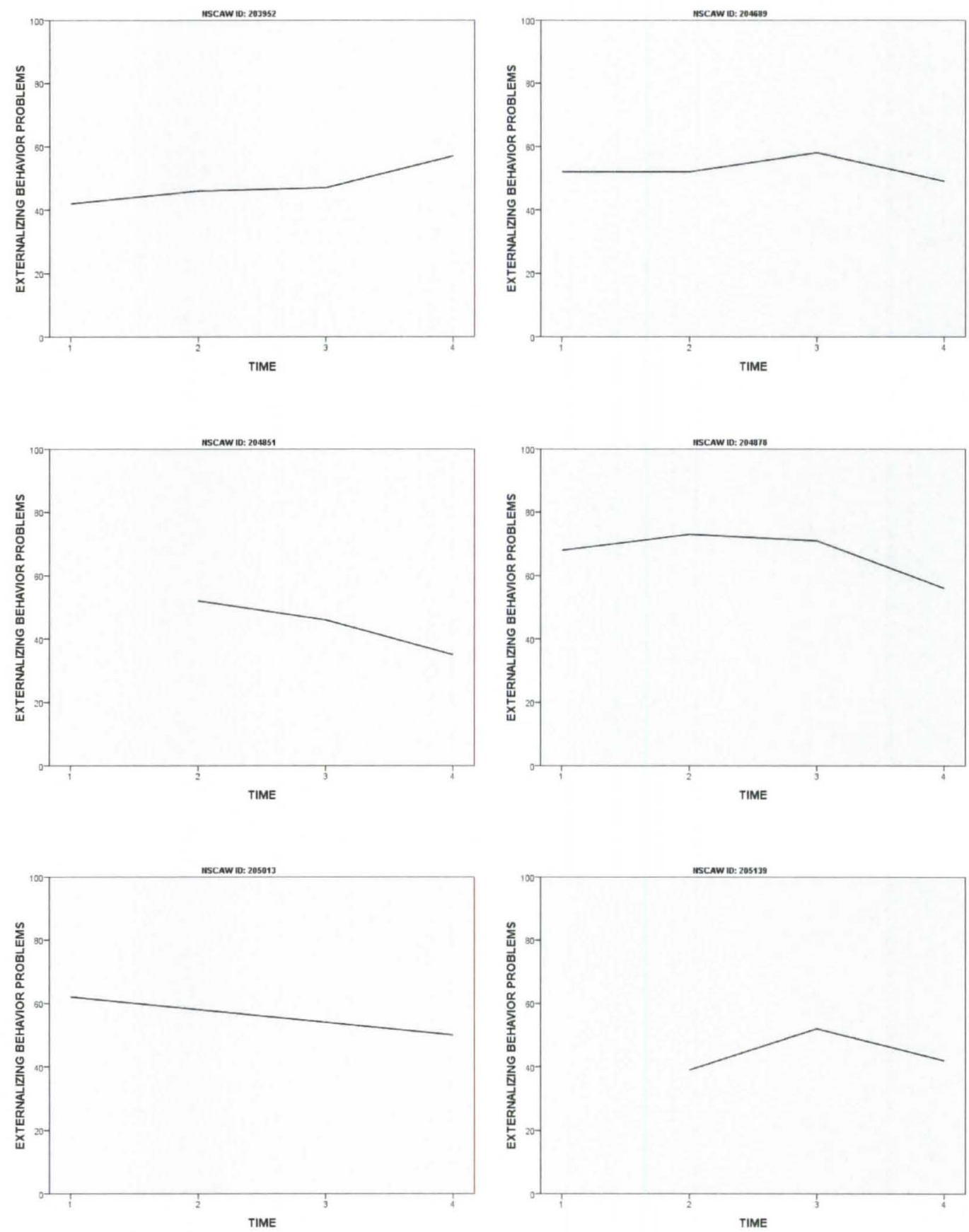

Figure 7. Externalizing behavior problems empirical growth plots.

Figure 8 below depicts the growth trajectories for total behavior problems. The trajectories for total behavior problems similarly demonstrate that individuals start at different levels and change differently over time. Some individuals increase 
and decrease over time (e.g., 205501), while others only increase (e.g., 200367), or only decrease (e.g., 200118), or remain flat (e.g., 203091).
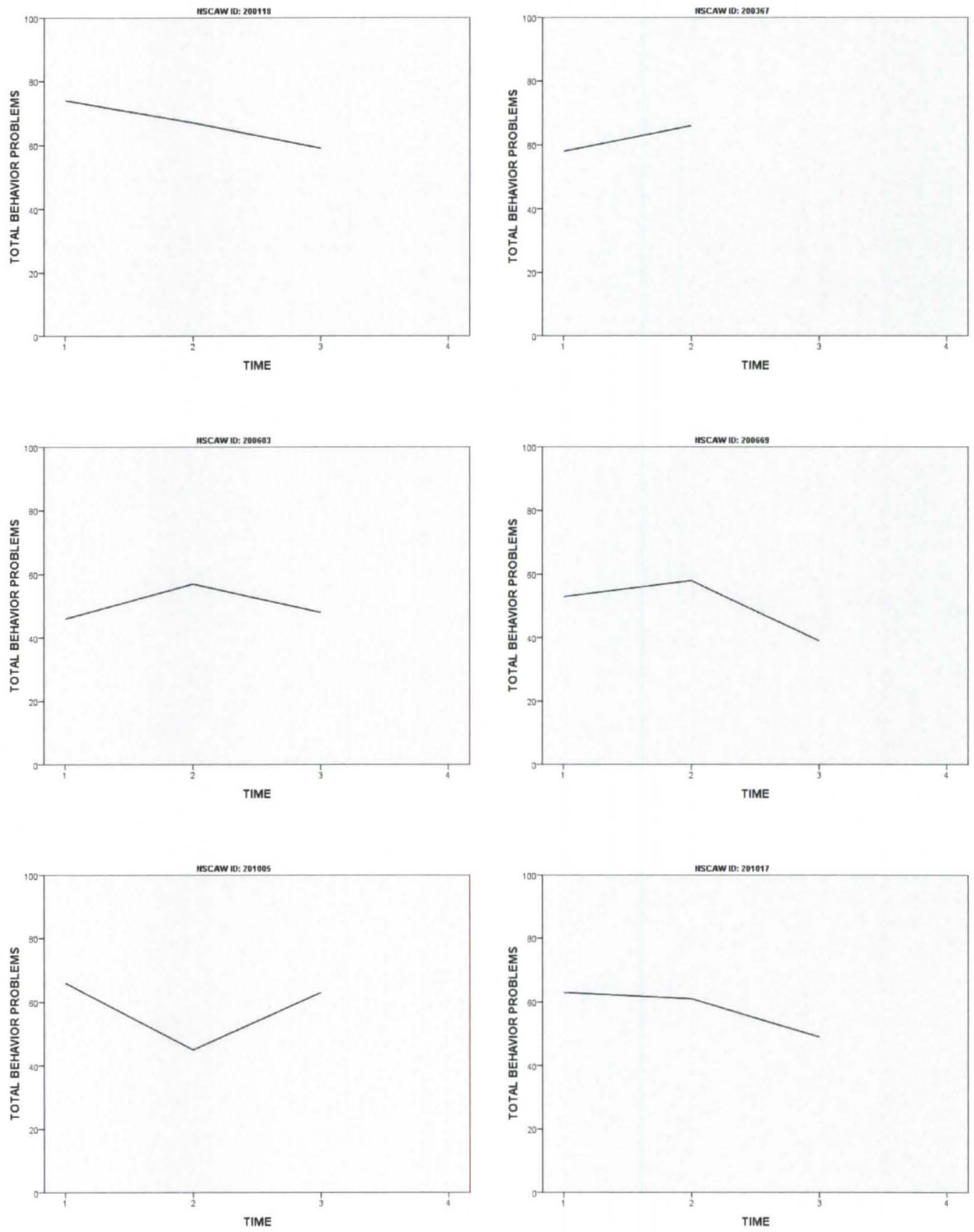

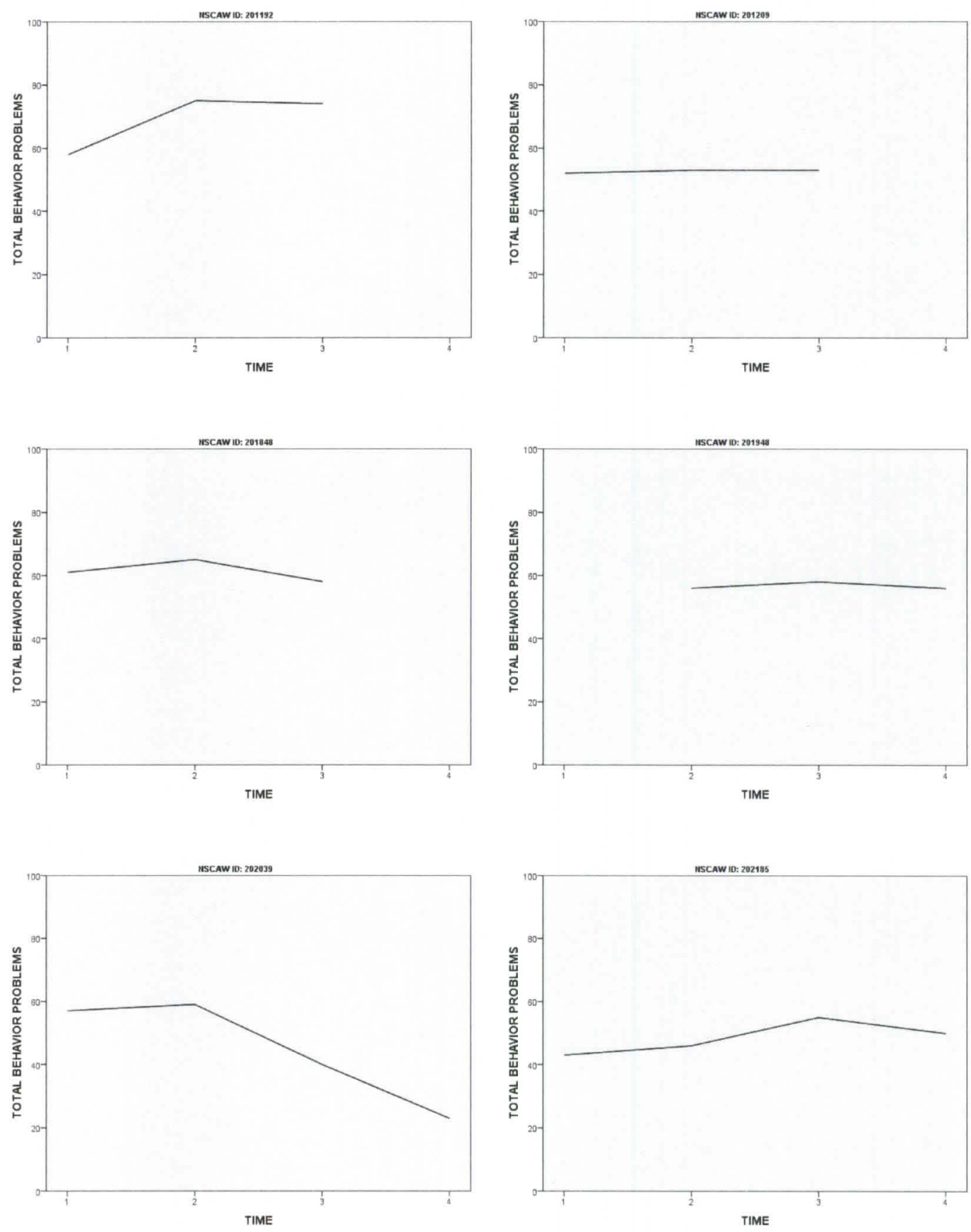

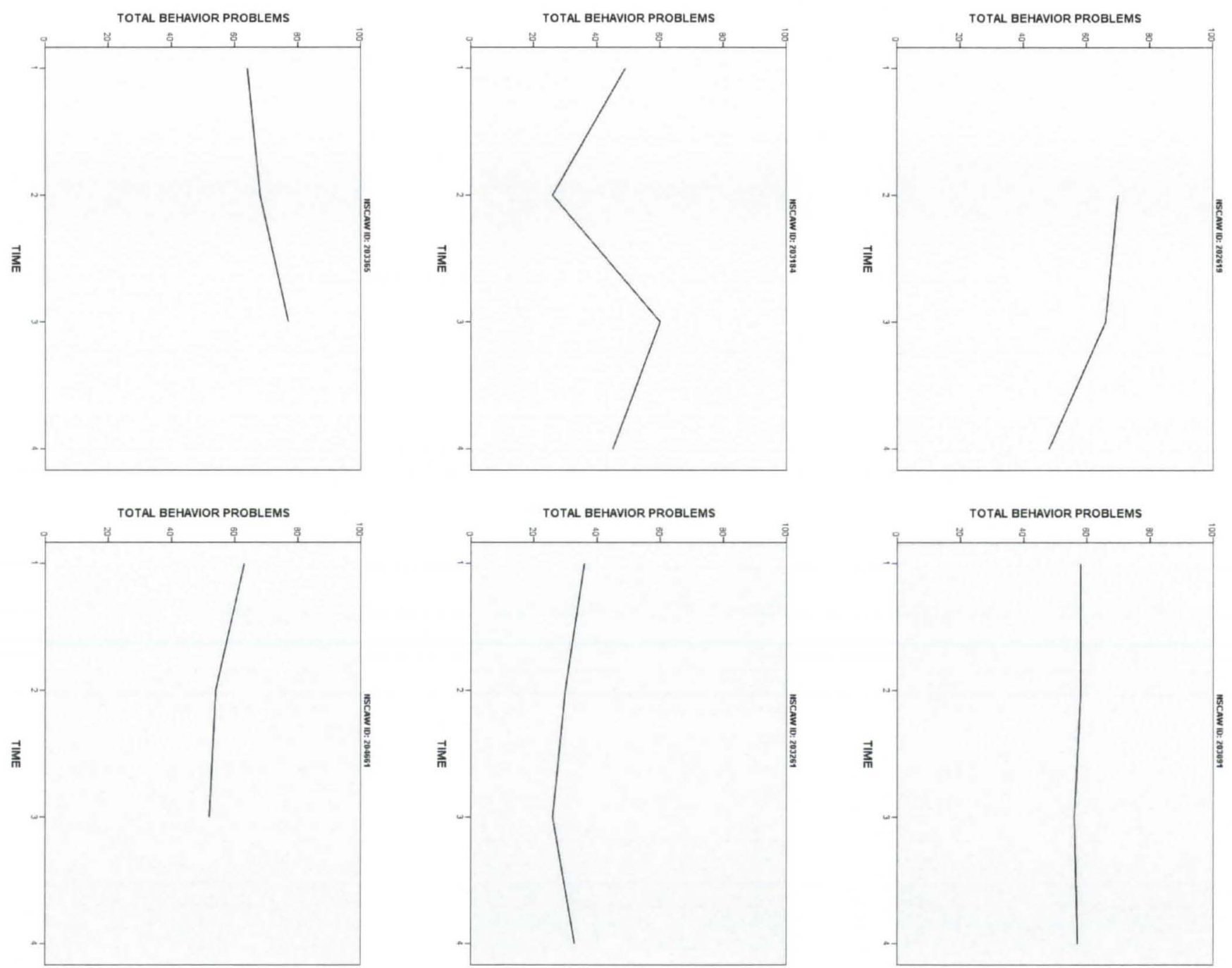

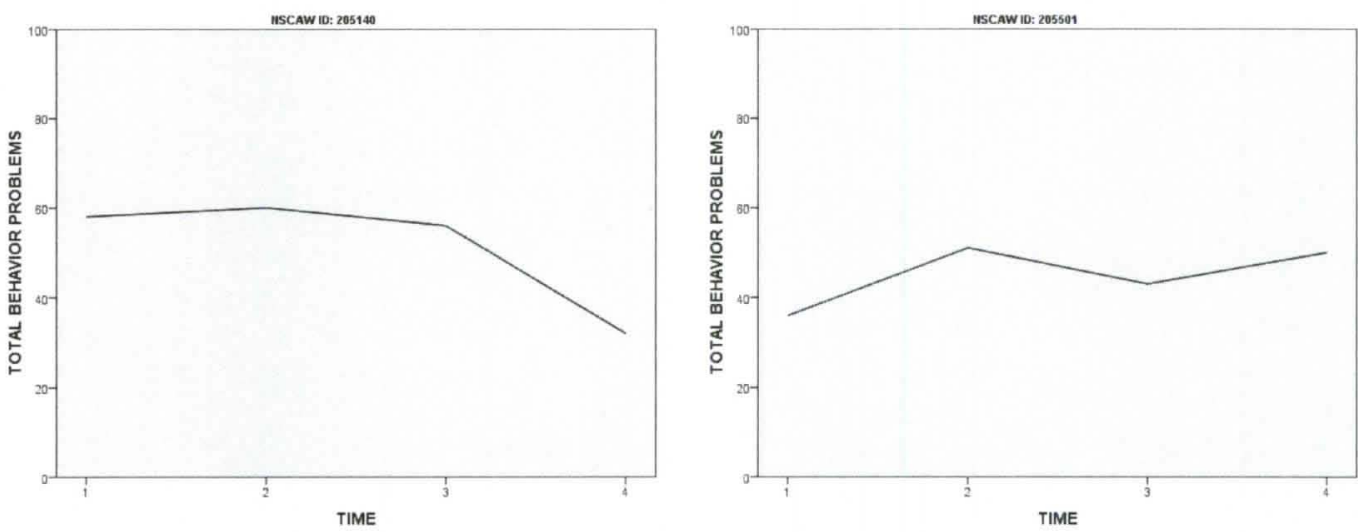

Figure 8. Total behavior problems empirical growth plots.

It is also important to examine the growth plots for the PSUs over time to determine if there is justification for nesting on the highest level. Figure 9 depicts the empirical growth plots for internalizing, externalizing, and total behavior problems over time between all PSUs in the sample. Clearly evident in Figure 9 is that PSUs are also different over time with some having relatively high levels of behavior problems while others demonstrate relatively low levels of behavior problem. 


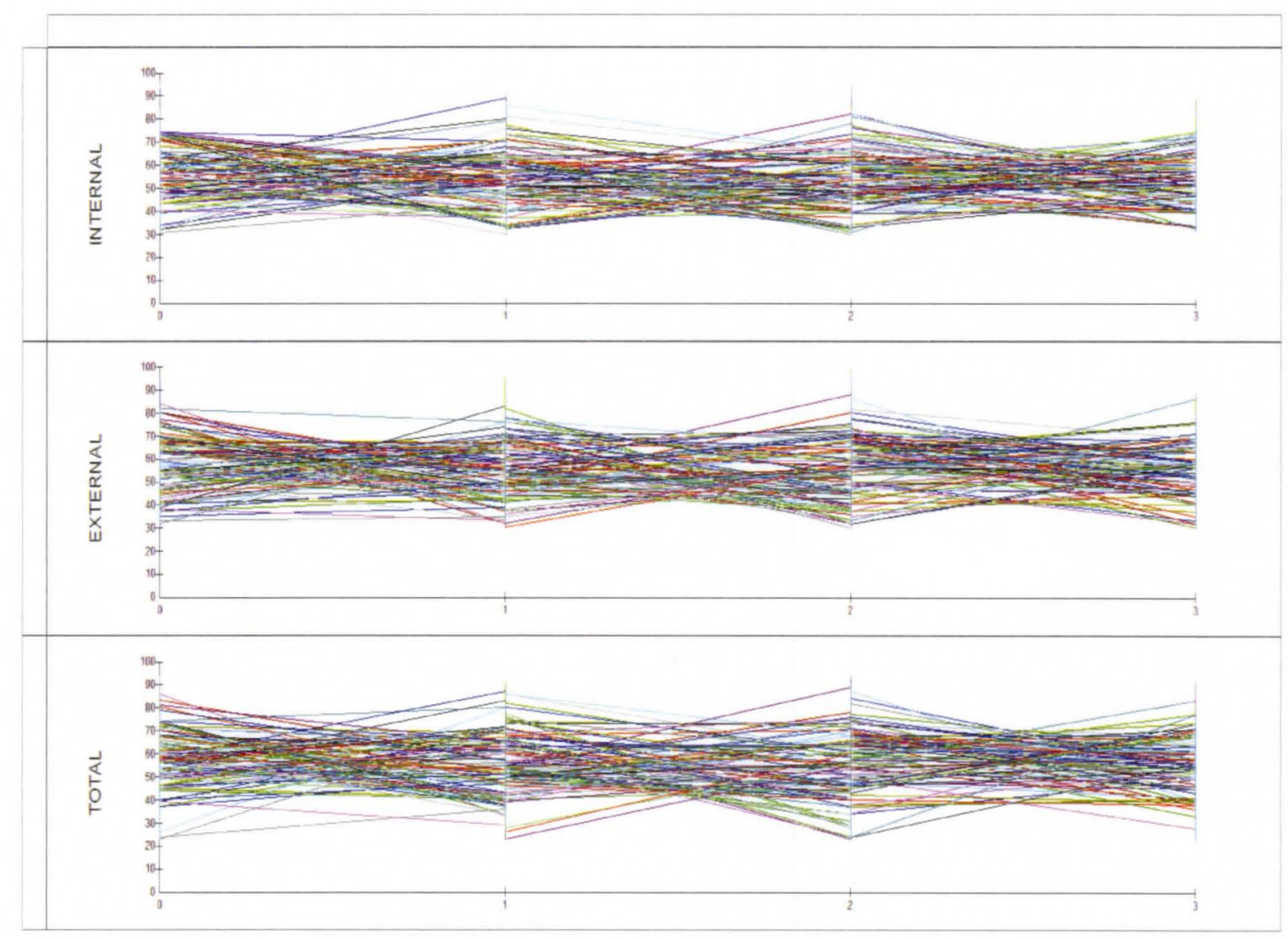

Figure 9. Collected growth trajectories for all PSUs in sample.

\section{Unconditional Model}

The second step in multilevel analysis is to run an unconditional, or null, model. This model gives the probability of having internalizing, externalizing, and total behavior problems without entering any predictor variables. The unconditional model also gives empirical confirmation of the appropriateness of utilizing multilevel analyses. Table 22 exhibits the empirical results of the final unconditional model. Prior to deciding on this final unconditional model, it was first important to compare the Deviance Information Criterion (DIC) for an unconditional model with no randomness and an unconditional model with randomness. Based on this analysis, it was determined that an unconditional model where the error term was allowed to vary on all levels was the most 
appropriate model as evidenced by the lower DIC statistic. This ultimately

means that the individuals in this model overall showed significant variations from

the mean within individuals over the 4 time periods (level 1), between individuals

(level 2) and between PSU's (level 3) with regard to internalizing, externalizing

and total behavior problems.

Table 22

Unconditional Model

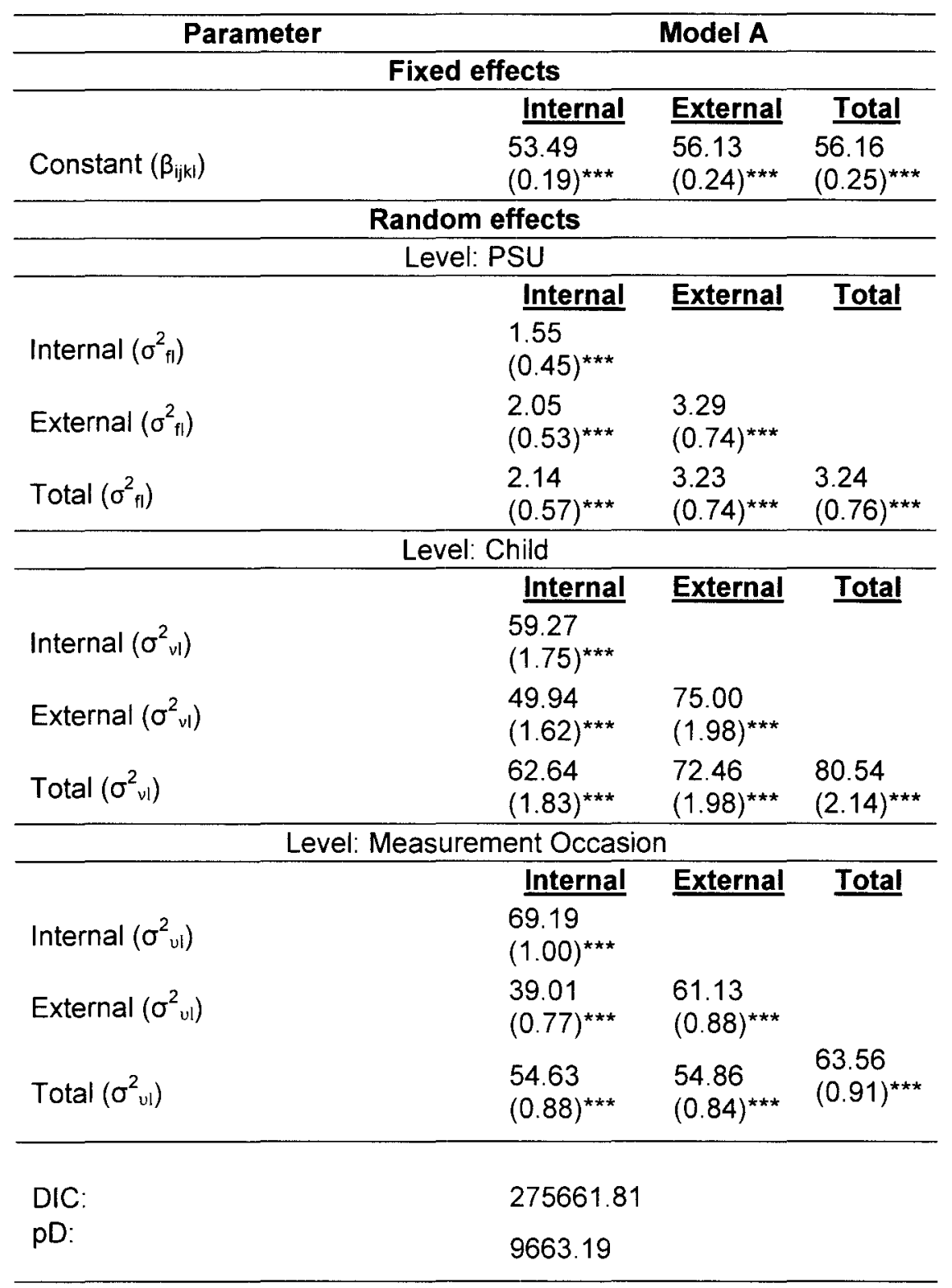




\begin{tabular}{lc}
\hline & Units \\
\hline PSU_long & 87 \\
NSCAWID_long & 4997 \\
Level1ID_long & 14659 \\
resp_indicator & 43977 \\
\hline Note: Standard errors are in parentheses \\
DIC: Diagnostic Information Criterion \\
pD: estimated degrees of freedom \\
${ }^{* * *} p \leq 0.001{ }^{* *} p \leq 0.01 ;{ }^{*} p \leq 0.05$
\end{tabular}

Table 22 indicates that the sample scored higher, on average across all measurement occasions, on the total behavior problems scale $\left(\beta_{1 \mathrm{jkl}}=56.16, p<\right.$ $.001)$ followed by externalizing behavior problems $\left(\beta_{2 j \mathrm{kl}}=56.13, p<.001\right)$ and internalizing behavior problems $\left(\beta_{0 \mathrm{jkl}}=53.49, \mathrm{p}<.001\right)$.

The intraclass correlation (ICC), which is an estimate of the amount of variability at a specified level (e.g., level-3, level-2), is calculated by taking the specified level variance divided by the total variance present in the model. Since this model has three (3) dependent variables this is calculated for each dependent variable. The level-3 ICC is calculated utilizing the following equation:

$$
\mid \mathrm{ICC}_{l}=\frac{\sigma_{f l}^{2}}{\sigma_{f l}^{2}+\sigma_{v l}^{2}+\sigma_{v l}^{2}}
$$

Where: $\quad \sigma_{f l}^{2}=$ level- 3 variance

$\sigma_{v l}^{2}=$ level -2 variance

$\sigma_{v l}^{2}=$ level -1 variance

Therefore, the level-3 $I C C_{\text {internalizing }}=1.55 /(1.55+59.27+69.19)=0.0119$. This indicates that $1.19 \%$ of the variance in internalizing behavior problems was between PSUs. The level-3 ICC externalizing $=3.29 /(3.29+75.00+61.13)=0.0236$, suggesting that $2.36 \%$ of the variance in externalizing behavior problems was between PSUs. Lastly, the level-3 ICC $\mathrm{Ittal}_{\text {tal }}=3.24 /(3.24+80.54+63.56)=$ 0.0220 , indicating that $2.20 \%$ of the variance in total behavior problems was 
between PSUs. The relatively low level-3 ICCs indicate that a majority of the variance in behavior problems is within PSUs rather than between PSUs. This may be due to the way in which the PSUs were defined and formed. The PSUs were comprised of one or more counties and may have been too large to capture the environmental impact on behavioral problems exhibited by children. Perhaps defining PSUs by zip codes, census tracts, or person-defined neighborhoods would better capture the environmental impact on child behavioral problems.

The level-2 ICC is calculated utilizing the following equation:

$$
\mid \mathrm{CC}_{l}=\frac{\sigma_{v l}^{2}}{\sigma_{v l}^{2}+\sigma_{v l}^{2}}
$$

Where: $\quad \sigma_{v l}^{2}=$ level-2 variance

$\sigma_{v l}^{2}=$ level- 1 variance

Therefore, the level-2 ICC internalizing $=59.27 /(59.27+69.19)=0.4614$. This indicates that $46.14 \%$ of the variance in internalizing behavior problems was between children/caregivers. The level-2 $I C C_{\text {externalizing }}=75.00 /(75.00+61.13)=$ 0.5509 , suggesting that $55.09 \%$ of the variance in externalizing behavior problems was between children/caregivers. Lastly, the level-2 $\mathrm{ICC}_{\text {total }}=$ $80.54 /(80.54+63.56)=0.5589$, indicating that $55.89 \%$ of the variance in total behavior problems was between children/caregivers. The level-2 ICCs indicate that a majority of the variance in behavior problems was between children/caregivers, indicating that there was a significant difference between children.

In sum, there appears to be much more variability within PSUs than between PSUs. This can be seen visually in Figure 10 below. Figure 10 shows 
the residuals and $95 \%$ confidence intervals for internalizing, externalizing, and total behavior problems for the unconditional model. In the figure below, each triangle represents the residual for each of the 87 PSUs while the lines extending from them represent the $95 \%$ confidence interval around the residual. As is evident in Figure 7, there are not many PSUs that are significantly different from one another (e.g., first 3 and last 3 on internalizing behavior problems). This further confirms the lack of variance between PSUs.

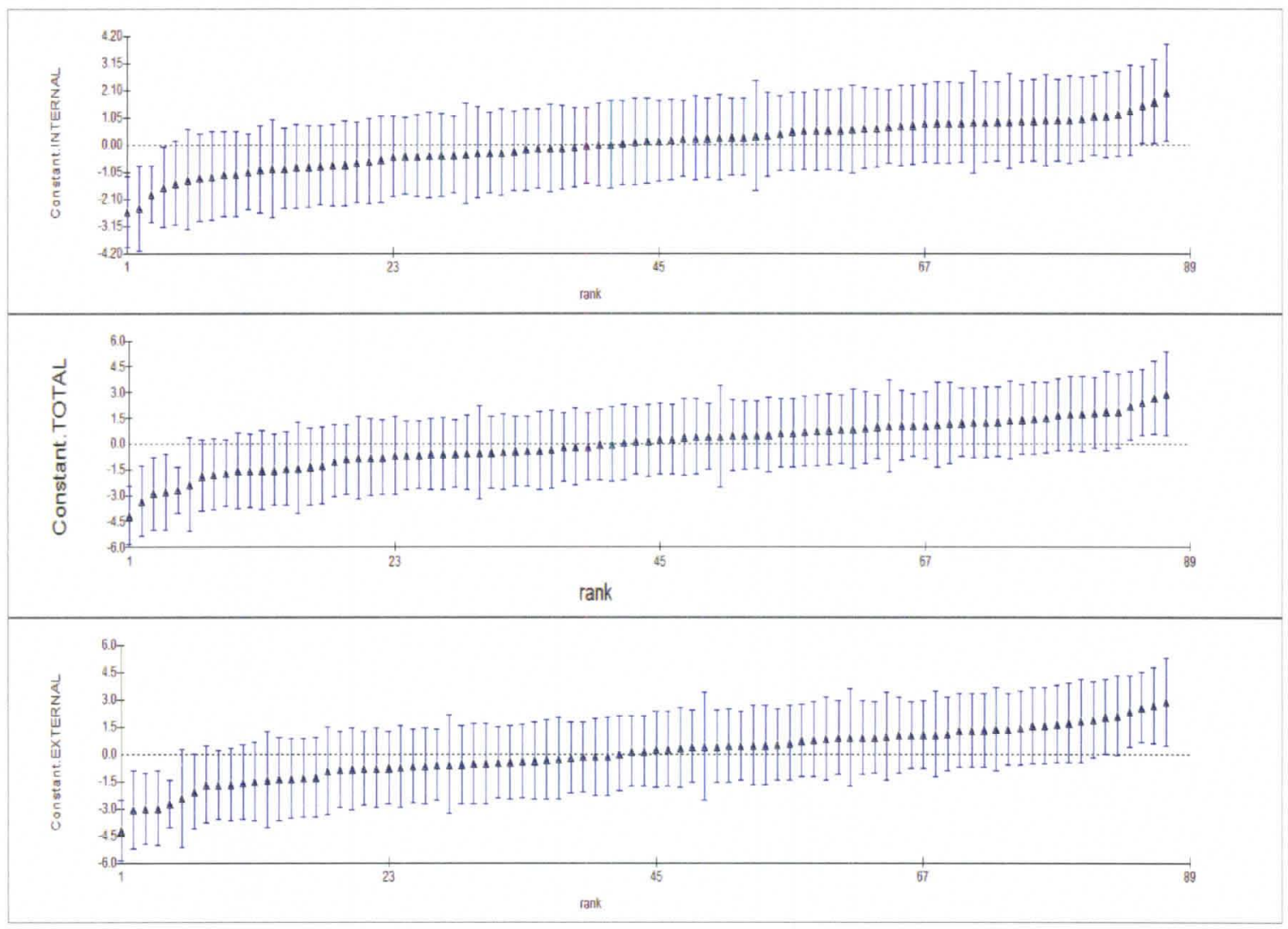

Figure 10. Ranked residuals for PSUs, unconditional model.

Figure 11 below shows the child/caregiver residuals and $95 \%$ confidence intervals for internalizing, externalizing, and total behavior problems. While it is virtually impossible to count the number of individuals who are significantly 
different from one another, it is easy to see that there is significantly more variance between children/caregivers.

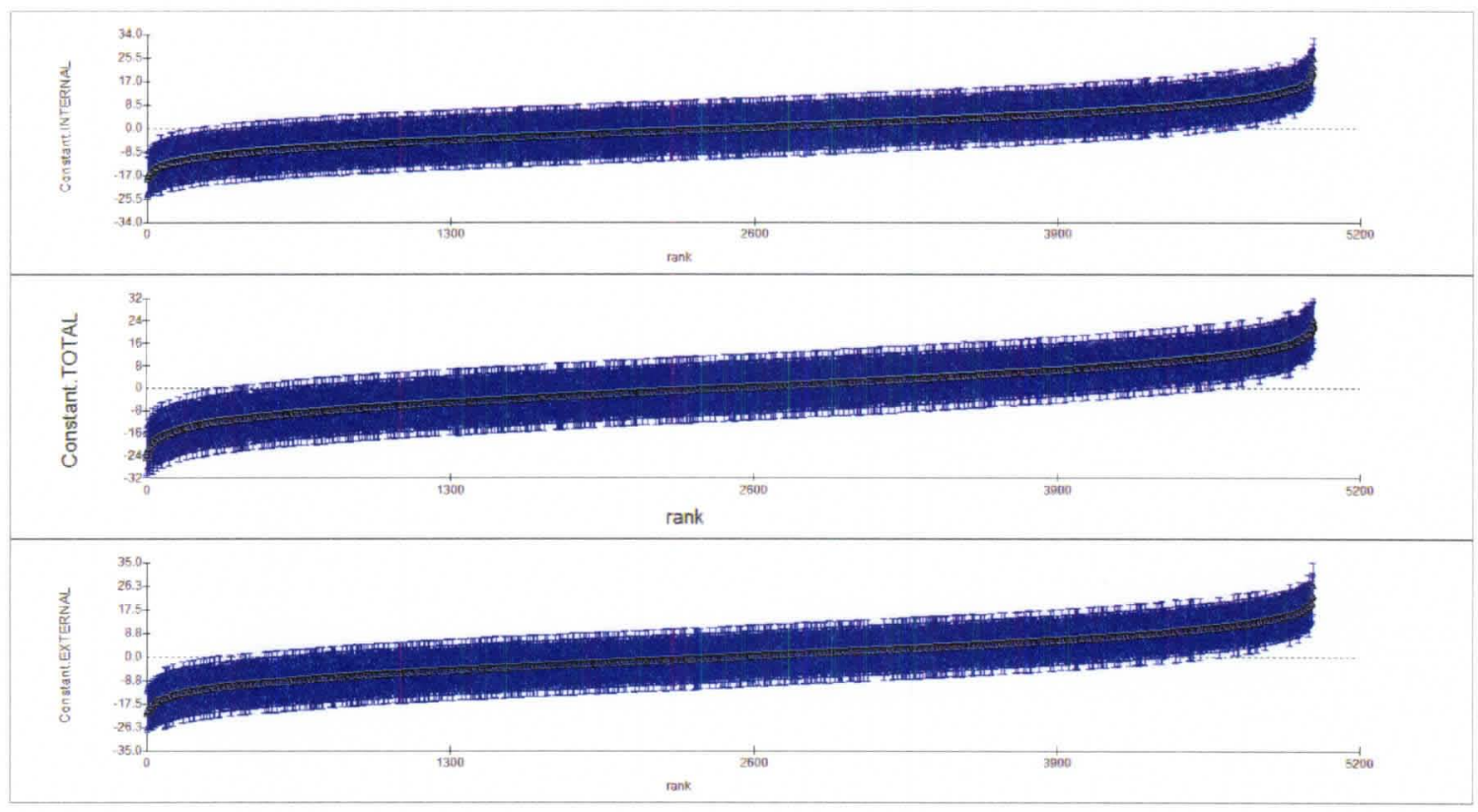

Figure 11. Ranked residuals for children/caregivers, unconditional model.

The Deviance Information Criterion (DIC) is a measure of model fit. It is utilized in order to determine the most parsimonious model based on both fit and complexity. Therefore, this is a comparative number where lower values are indicative of a more parsimonious model. A decrease of 8 is suggested in order to consider the decrease a significant improvement in parsimony (Jones, 2012). The DIC for the unconditional model (Model A, Table 20) was 275661.81.

\section{Unconditional Growth Model}

The third step in multilevel analysis is to estimate an unconditional growth model. Ultimately, the unconditional growth model is the unconditional model and the time variable. This model shows the growth trajectories of having internalizing, externalizing, or total behavior problems over time. Table 23 shows both Model A and Model B, which includes the time variable. While only the final 
Model $B$ is shown in Table 23 below, it is important to note that there were actually four (4) models fitted in order to determine whether it was appropriate to let time vary for each of the 3 levels. In the end, it was evident that time would vary on level-2 (e.g., child/caregiver) only based on convergence issues and the fact that there was relatively little variance on the PSU-level and measurement occasion-level. In sum, the constant was allowed to vary on all three (3) levels while the time variable was allowed to vary only on the child/caregiver level. This indicates that children started at different points and children changed differently over time, with some who increased, and some who decreased over time, but the within variance was not different over time, indicating that each child changed consistently over time with not big variations in scores. Also, the children in the different PSU's showed similar patterns over time. 
Table 23

Unconditional Growth Model

\begin{tabular}{|c|c|c|c|c|c|c|c|c|c|}
\hline \multirow{2}{*}{ Parameter } & \multicolumn{3}{|c|}{ Model A } & \multicolumn{6}{|c|}{ Model B } \\
\hline & & & & \multicolumn{6}{|c|}{ Fixed effects } \\
\hline & & Ext & Tot & Int & Ext & Tot & & & \\
\hline Cons $\left(\beta_{i j k l}\right)$ & $\begin{array}{l}53.49 \\
(0.19)^{\star \star \star}\end{array}$ & $\begin{array}{l}56.13 \\
(0.24)^{\star * *}\end{array}$ & $\begin{array}{l}56.16 \\
(0.25)^{\star * *}\end{array}$ & $\begin{array}{l}55.22 \\
(0.21)^{\star * *}\end{array}$ & $\begin{array}{l}56.85 \\
(0.26)^{\star \star \star *}\end{array}$ & $\begin{array}{l}57.24 \\
(0.26)^{* \star *}\end{array}$ & & & \\
\hline Time $\left(\beta_{\mathrm{ijk} k}\right)$ & & & & $\begin{array}{l}-1.14 \\
(0.08)^{\star \star \star}\end{array}$ & $\begin{array}{l}-0.48 \\
(0.07)^{\star \star \star \star}\end{array}$ & $\begin{array}{l}-0.72 \\
(0.07)^{\star \star \star}\end{array}$ & & & \\
\hline \multicolumn{10}{|c|}{ Random effects } \\
\hline \multicolumn{10}{|c|}{ Level: PSU } \\
\hline & $\underline{\text { Cont }}$ & $\begin{array}{l}\text { Ext } \\
\text { Cons }\end{array}$ & Tot & $\underset{\text { Cons }}{\text { Int }}$ & Ext & Tot & & & \\
\hline Internal $\left(\sigma_{f i}^{2}\right)$ & $\begin{array}{l}1.55 \\
(0.45)^{\star \star \star}\end{array}$ & & & $\begin{array}{l}1.49 \\
(0.42)^{\star * *}\end{array}$ & & & & & \\
\hline External $\left(\sigma_{f f}^{2}\right)$ & $\begin{array}{l}2.05 \\
(0.53)^{\star \star \star \star}\end{array}$ & $\begin{array}{l}3.29 \\
(0.74)^{\star \star \star}\end{array}$ & & $\begin{array}{l}1.98 \\
(0.51)^{\star \star \star \star}\end{array}$ & $\begin{array}{l}3.15 \\
(0.72)^{\star \star \star}\end{array}$ & & & & \\
\hline Total $\left(\sigma_{\mathrm{fil}}^{2}\right)$ & $\begin{array}{l}2.14 \\
(0.57)^{\star \star \star}\end{array}$ & $\begin{array}{l}3.23 \\
(0.74)^{\star * \star}\end{array}$ & $\begin{array}{l}3.24 \\
(0.76)^{\star * *}\end{array}$ & $\begin{array}{l}2.07 \\
(0.54)^{\star \star \star *}\end{array}$ & $\begin{array}{l}3.11 \\
(0.72)^{\star * *}\end{array}$ & $\begin{array}{l}3.13 \\
(0.75)^{\star \star \star}\end{array}$ & & & \\
\hline \multicolumn{10}{|c|}{ Level: Child } \\
\hline & Cons & $\begin{array}{l}\text { Ext } \\
\text { Cons }\end{array}$ & $\frac{\text { Tot }}{\text { Cons }}$ & $\underset{\text { Cons }}{\operatorname{lnt}}$ & 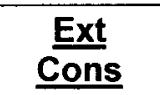 & $\frac{\text { Tot }}{\text { Cons }}$ & Int & Ext & $\underline{\text { Tot }}$ \\
\hline Internal $\left(\sigma^{2}{ }_{\mathrm{vl}}\right)$ & $\begin{array}{l}59.27 \\
(1.75)^{\star \star \star}\end{array}$ & & & $\begin{array}{l}75.98 \\
(2.94)^{\star \star \star \star}\end{array}$ & & & & & \\
\hline External $\left(\sigma^{2}{ }_{v l}\right)$ & $\begin{array}{l}49.94 \\
(1.62)^{\star \star \star}\end{array}$ & $\begin{array}{l}75.00 \\
(1.98)^{\star * *}\end{array}$ & & $\begin{array}{l}58.93 \\
(2.61)^{* * *}\end{array}$ & $\begin{array}{l}92.55 \\
(3.15)^{\star \star \star}\end{array}$ & & & & \\
\hline Total $\left(\sigma_{v 1}^{2}\right)$ & $\begin{array}{l}62.64 \\
(1.83)^{\star \star \star}\end{array}$ & $\begin{array}{l}72.46 \\
(1.98)^{\star \star \star}\end{array}$ & $\begin{array}{l}80.54 \\
(2.14)^{\star \star \star}\end{array}$ & $\begin{array}{l}74.62 \\
(2.87)^{\star \star \star}\end{array}$ & $\begin{array}{l}85.87 \\
(3.04)^{\star \star \star}\end{array}$ & $\begin{array}{l}93.64 \\
(3.20)^{\star \star \star}\end{array}$ & & & \\
\hline $\begin{array}{l}\text { Internal Time } \\
\left(\sigma^{2}{ }_{v 1}\right)\end{array}$ & & & & $\begin{array}{l}-9.74 \\
(1.12)^{\star \star \star}\end{array}$ & $\begin{array}{l}-4.28 \\
(1.02)^{\star \star \star *}\end{array}$ & $\begin{array}{l}-6.93 \\
(1.11)^{\star * *}\end{array}$ & $\begin{array}{l}6.32 \\
(0.61)^{* * *}\end{array}$ & & \\
\hline
\end{tabular}




\begin{tabular}{|c|c|c|c|c|c|c|c|c|c|}
\hline $\begin{array}{l}\text { External Time } \\
\left(\sigma^{2}{ }_{v 1}\right)\end{array}$ & & & & $\begin{array}{l}-7.85 \\
(0.98)^{* * *}\end{array}$ & $\begin{array}{l}-10.24 \\
(1.05)^{\star \star \star}\end{array}$ & $\begin{array}{l}-9.63 \\
(1.06)^{\star \star \star}\end{array}$ & $\begin{array}{l}4.35 \\
(0.47)^{* * *}\end{array}$ & $\begin{array}{l}6.40 \\
(0.54)^{* * *}\end{array}$ & \\
\hline $\begin{array}{l}\text { Total Time } \\
\left(\sigma_{v 1}^{2}\right)\end{array}$ & & & & $\begin{array}{l}-9.11 \\
(1.05)^{\star * \star}\end{array}$ & $\begin{array}{l}-7.43 \\
(1.04)^{\star \star \star}\end{array}$ & $\begin{array}{l}-9.05 \\
(1.12)^{\star \star \star}\end{array}$ & $\begin{array}{l}5.89 \\
(0.55)^{\star \star \star}\end{array}$ & $\begin{array}{l}5.89 \\
(0.52)^{\star \star \star *}\end{array}$ & $\begin{array}{l}6.87 \\
(0.57)^{\star \star \star} \\
\end{array}$ \\
\hline \multicolumn{10}{|c|}{ Level: Measurement Occasion } \\
\hline & $\stackrel{\text { Int }}{\text { Cons }}$ & Ext & $\frac{\text { Tot }}{\text { Cons }}$ & Cons & Ext & Tot & & & \\
\hline Internal $\left(\sigma^{2}{ }_{u l}\right)$ & $\begin{array}{l}69.19 \\
(1.00)^{* * *}\end{array}$ & & & $\begin{array}{l}58.58 \\
(1.09)^{\star \star \star}\end{array}$ & & & & & \\
\hline External $\left(\sigma^{2}{ }_{u l}\right)$ & $\begin{array}{l}39.01 \\
(0.77)^{\star \star \star}\end{array}$ & $\begin{array}{l}61.13 \\
(0.88)^{\star \star \star}\end{array}$ & & $\begin{array}{l}32.42 \\
(0.84)^{\star \star \star}\end{array}$ & $\begin{array}{l}52.09 \\
(0.96)^{* \star \star}\end{array}$ & & & & \\
\hline Total $\left(\sigma^{2}{ }_{u l}\right)$ & $\begin{array}{l}54.63 \\
(0.88)^{\star \star \star}\end{array}$ & $\begin{array}{l}54.86 \\
(0.84)^{\star \star \star}\end{array}$ & $\begin{array}{l}63.56 \\
(0.91)^{\star \star \star}\end{array}$ & $\begin{array}{l}45.42 \\
(0.96)^{\star \star \star}\end{array}$ & $\begin{array}{l}46.40 \\
(0.92)^{\star \star \star}\end{array}$ & $\begin{array}{l}53.46 \\
(1.01)^{\star * *} \\
\end{array}$ & & & \\
\hline DIC: & \multicolumn{3}{|c|}{275661.81} & \multicolumn{2}{|c|}{272928.27} & & & & \\
\hline pD: & \multicolumn{2}{|c|}{9663.19} & & \multicolumn{2}{|l|}{13095.66} & & & & \\
\hline \multicolumn{10}{|c|}{ Units } \\
\hline PSU_long & \multicolumn{2}{|l|}{87} & & \multicolumn{2}{|l|}{87} & & & & \\
\hline NSCĀWID_long & \multicolumn{2}{|l|}{4997} & & \multicolumn{2}{|l|}{4997} & & & & \\
\hline Level1ID_long & \multicolumn{2}{|l|}{14659} & & \multicolumn{2}{|l|}{14659} & & & & \\
\hline resp_indicator & \multicolumn{2}{|c|}{43977} & & \multicolumn{2}{|l|}{43977} & & & & \\
\hline $\begin{array}{l}\text { Note: Standard er } \\
\text { DIC: Diagnostic In } \\
\text { pD: estimated deg } \\
{ }^{* * *} p \leq 0.001,{ }^{* *} p \leq\end{array}$ & $\begin{array}{l}\text { ors are in } p \\
\text { formation } C \\
\text { rees of free } \\
0.01 ;{ }^{\star} p \leq\end{array}$ & $\begin{array}{l}\text { arenthese } \\
\text { riterion } \\
\text { dom } \\
0.05\end{array}$ & & & & & & & \\
\hline
\end{tabular}


The results presented in Table 23 indicate that over time, child internalizing, externalizing and total behavior problems decreased. The results in Table 23 show that internalizing behavior scores decrease more over time $\left(\beta_{3 \mathrm{jkl}}=-1.14, p\right.$ $<.001)$ compared to either externalizing $\left(\beta_{5 j \mathrm{kl}}=-0.48, p<.001\right)$ or total behavior problems $\left(\beta_{4 \mathrm{jkl}}=-0.72, \mathrm{p}<.001\right)$. The DIC statistic also decreased from 275661.81 to 272928.27 by adding the time variable indicating a more parsimonious model fit. Table 23 also shows that the variance components decreased from Model A to Model B indicating that time is accounting for some of the variance in child behavior problems. Figure 12 graphically displays the effect of time on child internalizing, externalizing, and total behavior problems.

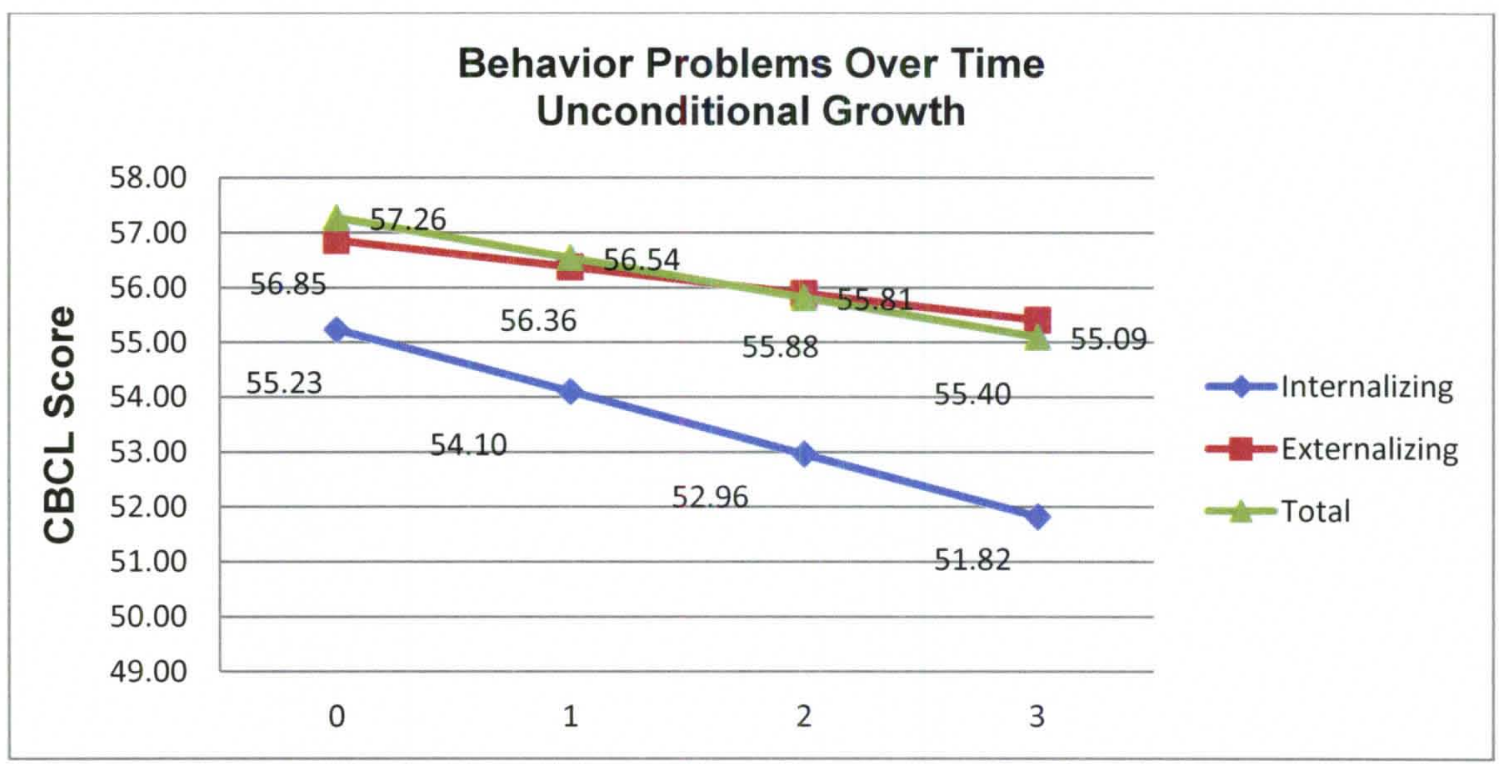

Figure 12. Child behavior problems over time.

\section{Conditional Growth Model}

The next step in multilevel analysis is to add explanatory or predictor variables to the unconditional growth model. The results in this section will be presented in four (4) steps: (a) conditional growth model with child main effects; 
(b) conditional growth model with child and caregiver main effects; (c) conditional growth model with child, caregiver, and PSU main effects; and (d) conditional growth with all main effects and interaction effects.

Child main effects. Child factors included in the model fell in four (4) categories: (a) demographics; (b) development; (c) maltreatment; and (d) health. Each of these blocks was entered separately to ensure that both the DIC and variance components fell and that the most parsimonious model was analyzed. The estimates in Table 24 depict the overall estimates for the final conditional growth model with all of the child main effects included. These estimates are displayed as Model C in Table 24. One predictor, risk factor index, was removed from the model displayed in Table 24 due it not being statistically significant. The remaining predictors shown in Model C in Table 24 are statistically significant predictors of child behavior problems. It is also important to note that the DIC continued to decrease from 272928.27 to 270222.01 and the variance components also decreased with the inclusion of child-level predictors. Figure 13 , following the table, graphically depicts child behavior problems over time after adding the child main effects. 
Table 24

Conditional Growth Model with Child Main Effects Only

\begin{tabular}{|c|c|c|c|c|c|c|}
\hline \multirow[t]{2}{*}{ Parameter } & \multirow{2}{*}{\multicolumn{3}{|c|}{ Model B }} & \multirow{2}{*}{\multicolumn{3}{|c|}{ Model C }} \\
\hline & & & & & & \\
\hline & Int & Ext & Tot & Int & Ext & Tot \\
\hline Cons $\left(\beta_{\mathrm{ijk}}\right)$ & $\begin{array}{l}55.22 \\
(0.21)^{\star \star \star}\end{array}$ & $\begin{array}{l}56.85 \\
(0.26)^{\star \star \star}\end{array}$ & $\begin{array}{l}57.24 \\
(0.26)^{\star \star \star}\end{array}$ & $\begin{array}{l}56.88 \\
(0.53)^{\star \star \star}\end{array}$ & $\begin{array}{l}57.37 \\
(0.56)^{\star \star \star}\end{array}$ & $\begin{array}{l}58.59 \\
(0.56)^{\star * *}\end{array}$ \\
\hline Time $\left(\beta_{\mathrm{ijk})}\right)$ & $\begin{array}{l}-1.14 \\
(0.08)^{\star \star \star \star}\end{array}$ & $\begin{array}{l}-0.48 \\
(0.07)^{\star \star \star}\end{array}$ & $\begin{array}{l}-0.72 \\
(0.07)^{\star \star \star}\end{array}$ & $\begin{array}{l}-0.96 \\
(0.08)^{\star \star \star}\end{array}$ & $\begin{array}{l}-0.58 \\
(0.08)^{\star \star \star *}\end{array}$ & $\begin{array}{l}-0.74 \\
(0.08)^{\star \star \star}\end{array}$ \\
\hline \multicolumn{7}{|l|}{ Child Factors: } \\
\hline Female $\left(\beta_{\mathrm{ijk}}\right)$ & & & & $\begin{array}{l}-1.63 \\
(0.23)^{\star \star \star}\end{array}$ & $\begin{array}{l}-0.71 \\
(0.24)^{\star \star}\end{array}$ & $\begin{array}{l}-1.53 \\
(0.24)^{\star \star \star}\end{array}$ \\
\hline White/Non-Hispanic $\left(\beta_{\mathrm{ijk} /}\right)$ & & & & $\begin{array}{l}0.42 \\
(0.30)\end{array}$ & $\begin{array}{l}1.69 \\
(0.33)^{\star \star \star}\end{array}$ & $\begin{array}{l}1.44 \\
(0.32)^{\star \star \star}\end{array}$ \\
\hline Black/Non-Hispanic $\left(\beta_{\mathrm{j} j \mathrm{kl}}\right)$ & & & & $\begin{array}{l}-0.87 \\
(0.33)^{\star \star}\end{array}$ & $\begin{array}{l}0.82 \\
(0.34)^{\star}\end{array}$ & $\begin{array}{l}0.09 \\
(0.34)\end{array}$ \\
\hline Age $\left(\beta_{\mathrm{j} j \mathrm{k}}\right)$ & & & & $\begin{array}{l}0.21 \\
(0.03)^{\star \star \star}\end{array}$ & $\begin{array}{l}0.48 \\
(0.03)^{\star \star \star}\end{array}$ & $\begin{array}{l}0.43 \\
(0.03)^{\star * \star}\end{array}$ \\
\hline Social Skills $\left(\beta_{\mathrm{ijk} k}\right)$ & & & & $\begin{array}{l}-0.24 \\
(0.01)^{\star \star \star}\end{array}$ & $\begin{array}{l}-0.29 \\
(0.01)^{* \star \star}\end{array}$ & $\begin{array}{l}-0.30 \\
(0.01)^{\star \star \star}\end{array}$ \\
\hline $\begin{array}{l}\text { Unsubstantiated } \\
\text { Maltreatment }\left(\beta_{i j k i}\right)\end{array}$ & & & & $\begin{array}{l}-0.88 \\
(0.46)\end{array}$ & $\begin{array}{l}-0.62 \\
(0.48)\end{array}$ & $\begin{array}{l}-1.11 \\
(0.47)^{\star}\end{array}$ \\
\hline $\begin{array}{l}\text { Physical Maltreatment } \\
\left(\beta_{i \mathrm{jk})}\right.\end{array}$ & & & & $\begin{array}{l}-0.80 \\
(0.53)\end{array}$ & $\begin{array}{l}-0.09 \\
(0.54)\end{array}$ & $\begin{array}{l}-0.72 \\
(0.54)\end{array}$ \\
\hline Neglect $\left(\beta_{j \mathrm{jk} k}\right)$ & & & & $\begin{array}{l}-0.85 \\
(0.49)\end{array}$ & $\begin{array}{l}-1.00 \\
(0.49)^{*}\end{array}$ & $\begin{array}{l}-1.37 \\
(0.49)^{\star \star}\end{array}$ \\
\hline Other Maltreatment $\left(\beta_{j k \mathrm{k}}\right)$ & & & & $\begin{array}{l}-1.01 \\
(0.54)\end{array}$ & $\begin{array}{l}-1.16 \\
(0.56)^{\star}\end{array}$ & $\begin{array}{l}-1.57 \\
(0.55)^{\star \star}\end{array}$ \\
\hline Exposure to Violence $\left(\beta_{\mathrm{j} k \mathrm{k}}\right)$ & & & & $\begin{array}{l}0.16 \\
(0.02)^{\star \star \star}\end{array}$ & $\begin{array}{l}0.21 \\
(0.02)^{\star \star \star}\end{array}$ & $\begin{array}{l}0.21 \\
(0.02)^{\star \star \star}\end{array}$ \\
\hline
\end{tabular}




\begin{tabular}{|c|c|c|c|c|c|c|c|c|c|c|c|c|}
\hline Physical Health $\left(\beta_{\mathrm{ijk} \mid}\right)$ & & & & & & & $\begin{array}{l}-1.76 \\
(0.09)^{\star \star \star}\end{array}$ & $\begin{array}{l}-0.99 \\
(0.09)^{\star \star \star}\end{array}$ & $\begin{array}{l}-1.65 \\
(0.09)^{\star \star \star}\end{array}$ & & & \\
\hline Physical Disability $\left(\beta_{i j k l}\right)$ & & & & & & & $\begin{array}{l}0.57 \\
(0.41)\end{array}$ & $\begin{array}{l}0.51 \\
(0.44)\end{array}$ & $\begin{array}{l}1.99 \\
(0.44)^{\star \star \star}\end{array}$ & & & \\
\hline Cognitive Health $\left(\beta_{\mathrm{ijk} \mid}\right)$ & & & & & & & $\begin{array}{l}0.02 \\
(0.01)^{*}\end{array}$ & $\begin{array}{l}-0.00 \\
(0.01)\end{array}$ & $\begin{array}{l}-0.01 \\
(0.01)^{\star}\end{array}$ & & & \\
\hline Cognitive Disability $\left(\beta_{i \mathrm{jk} l}\right)$ & & & & & & & $\begin{array}{l}-0.86 \\
(0.30)^{\star \star}\end{array}$ & $\begin{array}{l}-1.25 \\
(0.31)^{\star \star \star}\end{array}$ & $\begin{array}{l}-0.88 \\
(0.32)^{\star \star}\end{array}$ & & & \\
\hline \multicolumn{13}{|c|}{ Random effects } \\
\hline \multicolumn{13}{|c|}{ Level: PSU } \\
\hline & Cons & Ext & $\frac{\text { Tot }}{\text { Cons }}$ & & & & Cons & Ext & $\frac{\text { Tot }}{\text { Cons }}$ & & & \\
\hline Int Cons $\left(\sigma_{f l}^{2}\right)$ & $\begin{array}{l}1.49 \\
(0.42)^{\star \star \star}\end{array}$ & & & & & & $\begin{array}{l}0.85 \\
(0.26)^{\star \star}\end{array}$ & & & & & \\
\hline Ext Cons $\left(\sigma_{f 1}^{2}\right)$ & $\begin{array}{l}1.98 \\
(0.51)^{\star \star \star}\end{array}$ & $\begin{array}{l}3.15 \\
(0.72)^{\star \star \star}\end{array}$ & & & & & $\begin{array}{l}1.09 \\
(0.31)^{\star \star \star}\end{array}$ & $\begin{array}{l}1.74 \\
(0.44)^{\star \star \star}\end{array}$ & & & & \\
\hline Tot Cons $\left(\sigma_{\mathrm{fl}}^{2}\right)$ & $\begin{array}{l}2.07 \\
(0.54)^{\star \star \star}\end{array}$ & $\begin{array}{l}3.11 \\
(0.72)^{\star \star \star}\end{array}$ & $\begin{array}{l}3.13 \\
(0.75)^{\star \star \star}\end{array}$ & & & & $\begin{array}{l}1.15 \\
(0.32)^{\star \star \star}\end{array}$ & $\begin{array}{l}1.71 \\
(0.43)^{\star \star \star *}\end{array}$ & $\begin{array}{l}1.74 \\
(0.44)^{\star * *}\end{array}$ & & & \\
\hline \multicolumn{13}{|c|}{ Level: Child } \\
\hline & $\underline{\text { Int }}$ & $\begin{array}{c}\text { Ext } \\
\text { Cons }\end{array}$ & $\underline{\text { Tot }}$ & Int Time & $\begin{array}{l}\text { Ext } \\
\text { Time }\end{array}$ & $\frac{\text { Tot }}{\text { Time }}$ & $\underline{\text { Int }}$ & $\frac{\text { Ext }}{\text { Cons }}$ & $\frac{\text { Tot }}{\text { Cons }}$ & $\underline{\text { Int }}$ & $\underline{\text { Ext }}$ & $\underline{\text { Tot }}$ \\
\hline Int Cons $\left(\sigma^{2}{ }_{v 1}\right)$ & $\begin{array}{l}75.98 \\
(2.94)^{\star \star \star}\end{array}$ & & & & & & $\begin{array}{l}56.50 \\
(2.54)^{\star \star \star}\end{array}$ & & & & & \\
\hline Ext Cons $\left(\sigma^{2}{ }_{u l}\right)$ & $\begin{array}{l}58.93 \\
(2.61)^{\star \star \star}\end{array}$ & $\begin{array}{l}92.55 \\
(3.15)^{* * *}\end{array}$ & & & & & $\begin{array}{l}35.49 \\
(2.01)^{\star \star \star}\end{array}$ & $\begin{array}{l}61.35 \\
(2.37)^{\star \star \star}\end{array}$ & & & & \\
\hline Tot Cons $\left(\sigma^{2} v\right)$ & $\begin{array}{l}74.62 \\
(2.87)^{\star \star \star}\end{array}$ & $\begin{array}{l}85.87 \\
(3.04)^{\star \star \star}\end{array}$ & $\begin{array}{l}93.64 \\
(3.20)^{\star \star \star}\end{array}$ & & & & $\begin{array}{l}48.76 \\
(2.26)^{\star \star \star}\end{array}$ & $\begin{array}{l}52.73 \\
(2.23)^{\star \star \star}\end{array}$ & $\begin{array}{l}57.77 \\
(2.37)^{\star \star \star}\end{array}$ & & & \\
\hline Int Time $\left(\sigma^{2}{ }_{u l}\right)$ & $\begin{array}{l}-9.74 \\
(1.12)^{\star \star \star}\end{array}$ & $\begin{array}{l}-4.28 \\
(1.02)^{\star \star \star}\end{array}$ & $\begin{array}{l}-6.93 \\
(1.11)^{\star \star \star}\end{array}$ & $\begin{array}{l}6.32 \\
(0.61)^{\star * *}\end{array}$ & & & $\begin{array}{l}-8.71 \\
(1.00)^{\star \star \star}\end{array}$ & $\begin{array}{l}-3.06 \\
(0.86)^{\star \star \star}\end{array}$ & $\begin{array}{l}-5.50 \\
(0.93)^{\star \star \star}\end{array}$ & $\begin{array}{l}4.74 \\
(0.53)^{\star \star \star}\end{array}$ & & \\
\hline Ext Time $\left(\sigma^{2}{ }^{2}\right)$ & $\begin{array}{l}-7.85 \\
(0.98)^{\star \star \star}\end{array}$ & $\begin{array}{l}-10.24 \\
(1.05)^{\star \star \star \star}\end{array}$ & $\begin{array}{l}-9.63 \\
(1.06)^{\star \star \star}\end{array}$ & $\begin{array}{l}4.35 \\
(0.47)^{\star \star \star}\end{array}$ & $\begin{array}{l}6.40 \\
(0.54)^{* * *}\end{array}$ & & $\begin{array}{l}-5.50 \\
(0.85)^{\star \star \star}\end{array}$ & $\begin{array}{l}-7.29 \\
(0.86)^{\star \star \star}\end{array}$ & $\begin{array}{l}-6.49 \\
(0.86)^{\star \star \star *}\end{array}$ & $\begin{array}{l}2.54 \\
(0.45)^{\star \star \star}\end{array}$ & $\begin{array}{l}4.38 \\
(0.46)^{\star \star \star}\end{array}$ & \\
\hline Tot Time $\left(\sigma^{2}{ }_{v 1}\right)$ & $\begin{array}{l}-9.11 \\
(1.05)^{\star \star \star}\end{array}$ & $\begin{array}{l}-7.43 \\
(1.04)^{\star \star \star}\end{array}$ & $\begin{array}{l}-9.05 \\
(1.12)^{\star \star \star}\end{array}$ & $\begin{array}{l}5.89 \\
(0.55)^{\star \star \star}\end{array}$ & $\begin{array}{l}5.89 \\
(0.52)^{\star \star \star}\end{array}$ & $\begin{array}{l}6.87 \\
(0.57)^{\star \star}\end{array}$ & $\begin{array}{l}-7.24 \\
(0.91)^{\star \star \star}\end{array}$ & $\begin{array}{l}-4.96 \\
(0.85)^{\star \star \star \star}\end{array}$ & $\begin{array}{l}-6.50 \\
(0.91)^{\star \star *}\end{array}$ & $\begin{array}{l}3.83 \\
(0.49)^{\star \star \star}\end{array}$ & $\begin{array}{l}3.66 \\
(0.46)^{\star \star \star}\end{array}$ & $\begin{array}{l}4.36 \\
(0.51)^{\star \star \star}\end{array}$ \\
\hline
\end{tabular}




\begin{tabular}{|c|c|c|c|c|c|c|}
\hline \multicolumn{7}{|c|}{ Level: Measurement Occasion } \\
\hline & $\frac{\text { Int }}{\text { Cons }}$ & $\frac{\text { Ext }}{\text { Cons }}$ & $\frac{\text { Tot }}{\text { Cons }}$ & Cons & $\frac{\text { Ext }}{\text { Cons }}$ & $\frac{\text { Tot }}{\text { Cons }}$ \\
\hline Int Cons $\left(\sigma^{2}{ }_{v}\right)$ & $\begin{array}{l}58.58 \\
(1.09)^{\star \star \star}\end{array}$ & & & $\begin{array}{l}54.04 \\
(1.01)^{\star \star \star}\end{array}$ & & \\
\hline Ext Cons $\left(\sigma^{2}{ }_{u}\right)$ & $\begin{array}{l}32.42 \\
(0.84)^{\star \star \star}\end{array}$ & $\begin{array}{l}52.09 \\
(0.96)^{\star \star \star}\end{array}$ & & $\begin{array}{l}27.42 \\
(0.78)^{\star \star \star}\end{array}$ & $\begin{array}{l}46.11 \\
(0.86)^{\star \star \star}\end{array}$ & \\
\hline Tot Cons $\left(\sigma^{2}{ }_{u}\right)$ & $\begin{array}{l}45.42 \\
(0.96)^{\star \star \star}\end{array}$ & $\begin{array}{l}46.40 \\
(0.92)^{\star \star \star}\end{array}$ & $\begin{array}{l}53.46 \\
(1.01)^{\star \star \star}\end{array}$ & $\begin{array}{l}40.45 \\
(0.87)^{\star \star \star}\end{array}$ & $\begin{array}{l}40.56 \\
(0.83)^{\star \star \star}\end{array}$ & $\begin{array}{l}47.76 \\
(0.90)^{\star \star \star}\end{array}$ \\
\hline DIC: & \multicolumn{3}{|c|}{272928.27} & \multicolumn{3}{|c|}{270222.01} \\
\hline pD: & \multicolumn{3}{|c|}{13095.66} & \multicolumn{3}{|l|}{12387.72} \\
\hline \multicolumn{7}{|c|}{ Units } \\
\hline PSU_long & \multicolumn{3}{|l|}{87} & \multicolumn{3}{|l|}{87} \\
\hline NSCĀWID_long & \multicolumn{3}{|l|}{4997} & \multicolumn{3}{|l|}{4997} \\
\hline Level1ID_long & \multirow{2}{*}{\multicolumn{3}{|c|}{$\begin{array}{l}14659 \\
43977\end{array}$}} & \multicolumn{3}{|l|}{14659} \\
\hline resp_indicator & & \multicolumn{2}{|c|}{43977} & \multicolumn{3}{|l|}{43977} \\
\hline \multicolumn{7}{|c|}{$\begin{array}{l}\text { Note: Standard errors are in parentheses } \\
\text { DIC: Diagnostic Information Criterion } \\
\text { pD: estimated degrees of freedom } \\
{ }^{* * *} p \leq 0.001,{ }^{* *} p \leq 0.01 ;{ }^{*} p \leq 0.05\end{array}$} \\
\hline
\end{tabular}




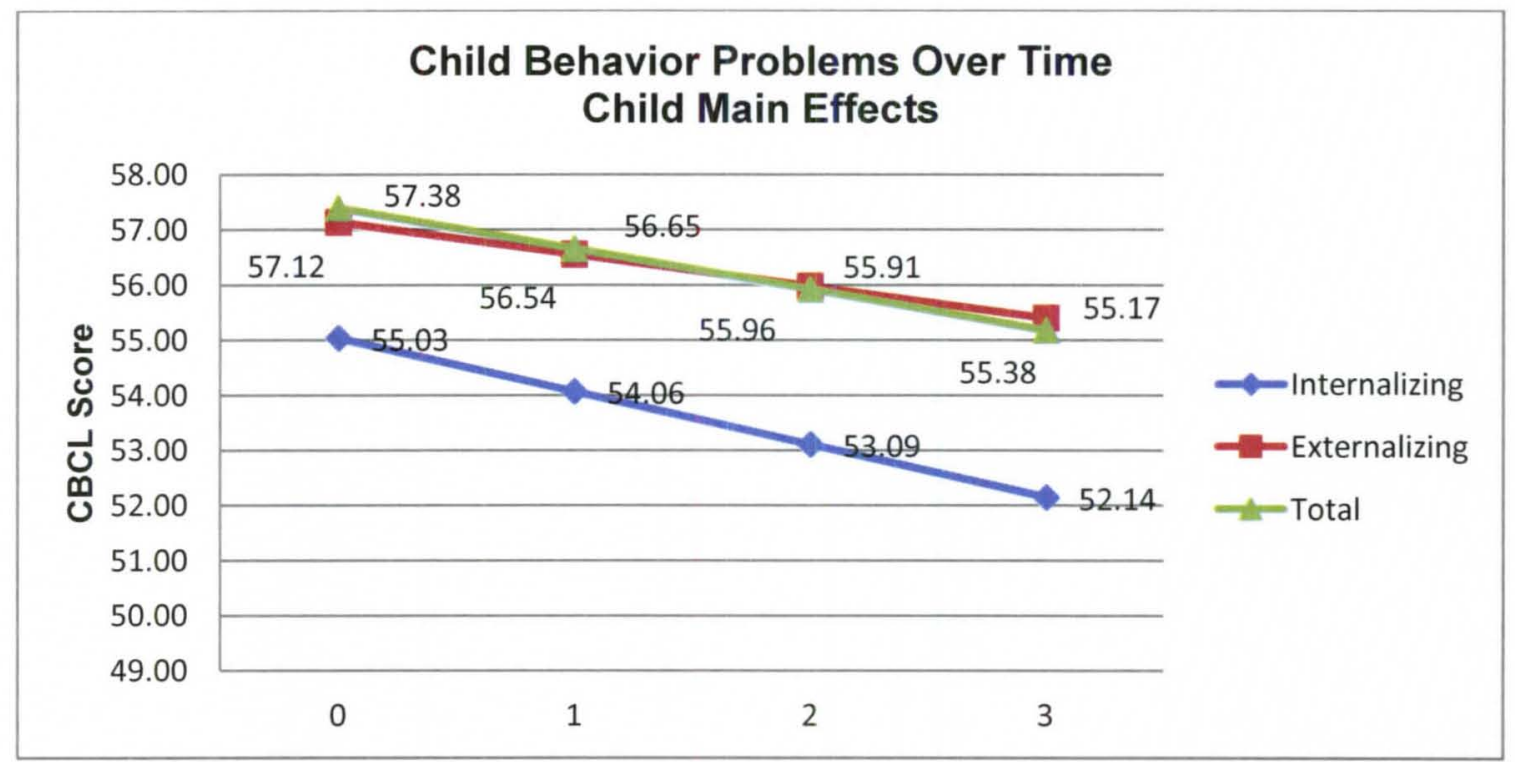

Figure 13. Child behavior problems over time with child main effects.

Caregiver main effects. Caregiver factors included in the model fell in three (3) categories: (a) demographics; (b) family structure; and (c) other factors. Each of these blocks was entered separately to ensure that the DIC and variance components fell and that the most parsimonious model was analyzed. The estimates in Table 25 depict the overall estimates for the final conditional growth model with all of the child and caregiver main effects included. These estimates are displayed as Model D in Table 25. There were several caregiver predictors that had to be removed from the analysis. Income, biological caregiver, and number of out-of-home placements were removed due to being non-statistically significant predictors of child behavior problems. Models C (growth model with child main effects) and D (growth model with child and caregiver main effects) are displayed in Table 25. As evidenced in Model D in Table 25, the DIC statistic decreased from 270222.01 to 269937.62 . Additionally, all of the variance components also decreased from Model C to Model D. Following the table 
below, Figure 14 visually depicts child behavior problems over time after adding both child and caregiver main effects. 
Table 25

Conditional Growth Model with Child and Caregiver Main Effects

\begin{tabular}{|c|c|c|c|c|c|c|}
\hline Parameter & & & Model C & & & Model D \\
\hline \multicolumn{7}{|c|}{ Fixed effects } \\
\hline & Int & Ext & $\underline{\text { Tot }}$ & Int & Ext & Tot \\
\hline Cons $\left(\beta_{i j k l}\right)$ & $\begin{array}{l}56.88 \\
(0.53)^{\star \star \star}\end{array}$ & $\begin{array}{l}57.37 \\
(0.56)^{\star \star \star}\end{array}$ & $\begin{array}{l}58.59 \\
(0.56)^{\star \star \star}\end{array}$ & $\begin{array}{l}58.47 \\
(0.58)^{\star \star \star *}\end{array}$ & $\begin{array}{l}58.79 \\
(0.58)^{\star \star \star}\end{array}$ & $\begin{array}{l}60.61 \\
(0.58)^{\star \star \star}\end{array}$ \\
\hline Time $\left(\beta_{\mathrm{j} k \mathrm{k}}\right)$ & $\begin{array}{l}-0.96 \\
(0.08)^{\star \star \star}\end{array}$ & $\begin{array}{l}-0.58 \\
(0.08)^{\star \star \star}\end{array}$ & $\begin{array}{l}-0.74 \\
(0.08)^{\star * \star}\end{array}$ & $\begin{array}{l}-0.87 \\
(0.08)^{\star \star \star}\end{array}$ & $\begin{array}{l}-0.52 \\
(0.08)^{\star \star \star}\end{array}$ & $\begin{array}{l}-0.65 \\
(0.08)^{\star \star \star}\end{array}$ \\
\hline \multicolumn{7}{|l|}{ Child Factors: } \\
\hline Female $\left(\beta_{j \mathrm{kl}}\right)$ & $\begin{array}{l}-1.63 \\
(0.23)^{\star \star *}\end{array}$ & $\begin{array}{l}-0.71 \\
(0.24)^{\star *}\end{array}$ & $\begin{array}{l}-1.53 \\
(0.24)^{\star \star \star}\end{array}$ & $\begin{array}{l}-1.54 \\
(0.23)^{\star \star \star}\end{array}$ & $\begin{array}{l}-0.65 \\
(0.24)^{\star *}\end{array}$ & $\begin{array}{l}-1.45 \\
(0.23)^{\star \star \star}\end{array}$ \\
\hline $\begin{array}{l}\text { White/Non-Hispanic } \\
\left(\beta_{i j k l}\right)\end{array}$ & $\begin{array}{l}0.42 \\
(0.30)\end{array}$ & $\begin{array}{l}1.69 \\
(0.33)^{\star \star \star}\end{array}$ & $\begin{array}{l}1.44 \\
(0.32)^{\star \star \star}\end{array}$ & $\begin{array}{l}0.47 \\
(0.30)\end{array}$ & $\begin{array}{l}1.79 \\
(0.32)^{\star \star \star}\end{array}$ & $\begin{array}{l}1.51 \\
(0.32)^{\star \star \star}\end{array}$ \\
\hline $\begin{array}{l}\text { Black/Non-Hispanic } \\
\left(\beta_{i j k \mathrm{k}}\right)\end{array}$ & $\begin{array}{l}-0.87 \\
(0.33)^{\star \star}\end{array}$ & $\begin{array}{l}0.82 \\
(0.34)^{*}\end{array}$ & $\begin{array}{l}0.09 \\
(0.34)\end{array}$ & $\begin{array}{l}-0.89 \\
(0.31)^{\star \star}\end{array}$ & $\begin{array}{l}0.80 \\
(0.34)^{\star}\end{array}$ & $\begin{array}{l}-0.10 \\
(0.33)\end{array}$ \\
\hline Age $\left(\beta_{\mathrm{ijk} k}\right)$ & $\begin{array}{l}0.21 \\
(0.03)^{\star \star \star}\end{array}$ & $\begin{array}{l}0.48 \\
(0.03)^{\star * *}\end{array}$ & $\begin{array}{l}0.43 \\
(0.03)^{\star \star \star}\end{array}$ & $\begin{array}{l}0.21 \\
(0.03)^{\star * *}\end{array}$ & $\begin{array}{l}0.48 \\
(0.03)^{\star * \star}\end{array}$ & $\begin{array}{l}0.43 \\
(0.03)^{\star \star *}\end{array}$ \\
\hline Social Skills $\left(\beta_{i j k l}\right)$ & $\begin{array}{l}-0.24 \\
(0.01)^{\star \star \star}\end{array}$ & $\begin{array}{l}-0.29 \\
(0.01)^{\star \star \star}\end{array}$ & $\begin{array}{l}-0.30 \\
(0.01)^{\star \star \star}\end{array}$ & $\begin{array}{l}-0.22 \\
(0.01)^{\star \star \star}\end{array}$ & $\begin{array}{l}-0.28 \\
(0.01)^{\star \star \star}\end{array}$ & $\begin{array}{l}-0.29 \\
(0.01)^{\star \star \star}\end{array}$ \\
\hline $\begin{array}{l}\text { Unsubstantiated } \\
\text { Maltreatment }\left(\beta_{i \mathrm{jk})}\right)\end{array}$ & $\begin{array}{l}-0.88 \\
(0.46)\end{array}$ & $\begin{array}{l}-0.62 \\
(0.48)\end{array}$ & $\begin{array}{l}-1.11 \\
(0.47)^{*}\end{array}$ & $\begin{array}{l}-0.91 \\
(0.48)\end{array}$ & $\begin{array}{l}-0.69 \\
(0.48)\end{array}$ & $\begin{array}{l}-1.15 \\
(0.48)^{*}\end{array}$ \\
\hline $\begin{array}{l}\text { Physical } \\
\text { Maltreatment }\left(\beta_{i j k}\right)\end{array}$ & $\begin{array}{l}-0.80 \\
(0.53)\end{array}$ & $\begin{array}{l}-0.09 \\
(0.54)\end{array}$ & $\begin{array}{l}-0.72 \\
(0.54)\end{array}$ & $\begin{array}{l}-0.85 \\
(0.54)\end{array}$ & $\begin{array}{l}-0.13 \\
(0.53)\end{array}$ & $\begin{array}{l}-0.78 \\
(0.54)\end{array}$ \\
\hline Neglect $\left(\beta_{\mathrm{ijk}}\right)$ & $\begin{array}{l}-0.85 \\
(0.49)\end{array}$ & $\begin{array}{l}-1.00 \\
(0.49)^{*}\end{array}$ & $\begin{array}{l}-1.37 \\
(0.49)^{\star *}\end{array}$ & $\begin{array}{l}-0.97 \\
(0.47)^{*}\end{array}$ & $\begin{array}{l}-1.06 \\
(0.50)^{*}\end{array}$ & $\begin{array}{l}-1.48 \\
(0.50)^{\star \star}\end{array}$ \\
\hline $\begin{array}{l}\text { Other Maltreatment } \\
\left(\beta_{i \mathrm{ik})}\right)\end{array}$ & $\begin{array}{l}-1.01 \\
(0.54)\end{array}$ & $\begin{array}{l}-1.16 \\
(0.56)^{\star}\end{array}$ & $\begin{array}{l}-1.57 \\
(0.55)^{\star \star}\end{array}$ & $\begin{array}{l}-1.06 \\
(0.53)^{\star}\end{array}$ & $\begin{array}{l}-1.19 \\
(0.55)^{*}\end{array}$ & $\begin{array}{l}-1.63 \\
(0.54)^{\star \star}\end{array}$ \\
\hline $\begin{array}{l}\text { Exposure to } \\
\text { Violence }\left(\beta_{\mathrm{ijk}}\right)\end{array}$ & $\begin{array}{l}0.16 \\
(0.02)^{\star \star \star}\end{array}$ & $\begin{array}{l}0.21 \\
(0.02)^{\star \star \star}\end{array}$ & $\begin{array}{l}0.21 \\
(0.02)^{\star * *}\end{array}$ & $\begin{array}{l}0.14 \\
(0.02)^{\star \star \star}\end{array}$ & $\begin{array}{l}0.20 \\
(0.02)^{\star \star \star}\end{array}$ & $\begin{array}{l}0.19 \\
(0.02)^{\star \star *}\end{array}$ \\
\hline
\end{tabular}




\begin{tabular}{|c|c|c|c|}
\hline $\begin{array}{l}\text { Physical Health } \\
\left(\beta_{i \mathrm{ikl}}\right)\end{array}$ & $\begin{array}{l}-1.76 \\
(0.09)^{\star \star \star}\end{array}$ & $\begin{array}{l}-0.99 \\
(0.09)^{\star \star \star}\end{array}$ & $\begin{array}{l}-1.65 \\
(0.09)^{\star \star \star}\end{array}$ \\
\hline $\begin{array}{l}\text { Physical Disability } \\
\left(\beta_{i j k l}\right)\end{array}$ & $\begin{array}{l}0.57 \\
(0.41)\end{array}$ & $\begin{array}{l}0.51 \\
(0.44)\end{array}$ & $\begin{array}{l}1.99 \\
(0.44)^{\star \star \star}\end{array}$ \\
\hline K-BIT $\left(\beta_{\mathrm{ijk}}\right)$ & $\begin{array}{l}0.02 \\
(0.01)^{*}\end{array}$ & $\begin{array}{l}-0.00 \\
(0.01)\end{array}$ & $\begin{array}{l}-0.01 \\
(0.01)^{*}\end{array}$ \\
\hline $\begin{array}{l}\text { Cognitive Disability } \\
\left(\beta_{\mathrm{ijk}}\right)\end{array}$ & $\begin{array}{l}-0.86 \\
(0.30)^{\star \star}\end{array}$ & $\begin{array}{l}-1.25 \\
(0.31)^{\star \star \star}\end{array}$ & $\begin{array}{l}-0.88 \\
(0.32)^{\star \star}\end{array}$ \\
\hline
\end{tabular}

Caregiver Factors:

Age $\left(\beta_{i j k}\right)$

Less than 12th

grade $\left(\beta_{\mathrm{j} k \mathrm{k}}\right)$

HS diploma or

equivalent ( $\left.\beta_{\mathrm{ijk} k}\right)$

$\vec{\infty} \quad$ Education Unknown

( $\left.\beta_{i j k}\right)$

Separated/Divorced/ Widowed $\left(\beta_{\mathrm{ijk} k}\right)$

Never Married $\left(\beta_{i, k \mathrm{k}}\right)$

Number of Children in Household $\left(\beta_{\mathrm{ijk} k \mathrm{l}}\right)$

Changes in

Caregiver $\left(\beta_{i j k 1}\right)$

Permanent

Caregiver $\left(\beta_{i j k l}\right)$

Physical Health

$\left(\beta_{\mathrm{ijk}}\right)$

Domestic Violence

$\left(\beta_{\mathrm{ijk})}\right.$

Social Support $\left(\beta_{\mathrm{ijk} k}\right)$

$\begin{array}{lll}-1.49 & -0.74 & -1.36 \\ (0.09)^{\star \star \star} & (0.09)^{\star \star \star} & (0.09)^{\star \star \star} \\ 0.68 & 0.65 & 2.12 \\ (0.39) & (0.40) & (0.41)^{\star \star \star} \\ 0.02 & -0.00 & -0.02 \\ (0.01)^{\star} & (0.01) & (0.01)^{\star} \\ -0.86 & -1.22 & -0.86 \\ (0.29)^{\star \star} & (0.31)^{\star \star \star} & (0.30)^{\star \star} \\ & & \\ -0.38 & -0.49 & -0.51 \\ (0.10)^{\star \star \star} & (0.10)^{\star \star \star} & (0.10)^{\star \star \star} \\ -0.76 & -1.15 & -1.28 \\ (0.24)^{\star \star} & (0.25)^{\star \star \star} & (0.24)^{\star \star \star} \\ -0.82 & -1.08 & -1.22 \\ (0.23)^{\star \star \star} & (0.23)^{\star \star \star} & (0.22)^{\star \star \star} \\ -0.39 & -0.56 & -0.64 \\ (0.26) & (0.25)^{\star} & (0.25)^{\star} \\ -0.49 & -0.26 & -0.57 \\ (0.20)^{\star} & (0.20) & (0.19)^{\star \star} \\ -0.43 & -0.51 & -0.75 \\ (0.25) & (0.25)^{\star} & (0.25)^{\star \star} \\ -0.20 & -0.02 & -0.15 \\ (0.07)^{\star \star} & (0.06) & (0.07)^{\star} \\ 0.95 & 0.94 & 1.07 \\ (0.17)^{\star \star \star} & (0.17)^{\star \star \star} & (0.17)^{\star \star *} \\ -1.15 & -0.73 & -1.16 \\ (0.25)^{\star \star \star} & (0.24)^{\star \star} & (0.24)^{\star \star \star} \\ -0.77 & -0.74 & -0.89 \\ (0.08)^{\star \star \star} & (0.08)^{\star \star \star} & (0.08)^{\star \star \star} \\ 0.04 & 0.03 & 0.04 \\ (0.01)^{\star \star \star} & (0.01)^{\star \star \star} & (0.01)^{\star \star \star} \\ -0.92 & -0.80 & -0.84 \\ (0.15)^{\star \star \star} & (0.13)^{\star \star \star} & (0.14)^{\star \star \star}\end{array}$




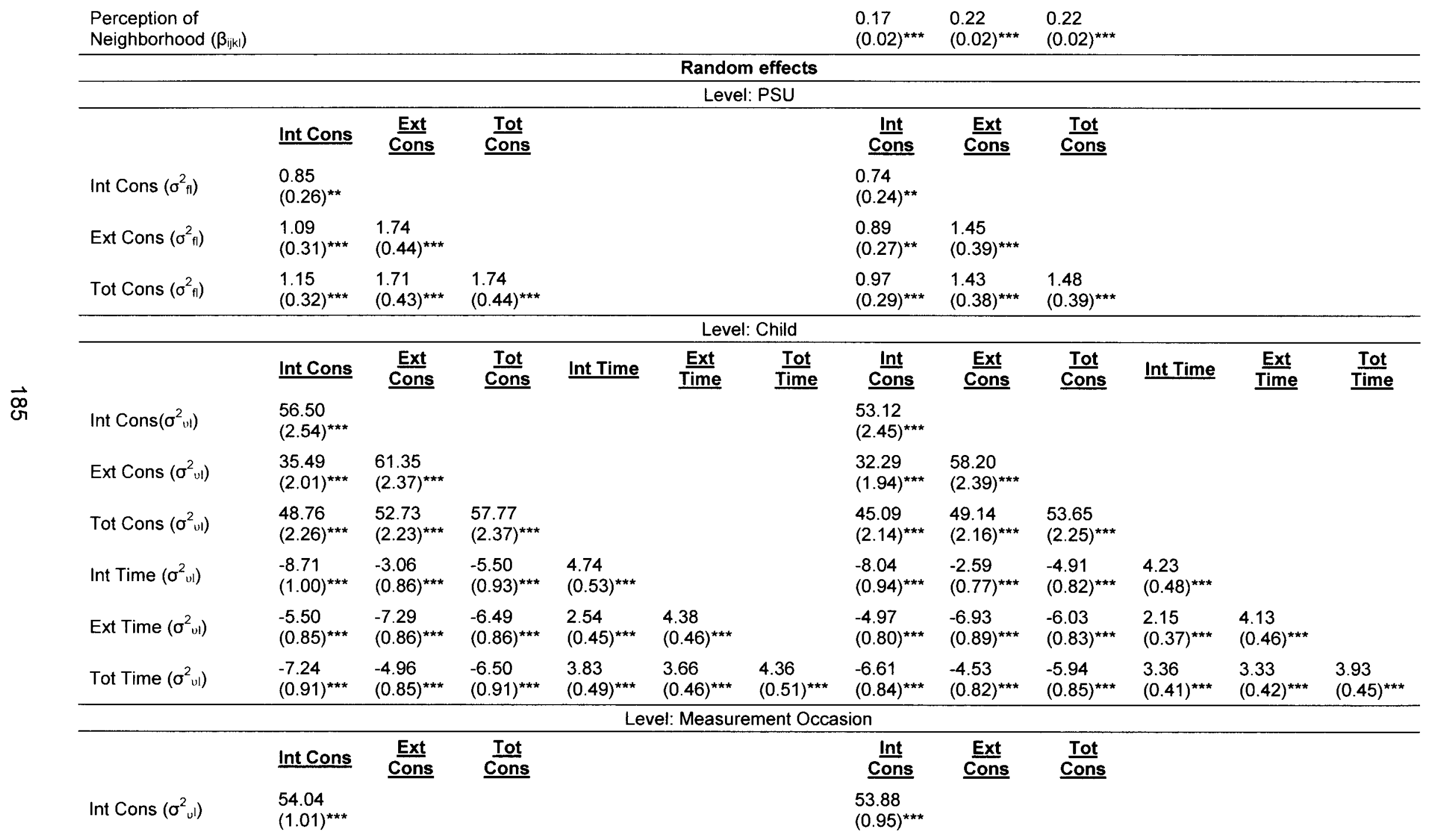




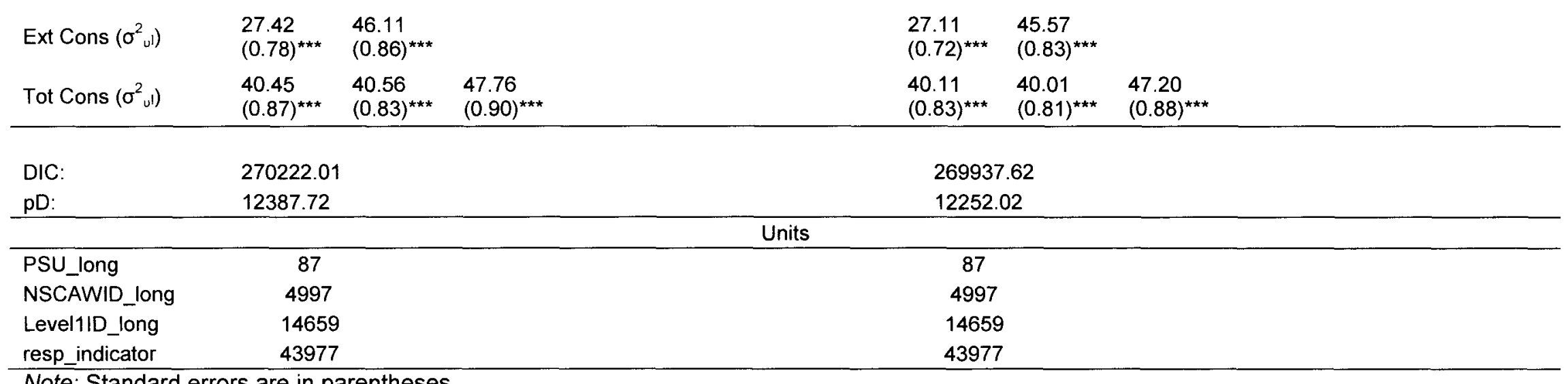

Note: Standard errors are in parentheses

DIC: Diagnostic Information Criterion

pD: estimated degrees of freedom

o $\quad{ }^{* * *} p \leq 0.001,{ }^{* *} p \leq 0.01 ;{ }^{*} p \leq 0.05$ 


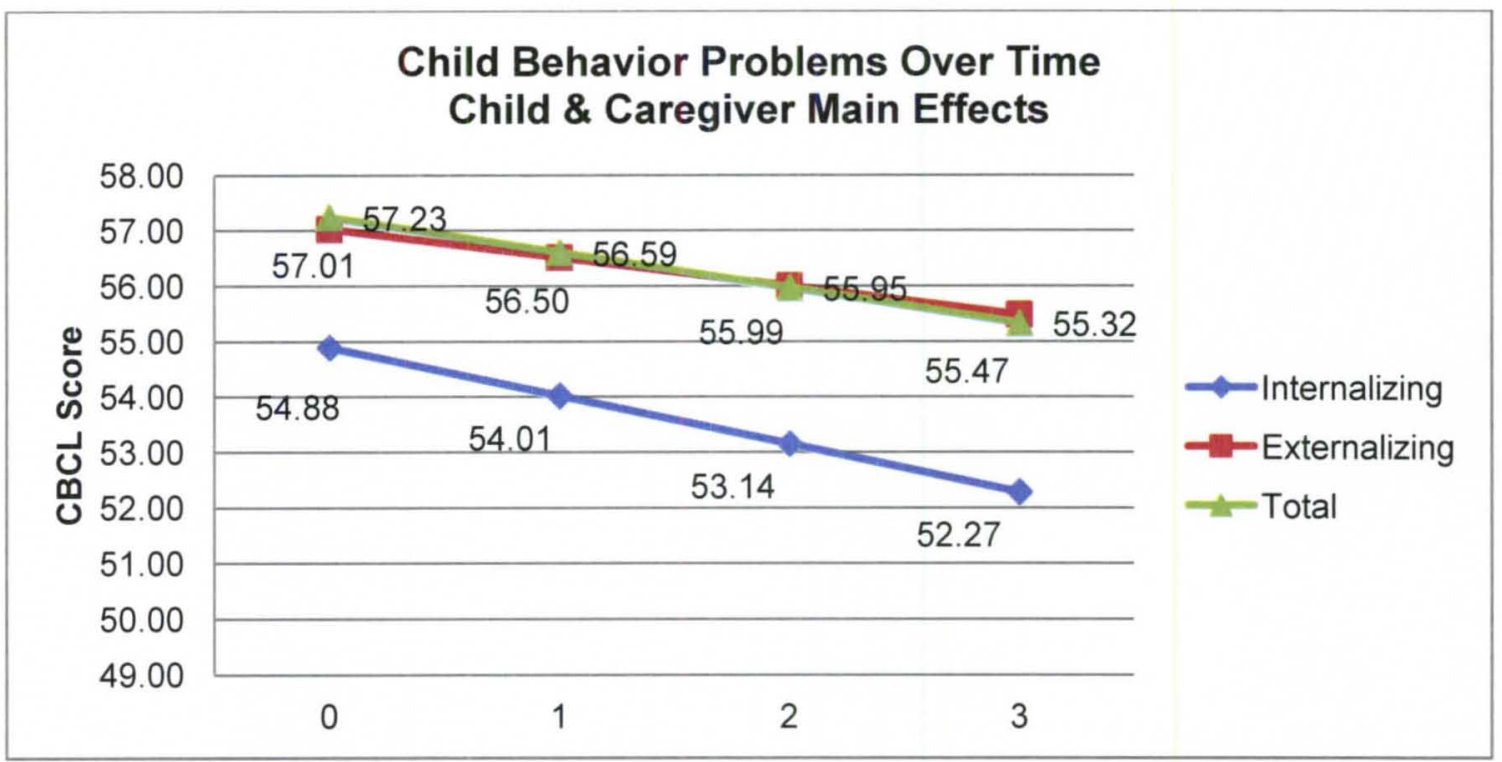

Figure 14. Child behavior problems over time with child and caregiver main effects.

Environmental main effects. Environmental factors included in the model included PSU race/ethnicity, PSU income, PSU family structure, PSU crime, PSU access to services, and PSU civic engagement. The estimates for the conditional growth model with child, caregiver, and environmental main effects are displayed as Model E in Table 26. PSU child poverty, PSU number of juvenile arrests, and PSU civic engagement were removed from Model E due to these predictors not being statistically significant. While the DIC did increase from 269937.62 in Model D to 269945.78 in Model E, the increase was only 8 points, indicating that the change was not significant. However, this increase may have been due to the fact that the DIC is not as sensitive to predictors on the higher levels as it is for predictors on lower levels (Jones, 2012). Therefore, the minimal increase was not of concern, especially since the variance components on the PSU level continued to decrease with the addition of these predictors. Following Table 26, there is a graphical representation of child 
behavior problems over time after accounting for child, caregiver, and environmental main effects (see Figure 15). 
Table 26

Conditional Growth Model with Child, Caregiver, and Environmental Main Effects

\begin{tabular}{|c|c|c|c|c|c|c|}
\hline \multirow[t]{2}{*}{ Parameter } & \multirow{2}{*}{\multicolumn{3}{|c|}{ Model D }} & \multirow{2}{*}{\multicolumn{3}{|c|}{ Model E }} \\
\hline & & & & & & \\
\hline & Int & Ext & Tot & $\underline{\text { Int }}$ & Ext & Tot \\
\hline Cons $\left(\beta_{\mathrm{ijk}}\right)$ & $\begin{array}{l}58.47 \\
(0.58)^{\star \star *}\end{array}$ & $\begin{array}{l}58.79 \\
(0.58)^{\star \star \star *}\end{array}$ & $\begin{array}{l}60.61 \\
(0.58)^{\star * \star}\end{array}$ & $\begin{array}{l}58.56 \\
(0.54)^{\star \star \star}\end{array}$ & $\begin{array}{l}58.86 \\
(0.55)^{\star \star \star}\end{array}$ & $\begin{array}{l}60.69 \\
(0.55)^{\star \star \star}\end{array}$ \\
\hline Time $\left(\beta_{i \mathrm{jk}}\right)$ & $\begin{array}{l}-0.87 \\
(0.08)^{\star \star \star}\end{array}$ & $\begin{array}{l}-0.52 \\
(0.08)^{\star \star \star}\end{array}$ & $\begin{array}{l}-0.65 \\
(0.08)^{\star \star \star}\end{array}$ & $\begin{array}{l}-0.87 \\
(0.08)^{\star \star \star}\end{array}$ & $\begin{array}{l}-0.50 \\
(0.08)^{\star \star \star}\end{array}$ & $\begin{array}{l}-0.63 \\
(0.08)^{\star \star \star}\end{array}$ \\
\hline \multicolumn{7}{|l|}{ Child Factors: } \\
\hline Female $\left(\beta_{i j k}\right)$ & $\begin{array}{l}-1.54 \\
(0.23)^{\star \star \star *}\end{array}$ & $\begin{array}{l}-0.65 \\
(0.24)^{\star \star}\end{array}$ & $\begin{array}{l}-1.45 \\
(0.23)^{\star \star \star}\end{array}$ & $\begin{array}{l}-1.54 \\
(0.22)^{\star \star \star}\end{array}$ & $\begin{array}{l}-0.62 \\
(0.24)^{\star \star}\end{array}$ & $\begin{array}{l}-1.42 \\
(0.23)^{\star \star \star}\end{array}$ \\
\hline $\begin{array}{l}\text { White/Non-Hispanic } \\
\left(\beta_{i j k \mathrm{k}}\right)\end{array}$ & $\begin{array}{l}0.47 \\
(0.30)\end{array}$ & $\begin{array}{l}1.79 \\
(0.32)^{\star \star \star *}\end{array}$ & $\begin{array}{l}1.51 \\
(0.32)^{\star \star \star *}\end{array}$ & $\begin{array}{l}0.28 \\
(0.31)\end{array}$ & $\begin{array}{l}1.52 \\
(0.33)^{\star \star \star}\end{array}$ & $\begin{array}{l}1.22 \\
(0.32)^{\star \star \star}\end{array}$ \\
\hline $\begin{array}{l}\text { Black/Non-Hispanic } \\
\left(\beta_{\mathrm{ijk} \mid}\right)\end{array}$ & $\begin{array}{l}-0.89 \\
(0.31)^{\star \star}\end{array}$ & $\begin{array}{l}0.80 \\
(0.34)^{\star}\end{array}$ & $\begin{array}{l}-0.10 \\
(0.33)\end{array}$ & $\begin{array}{l}-0.89 \\
(0.33)^{\star \star}\end{array}$ & $\begin{array}{l}0.68 \\
(0.36)\end{array}$ & $\begin{array}{l}0.04 \\
(0.35)\end{array}$ \\
\hline Age $\left(\beta_{\mathrm{ijk} k}\right)$ & $\begin{array}{l}0.21 \\
(0.03)^{\star * *}\end{array}$ & $\begin{array}{l}0.48 \\
(0.03)^{\star \star *}\end{array}$ & $\begin{array}{l}0.43 \\
(0.03)^{\star \star \star \star}\end{array}$ & $\begin{array}{l}0.20 \\
(0.03)^{\star \star \star}\end{array}$ & $\begin{array}{l}0.48 \\
(0.03)^{\star * *}\end{array}$ & $\begin{array}{l}0.42 \\
(0.03)^{\star \star \star}\end{array}$ \\
\hline Social Skills $\left(\beta_{|j| k \mid}\right)$ & $\begin{array}{l}-0.22 \\
(0.01)^{\star \star \star}\end{array}$ & $\begin{array}{l}-0.28 \\
(0.01)^{\star \star \star}\end{array}$ & $\begin{array}{l}-0.29 \\
(0.01)^{\star \star \star}\end{array}$ & $\begin{array}{l}-0.22 \\
(0.01)^{\star \star \star}\end{array}$ & $\begin{array}{l}-0.28 \\
(0.01)^{\star \star \star *}\end{array}$ & $\begin{array}{l}-0.28 \\
(0.01)^{\star \star \star}\end{array}$ \\
\hline $\begin{array}{l}\text { Unsubstantiated } \\
\text { Maltreatment }\left(\beta_{i j k}\right)\end{array}$ & $\begin{array}{l}-0.91 \\
(0.48)\end{array}$ & $\begin{array}{l}-0.69 \\
(0.48)\end{array}$ & $\begin{array}{l}-1.15 \\
(0.48)^{\star}\end{array}$ & $\begin{array}{l}-0.93 \\
(0.47)^{\star}\end{array}$ & $\begin{array}{l}-0.64 \\
(0.45)\end{array}$ & $\begin{array}{l}-1.12 \\
(0.46)^{\star}\end{array}$ \\
\hline $\begin{array}{l}\text { Physical Maltreatment } \\
\left(\beta_{i j k l}\right)\end{array}$ & $\begin{array}{l}-0.85 \\
(0.54)\end{array}$ & $\begin{array}{l}-0.13 \\
(0.53)\end{array}$ & $\begin{array}{l}-0.78 \\
(0.54)\end{array}$ & $\begin{array}{l}-0.87 \\
(0.52)\end{array}$ & $\begin{array}{l}-0.10 \\
(0.56)\end{array}$ & $\begin{array}{l}-0.76 \\
(0.54)\end{array}$ \\
\hline Neglect $\left(\beta_{i j k 1}\right)$ & $\begin{array}{l}-0.97 \\
(0.47)^{\star}\end{array}$ & $\begin{array}{l}-1.06 \\
(0.50)^{*}\end{array}$ & $\begin{array}{l}-1.48 \\
(0.50)^{\star *}\end{array}$ & $\begin{array}{l}-0.98 \\
(0.48)^{\star}\end{array}$ & $\begin{array}{l}-1.05 \\
(0.48)^{*}\end{array}$ & $\begin{array}{l}-1.46 \\
(0.49)^{\star \star}\end{array}$ \\
\hline $\begin{array}{l}\text { Other Maltreatment } \\
\left(\beta_{j \mathrm{jk})}\right)\end{array}$ & $\begin{array}{l}-1.06 \\
(0.53)^{\star}\end{array}$ & $\begin{array}{l}-1.19 \\
(0.55)^{*}\end{array}$ & $\begin{array}{l}-1.63 \\
(0.54)^{\star \star}\end{array}$ & $\begin{array}{l}-1.03 \\
(0.52)^{*}\end{array}$ & $\begin{array}{l}-1.15 \\
(0.53)^{\star}\end{array}$ & $\begin{array}{l}-1.58 \\
(0.53)^{\star *}\end{array}$ \\
\hline $\begin{array}{l}\text { Exposure to Violence } \\
\left(\beta_{\mathrm{ijk})}\right)\end{array}$ & $\begin{array}{l}0.14 \\
(0.02)^{\star \star \star \star}\end{array}$ & $\begin{array}{l}0.20 \\
(0.02)^{\star \star \star *}\end{array}$ & $\begin{array}{l}0.19 \\
(0.02)^{\star \star \star *}\end{array}$ & $\begin{array}{l}0.14 \\
(0.02)^{\star * *}\end{array}$ & $\begin{array}{l}0.20 \\
(0.02)^{\star \star \star}\end{array}$ & $\begin{array}{l}0.19 \\
(0.02)^{\star \star \star}\end{array}$ \\
\hline
\end{tabular}




\begin{tabular}{|c|c|c|c|}
\hline Physical Health $\left(\beta_{\mathrm{ijk}}\right)$ & $\begin{array}{l}-1.49 \\
(0.09)^{\star \star \star}\end{array}$ & $\begin{array}{l}-0.74 \\
(0.09)^{\star \star \star}\end{array}$ & $\begin{array}{l}-1.36 \\
(0.09)^{* * *}\end{array}$ \\
\hline $\begin{array}{l}\text { Physical Disability } \\
\left(\beta_{i j k \mid}\right)\end{array}$ & $\begin{array}{l}0.68 \\
(0.39)\end{array}$ & $\begin{array}{l}0.65 \\
(0.40)\end{array}$ & $\begin{array}{l}2.12 \\
(0.41)^{\star \star \star}\end{array}$ \\
\hline $\mathrm{K}-\mathrm{BIT}\left(\beta_{\mathrm{ijk} \mid}\right)$ & $\begin{array}{l}0.02 \\
(0.01)^{*}\end{array}$ & $\begin{array}{l}-0.00 \\
(0.01)\end{array}$ & $\begin{array}{l}-0.02 \\
(0.01)^{*}\end{array}$ \\
\hline $\begin{array}{l}\text { Cognitive Disability } \\
\left(\beta_{i \mid \mathrm{k} k}\right)\end{array}$ & $\begin{array}{l}-0.86 \\
(0.29)^{\star \star}\end{array}$ & $\begin{array}{l}-1.22 \\
(0.31)^{\star \star \star \star}\end{array}$ & $\begin{array}{l}-0.86 \\
(0.30)^{\star \star}\end{array}$ \\
\hline \multicolumn{4}{|l|}{ Caregiver Factors: } \\
\hline Age $\left(\beta_{i \mathrm{jk}}\right)$ & $\begin{array}{l}-0.38 \\
(0.10)^{\star \star \star}\end{array}$ & $\begin{array}{l}-0.49 \\
(0.10)^{\star \star \star}\end{array}$ & $\begin{array}{l}-0.51 \\
(0.10)^{\star \star \star}\end{array}$ \\
\hline $\begin{array}{l}\text { Less than } 12 \text { th grade } \\
\left(\beta_{j, k 1}\right)\end{array}$ & $\begin{array}{l}-0.76 \\
(0.24)^{\star \star}\end{array}$ & $\begin{array}{l}-1.15 \\
(0.25)^{\star \star \star}\end{array}$ & $\begin{array}{l}-1.28 \\
(0.24)^{\star \star \star}\end{array}$ \\
\hline $\begin{array}{l}\text { HS diploma or } \\
\text { equivalent }\left(\beta_{i j k l}\right)\end{array}$ & $\begin{array}{l}-0.82 \\
(0.23)^{\star \star \star}\end{array}$ & $\begin{array}{l}-1.08 \\
(0.23)^{\star \star \star}\end{array}$ & $\begin{array}{l}-1.22 \\
(0.22)^{\star \star \star}\end{array}$ \\
\hline $\begin{array}{l}\text { Education Unknown } \\
\left(\beta_{j \mathrm{kk}}\right)\end{array}$ & $\begin{array}{l}-0.39 \\
(0.26)\end{array}$ & $\begin{array}{l}-0.56 \\
(0.25)^{\star}\end{array}$ & $\begin{array}{l}-0.64 \\
(0.25)^{\star}\end{array}$ \\
\hline $\begin{array}{l}\text { Separated/Divorced/ } \\
\text { Widowed }\left(\beta_{\mathrm{ijk} k}\right)\end{array}$ & $\begin{array}{l}-0.49 \\
(0.20)^{\star}\end{array}$ & $\begin{array}{l}-0.26 \\
(0.20)\end{array}$ & $\begin{array}{l}-0.57 \\
(0.19)^{\star \star}\end{array}$ \\
\hline Never Married $\left(\beta_{i j k}\right)$ & $\begin{array}{l}-0.43 \\
(0.25)\end{array}$ & $\begin{array}{l}-0.51 \\
(0.25)^{*}\end{array}$ & $\begin{array}{l}-0.75 \\
(0.25)^{* \star}\end{array}$ \\
\hline $\begin{array}{l}\text { Number of Children in } \\
\text { Household }\left(\beta_{i j k}\right)\end{array}$ & $\begin{array}{l}-0.20 \\
(0.07)^{\star \star}\end{array}$ & $\begin{array}{l}-0.02 \\
(0.06)\end{array}$ & $\begin{array}{l}-0.15 \\
(0.07)^{\star}\end{array}$ \\
\hline $\begin{array}{l}\text { Changes in Caregiver } \\
\left(\beta_{j \mathrm{k} k}\right)\end{array}$ & $\begin{array}{l}0.95 \\
(0.17)^{\star \star \star}\end{array}$ & $\begin{array}{l}0.94 \\
(0.17)^{\star \star \star \star}\end{array}$ & $\begin{array}{l}1.07 \\
(0.17)^{\star \star \star}\end{array}$ \\
\hline $\begin{array}{l}\text { Permanent Caregiver } \\
\left(\beta_{i j k l}\right)\end{array}$ & $\begin{array}{l}-1.15 \\
(0.25)^{\star \star \star}\end{array}$ & $\begin{array}{l}-0.73 \\
(0.24)^{\star \star}\end{array}$ & $\begin{array}{l}-1.16 \\
(0.24)^{\star \star \star}\end{array}$ \\
\hline Physical Health $\left(\beta_{\mathrm{ijk}}\right)$ & $\begin{array}{l}-0.77 \\
(0.08)^{\star \star \star}\end{array}$ & $\begin{array}{l}-0.74 \\
(0.08)^{\star \star \star}\end{array}$ & $\begin{array}{l}-0.89 \\
(0.08)^{\star * *}\end{array}$ \\
\hline $\begin{array}{l}\text { Domestic Violence } \\
\left(\beta_{i j k}\right)\end{array}$ & $\begin{array}{l}0.04 \\
(0.01)^{\star \star \star}\end{array}$ & $\begin{array}{l}0.03 \\
(0.01)^{\star \star \star}\end{array}$ & $\begin{array}{l}0.04 \\
(0.01)^{\star \star \star}\end{array}$ \\
\hline Social Support $\left(\beta_{\mathrm{ijk}}\right)$ & $\begin{array}{l}-0.92 \\
(0.15)^{\star * *}\end{array}$ & $\begin{array}{l}-0.80 \\
(0.13)^{\star * \star}\end{array}$ & $\begin{array}{l}-0.84 \\
(0.14)^{\star \star \star}\end{array}$ \\
\hline
\end{tabular}

\begin{tabular}{|c|c|c|}
\hline $\begin{array}{l}-1.49 \\
(0.09)^{\star \star *}\end{array}$ & $\begin{array}{l}-0.75 \\
(0.09)^{* \star *}\end{array}$ & $\begin{array}{l}-1.37 \\
(0.09)^{\star * *}\end{array}$ \\
\hline $\begin{array}{l}0.69 \\
(0.40)\end{array}$ & $\begin{array}{l}0.64 \\
(0.43)\end{array}$ & $\begin{array}{l}2.12 \\
(0.41)^{\star \star \star}\end{array}$ \\
\hline $\begin{array}{l}0.02 \\
(0.01)^{*}\end{array}$ & $\begin{array}{l}-0.00 \\
(0.01)\end{array}$ & $\begin{array}{l}-0.02 \\
(0.01)^{\star}\end{array}$ \\
\hline $\begin{array}{l}-0.87 \\
(0.30)^{\star \star}\end{array}$ & $\begin{array}{l}-1.23 \\
(0.31)^{\star \star \star}\end{array}$ & $\begin{array}{l}-0.87 \\
(0.31)^{\star \star}\end{array}$ \\
\hline $\begin{array}{l}-0.37 \\
(0.10)^{\star \star \star}\end{array}$ & $\begin{array}{l}-0.47 \\
(0.10)^{\star \star \star}\end{array}$ & $\begin{array}{l}-0.50 \\
(0.10)^{\star \star \star}\end{array}$ \\
\hline $\begin{array}{l}-0.76 \\
(0.22)^{\star \star \star}\end{array}$ & $\begin{array}{l}-1.15 \\
(0.22)^{\star \star \star}\end{array}$ & $\begin{array}{l}-1.29 \\
(0.23)^{\star \star \star}\end{array}$ \\
\hline $\begin{array}{l}-0.86 \\
(0.23)^{\star \star \star}\end{array}$ & $\begin{array}{l}-1.10 \\
(0.23)^{\star \star \star \star}\end{array}$ & $\begin{array}{l}-1.26 \\
(0.22)^{\star \star \star}\end{array}$ \\
\hline $\begin{array}{l}-0.42 \\
(0.26)\end{array}$ & $\begin{array}{l}-0.56 \\
(0.24)^{*}\end{array}$ & $\begin{array}{l}-0.65 \\
(0.24)^{\star \star}\end{array}$ \\
\hline $\begin{array}{l}-0.48 \\
(0.20)^{\star}\end{array}$ & $\begin{array}{l}-0.27 \\
(0.20)\end{array}$ & $\begin{array}{l}-0.58 \\
(0.20)^{\star \star}\end{array}$ \\
\hline $\begin{array}{l}-0.41 \\
(0.24)\end{array}$ & $\begin{array}{l}-0.52 \\
(0.24)^{\star}\end{array}$ & $\begin{array}{l}-0.74 \\
(0.23)^{\star *}\end{array}$ \\
\hline $\begin{array}{l}-0.19 \\
(0.07)^{\star \star}\end{array}$ & $\begin{array}{l}-0.02 \\
(0.06)\end{array}$ & $\begin{array}{l}-0.14 \\
(0.06)^{\star}\end{array}$ \\
\hline $\begin{array}{l}0.97 \\
(0.17)^{\star \star \star}\end{array}$ & $\begin{array}{l}0.95 \\
(0.18)^{\star \star \star}\end{array}$ & $\begin{array}{l}1.08 \\
(0.18)^{\star \star \star *}\end{array}$ \\
\hline $\begin{array}{l}-1.16 \\
(0.26)^{\star \star \star}\end{array}$ & $\begin{array}{l}-0.73 \\
(0.24)^{\star \star}\end{array}$ & $\begin{array}{l}-1.18 \\
(0.24)^{\star \star \star}\end{array}$ \\
\hline $\begin{array}{l}-0.76 \\
(0.08)^{\star \star \star}\end{array}$ & $\begin{array}{l}-0.73 \\
(0.07)^{\star \star \star}\end{array}$ & $\begin{array}{l}-0.88 \\
(0.08)^{\star \star \star}\end{array}$ \\
\hline $\begin{array}{l}0.04 \\
(0.01)^{\star \star \star}\end{array}$ & $\begin{array}{l}0.03 \\
(0.01)^{\star \star \star}\end{array}$ & $\begin{array}{l}0.04 \\
(0.01)^{\star \star \star}\end{array}$ \\
\hline $\begin{array}{l}-0.94 \\
(0.14)^{* \star *}\end{array}$ & $\begin{array}{l}-0.82 \\
(0.13)^{\star \star \star}\end{array}$ & $\begin{array}{l}-0.86 \\
(0.14)^{\star \star \star}\end{array}$ \\
\hline
\end{tabular}


$\begin{array}{llll}\text { Perception of } & 0.17 & 0.22 & 0.22 \\ \text { Neighborhood }\left(\beta_{i j k 1}\right) & (0.02)^{\star \star \star} & (0.02)^{\star \star \star} & (0.02)^{\star \star \star}\end{array}$

$\begin{array}{lll}0.17 & 0.22 & 0.22\end{array}$

Environmental Factors:

Single Parents $\left(\beta_{\mathrm{ijk} \mathrm{k}}\right)$

$\begin{array}{lll}-0.01 & 0.07 & 0.04 \\ (0.07) & (0.09) & (0.09) \\ 2.41 & 2.72 & 2.89 \\ (2.73) & (3.25) & (3.20) \\ -0.49 & -0.00 & -0.53 \\ (0.63) & (0.77) & (0.77) \\ 0.02 & 0.03 & 0.03 \\ (0.01) & (0.01)^{\star \star} & (0.01)^{\star}\end{array}$

\section{Access to Social}

Services $\left(\beta_{\mathrm{ijk} k}\right)$

Access to Health

Services $\left(\beta_{i j k l}\right)$

White $\left(\beta_{\mathrm{jjk}}\right)$

(0.01)

Random effects

\begin{tabular}{|c|c|c|c|c|c|c|c|c|c|c|c|c|}
\hline \multicolumn{13}{|c|}{ Level: PSU } \\
\hline & $\underline{\text { Int }}$ & $\underline{\text { Ext }}$ & Tot & & & & $\underline{\text { Int }}$ & $\underline{\text { Ext }}$ & $\underline{\text { Tot }}$ & & & \\
\hline Int Cons $\left(\sigma_{f i}^{2}\right)$ & $\begin{array}{l}0.74 \\
(0.24)^{\star *}\end{array}$ & & & & & & $\begin{array}{l}0.57 \\
(0.22)^{*}\end{array}$ & & & & & \\
\hline Ext Cons $\left(\sigma_{\mathrm{ff}}^{2}\right)$ & $\begin{array}{l}0.89 \\
(0.27)^{\star \star}\end{array}$ & $\begin{array}{l}1.45 \\
(0.39)^{\star \star \star}\end{array}$ & & & & & $\begin{array}{l}0.68 \\
(0.24)^{\star}\end{array}$ & $\begin{array}{l}1.16 \\
(0.34)^{\star \star \star}\end{array}$ & & & & \\
\hline Tot Cons $\left(\sigma_{f i l}^{2}\right)$ & $\begin{array}{l}0.97 \\
(0.29)^{\star \star \star}\end{array}$ & $\begin{array}{l}1.43 \\
(0.38)^{\star \star \star}\end{array}$ & $\begin{array}{l}1.48 \\
(0.39)^{\star \star \star}\end{array}$ & & & & $\begin{array}{l}0.81 \\
(0.27)^{\star \star}\end{array}$ & $\begin{array}{l}1.13 \\
(0.33)^{\star \star \star}\end{array}$ & $\begin{array}{l}1.16 \\
(0.34)^{\star * *}\end{array}$ & & & \\
\hline \multicolumn{13}{|c|}{ Level: Child } \\
\hline & Cons & $\begin{array}{l}\text { Ext } \\
\text { Cons }\end{array}$ & $\frac{\text { Tot }}{\text { Cons }}$ & Int Time & $\underline{\text { Ext }}$ & $\underline{\text { Tot }}$ & Cons & Ext & $\frac{\text { Tot }}{\text { Cons }}$ & Int Time & $\begin{array}{l}\text { Ext } \\
\text { Time }\end{array}$ & $\underline{\text { Tot }}$ \\
\hline Int Cons $\left(\sigma^{2}{ }_{u l}\right)$ & $\begin{array}{l}53.12 \\
(2.45)^{\star \star \star}\end{array}$ & & & & & & $\begin{array}{l}52.95 \\
(2.39)^{\star \star \star}\end{array}$ & & & & & \\
\hline Ext Cons $\left(\sigma^{2}{ }_{v 1}\right)$ & $\begin{array}{l}32.29 \\
(1.94)^{\star \star \star *}\end{array}$ & $\begin{array}{l}58.20 \\
(2.39)^{\star * *}\end{array}$ & & & & & $\begin{array}{l}32.48 \\
(1.77)^{\star \star \star}\end{array}$ & $\begin{array}{l}58.46 \\
(2.21)^{\star \star \star *}\end{array}$ & & & & \\
\hline Tot Cons $\left(\sigma^{2}{ }_{v 1}\right)$ & $\begin{array}{l}45.09 \\
(2.14)^{\star \star \star}\end{array}$ & $\begin{array}{l}49.14 \\
(2.16)^{\star \star \star}\end{array}$ & $\begin{array}{l}53.65 \\
(2.25)^{\star \star \star}\end{array}$ & & & & $\begin{array}{l}45.08 \\
(2.02)^{\star \star \star}\end{array}$ & $\begin{array}{l}49.32 \\
(2.04)^{\star \star \star}\end{array}$ & $\begin{array}{l}53.71 \\
(2.14)^{\star \star \star}\end{array}$ & & & \\
\hline
\end{tabular}




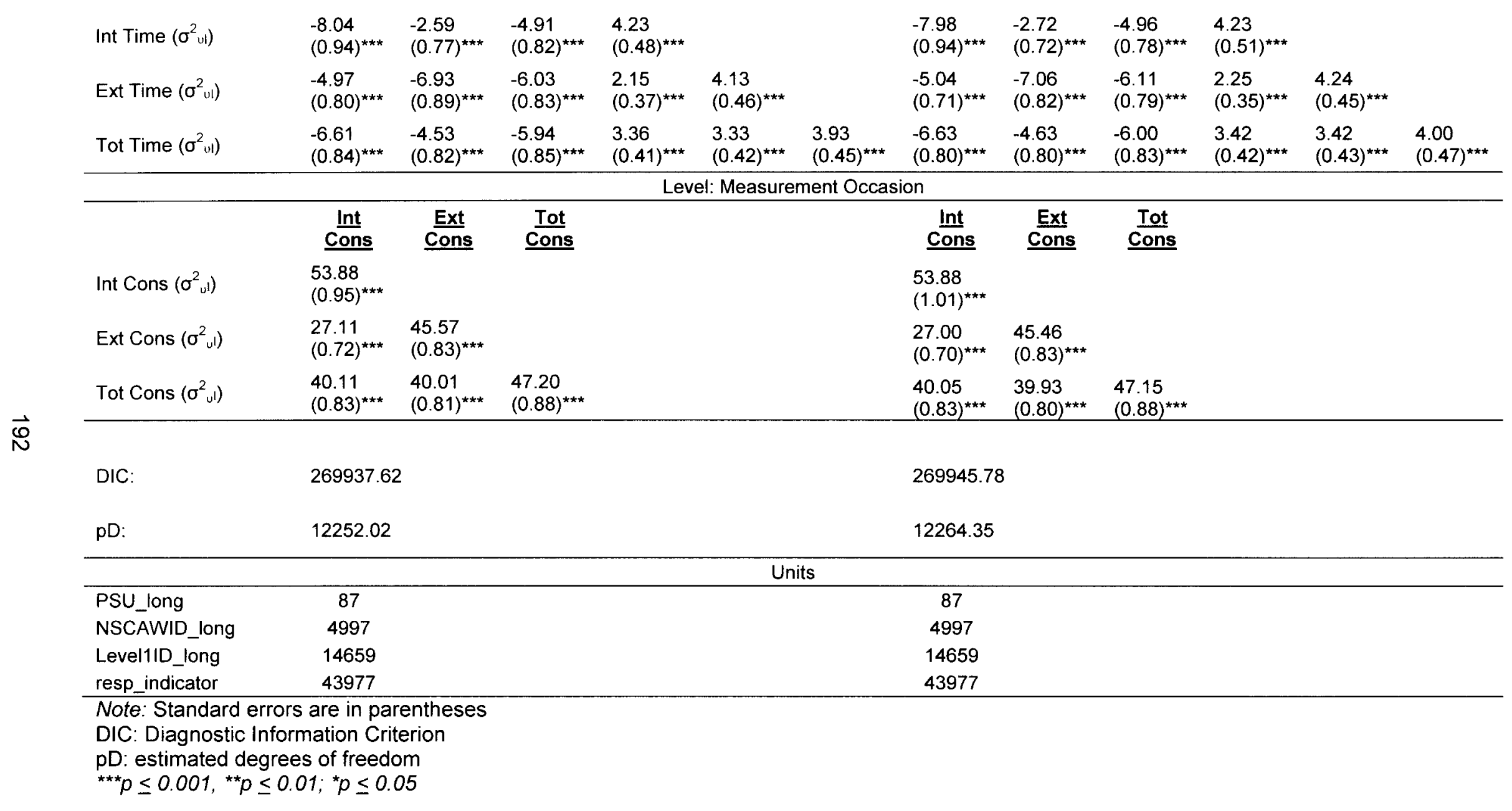




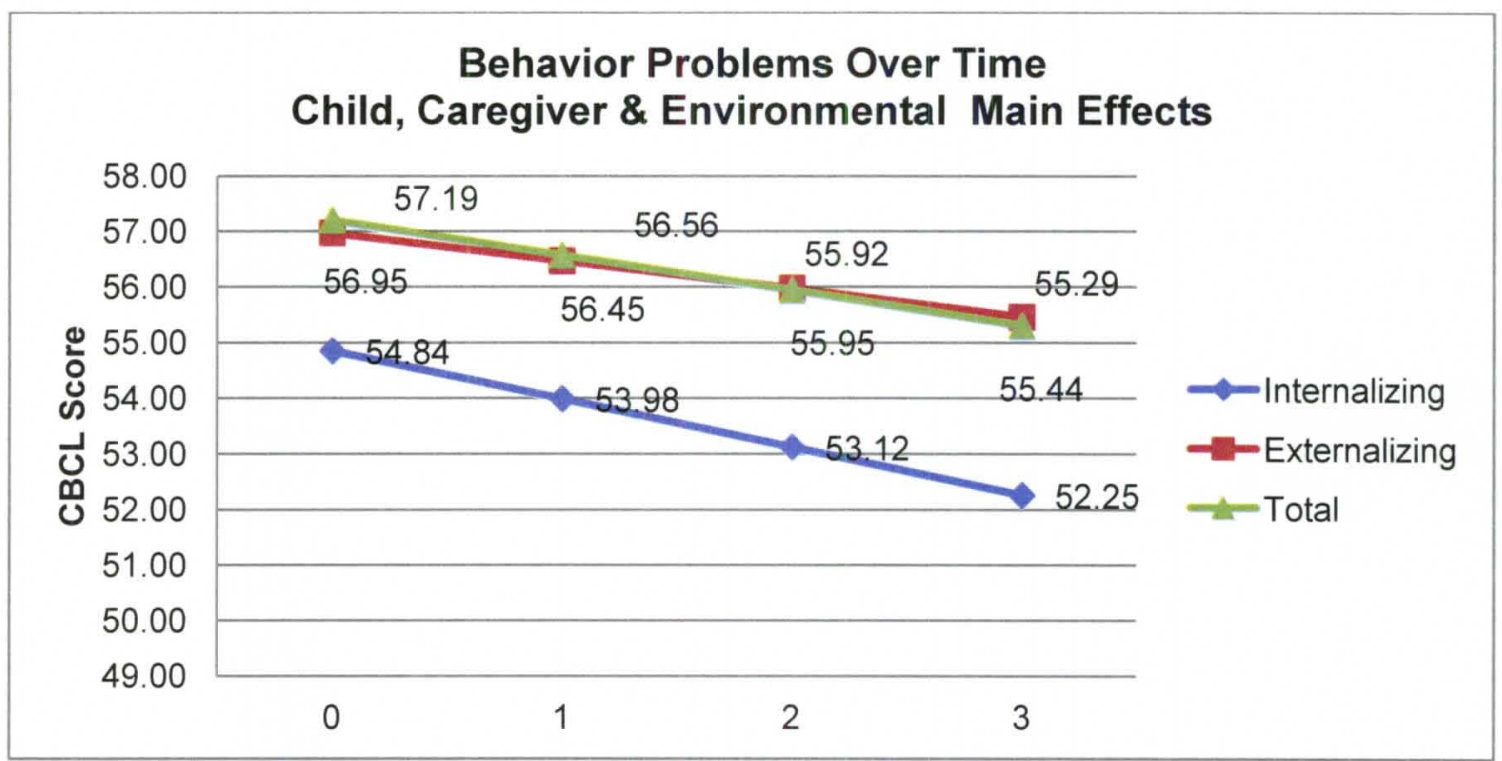

Figure 15. Child behavior problems over time with all main effects.

Interaction effects. Interaction effects were estimated for the PSU-level variables and between PSU-level variables and maltreatment. Several interactions were tested; however, Model F presented in Table 27 below presents the final model with only statistically significant interactions that were found. By adding the interaction effects, the DIC decreased from both Model D (269937.62) and Model E (269945.78) to 269923.63 in Model F, indicating that Model $F$ is the most parsimonious model. Additionally, the variance components also continued to decrease with the addition of the interaction effects. Following Table 27, there is a graphical representation of child behavior problems over time after accounting for all main and interaction effects (see Figure 16). 
Table 27

Conditional Growth Model with Child, Caregiver, and Environmental Main Effects and Interaction Effects

\begin{tabular}{|c|c|c|c|c|c|c|}
\hline Parameter & \multicolumn{3}{|r|}{ Model E } & \multicolumn{3}{|r|}{ Model F } \\
\hline \multicolumn{7}{|c|}{ Fixed effects } \\
\hline & $\underline{\text { Int }}$ & Ext & Tot & Int & Ext & Tot \\
\hline Constant $\left(\beta_{\mathrm{ijk} k}\right)$ & $\begin{array}{l}58.56 \\
(0.54)^{\star \star \star}\end{array}$ & $\begin{array}{l}58.86 \\
(0.55)^{\star \star \star}\end{array}$ & $\begin{array}{l}60.69 \\
(0.55)^{\star \star \star}\end{array}$ & $\begin{array}{l}58.71 \\
(0.53)^{\star \star \star}\end{array}$ & $\begin{array}{l}59.02 \\
(0.57)^{\star \star \star}\end{array}$ & $\begin{array}{l}60.89 \\
(0.55)^{\star \star \star}\end{array}$ \\
\hline Time $\left(\beta_{\mathrm{ijk} k}\right)$ & $\begin{array}{l}-0.87 \\
(0.08)^{\star \star \star}\end{array}$ & $\begin{array}{l}-0.50 \\
(0.08)^{\star \star \star}\end{array}$ & $\begin{array}{l}-0.63 \\
(0.08)^{\star \star \star}\end{array}$ & $\begin{array}{l}-0.87 \\
(0.08)^{\star \star \star}\end{array}$ & $\begin{array}{l}-0.50 \\
(0.08)^{\star \star \star}\end{array}$ & $\begin{array}{l}-0.63 \\
(0.08)^{\star \star \star}\end{array}$ \\
\hline \multicolumn{7}{|l|}{ Child Factors: } \\
\hline Female $\left(\beta_{\mathrm{ijk} k}\right)$ & $\begin{array}{l}-1.54 \\
(0.22)^{\star \star \star}\end{array}$ & $\begin{array}{l}-0.62 \\
(0.24)^{\star \star}\end{array}$ & $\begin{array}{l}-1.42 \\
(0.23)^{\star \star \star}\end{array}$ & $\begin{array}{l}-1.55 \\
(0.23)^{\star * *}\end{array}$ & $\begin{array}{l}-0.63 \\
(0.22)^{\star \star}\end{array}$ & $\begin{array}{l}-1.43 \\
(0.22)^{\star \star \star}\end{array}$ \\
\hline $\begin{array}{l}\text { White/Non-Hispanic } \\
\left(\beta_{\mathrm{ijk} \mid}\right)\end{array}$ & $\begin{array}{l}0.28 \\
(0.31)\end{array}$ & $\begin{array}{l}1.52 \\
(0.33)^{\star \star \star}\end{array}$ & $\begin{array}{l}1.22 \\
(0.32)^{\star \star \star}\end{array}$ & $\begin{array}{l}0.29 \\
(0.31)\end{array}$ & $\begin{array}{l}1.55 \\
(0.34)^{\star \star \star}\end{array}$ & $\begin{array}{l}1.24 \\
(0.33)^{\star \star \star}\end{array}$ \\
\hline $\begin{array}{l}\text { Black/Non-Hispanic } \\
\left(\beta_{i, j k 1}\right)\end{array}$ & $\begin{array}{l}-0.89 \\
(0.33)^{\star *}\end{array}$ & $\begin{array}{l}0.68 \\
(0.36)\end{array}$ & $\begin{array}{l}0.04 \\
(0.35)\end{array}$ & $\begin{array}{l}-0.89 \\
(0.31)^{\star \star}\end{array}$ & $\begin{array}{l}0.70 \\
(0.32)^{\star}\end{array}$ & $\begin{array}{l}0.05 \\
(0.32)\end{array}$ \\
\hline Age $\left(\beta_{\mathrm{ijk} l}\right)$ & $\begin{array}{l}0.20 \\
(0.03)^{\star \star \star}\end{array}$ & $\begin{array}{l}0.48 \\
(0.03)^{\star \star \star}\end{array}$ & $\begin{array}{l}0.42 \\
(0.03)^{\star \star \star}\end{array}$ & $\begin{array}{l}0.20 \\
(0.02)^{\star \star \star}\end{array}$ & $\begin{array}{l}0.48 \\
(0.03)^{\star \star \star}\end{array}$ & $\begin{array}{l}0.42 \\
(0.03)^{\star \star \star}\end{array}$ \\
\hline Social Skills $\left(\beta_{i j k l}\right)$ & $\begin{array}{l}-0.22 \\
(0.01)^{\star \star \star}\end{array}$ & $\begin{array}{l}-0.28 \\
(0.01)^{\star \star \star}\end{array}$ & $\begin{array}{l}-0.28 \\
(0.01)^{\star \star \star}\end{array}$ & $\begin{array}{l}-0.22 \\
(0.01)^{\star \star \star}\end{array}$ & $\begin{array}{l}-0.28 \\
(0.01)^{\star \star \star}\end{array}$ & $\begin{array}{l}-0.28 \\
(0.01)^{\star \star \star}\end{array}$ \\
\hline $\begin{array}{l}\text { Unsubstantiated } \\
\text { Maltreatment }\left(\beta_{\mathrm{ijk}}\right)\end{array}$ & $\begin{array}{l}-0.93 \\
(0.47)^{\star}\end{array}$ & $\begin{array}{l}-0.64 \\
(0.45)\end{array}$ & $\begin{array}{l}-1.12 \\
(0.46)^{\star}\end{array}$ & $\begin{array}{l}-1.00 \\
(0.45)^{\star}\end{array}$ & $\begin{array}{l}-0.71 \\
(0.46)\end{array}$ & $\begin{array}{l}-1.22 \\
(0.45)^{\star \star}\end{array}$ \\
\hline Physical Maltx $\left(\beta_{i j \mathrm{kl}}\right)$ & $\begin{array}{l}-0.87 \\
(0.52)\end{array}$ & $\begin{array}{l}-0.10 \\
(0.56)\end{array}$ & $\begin{array}{l}-0.76 \\
(0.54)\end{array}$ & $\begin{array}{l}-0.83 \\
(0.51)\end{array}$ & $\begin{array}{l}-0.06 \\
(0.53)\end{array}$ & $\begin{array}{l}-0.74 \\
(0.53)\end{array}$ \\
\hline Neglect $\left(\beta_{i j k l}\right)$ & $\begin{array}{l}-0.98 \\
(0.48)^{\star}\end{array}$ & $\begin{array}{l}-1.05 \\
(0.48)^{\star}\end{array}$ & $\begin{array}{l}-1.46 \\
(0.49)^{\star \star}\end{array}$ & $\begin{array}{l}-0.97 \\
(0.46)^{*}\end{array}$ & $\begin{array}{l}-1.08 \\
(0.48)^{\star}\end{array}$ & $\begin{array}{l}-1.49 \\
(0.47)^{\star \star}\end{array}$ \\
\hline $\begin{array}{l}\text { Other Maltreatment } \\
\left(\beta_{\mathrm{ijk} \mid}\right)\end{array}$ & $\begin{array}{l}-1.03 \\
(0.52)^{\star}\end{array}$ & $\begin{array}{l}-1.15 \\
(0.53)^{\star}\end{array}$ & $\begin{array}{l}-1.58 \\
(0.53)^{\star \star}\end{array}$ & $\begin{array}{l}-0.96 \\
(0.54)\end{array}$ & $\begin{array}{l}-1.11 \\
(0.55)^{\star}\end{array}$ & $\begin{array}{l}-1.50 \\
(0.54)^{\star \star}\end{array}$ \\
\hline $\begin{array}{l}\text { Exposure to } \\
\text { Violence }\left(\beta_{\mathrm{ijk} k}\right)\end{array}$ & $\begin{array}{l}0.14 \\
(0.02)^{\star * *}\end{array}$ & $\begin{array}{l}0.20 \\
(0.02)^{\star \star \star}\end{array}$ & $\begin{array}{l}0.19 \\
(0.02)^{\star \star *}\end{array}$ & $\begin{array}{l}0.14 \\
(0.02)^{\star \star \star}\end{array}$ & $\begin{array}{l}0.20 \\
(0.02)^{\star \star \star}\end{array}$ & $\begin{array}{l}0.19 \\
(0.02)^{\star * \star}\end{array}$ \\
\hline
\end{tabular}




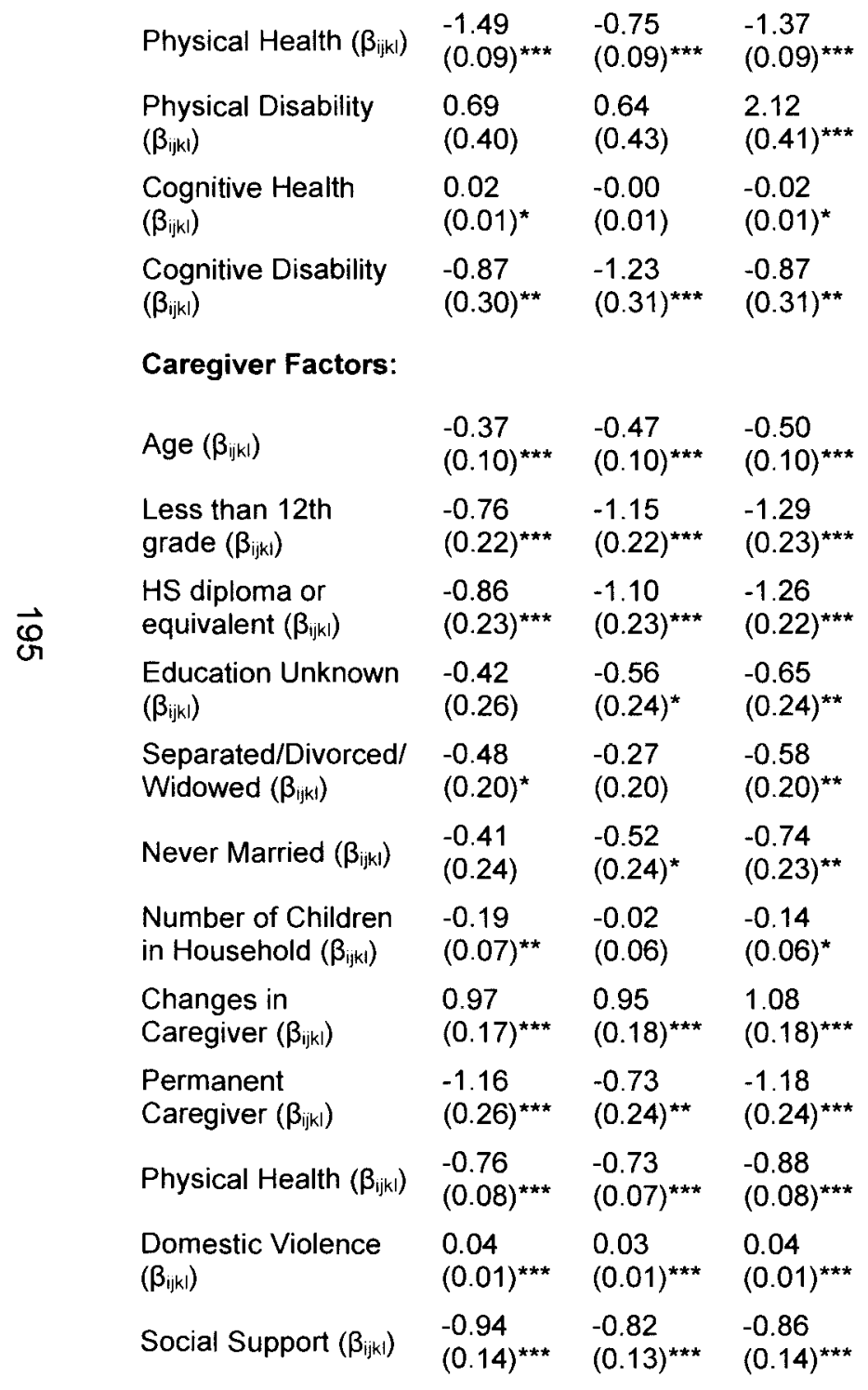

$\begin{array}{lll}-1.49 & -0.74 & -1.35 \\ (0.09)^{\star \star \star} & (0.09)^{\star \star \star} & (0.09)^{\star \star \star} \\ 0.71 & 0.64 & 2.13 \\ (0.39) & (0.41) & (0.40)^{\star \star \star} \\ 0.01 & 0.00 & -0.02 \\ (0.01)^{\star} & (0.01) & (0.01)^{\star} \\ -0.86 & -1.23 & -0.87 \\ (0.30)^{\star \star} & (0.31)^{\star \star \star} & (0.30)^{\star \star}\end{array}$

$\begin{array}{lll}-0.37 & -0.48 & -0.49 \\ (0.10)^{\star \star \star} & (0.10)^{\star \star \star} & (0.10)^{\star \star \star} \\ -0.76 & -1.15 & -1.28 \\ (0.23)^{\star \star} & (0.23)^{\star \star \star} & (0.23)^{\star \star \star} \\ -0.84 & -1.08 & -1.23 \\ (0.23)^{\star \star \star} & (0.23)^{\star \star \star} & (0.23)^{\star \star \star} \\ -0.42 & -0.60 & -0.68 \\ (0.26) & (0.26)^{\star} & (0.26)^{\star \star} \\ -0.48 & -0.28 & -0.59 \\ (0.20)^{\star} & (0.20) & (0.20)^{\star \star} \\ -0.43 & -0.53 & -0.75 \\ (0.25) & (0.24)^{\star} & (0.23)^{\star \star} \\ -0.20 & -0.02 & -0.15 \\ (0.06)^{\star \star} & (0.07) & (0.07)^{\star} \\ 0.96 & 0.92 & 1.06 \\ (0.16)^{\star \star \star} & (0.17)^{\star \star \star} & (0.17)^{\star \star \star} \\ -1.19 & -0.76 & -1.21 \\ (0.24)^{\star \star \star} & (0.21)^{\star \star \star} & (0.22)^{\star \star \star} \\ -0.76 & -0.72 & -0.88 \\ (0.08)^{\star \star \star} & (0.07)^{\star \star \star} & (0.08)^{\star \star \star} \\ 0.04 & 0.03 & 0.04 \\ (0.01)^{\star \star \star} & (0.01)^{\star \star \star} & (0.01)^{\star \star \star} \\ -0.94 & -0.81 & -0.86 \\ (0.14)^{\star \star \star} & (0.14)^{\star \star \star} & (0.14)^{\star \star \star}\end{array}$


$\begin{array}{llll}\text { Perception of } & 0.17 & 0.22 & 0.22 \\ \text { Neighborhood }\left(\beta_{\mathrm{j} k \mathrm{k}}\right) & (0.02)^{\star \star \star} & (0.02)^{\star \star \star} & (0.02)^{\star \star \star}\end{array}$

Environmental Factors:

$\begin{array}{llll}\text { Single Parents }\left(\beta_{\mathrm{ijkl}}\right) & -0.01 & 0.07 & 0.04 \\ & (0.07) & (0.09) & (0.09) \\ \text { Access to Social } & 2.41 & 2.72 & 2.89 \\ \text { Services }\left(\beta_{\mathrm{ijk}}\right) & (2.73) & (3.25) & (3.20) \\ \text { Access to Health } & -0.49 & -0.00 & -0.53 \\ \text { Services }\left(\beta_{\mathrm{ijkl}}\right) & (0.63) & (0.77) & (0.77) \\ & 0.02 & 0.03 & 0.03 \\ \text { White }\left(\beta_{\mathrm{ijk}}\right) & (0.01) & (0.01)^{\star \star} & (0.01)^{\star}\end{array}$

Interactions:

Single Parents $\times$ Not

Substantiated $\left(\beta_{\mathrm{ijk} k}\right)$

Single Parents $\mathrm{x}$

Physical

Maltreatment $\left(\beta_{i j k l}\right)$

Single Parents $\mathrm{x}$

Neglect $\left(\beta_{\mathrm{ijk} k \mathrm{k}}\right)$

Single Parents $x$

Other Maltreatment

$\left(\beta_{i j \mathrm{k} k}\right)$

White $x$ Access to

Health Services

$\left(\beta_{\mathrm{ijk} k}\right)$

Access to Health

Services $x$ Not

Substantiated $\left(\beta_{i j k l}\right)$

Access to Health

Services $x$ Physical

Maltreatment $\left(\beta_{i j k)}\right)$

Access to Health

Services $\times$ Neglect

$\left(\beta_{i \mathrm{ik} k}\right)$ $\begin{array}{lll}0.17 & 0.22 & 0.22\end{array}$

$(0.02)^{\star \star \star} \quad(0.02)^{\star \star \star} \quad(0.02)^{\star \star \star}$

$\begin{array}{lll}-0.17 & 0.34 & 0.10 \\ (0.15) & (0.16)^{\star} & (0.16) \\ 5.81 & 6.16 & 6.94 \\ (2.93)^{\star} & (3.27) & (3.27)^{\star} \\ 1.68 & 2.03 & 1.69 \\ (1.74) & (1.76) & (1.76) \\ 0.01 & 0.03 & 0.02 \\ (0.01) & (0.01)^{\star} & (0.01)^{\star} \\ & & \\ 0.05 & -0.36 & -0.16 \\ (0.15) & (0.16)^{\star} & (0.16) \\ & & \\ 0.08 & -0.38 & -0.17 \\ (0.19) & (0.20) & (0.20) \\ & & \\ 0.31 & -0.22 & 0.06 \\ (0.16) & (0.17) & (0.17) \\ & & \\ 0.26 & -0.34 & 0.00 \\ (0.19) & (0.20) & (0.19) \\ & & \\ 0.06 & 0.07 & 0.08 \\ (0.03)^{\star} & (0.03)^{\star} & (0.03)^{\star \star} \\ & & \\ -3.12 & -2.97 & -3.22 \\ (1.86) & (1.90) & (1.87) \\ & & \\ -3.05 & -5.10 & -4.27 \\ (2.16) & (2.25)^{\star} & (2.20) \\ & & \\ -2.00 & -0.93 & -1.44 \\ (1.92) & (1.91) & (1.90) \\ & & \\ & & \\ & & \\ & & \\ & & \\ & & \\ & & \\ & & \\ & & \\ & & \end{array}$




\begin{tabular}{|c|c|c|c|c|c|c|c|c|c|c|c|c|}
\hline $\begin{array}{l}\text { Access to Health } \\
\text { Services } \times \text { Other } \\
\text { Maltreatment }\left(\beta_{\text {ijkl }}\right)\end{array}$ & & & & & & & $\begin{array}{l}-3.45 \\
(2.10)\end{array}$ & $\begin{array}{l}-2.16 \\
(2.24)\end{array}$ & $\begin{array}{l}-3.53 \\
(2.14)\end{array}$ & & & \\
\hline \multicolumn{13}{|c|}{ Random effects } \\
\hline \multicolumn{13}{|c|}{ Level: PSU } \\
\hline & Int Cons & $\underline{\text { Ext }}$ & $\underline{\text { Tot }}$ & & & & Int Cons & $\underline{\text { Ext }}$ & $\underline{\text { Tot }}$ & & & \\
\hline Int Cons $\left(\sigma_{\mathrm{fl}}^{2}\right)$ & $\begin{array}{l}0.57 \\
(0.22)^{\star}\end{array}$ & & & & & & $\begin{array}{l}0.43 \\
(0.18)^{*}\end{array}$ & & & & & \\
\hline Ext Cons $\left(\sigma_{\mathrm{fl}}^{2}\right)$ & $\begin{array}{l}0.68 \\
(0.24)^{\star}\end{array}$ & $\begin{array}{l}1.16 \\
(0.34)^{\star \star \star}\end{array}$ & & & & & $\begin{array}{l}0.54 \\
(0.21)^{\star}\end{array}$ & $\begin{array}{l}1.05 \\
(0.33)^{\star \star}\end{array}$ & & & & \\
\hline Tot Cons $\left(\sigma_{f i}^{2}\right)$ & $\begin{array}{l}0.81 \\
(0.27)^{\star \star}\end{array}$ & $\begin{array}{l}1.13 \\
(0.33)^{\star \star \star}\end{array}$ & $\begin{array}{l}1.16 \\
(0.34)^{\star \star \star}\end{array}$ & & & & $\begin{array}{l}0.57 \\
(0.22)^{\star *}\end{array}$ & $\begin{array}{l}0.98 \\
(0.31)^{\star *}\end{array}$ & $\begin{array}{l}0.97 \\
(0.30)^{\star \star}\end{array}$ & & & \\
\hline \multicolumn{13}{|c|}{ Level: Child } \\
\hline & $\underline{\text { Int Cons }}$ & $\begin{array}{l}\text { Ext } \\
\text { Cons }\end{array}$ & $\underline{\text { Tot }}$ & Int Time & $\underline{\text { Ext }}$ & $\underline{\text { Tot }}$ & Int Cons & $\begin{array}{c}\text { Ext } \\
\text { Cons }\end{array}$ & Tot & Int Time & $\begin{array}{l}\text { Ext } \\
\text { Time }\end{array}$ & $\underline{\text { Tot }}$ \\
\hline Int Cons $\left(\sigma^{2}{ }_{u}\right)$ & $\begin{array}{l}52.95 \\
(2.39)^{\star \star \star}\end{array}$ & & & & & & $\begin{array}{l}52.95 \\
(2.30)^{\star \star \star}\end{array}$ & & & & & \\
\hline Ext Cons $\left(\sigma^{2}{ }_{u l}\right)$ & $\begin{array}{l}32.48 \\
(1.77)^{\star * \star}\end{array}$ & $\begin{array}{l}58.46 \\
(2.21)^{\star \star \star}\end{array}$ & & & & & $\begin{array}{l}32.29 \\
(1.92)^{\star \star \star}\end{array}$ & $\begin{array}{l}58.11 \\
(2.42)^{\star \star \star}\end{array}$ & & & & \\
\hline Tot Cons $\left(\sigma^{2}{ }_{v 1}\right)$ & $\begin{array}{l}45.08 \\
(2.02)^{\star \star \star}\end{array}$ & $\begin{array}{l}49.32 \\
(2.04)^{\star \star \star}\end{array}$ & $\begin{array}{l}53.71 \\
(2.14)^{\star \star \star}\end{array}$ & & & & $\begin{array}{l}44.94 \\
(2.05)^{\star \star \star}\end{array}$ & $\begin{array}{l}49.07 \\
(2.23)^{\star \star \star}\end{array}$ & $\begin{array}{l}53.51 \\
(2.28)^{\star \star \star}\end{array}$ & & & \\
\hline Int Time $\left(\sigma^{2}{ }_{u l}\right)$ & $\begin{array}{l}-7.98 \\
(0.94)^{\star \star \star}\end{array}$ & $\begin{array}{l}-2.72 \\
(0.72)^{\star \star \star}\end{array}$ & $\begin{array}{l}-4.96 \\
(0.78)^{\star * \star}\end{array}$ & $\begin{array}{l}4.23 \\
(0.51)^{\star * \star}\end{array}$ & & & $\begin{array}{l}-7.99 \\
(0.87)^{\star \star \star}\end{array}$ & $\begin{array}{l}-2.59 \\
(0.72)^{\star \star \star}\end{array}$ & $\begin{array}{l}-4.85 \\
(0.73)^{\star \star \star}\end{array}$ & $\begin{array}{l}4.31 \\
(0.46)^{\star \star \star}\end{array}$ & & \\
\hline Ext Time $\left(\sigma^{2}{ }_{w 1}\right)$ & $\begin{array}{l}-5.04 \\
(0.71)^{\star \star \star}\end{array}$ & $\begin{array}{l}-7.06 \\
(0.82)^{\star \star \star}\end{array}$ & $\begin{array}{l}-6.11 \\
(0.79)^{\star \star \star}\end{array}$ & $\begin{array}{l}2.25 \\
(0.35)^{\star \star \star}\end{array}$ & $\begin{array}{l}4.24 \\
(0.45)^{\star \star \star}\end{array}$ & & $\begin{array}{l}-5.01 \\
(0.75)^{\star \star \star}\end{array}$ & $\begin{array}{l}-6.92 \\
(0.85)^{\star \star \star}\end{array}$ & $\begin{array}{l}-6.02 \\
(0.83)^{\star \star \star}\end{array}$ & $\begin{array}{l}2.24 \\
(0.34)^{\star \star \star}\end{array}$ & $\begin{array}{l}4.16 \\
(0.46)^{\star \star \star}\end{array}$ & \\
\hline Tot Time $\left(\sigma^{2}{ }_{v i}\right)$ & $\begin{array}{l}-6.63 \\
(0.80)^{\star \star \star}\end{array}$ & $\begin{array}{l}-4.63 \\
(0.80)^{\star \star \star}\end{array}$ & $\begin{array}{l}-6.00 \\
(0.83)^{\star \star \star}\end{array}$ & $\begin{array}{l}3.42 \\
(0.42)^{\star \star \star}\end{array}$ & $\begin{array}{l}3.42 \\
(0.43)^{\star \star \star}\end{array}$ & $\begin{array}{l}4.00 \\
(0.47)^{\star \star \star}\end{array}$ & $\begin{array}{l}-6.57 \\
(0.76)^{\star \star \star}\end{array}$ & $\begin{array}{l}-4.49 \\
(0.79)^{\star \star \star}\end{array}$ & $\begin{array}{l}-5.87 \\
(0.82)^{\star \star \star}\end{array}$ & $\begin{array}{l}3.42 \\
(0.38)^{\star \star \star}\end{array}$ & $\begin{array}{l}3.37 \\
(0.43)^{\star \star \star}\end{array}$ & $\begin{array}{l}3.95 \\
(0.45)^{\star \star \star}\end{array}$ \\
\hline \multicolumn{13}{|c|}{ Level: Measurement Occasion } \\
\hline & $\underline{\text { Int Cons }}$ & $\underline{\text { Ext }}$ & $\frac{\text { Tot }}{\text { Cons }}$ & & & & $\underline{\text { Int Cons }}$ & $\begin{array}{l}\text { Ext } \\
\text { Cons }\end{array}$ & $\underline{\text { Tot }}$ & & & \\
\hline Int Cons $\left(\sigma^{2}{ }_{u}\right)$ & $\begin{array}{l}53.88 \\
(1.01)^{\star \star \star}\end{array}$ & & & & & & $\begin{array}{l}53.71 \\
(0.92)^{\star \star \star}\end{array}$ & & & & & \\
\hline
\end{tabular}




\begin{tabular}{lllllll} 
Ext Cons $\left(\sigma^{2}{ }_{u}\right)$ & 27.00 & 45.46 & & \multicolumn{2}{l}{26.96} & 45.47 \\
& $(0.70)^{\star \star \star}$ & $(0.83)^{\star \star \star}$ & & $(0.69)^{\star \star \star}$ & $(0.84)^{\star \star \star}$ & \\
& 40.05 & 39.93 & 47.15 & 39.99 & 39.92 & 47.14 \\
Tot Cons $\left(\sigma^{2}{ }_{u l}\right)$ & $(0.83)^{\star \star \star}$ & $(0.80)^{\star \star \star}$ & $(0.88)^{\star \star \star}$ & $(0.76)^{\star \star \star}$ & $(0.79)^{\star \star \star}$ & $(0.83)^{\star \star \star}$
\end{tabular}

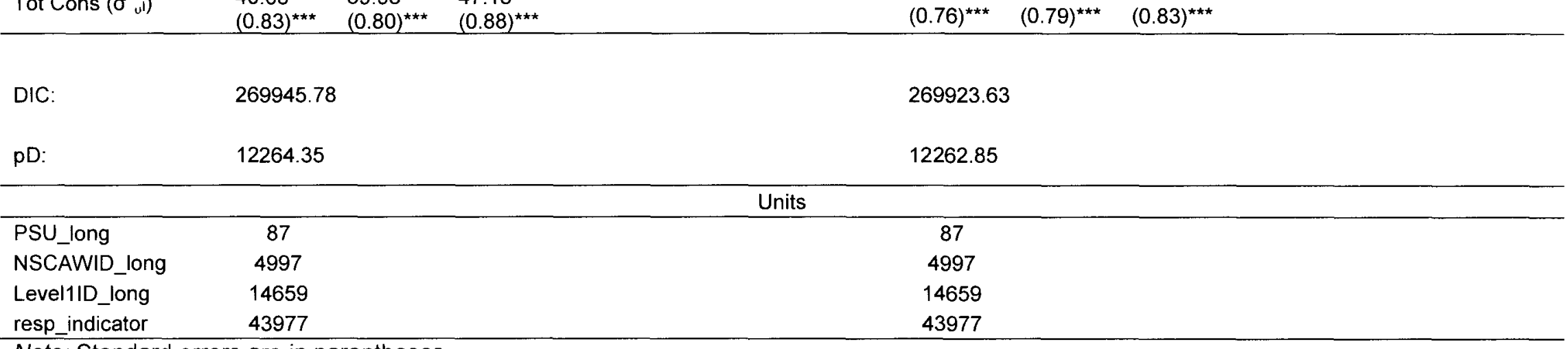

resp_indicator

Note: Standard errors are in parentheses

$\vec{\infty} \quad$ DIC: Diagnostic Information Criterion
pD: estimated degrees of freedom

${ }^{\star \star *} p \leq 0.001,{ }^{* *} p \leq 0.01 ;{ }^{*} p \leq 0.05$ 


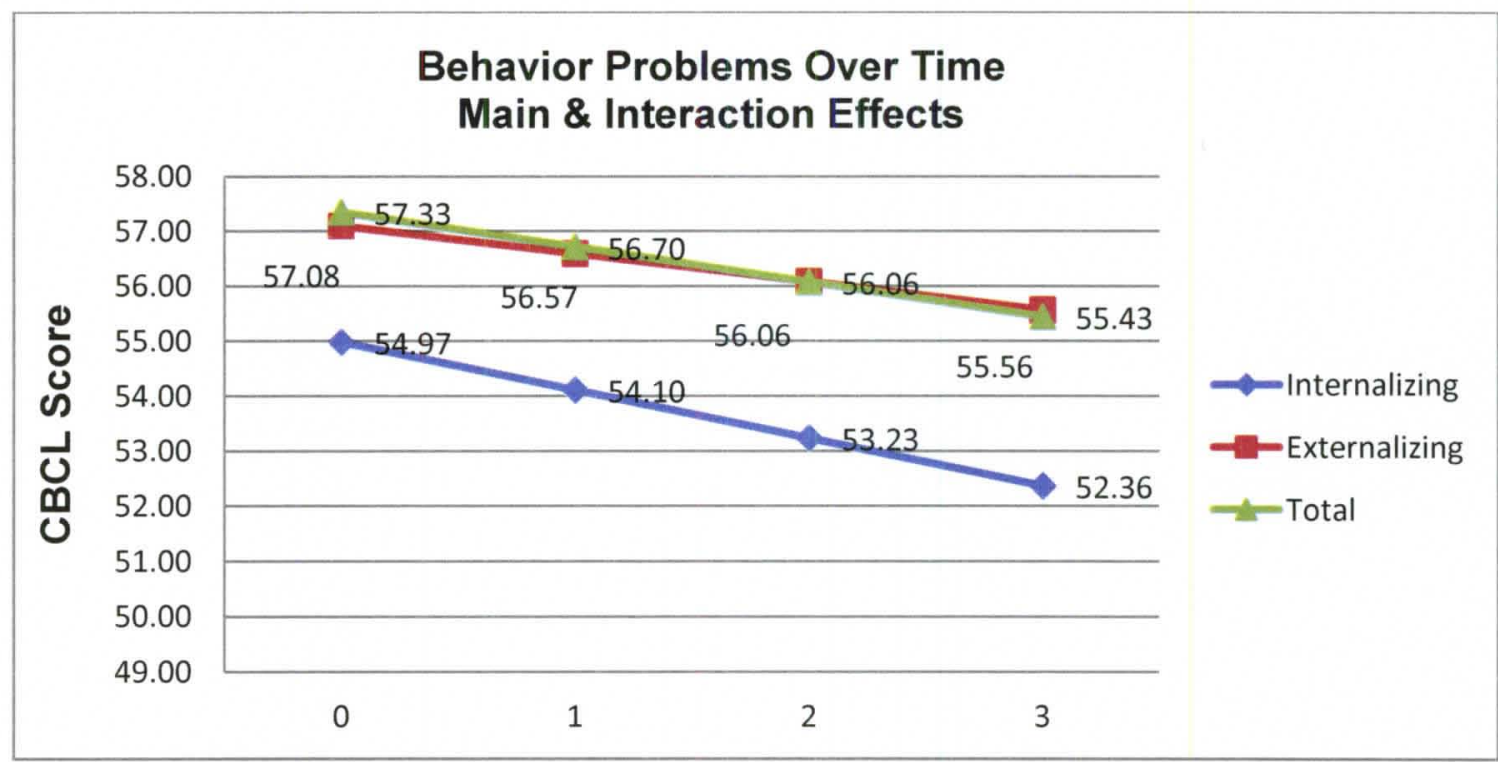

Figure 16. Child behavior problems over time with all main and interaction effects.

Tables 22 through 27 displayed the results for six (6) models: (a) unconditional (Model A); (b) unconditional growth (Model B); (c) conditional growth with child main effects (Model C); (d) conditional growth with child and caregiver main effects (Model D); (e) conditional growth with child, caregiver, and environment main effects (Model E); and (f) conditional growth model with child, caregiver, and environment main effects and interaction effects (Model F).

The next section gives a more detailed description of all statistically significant predictors shown in Table 27 in Model F. Please note that for the discussion below, it is assumed that all other predictors are held constant at the group mean or at the reference category. Information is presented in four (4) subsections: (a) child factors; (b) caregiver factors; (c) environmental factors; and (d) interaction effects.

Child factors. Child factors were divided into four (4) categories: (a) demographics; (b) development; (c) maltreatment; and (d) health. 
Demographics. Child demographic predictors that were statistically significant predictors of child behavioral problems included child gender and race/ethnicity. Females demonstrated statistically significantly lower internalizing $\left(\beta_{6 \mathrm{jkl}}=-1.55, \mathrm{p}<.001\right)$, externalizing $\left(\beta_{8 \mathrm{jkl}}=-1.43, \mathrm{p}<.001\right)$, and total $\left(\beta_{7 \mathrm{jkl}}=\right.$ $-0.63, p<.01$ ) behavior problems than males (reference category). Therefore, females were scored consistently lower than males with respect to behavior problems over time, with the biggest difference seen in internalizing behavior problems. Figure 17 below shows the main effect of gender on child behavioral problems over time holding everything else constant at the grand mean or reference category.

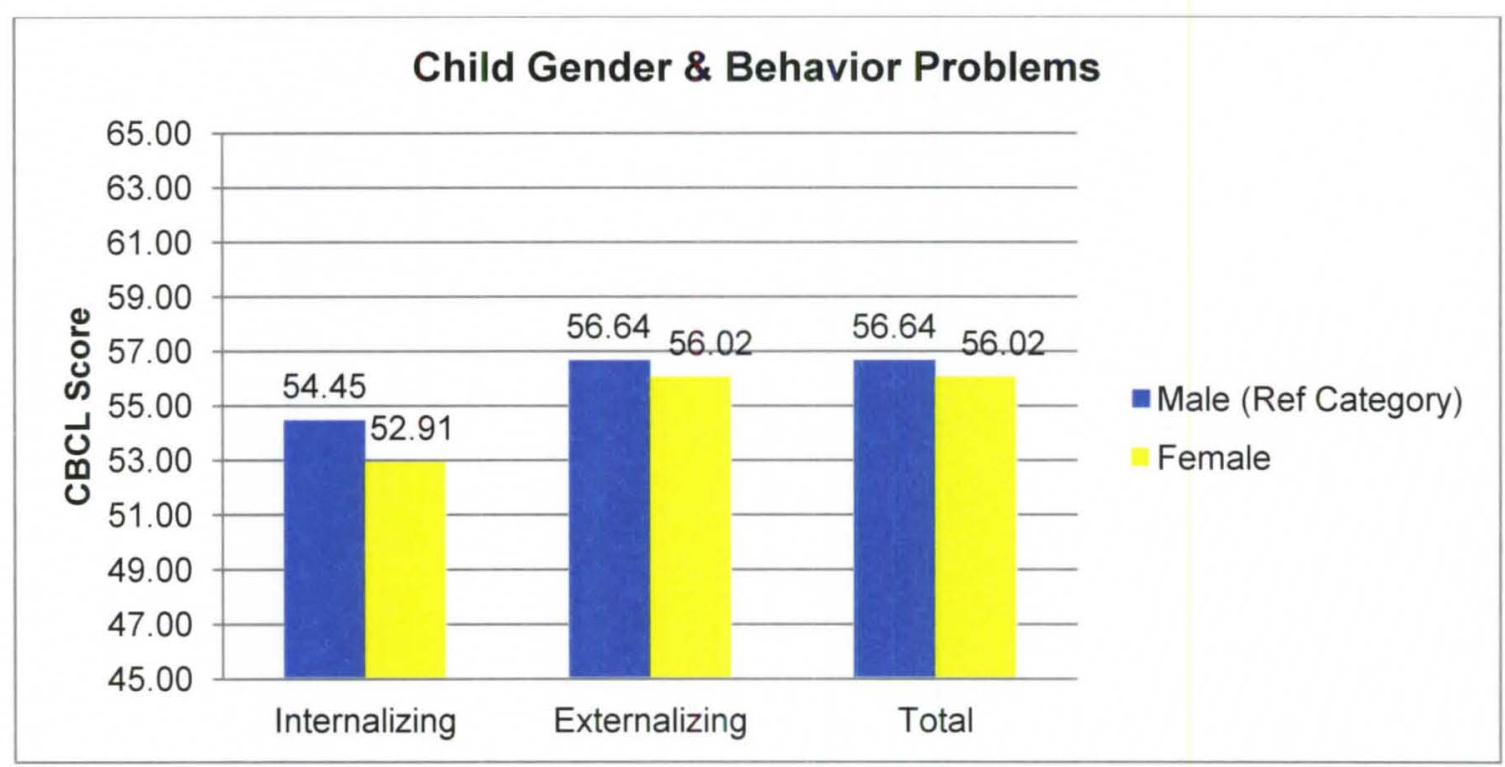

Figure 17. Child gender main effect on child behavior problems.

With regard to race, Caucasian children were not significantly different from the Hispanic/Native Indian/Alaskan/Other category in terms of internalizing behavior problems and African American children were not significantly different from the Hispanic/Native Indian/Alaskan/Other category (reference category) in 
terms of total behavior problems. However Caucasian children did score significantly higher than the Hispanic/Native Indian/Alaskan/Other category (reference category) in terms of externalizing $\left(\beta_{14 \mathrm{jkl}}=1.55, \mathrm{p}<.001\right)$ and total $\left(\beta_{12 \mathrm{jkl}}=1.24, \mathrm{p}<.001\right)$ behavior problems. African American children scored significantly lower than the Hispanic/Native Indian/Alaskan/Other group (reference category) with regard to internalizing $\left(\beta_{9 \mathrm{jkl}}=-0.89, p<.01\right)$ behavior problems, but higher with regard to externalizing behavior problems $\left(\beta_{13 \mathrm{jk} \mid}=0.70\right.$, $p<.05)$. Figure 18 shows the main effect of race/ethnicity on child behavioral problems over time, holding everything else constant at the grand mean or reference category.

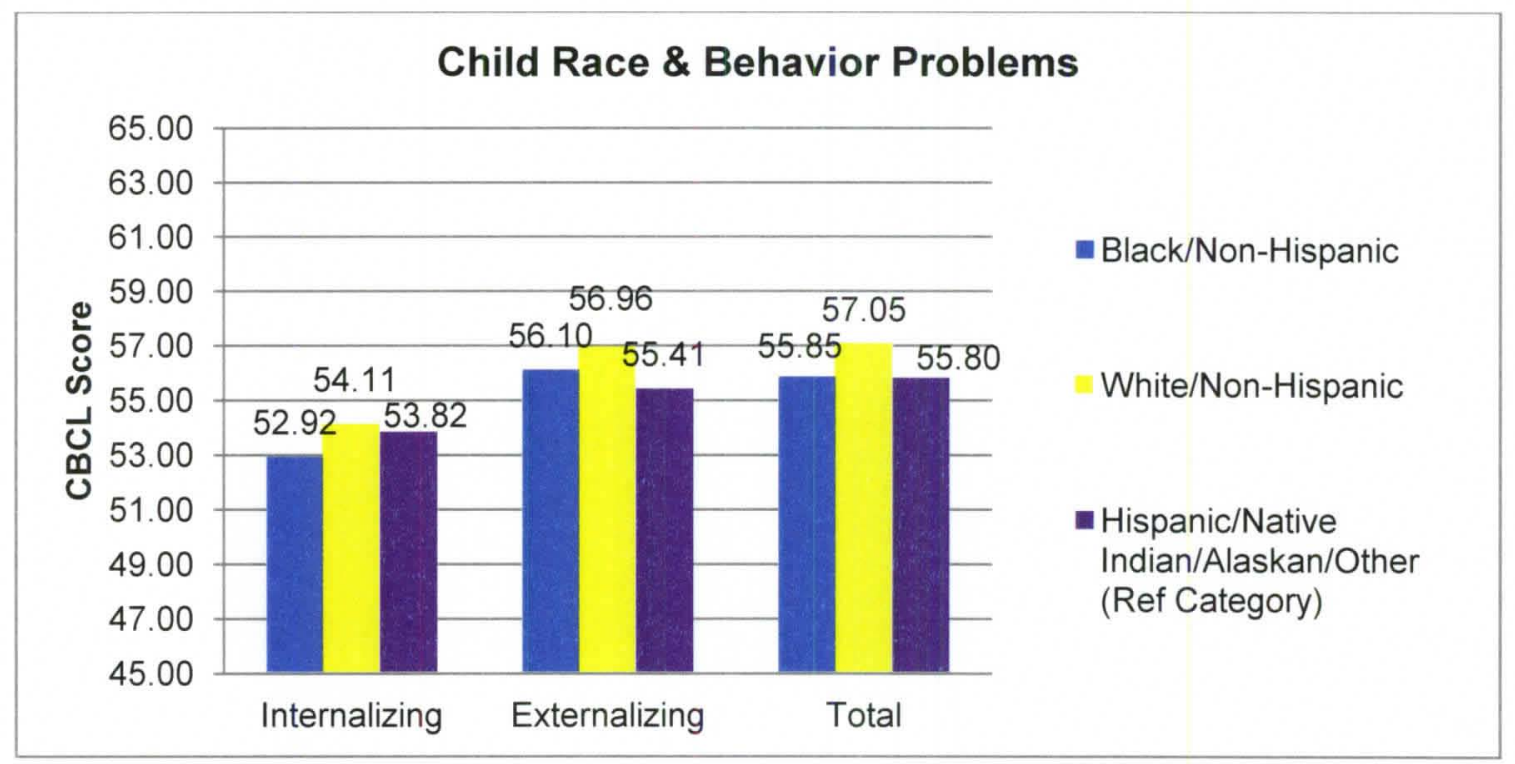

Figure 18. Child race/ethnicity main effect on child behavior problems.

Development. Child development statistically significant predictors included child age and social skills. Child age was significant for internalizing $\left(\beta_{15 \mathrm{jkl}}=0.20, p<.001\right)$, externalizing $\left(\beta_{17 \mathrm{jkl}}=0.48, p<.001\right)$, and total behavior problems $\left(\beta_{16 \mathrm{jk} l}=0.42, p<.001\right)$. This indicates that caregivers reported more 
internalizing, externalizing, and total behavior problems for older children than they did for younger children. Figure 19 shows the predicted child age main effect on child behavioral problems over time. The graph shows that children in the $90^{\text {th }}$ percentile $($ age $=15)$ are approaching "borderline" levels of externalizing and total behavior problems as reported by the caregiver.

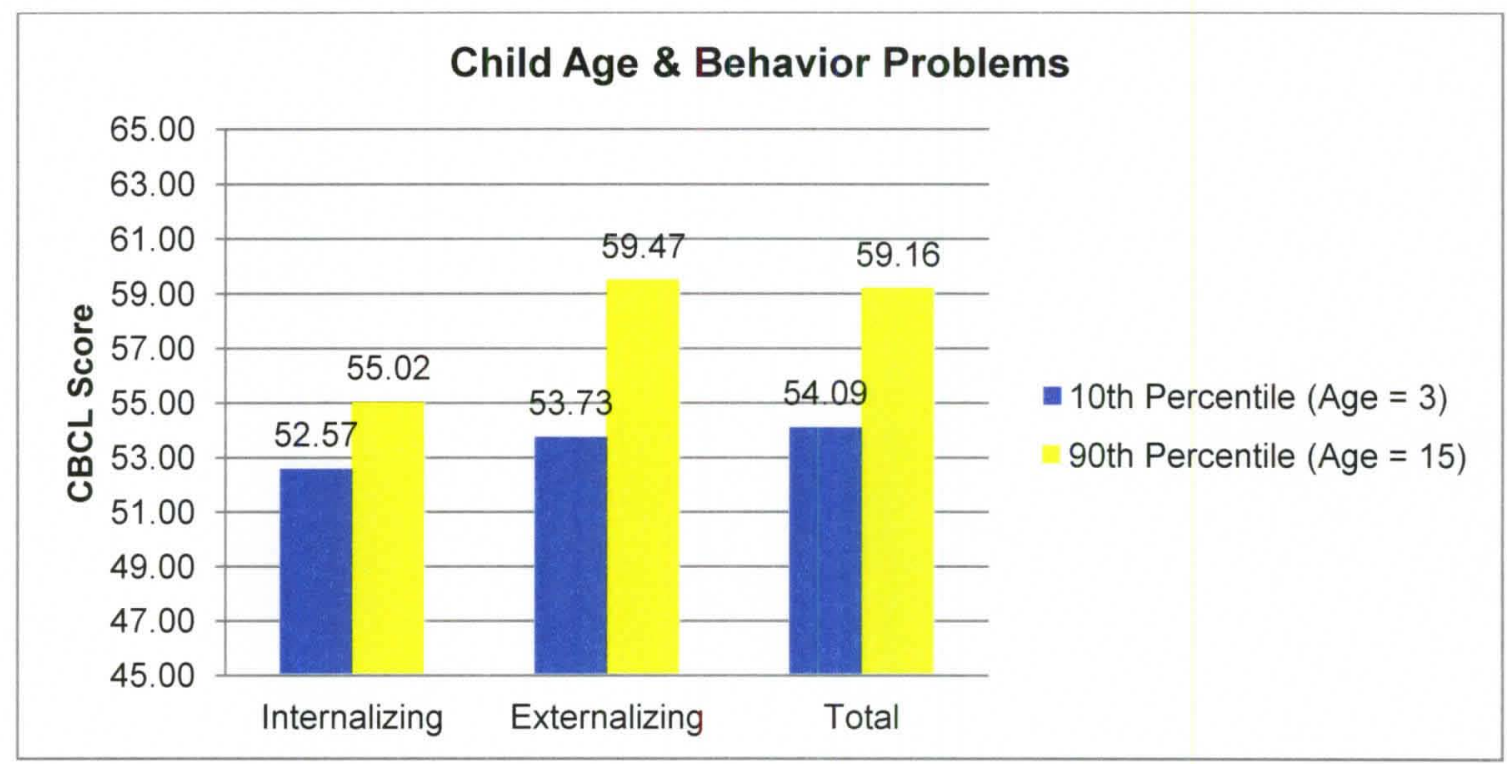

Figure 19. Child age main effect on child behavior problems.

Social skills also proved to be an important predictor of child internalizing $\left(\beta_{18 \mathrm{jkl}}=-0.22, p<.001\right)$, externalizing $\left(\beta_{20 \mathrm{jkl}}=-0.28, p<.001\right)$, and total behavior problems $\left(\beta_{19 \mathrm{jkl}}=-0.28, p<.001\right)$. The beta coefficients indicate that children with a higher level of social skills, on average, display fewer behavioral problems of all types as reported by the caregiver. Figure 20 displays the predicted child social skills main effect on child behavior problems over time. It is interesting to note that children in the $10^{\text {th }}$ percentile (social skills score $=70$ ) group, indicating a lower level of social skills, are approaching the "borderline" category with 
regard to internalizing behavior problems and are approaching the "clinical" category with regard to externalizing and total behavior problems.

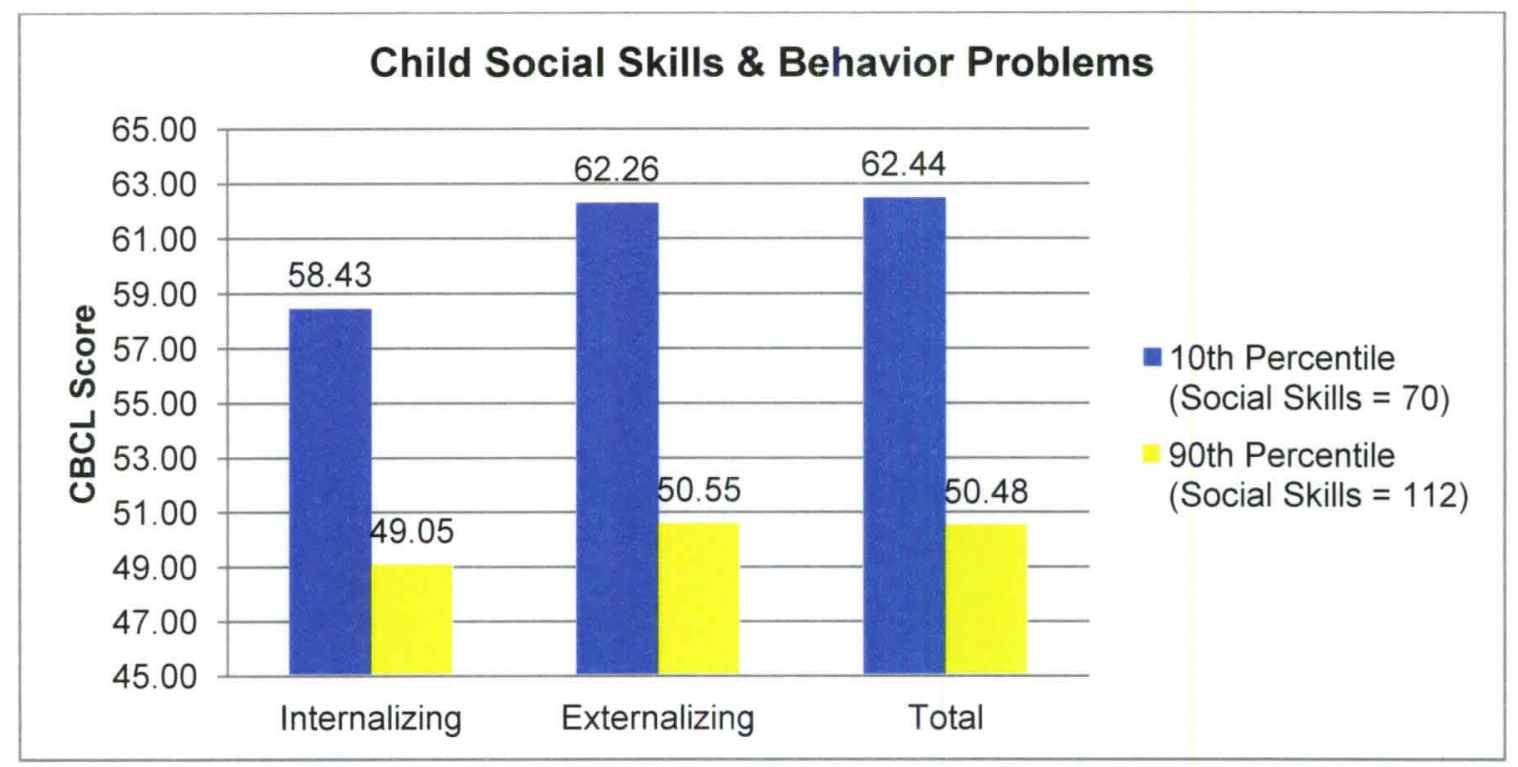

Figure 20. Child social skills main effect on child behavior problems.

Maltreatment. Statistically significant predictors under the child maltreatment construct included maltreatment type and exposure to violence. With regard to the type of maltreatment experienced by children included in this sample, children who were physically maltreated were not significantly different from children exposed to sexual maltreatment (reference category) across all behavior problems. Children with unsubstantiated cases of maltreatment scored significantly lower on the internalizing $\left(\beta_{21 \mathrm{jk} l}=-1.00, \mathrm{p}<.05\right)$ and total $\left(\beta_{29 \mathrm{jkl}}=-\right.$ $1.22, p<.01)$ behavior problems scale compared to children in the sexually maltreated group (reference category). Children who were neglected scored significantly lower with respect to internalizing $\left(\beta_{24 \mathrm{jkl}}=-0.97, \mathrm{p}<.05\right)$, externalizing $\left(\beta_{32 \mathrm{j} k \mathrm{l}}=-1.08, \mathrm{p}<.05\right)$, and total $\left(\beta_{28 \mathrm{j} \mathrm{kl}}=-1.49, \mathrm{p}<.01\right)$ behavior problems than children who had been sexually maltreated (reference category). 
Children with other types of maltreatment (e.g., abandonment, emotional, etc., see table 8 for a full listing of other types of maltreatment) scored significantly lower on the externalizing $\left(\beta_{31 \mathrm{jkl}}=-1.11, \mathrm{p}<.05\right)$ and total $\left(\beta_{27 \mathrm{jkl}}=-1.50, \mathrm{p}<.01\right)$ behavior problems scale than children in the sexually maltreated group (reference category). Figure 21 below show the predicted child maltreatment main effect on child behavior problems. The graph shows that sexual maltreatment resulted in the highest predicted scores on the CBCL Total Behavior Problems scale.

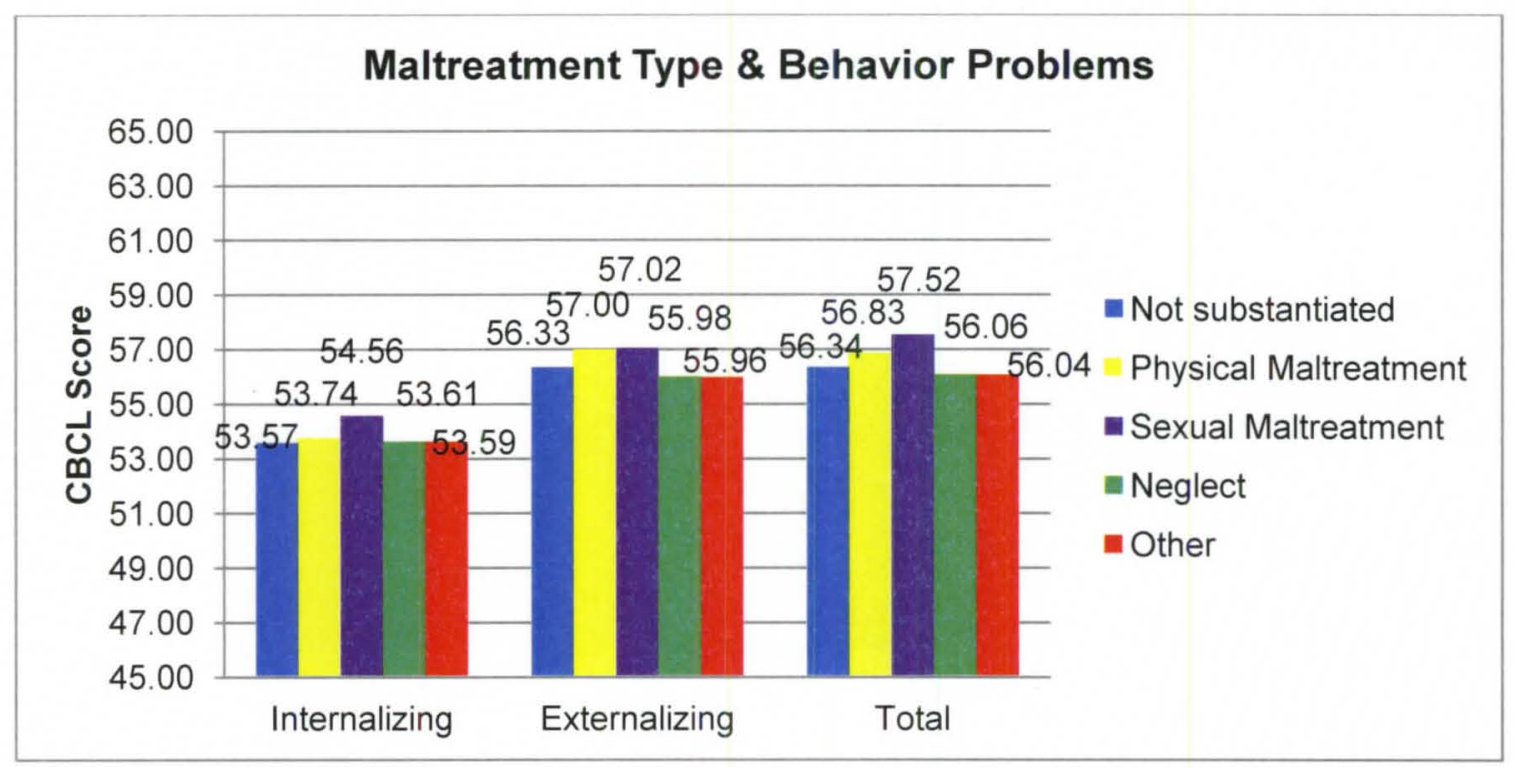

Figure 21. Child maltreatment main effect on child behavior problems.

Child exposure to violence was a statistically significant predictor of internalizing $\left(\beta_{33 \mathrm{jk} l}=0.14, p<.001\right)$, externalizing $\left(\beta_{35 \mathrm{jkl}}=0.20, p<.001\right)$, and total $\left(\beta_{34 \mathrm{jkl}}=019, p<.001\right)$ behavior problems. The beta coefficients suggest that more exposure to violence leads to higher behavior problems across the spectrum. Figure 22 visually depicts the predicted exposure to violence main effect for the $10^{\text {th }}$ percentile (exposure to violence score $=1$ ) and $90^{\text {th }}$ percentile 
(exposure to violence score $=11$ ) on child behavior problems over time. The graph clearly shows that children with more exposure to violence are consistently demonstrating more behavior problems. Further, the graph also shows that children in the $90^{\text {th }}$ percentile (exposure to violence score $=11$ ), indicating greater exposure to violence) are approaching the "borderline" range with respect to both externalizing and total behavior problems.

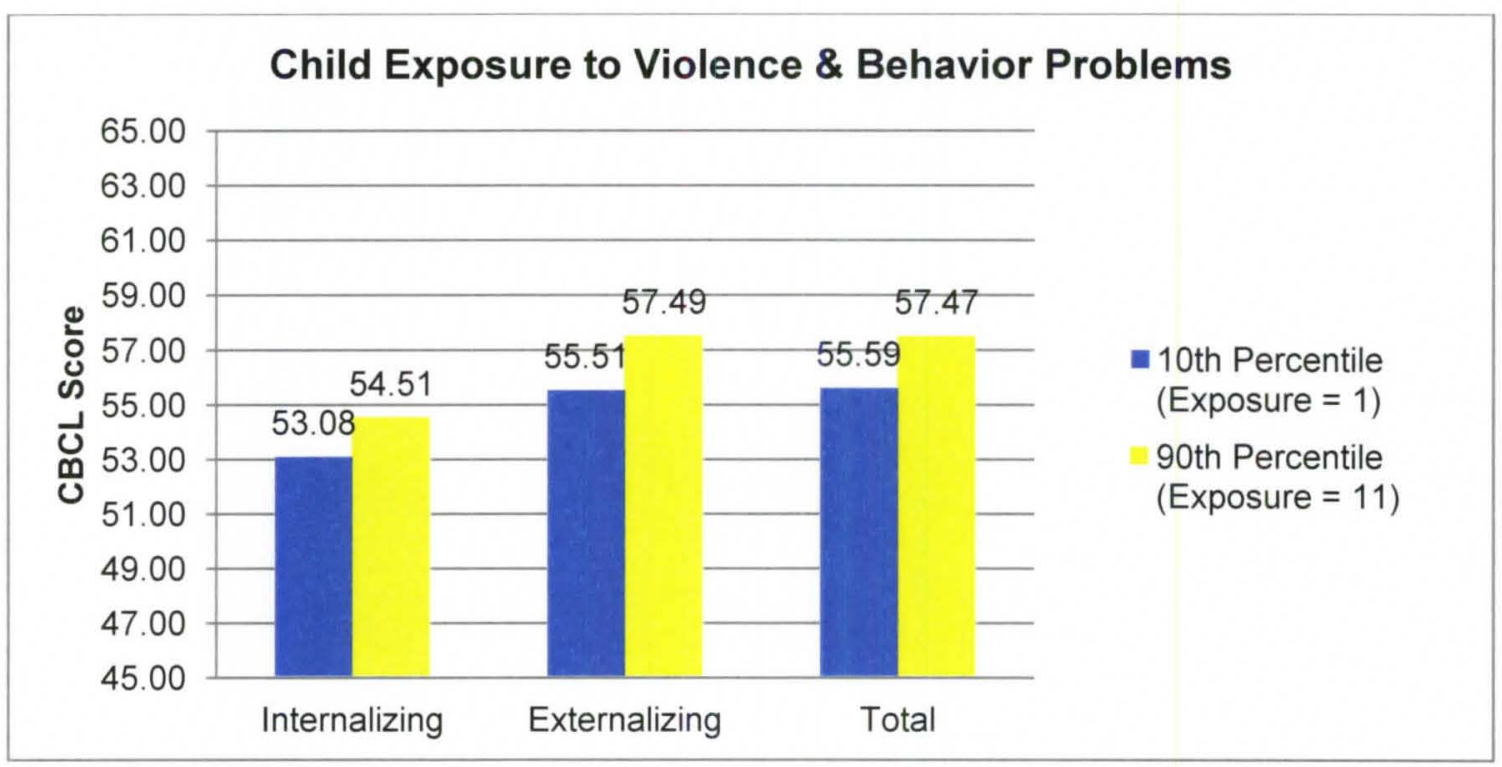

Figure 22. Child exposure to violence main effect on child behavior problems.

Health. Child physical disability, physical health, cognitive disability, and cognitive health scores were all statistically significant predictors of child behavioral problems related to health. Children with physical disabilities reported significantly higher levels of total behavior problems $\left(\beta_{37 \mathrm{jkl}}=2.13, p<.001\right)$ than children with no physical disabilities (reference category), but having a physical disability was not predictive of internalizing or externalizing behavior problems. Figure 23 depicts the estimated main effects of having a physical disability on child total behavior problems over time. The graph below shows that children 
with physical disabilities are reported as having total behavior problems that are approaching the "borderline" range.

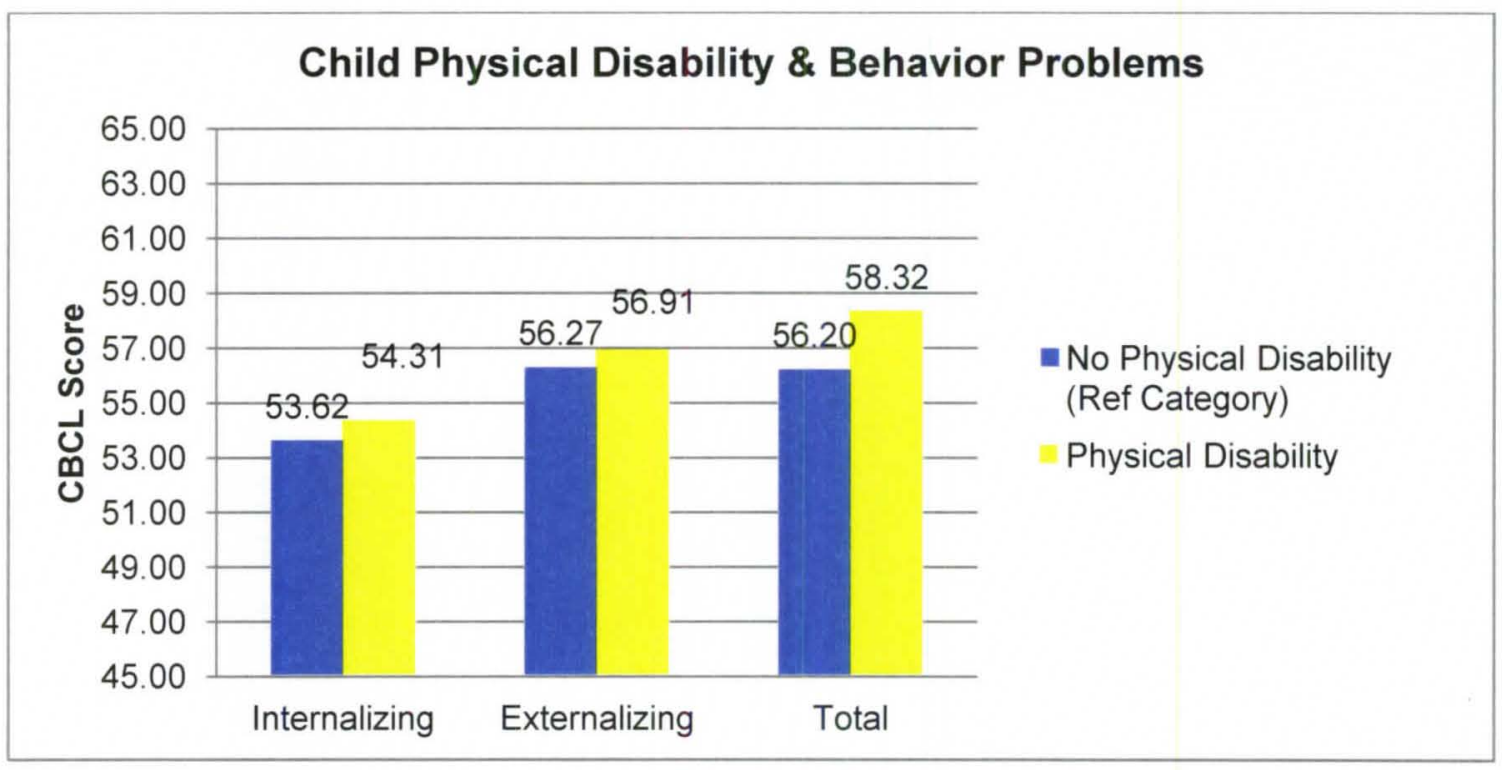

Figure 23. Child physical disability main effect on child behavior problems.

Child physical health was a statistically significant predictor of internalizing $\left(\beta_{39 \mathrm{j} k \mathrm{l}}=-1.49, \mathrm{p}<.001\right)$, externalizing $\left(\beta_{41 \mathrm{jkl}}=-0.74, \mathrm{p}<.001\right)$, and total $\left(\beta_{40 \mathrm{jkl}}=\right.$ $-1.35, p<.001)$ behavior problems over time. Results indicate that reported better levels of health are indicative of lower levels of behavioral problems.

Figure 24 visually depicts predicted child physical health main effects for the $10^{\text {th }}$ percentile $($ physical health $=3=$ good $)$ and the $90^{\text {th }}$ percentile $($ physical health $=$ 5 = excellent) on child behavior problems. 


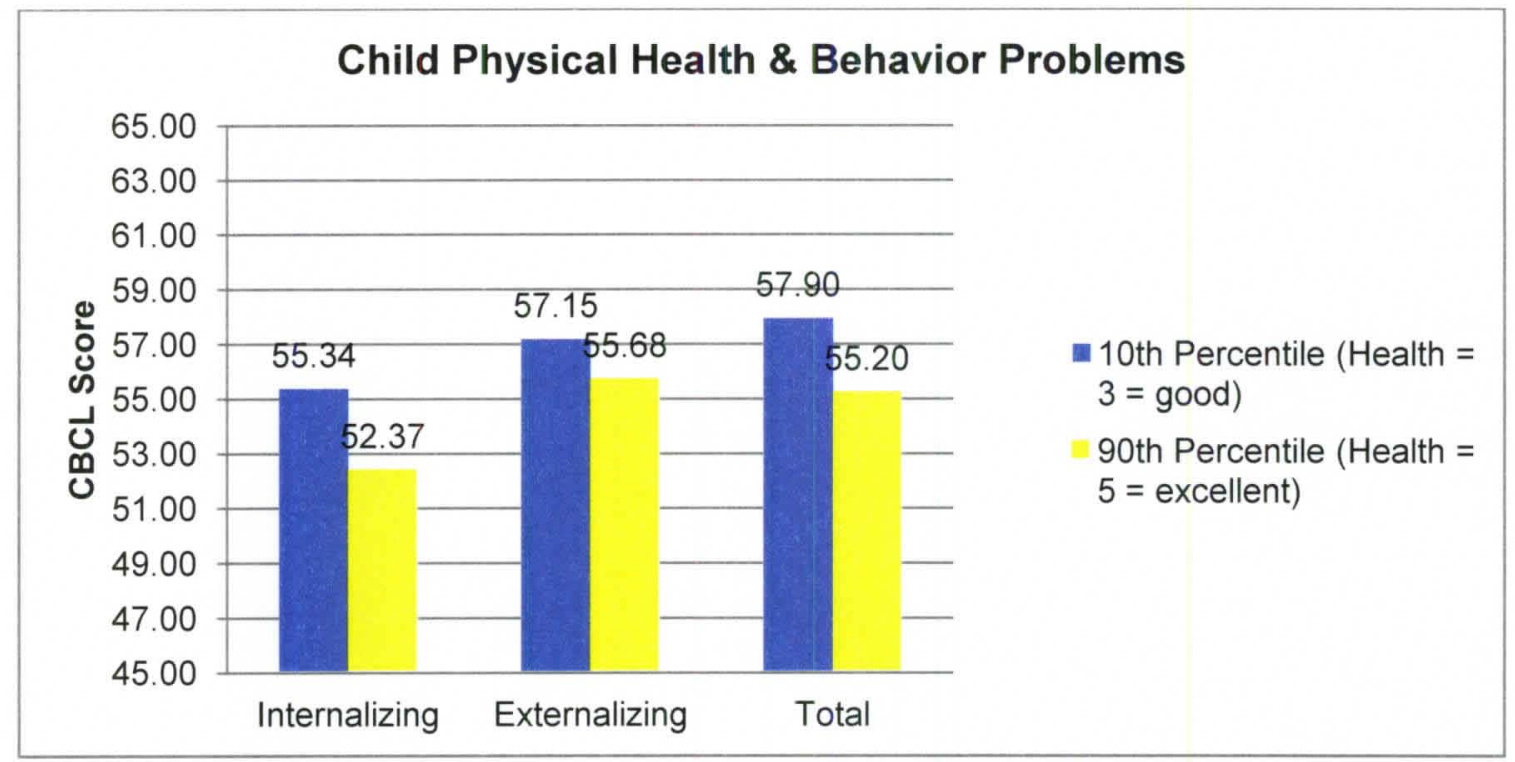

Figure 24. Child physical health main effect on child behavior problems.

Child cognitive disability was a statistically significant predictor of child internalizing $\left(\beta_{42 \mathrm{jkl}}=-0.86, p<.01\right)$, externalizing $\left(\beta_{44 \mathrm{jk} l}=-1.23, p<.001\right)$, and total $\left(\beta_{43 j \mathrm{kl}}=-0.87, \mathrm{p}<.01\right)$ behavior problems over time. This indicates that children with cognitive disabilities have lower behavioral problems as reported by their caregiver than children with no cognitive disabilities (reference category). Figure 25 shows the predicted main effect of cognitive disability on behavioral problems over time. The graph below shows that children with no cognitive disability consistently scored lower with respect to behavioral problems compared to children with a cognitive disability. 


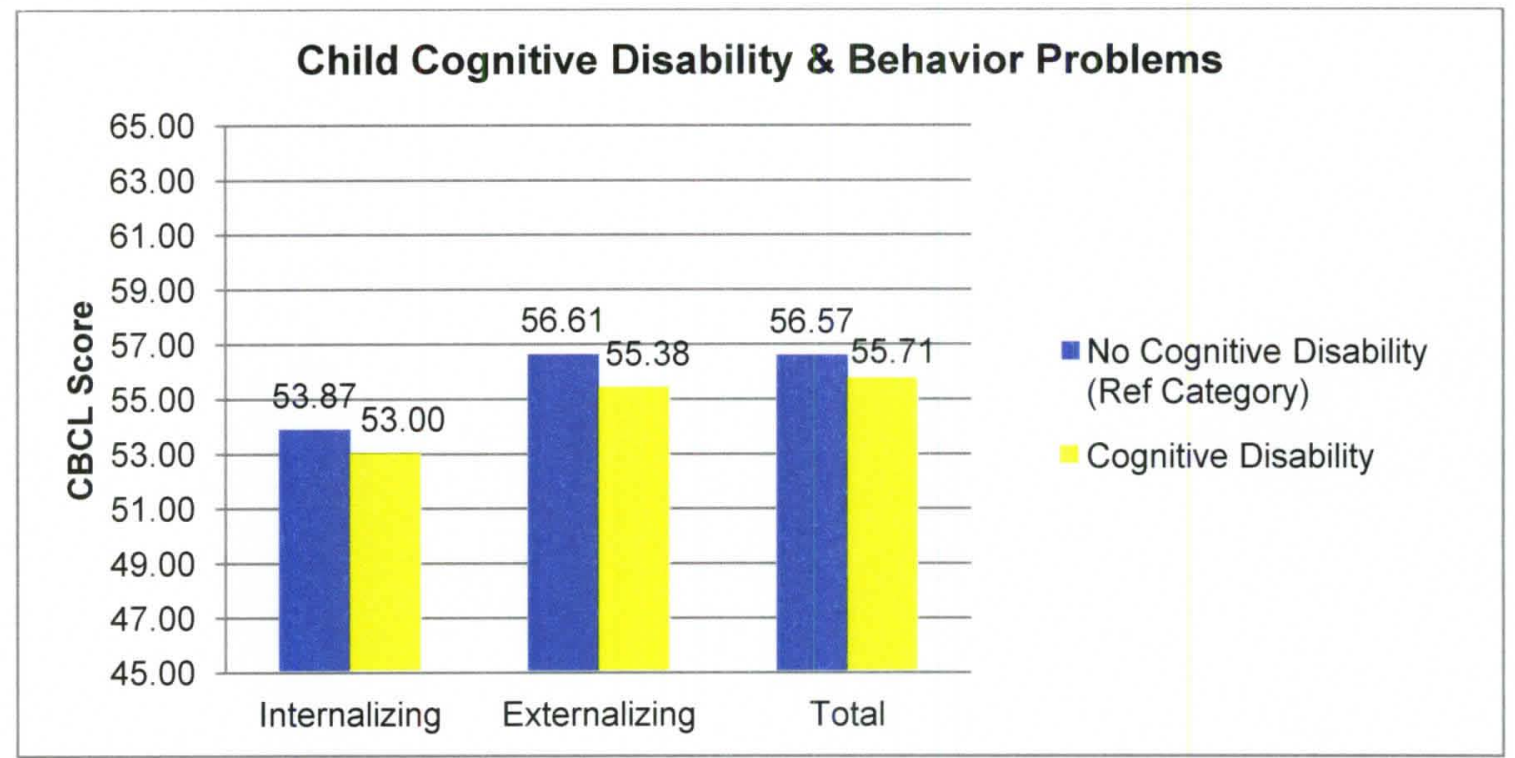

Figure 25. Child cognitive disability main effect on child behavior problems.

Child cognitive health, measured using the K-BIT, was also a significant predictor of internalizing $\left(\beta_{45 \mathrm{jk} l}=0.01, p<.05\right)$ and total $\left(\beta_{46 \mathrm{jk} l}=-0.02, p<.05\right)$ behavior problems but not of externalizing behavior problems. Higher scores on the K-BIT resulted in higher levels of internalizing behavior problems but lower levels of total behavior problems. Figure 26 displays child K-BIT main effects on child behavior problems over time for the $10^{\text {th }}$ percentile $(\mathrm{K}-\mathrm{BIT}=75)$ and $90^{\text {th }}$ percentile $(\mathrm{K}-\mathrm{BIT}=110)$. Based on the figure below, children in the $90^{\text {th }}$ percentile (higher cognitive health) scored higher with respect to internalizing behavior problems while children in the $10^{\text {th }}$ percentile (lower cognitive health) scored higher with respect to total behavior problems. 


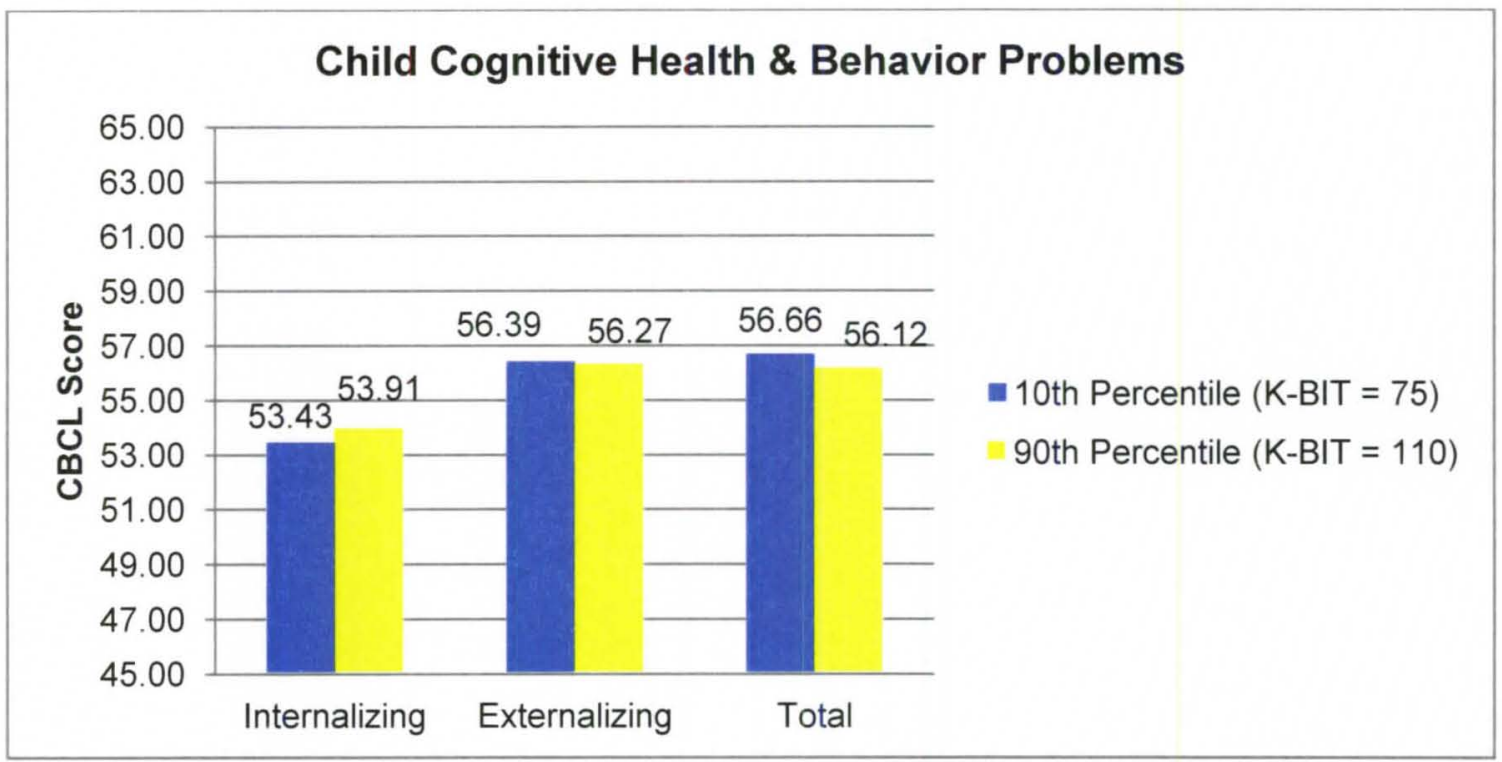

Figure 26. Child cognitive health scores main effect on child behavior problems.

Caregiver factors. Caregiver factors were divided into three (3) sections:

(a) demographics; (b) family structure; and (c) other factors.

Demographics. Caregiver age and education were statistically significant predictors of child behavioral problems. Caregiver age was a statistically significant predictor of child internalizing $\left(\beta_{48 j \mathrm{kl}}=-0.37, p<.001\right)$, externalizing $\left(\beta_{50 \mathrm{jkl}}=-0.48, p<.001\right)$, and total $\left(\beta_{49 \mathrm{jk} l}=-0.49, \mathrm{p}<.001\right)$ behavioral problems. Results indicate that as caregivers become older, reported behavior problems of all types decrease. Figure 27 shows caregiver age main effects on child behavioral problems over time. The graph below clearly shows that caregivers with an age range in the $10^{\text {th }}$ percentile (younger than 26) consistently reported higher levels of behavior problems for the children in their care, as compared to caregivers with the age range in the $90^{\text {th }}$ percentile (between 48 and 55 years of age). 


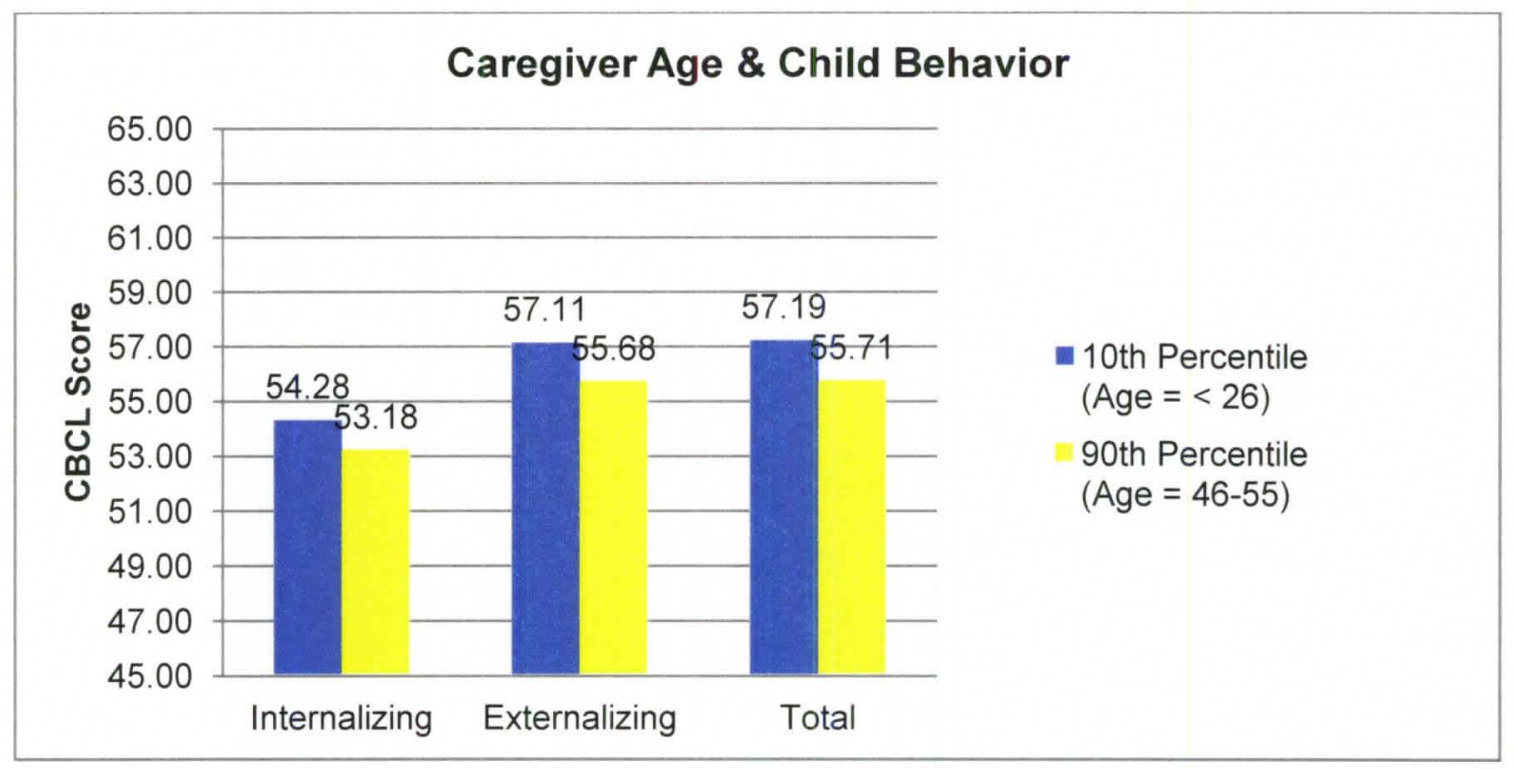

Figure 27. Caregiver age main effect on child behavior problems.

Caregiver level of education was also an important predictor of behavioral problems. Caregivers with less than a $12^{\text {th }}$ grade education reported less internalizing $\left(\beta_{51 \mathrm{jk} \mathrm{l}}=-0.76, \mathrm{p}<.01\right)$, externalizing $\left(\beta_{57 \mathrm{jk} \mathrm{l}}=-1.15, \mathrm{p}<.001\right)$, and total $\left(\beta_{54 \mathrm{jkl}}=-1.28, p<.001\right)$ behavioral problems than caregivers with some college (reference category). Caregivers with a high school diploma or equivalent reported less internalizing $\left(\beta_{52 \mathrm{jk} l}=-0.84, \mathrm{p}<.001\right)$, externalizing $\left(\beta_{58 \mathrm{j} k \mathrm{l}}\right.$ $=-1.08, \mathrm{p}<.001)$, and total $\left(\beta_{55 \mathrm{jk} \mathrm{l}}=-1.23, \mathrm{p}<.001\right)$ behavioral problems than caregivers with some college (reference category). Caregivers who were in the "don't know education level" group reported significantly lower externalizing ( $\beta_{59 \mathrm{jk} /}$ $=-0.60, p<.05)$ and total $\left(\beta_{56 \mathrm{jk} l}=-0.68, \mathrm{p}<.01\right)$ behavioral problems than those caregivers who reported having some college (reference category); however, there was no difference between those caregivers who comprised the "don't know" group from those reporting some college (reference category) with regard 
to internalizing behavior problems. Figure 28 below displays caregiver education main effects on child behavior problems over time.

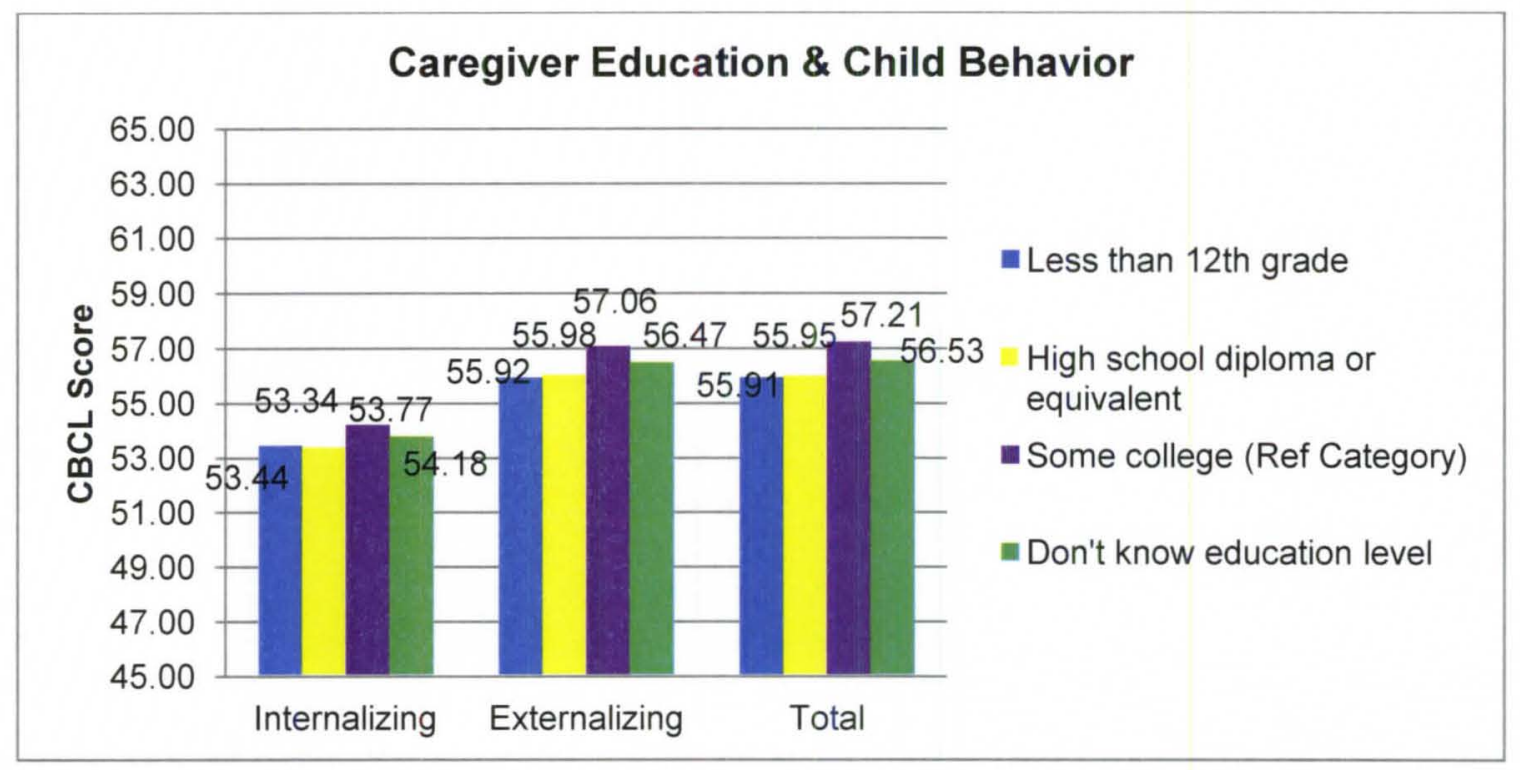

Figure 28. Caregiver education main effect on child behavior problems.

Family structure. There were several statistically significant family structure predictors of child behavioral problems including marital status, number of children in the household, number of changes in caregiver, and being a permanent caregiver. Caregiver marital status was a statistically significant predictor of child behavior problems. More specifically, caregivers who comprised the separated/divorced/widowed group reported significantly less internalizing $\left(\beta_{60 \mathrm{jkl}}=-0.48, \mathrm{p}<.05\right)$ and total $\left(\beta_{62 \mathrm{jkl}}=-0.59, \mathrm{p}<.01\right)$ behavior problems for the children in their care than the caregivers in the married group (reference category). Additionally, caregivers in the never married group reported significantly lower externalizing $\left(\beta_{65 \mathrm{j} k \mathrm{l}}=-0.53, \mathrm{p}<.05\right)$ and total $\left(\beta_{63 \mathrm{jkl}}=-\right.$ $0.75, p<.01)$ behavior problems scores on the CBCL for the children in their 
care than the married group (reference category). Figure 29 shows the caregiver marital status main effect on child behavior problems over time.

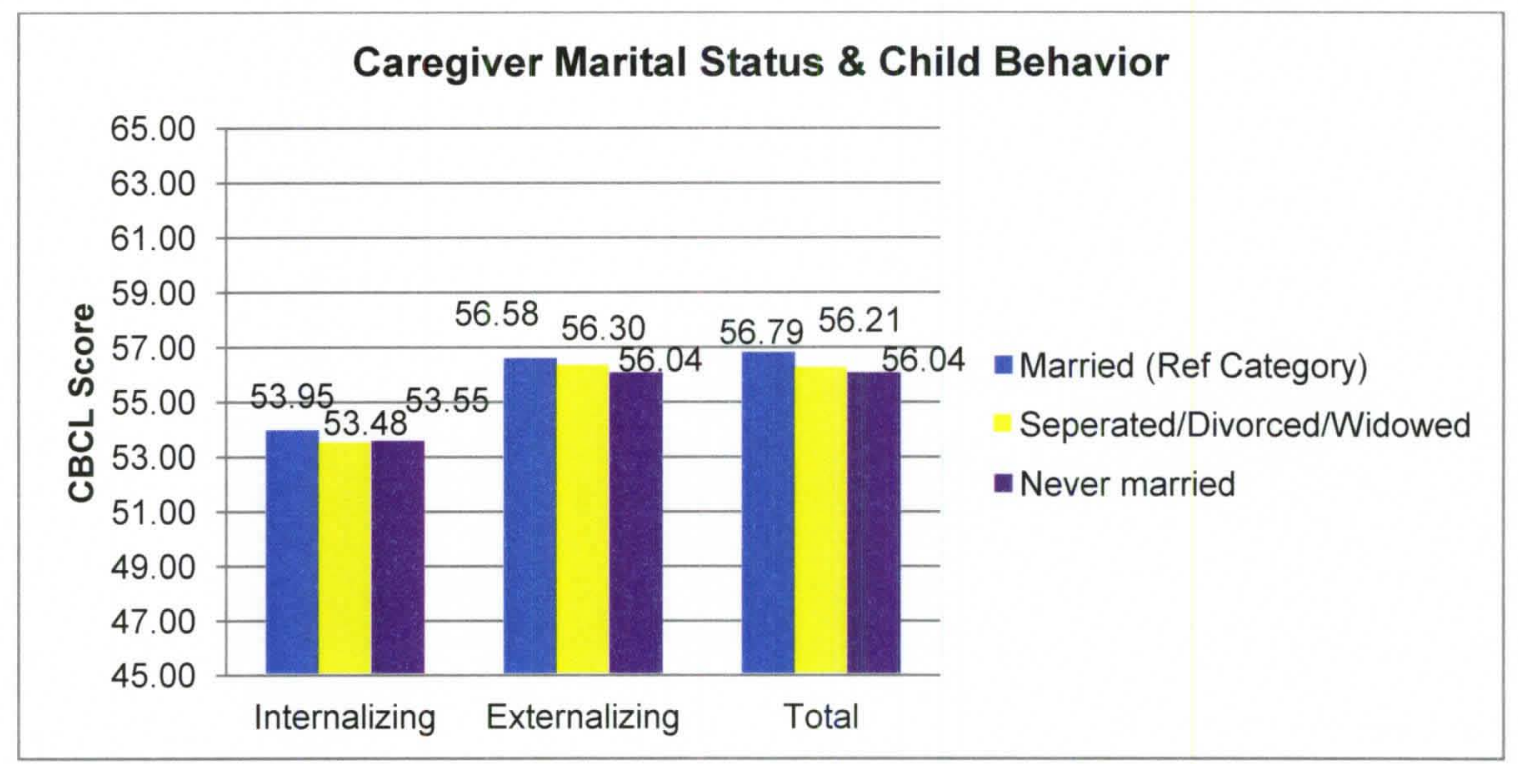

Figure 29. Caregiver marital status main effect on child behavior problems.

Number of children in the household was also a statistically significant predictor of internalizing $\left(\beta_{66 \mathrm{jk}}=-0.20, \mathrm{p}<.01\right)$ and total $\left(\beta_{67 \mathrm{jk} \mathrm{l}}=-0.15, \mathrm{p}<.05\right)$ behavior problems over time. Figure 30 depicts the number of children in the household main effect on child behavior problems over time for the $10^{\text {th }}$ percentile (number of children $=1$ ) and $90^{\text {th }}$ percentile (number of children $=5=$ $5+$ children). The graph below shows that caregivers report more negative internalizing and externalizing behavior problems for those children residing in households with fewer numbers of children. 


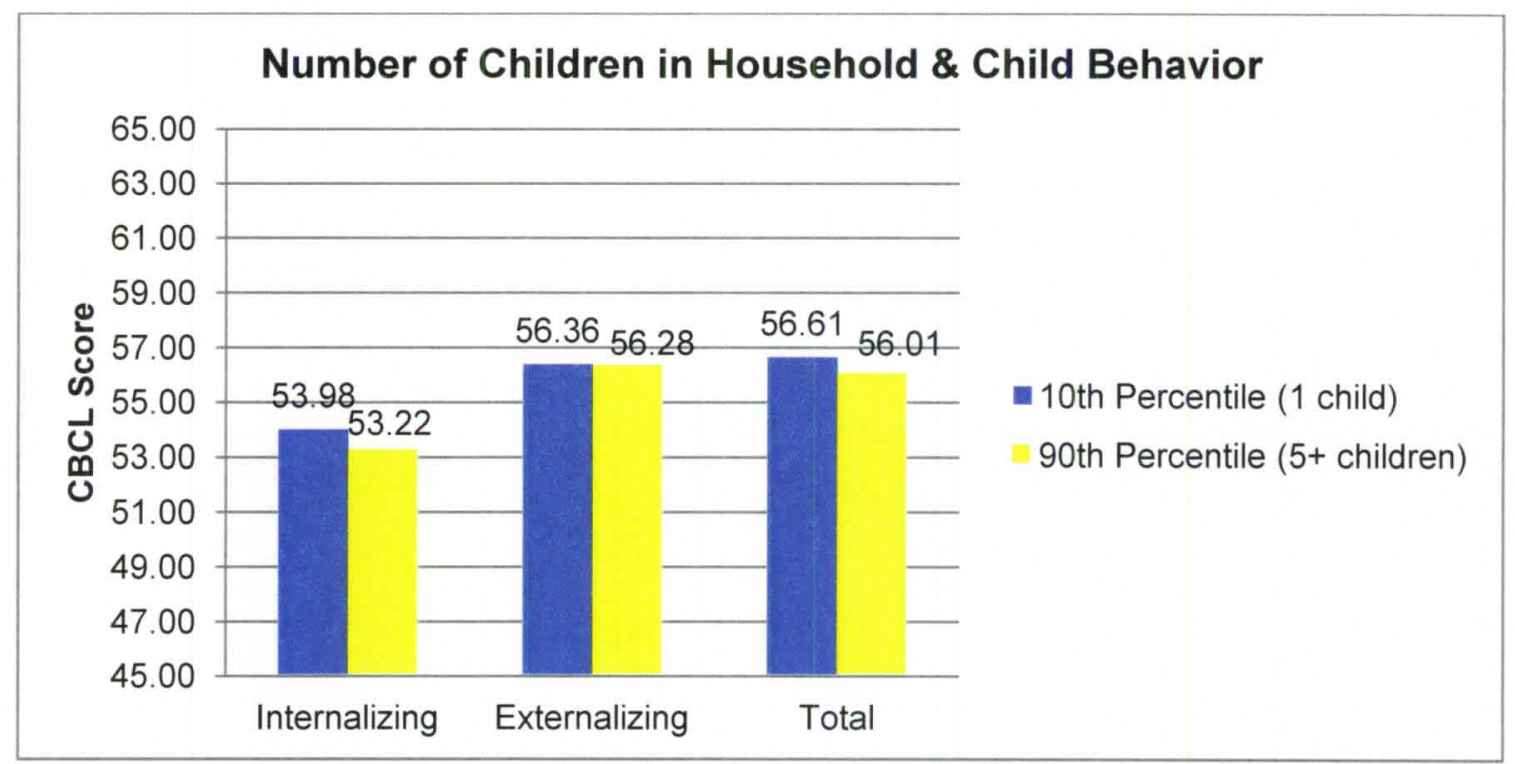

Figure 30. Number of children in household main effect on child behavior problems.

The number of changes in caregiver was a statistically significant predictor of child internalizing $\left(\beta_{69 \mathrm{jk} l}=0.96, p<.001\right)$, externalizing $\left(\beta_{71 \mathrm{jkl}}=0.92, p<.001\right)$, and total $\left(\beta_{67 \mathrm{jkl}}=1.06, p<.001\right)$ behavior problems. As the number of changes in caregivers increase, behavioral problems also increase. Figure 31 below graphically displays the number of changes in caregiver predicted main effect on child behavior problems over time. The graph indicates that children who experience a change in caregiver consistently exhibit more behavior problems on average than children who do not experience a change in caregiver. 


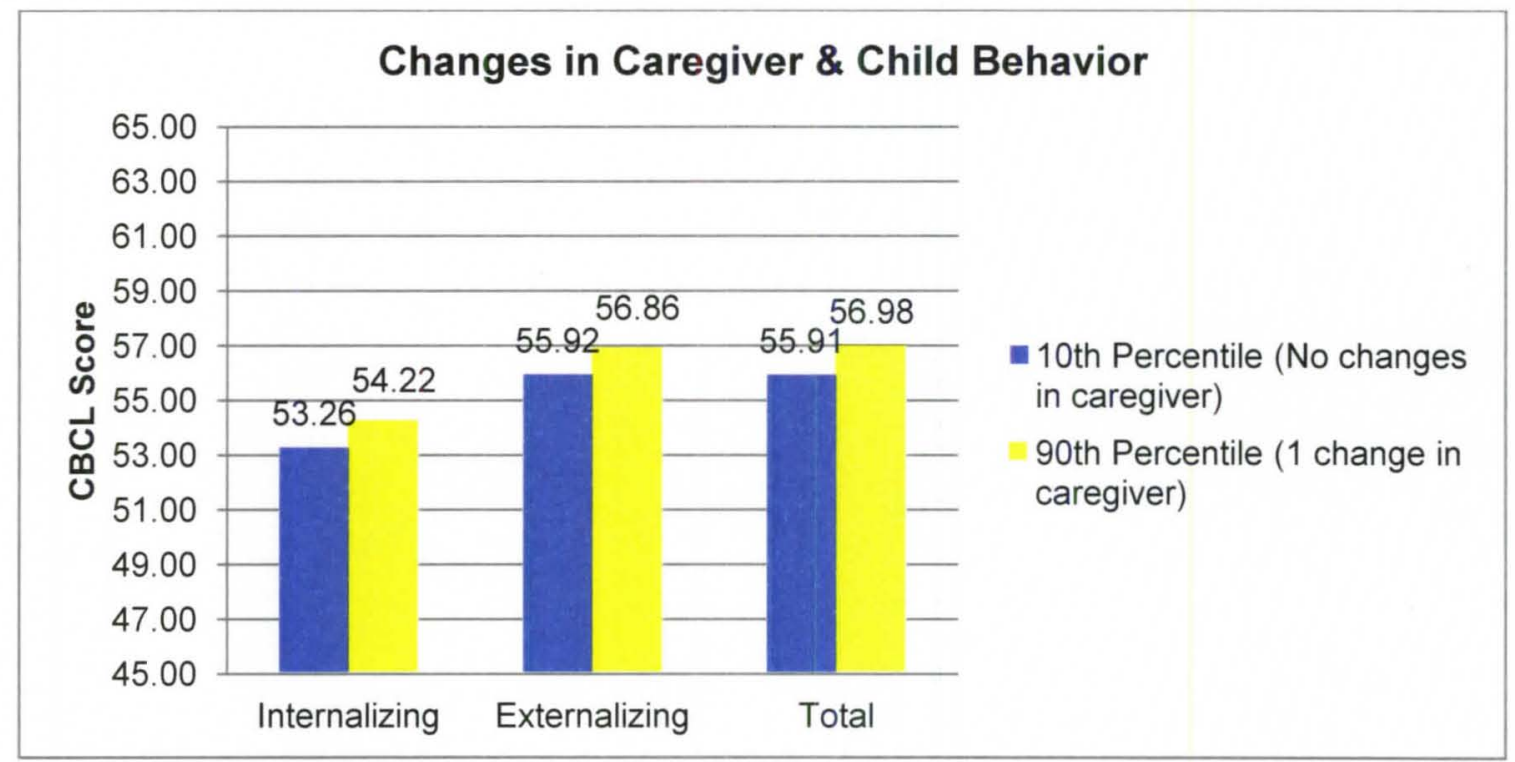

Figure 31. Number of changes in caregiver main effect on child behavior problems.

Being in a permanent placement was a statistically significant predictor of child internalizing $\left(\beta_{72 \mathrm{jk} l}=-1.19, \mathrm{p}<.001\right)$, externalizing $\left(\beta_{74 \mathrm{jk} l}=-0.76, p<.001\right)$, and total $\left(\beta_{73 \mathrm{jkl}}=-1.21, \mathrm{p}<.001\right)$ behavior problems compared to being placed in an out-of-home care setting (reference category). Children in a permanent placement scored significantly lower on all three behavior problem scales than those in an out-of-home placement. Figure 32 below displays the permanent placement main effects on child behavior problems. Children with a permanent caregiver consistently demonstrate lower behavior problems on average than those children in an out-of-home setting. 


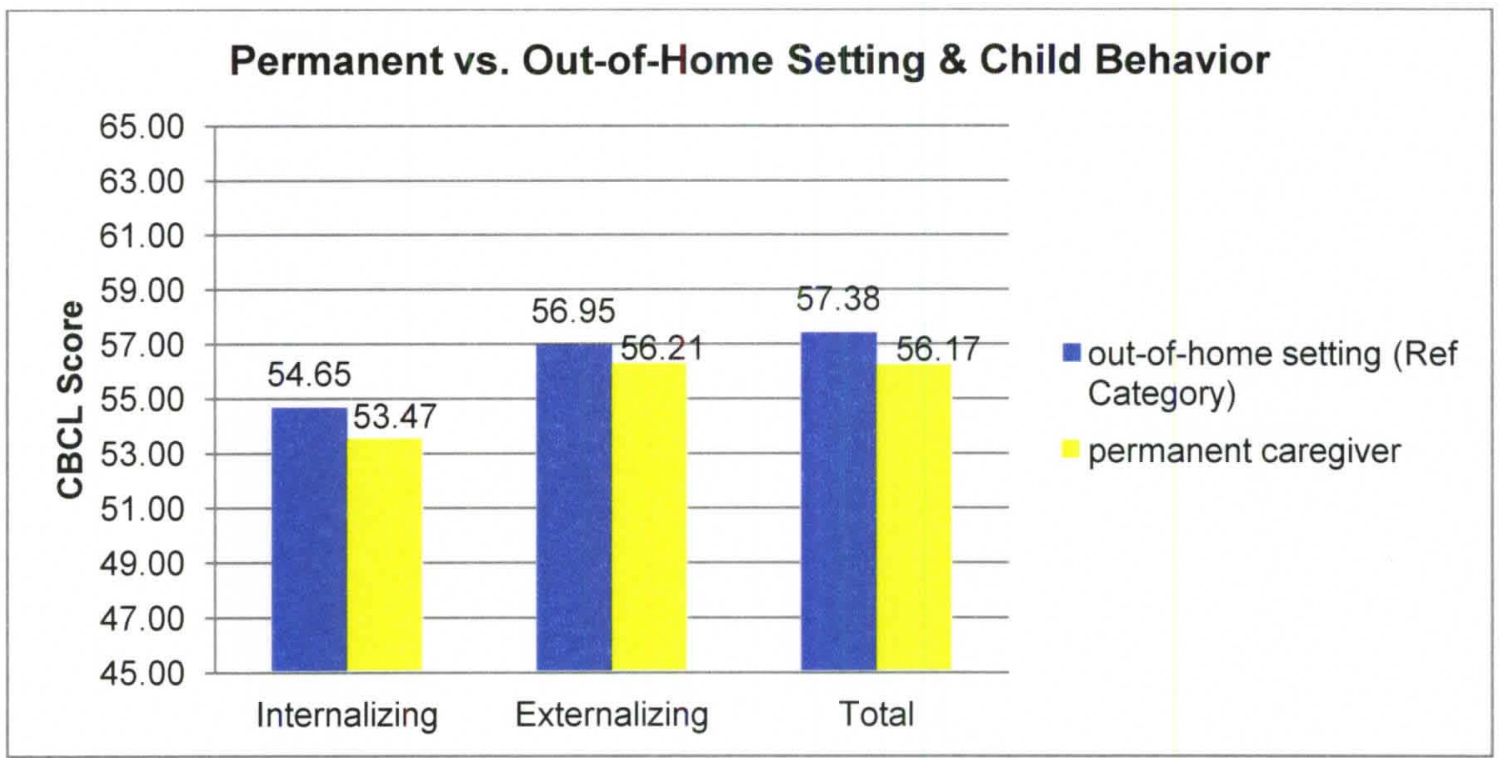

Figure 32. Permanent caregiver main effect on child behavior problems.

Other factors. All of the "other factors" predictors (e.g., caregiver physical health, domestic violence, social support, and perception of neighborhood) were statistically significant predictors of child behavioral problems. Caregiver physical health was a significant predictor of child internalizing $\left(\beta_{75 \mathrm{jk} l}=-0.76, p<.001\right)$, externalizing $\left(\beta_{77 \mathrm{jkl}}=-0.72, p<.001\right)$, and total $\left(\beta_{76 \mathrm{jk} \mathrm{l}}=-0.88, p<.001\right)$ behavior problems. This indicates that as caregiver physical health increased, child behavior problems decreased. Figure 33 graphically depicts caregiver physical health main effect on child behavior problems. The graph below clearly shows that caregivers with a lower level of self-rated physical health consistently rated their children as having a higher level of behavioral problems. 


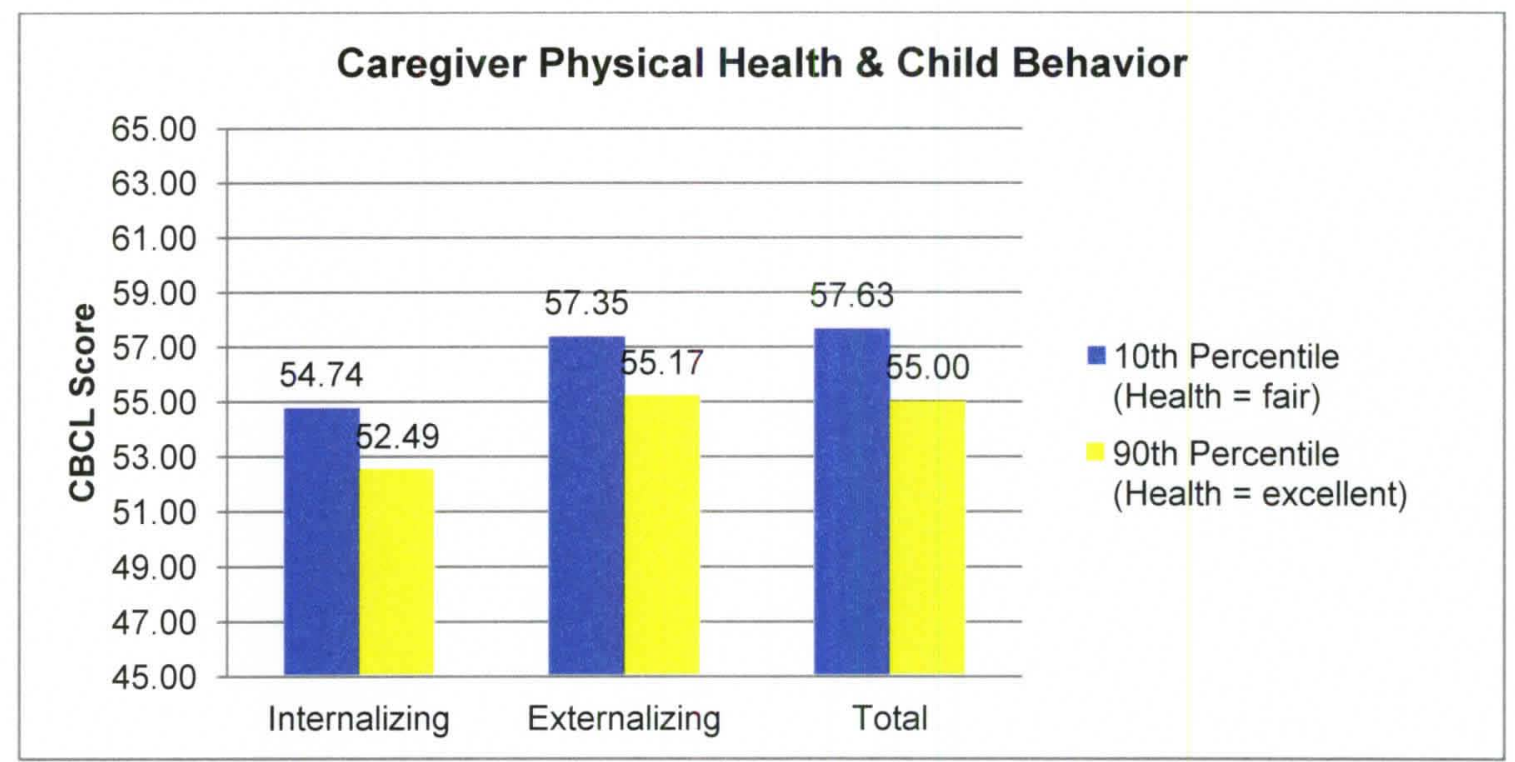

Figure 33. Caregiver physical health main effect on child behavior problems.

Caregiver domestic violence was a significant predictor of child internalizing $\left(\beta_{78 \mathrm{jkl}}=0.04, p<.001\right)$, externalizing $\left(\beta_{80 \mathrm{jkl}}=0.03, p<.001\right)$, and total $\left(\beta_{79 \mathrm{jkl}}=0.04, p<.001\right)$ behavior problems. This indicates that as domestic violence in the home increased, child behavior problems increased as well. Figure 34 visually demonstrates the impact domestic violence had on child behavior problems. It is evident from the graph below that caregivers who reported higher levels of domestic violence consistently rated their children as having higher levels of behavioral problems. 


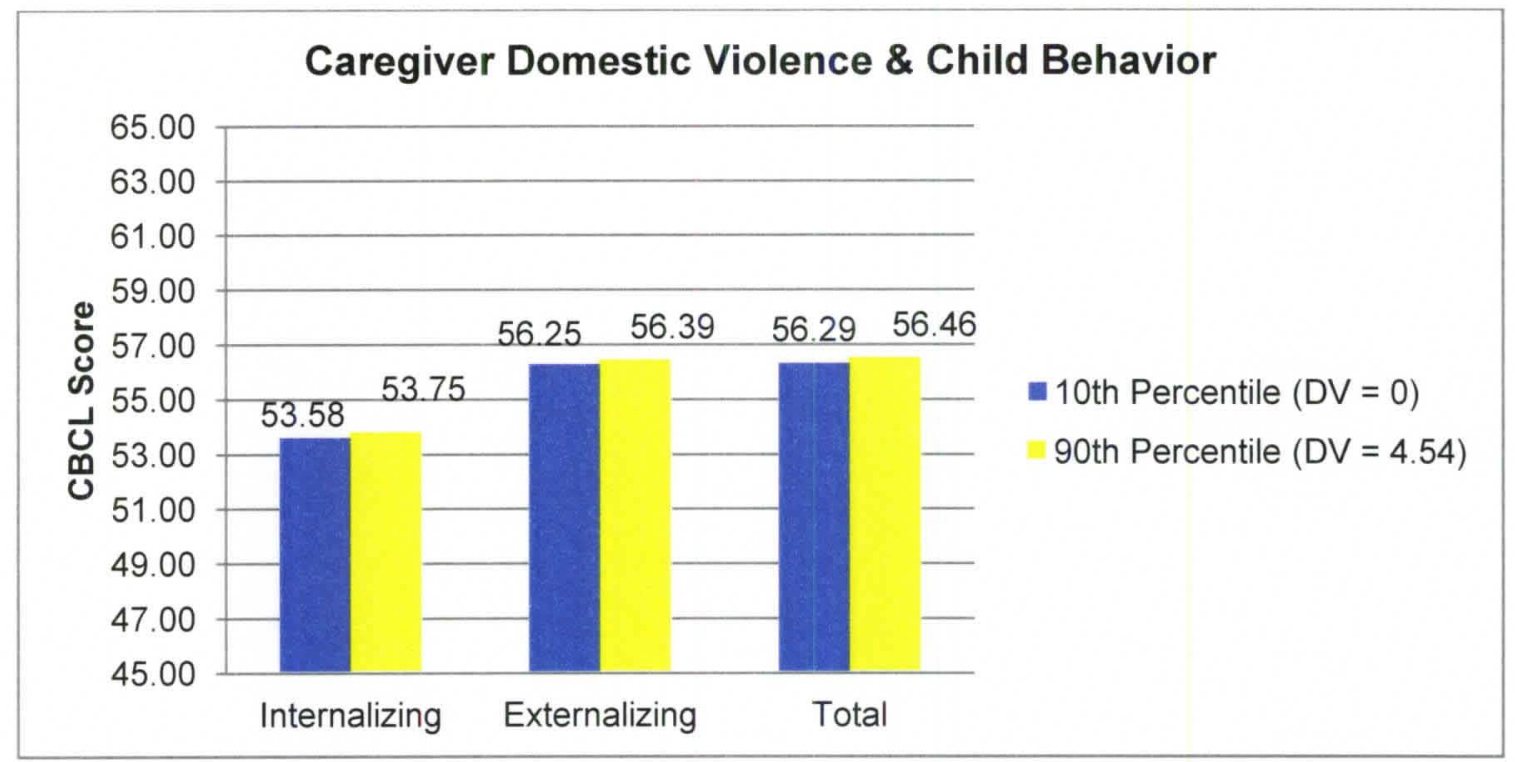

Figure 34. Caregiver domestic violence main effect on child behavior problems.

Caregiver social support was also predictive of child internalizing $\left(\beta_{81 \mathrm{jk} k}=\right.$ $-0.94, p<.001)$, externalizing $\left(\beta_{83 \mathrm{jkl}}=-0.81, p<.001\right)$, and total $\left(\beta_{82 \mathrm{jkl}}=-0.86, p<\right.$ .001) behavior problems. This indicates that as mean satisfaction with the amount of social support received by the caregiver increased, child behavior problems decreased. Figure 35 visually depicts the main effect of social support had on child behavior problems. It is evident from the graph below that caregivers who reported lower mean satisfaction with social support reported higher levels of behavioral problems for their children. 


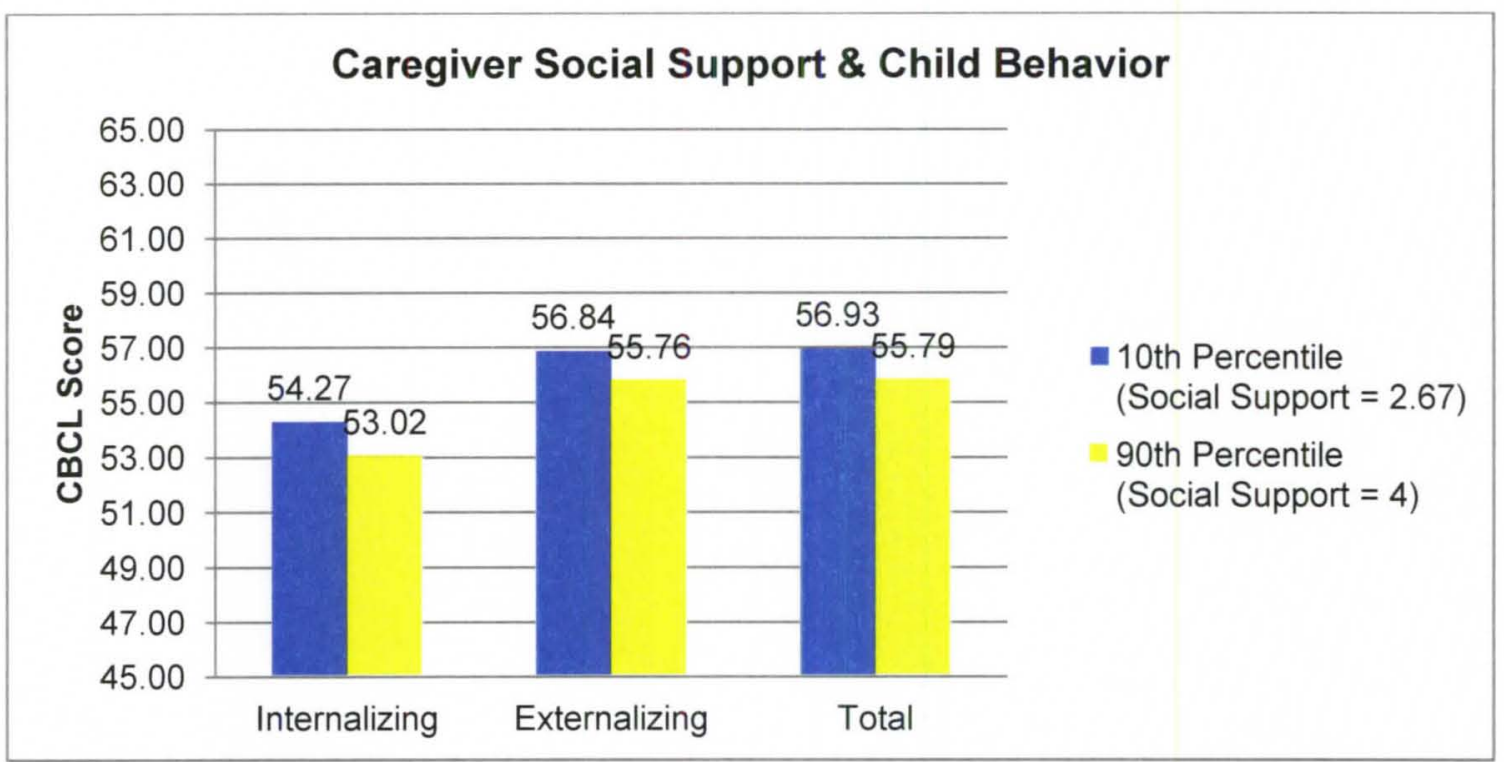

Figure 35. Caregiver social support main effect on child behavior problems.

Caregiver perception of neighborhood proved to be a significant predictor of child internalizing $\left(\beta_{84 \mathrm{jkl}}=0.17, p<.001\right)$, externalizing $\left(\beta_{86 \mathrm{jkl}}=0.22, p<.001\right)$, and total $\left(\beta_{85 \mathrm{jkl}}=0.22, p<.001\right)$ behavior problems. This indicates that as caregiver perception of their neighborhood worsened (e.g., higher scores), child behavior problems increased. Figure 36 visually depicts the main effect of caregiver perception of neighborhood on child behavior problems. It is evident from the graph below that caregivers who reported higher on the perception of neighborhood scale, indicating a more negative view of their neighborhood, consistently reported higher levels of behavioral problems for their children. 


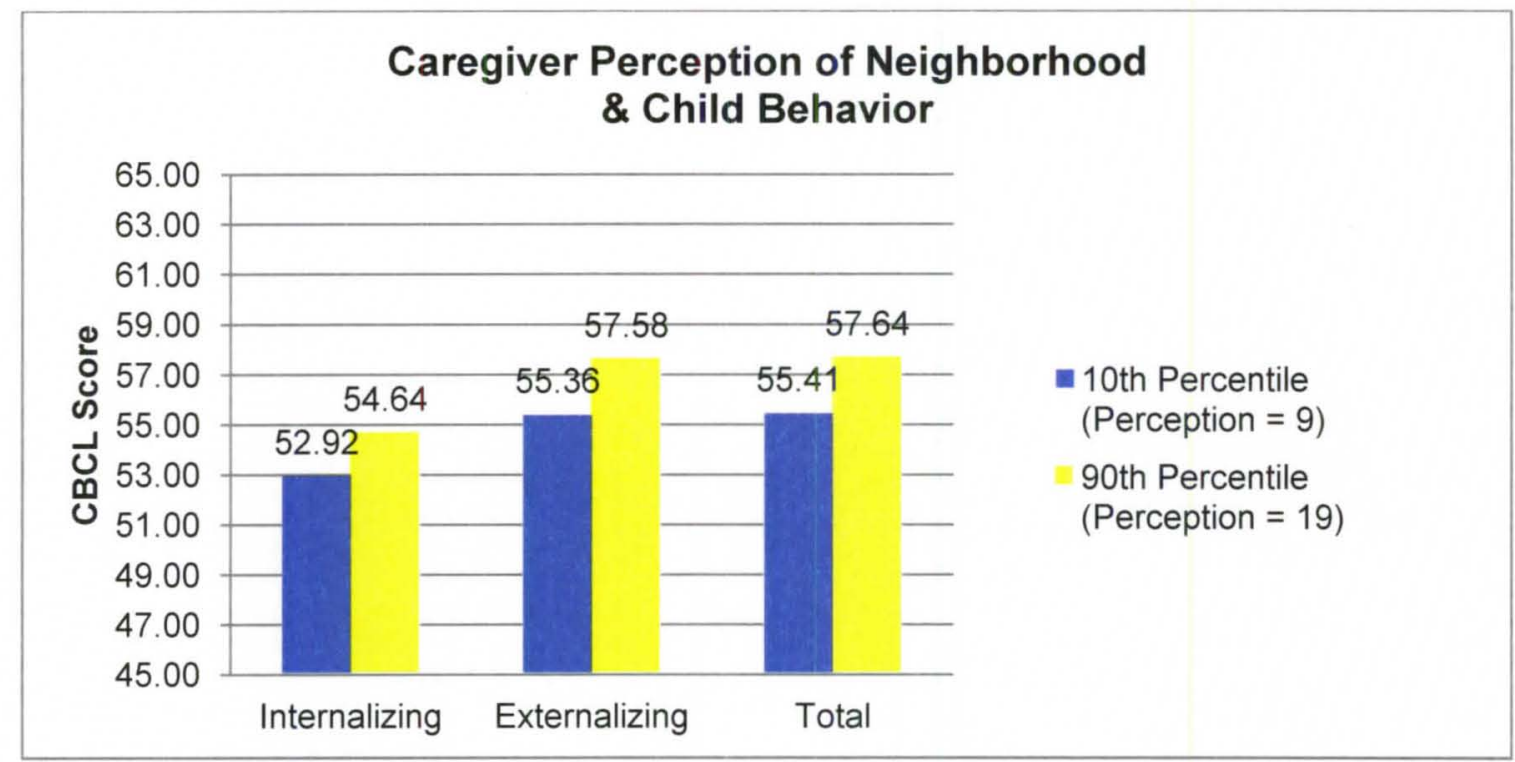

Figure 36. Caregiver perception of neighborhood main effect on child behavior problems.

Environmental factors. There were three (3) environmental factors that proved to be statistically significant predictors of child behavioral problems, including the percentage of Caucasians residing within a PSU, the percentage of single parents in a PSU, and access to social services per capita in a PSU.

Results indicated that PSUs with a higher percentage of Caucasians demonstrate higher levels of externalizing $\left(\beta_{98 \mathrm{jk}}=0.03, p<.05\right)$ and total $\left(\beta_{97 \mathrm{jk}}=\right.$ $0.02, p<.05)$ behavior problems. However, percentage of Caucasians in a PSU was not a statistically significant predictor of internalizing behavior problems.

Figure 37 visually depicts PSU percentage of white population main effect on child behavior problems. Clearly evident in the graph below is that caregivers living in PSUs with a higher percentage of Caucasians report more externalizing and total behavior problems than those caregivers living in PSUs with a lower concentration of Caucasians. 


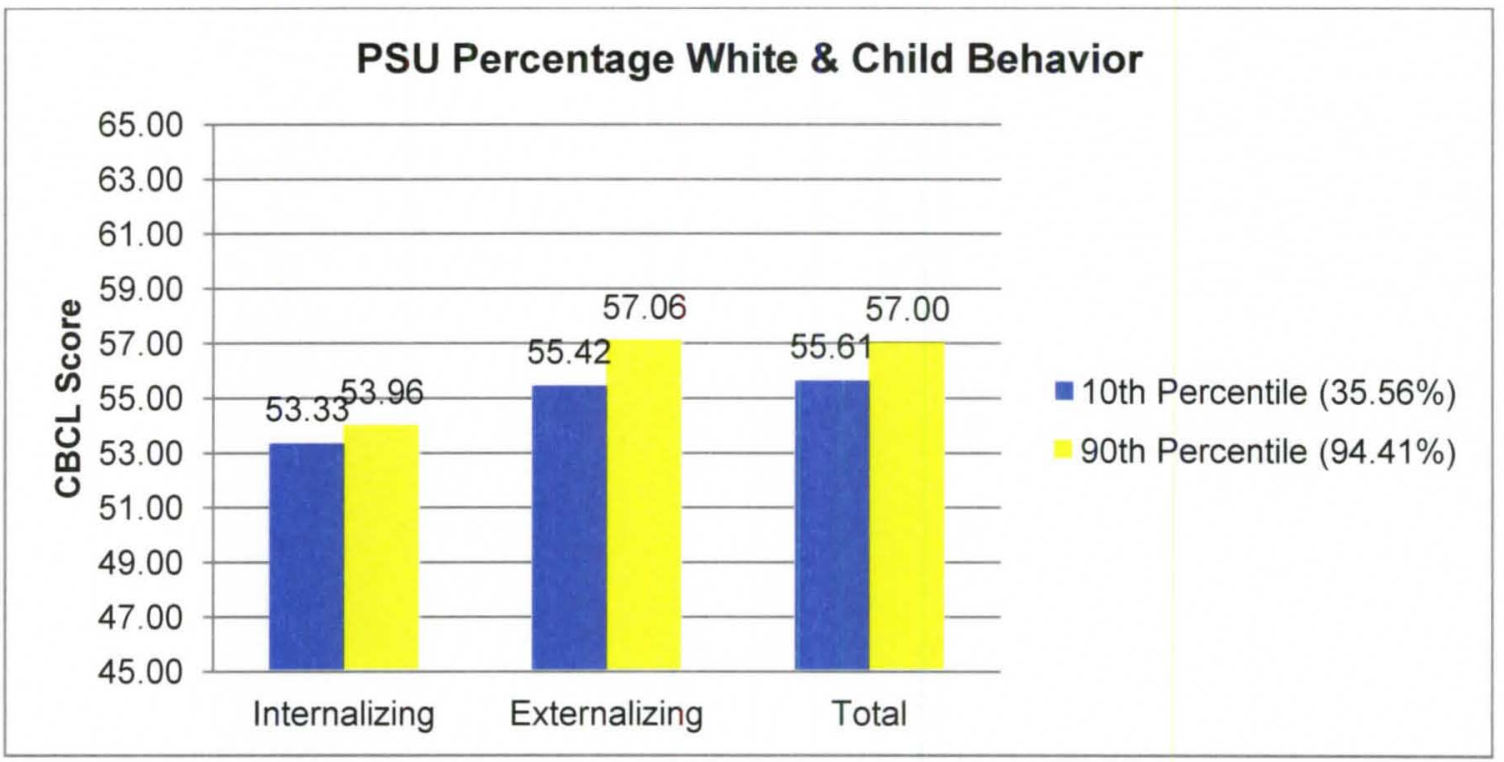

Figure 37. PSU percentage of white population main effect on child behavior problems.

The percentage of single parents within a PSU was a significant predictor of child externalizing $\left(\beta_{89 \mathrm{jkl}}=0.02, \mathrm{p}<.05\right)$ behavior problems, indicating that caregivers residing in PSUs with a higher percentage of single parents reported higher externalizing behavior problems than those caregivers residing in PSUs with a low concentration of single parents. Figure 38 exhibits PSU percentage of single parents' main effect on child externalizing behavior problems. 


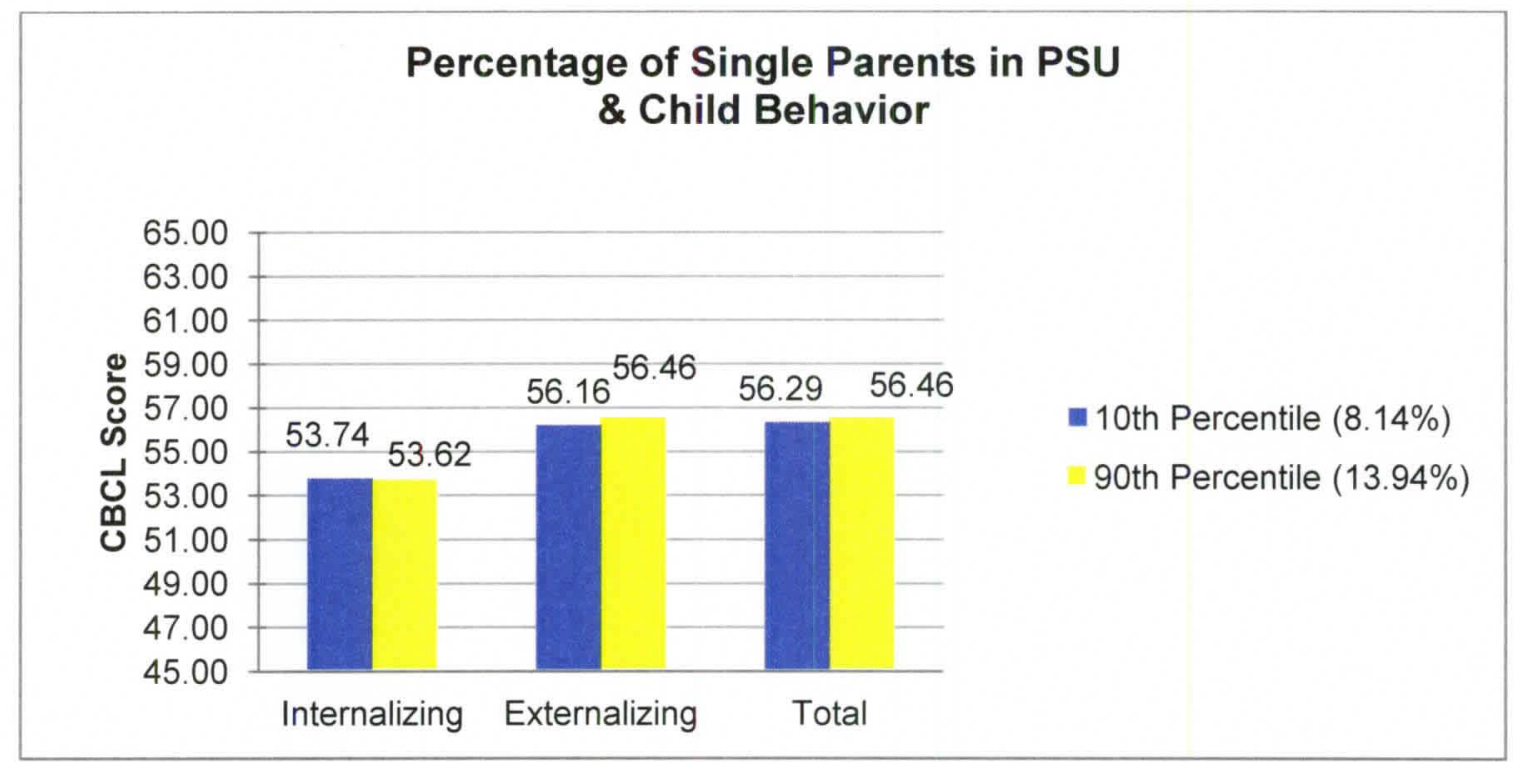

Figure 38. PSU percentage of single parents' main effect on child behavior problems.

Access to social services per capita within a PSU was a significant predictor of child internalizing $\left(\beta_{90 \mathrm{jkl}}=5.81, p<.05\right)$ and total $\left(\beta_{91 \mathrm{jk}}=6.94, p<\right.$ .05) behavior problems, but not of child externalizing behavior problems. This indicates that caregivers living in PSUs with more access to social services reported higher levels of internalizing and total behavior problems than caregivers living in PSUs with less access to social services per capita. Figure 39 visually depicts PSU social services per capita main effect on child behavior problems. 


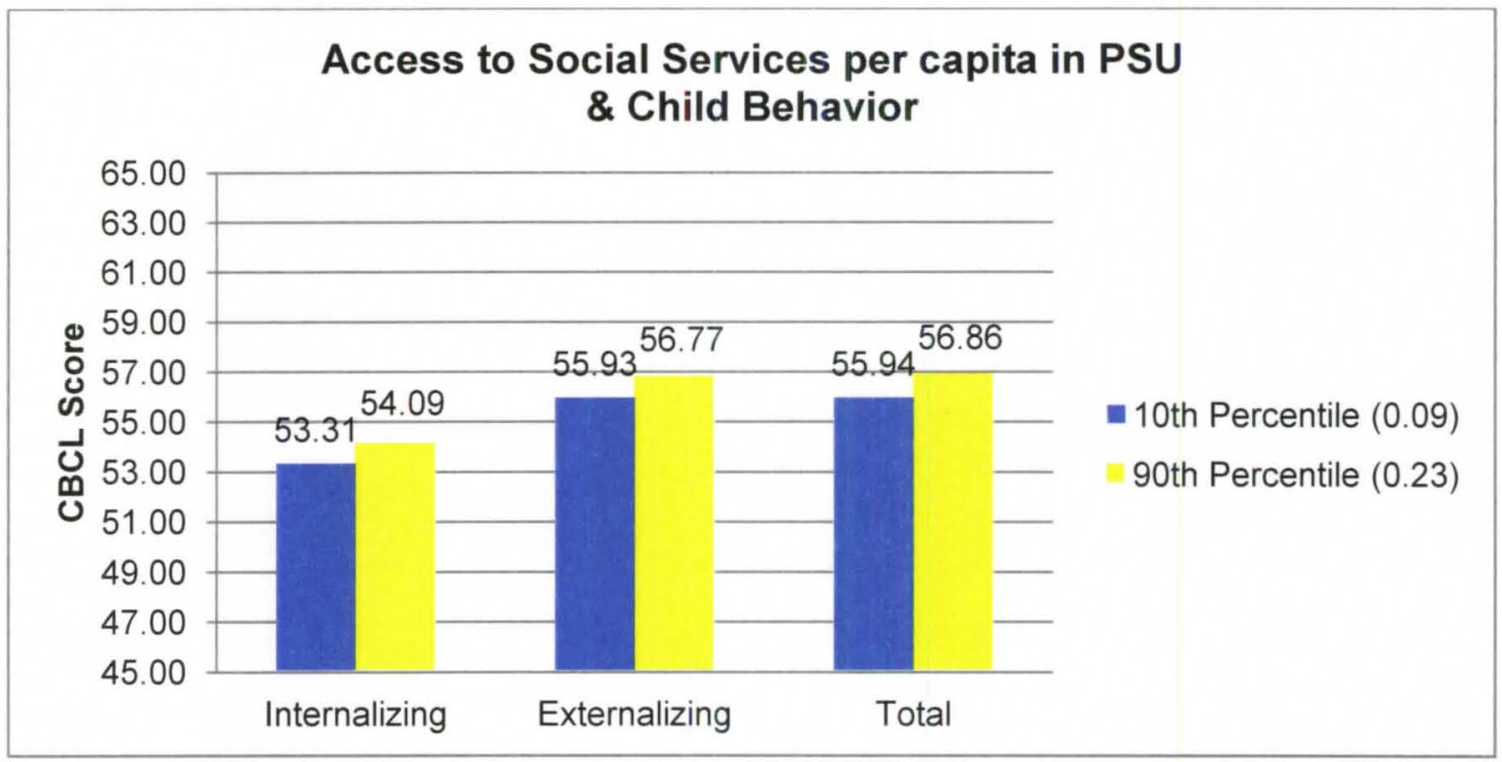

Figure 39. PSU access to social services per capita main effect on child behavior problems.

Interaction effects. There were a few interaction effects that proved to be statistically significant predictors of child behavior problems: (a) percentage of single parents in PSU and maltreatment type; (b) access to health services per capita in PSU and maltreatment type; and (c) access to health services per capita in PSU and percentage of Caucasians in PSU.

The percentage of single parents in a PSU had a differential effect on child externalizing behavior problems depending on the type of maltreatment. The difference was noted between children where the maltreatment was unsubstantiated and children who were sexually maltreated (reference category) $\left(\beta_{107 \mathrm{jkl}}=-0.36, p<.05\right)$. All children in the other maltreatment groups were not significantly different from the sexually maltreated group. Figure 40 displays a graph of the interaction effect of the percentage of single parents in PSU and maltreatment type on child externalizing behavior problems. The graph below shows that sexually maltreated children (and all other maltreatment types) living 
in PSUs with a higher percentage of single parents are the most at risk to experience externalizing behavior problems. This same effect is not seen for unsubstantiated cases, showing that for these children, the percentage of single parents in a PSU did not have an effect on the externalizing behavior problems.

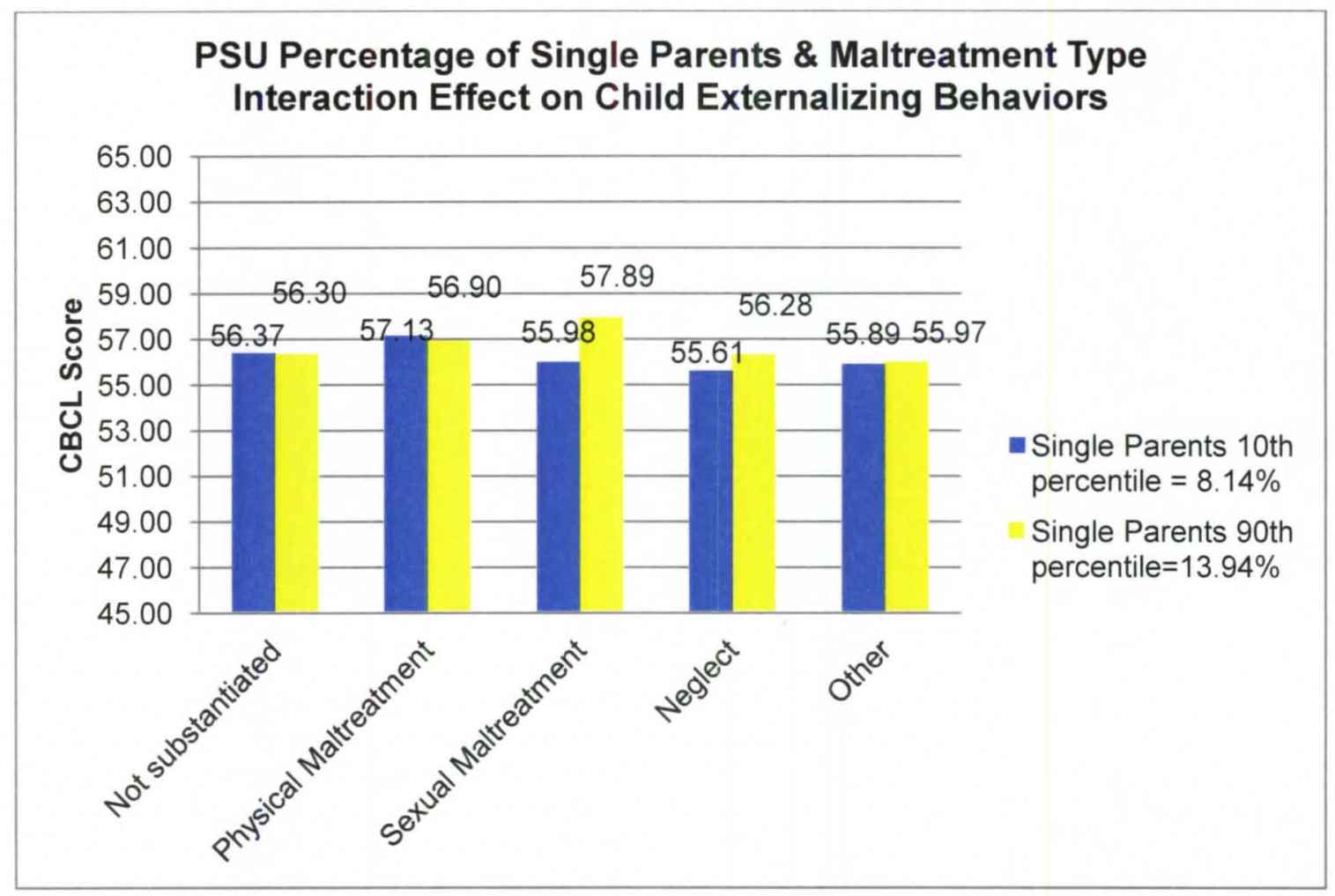

Figure 40. Interaction effect of PSU percentage of single parents and maltreatment type on child externalizing behavior problems.

Access to health services per capita within a PSU had a differential effect on child externalizing behavior problems depending on the type of maltreatment. The difference was noted between children where the maltreatment type was physical and where the maltreatment type was sexual (reference category) $\left(\beta_{123 j \mathrm{kl}}\right.$ $=-5.10, p<.05)$. All children in the other maltreatment groups were not significantly different from the sexually maltreated group. Figure 41 displays a graph of the interaction effect of access to health services per capita in a PSU 
and maltreatment type on children externalizing behavior problems. The graph below shows that physically maltreated children residing in PSUs with less access to health services per capita are more at risk for experiencing externalizing behavior problems than children who are in the sexually maltreated group, the neglect maltreated group, the "other" maltreated group and the not substantiated group. However, the graph also indicates that these other groups (sexually maltreated group, neglect group, "other" maltreated group and the not substantiated group) living in PSUs with greater access to health services per capita are more at risk for experiencing externalizing behavior problems than children who are physically maltreated.

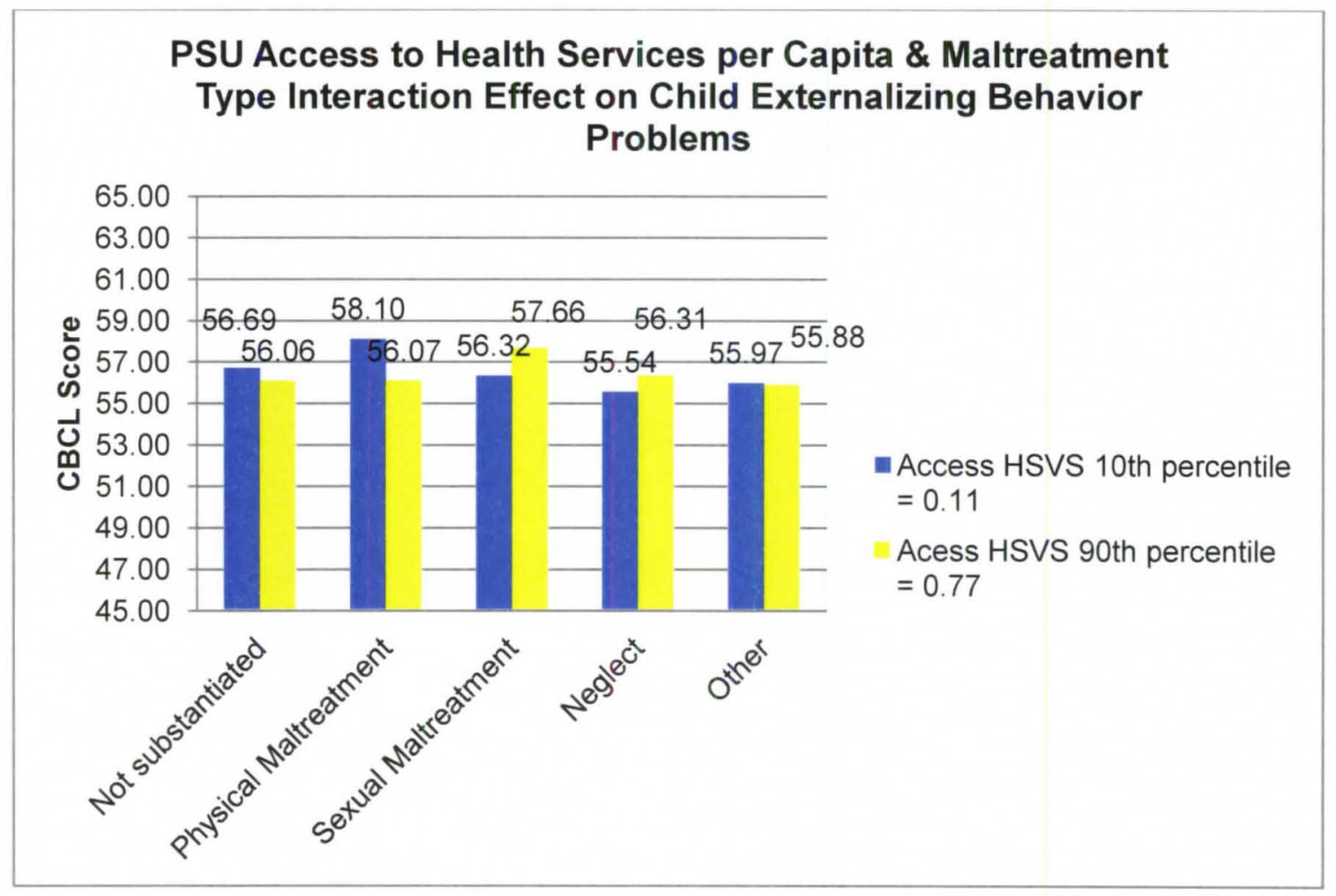

Figure 41. Interaction effect of PSU access to health services per capita and maltreatment type on child externalizing behavior problems. 
Access to health services per capita within a PSU had a differential effect on child behavior problems depending on the percentage of Caucasians in a PSU (Internalizing $\beta_{111 \mathrm{jkl}}=0.06, p<.05$; externalizing $\beta_{113 \mathrm{jk}}=0.07, p<.05$; total $\left(\beta_{112 j \mathrm{kl}}=0.08, p<.01\right)$. Figures 42 through 44 below graphically displays the interaction effect of PSU access to health services per capita and percentage of Caucasians in a PSU on child behavior problems. The figures below show that living in areas where there is a low percentage of Caucasians and lower access to health services puts a child more at risk of having behavior problems than living in higher access areas. Additionally, living in areas with higher access to health services combined with a high percentage of Caucasians puts a child more at risk of having behavior problems. This indicates that caregivers reported higher levels of behavior problems for children residing in PSUs with more access to health services per capita and a higher concentration of Caucasians.

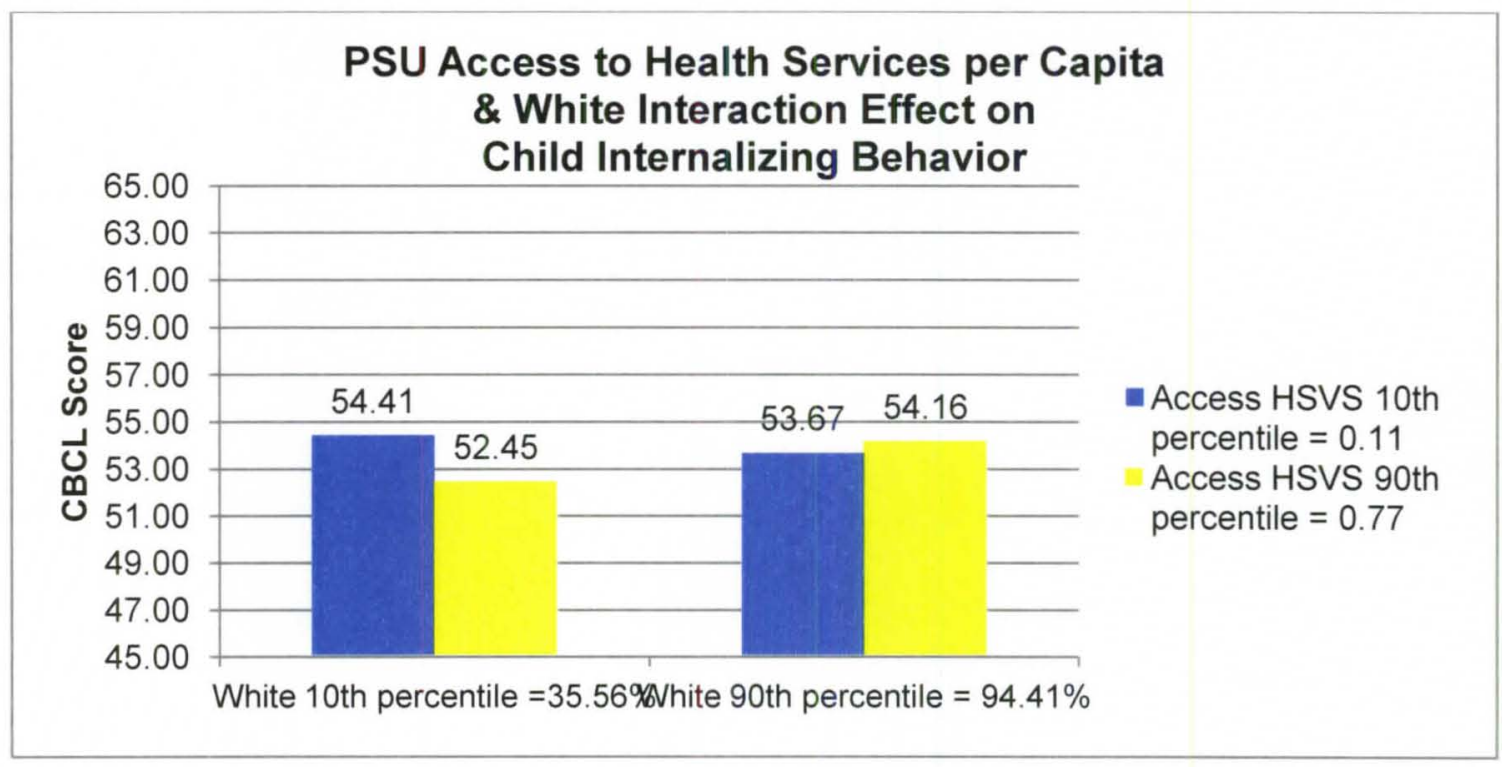

Figure 42. Interaction effect of PSU access to health services per capita and PSU percentage of Caucasians on child internalizing behavior problems. 


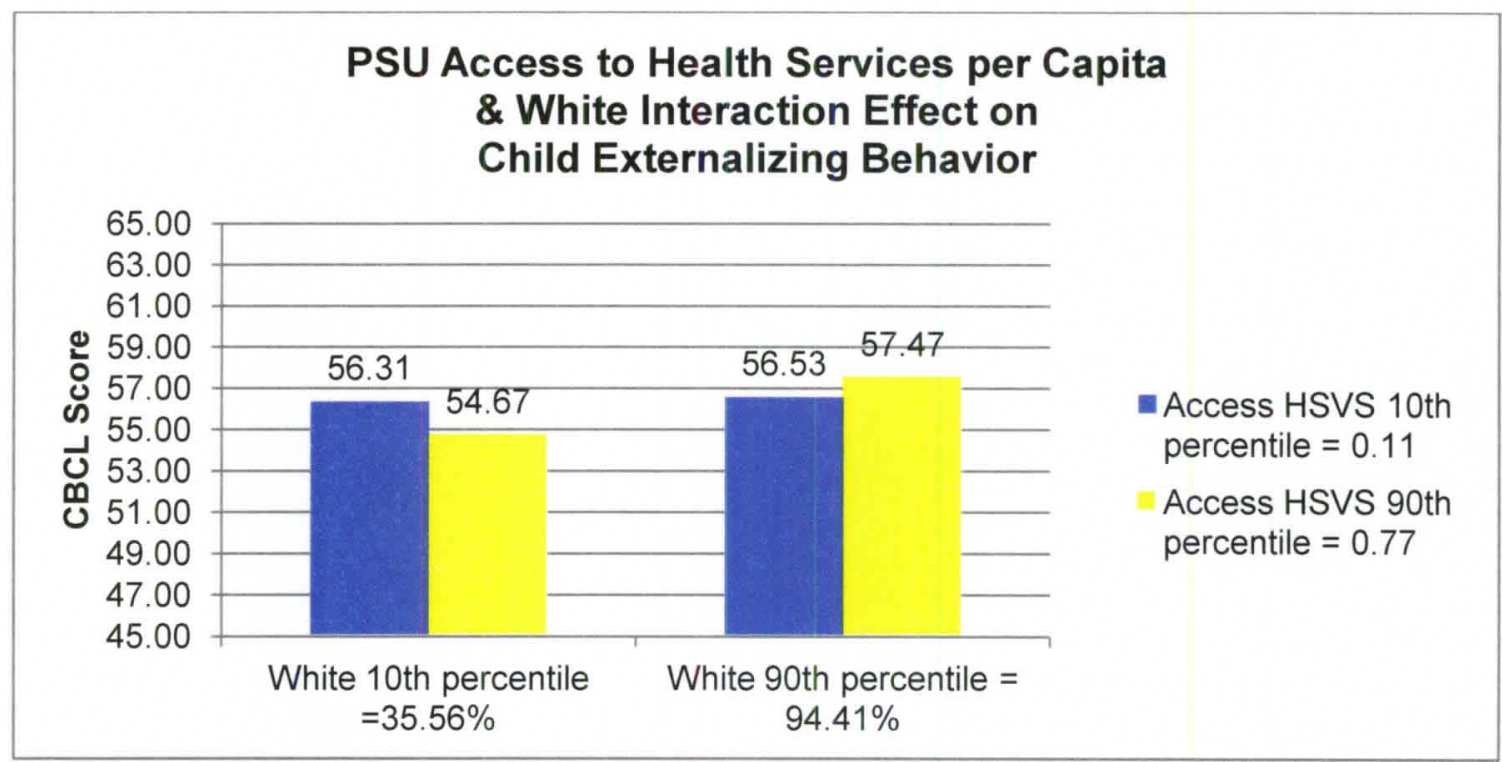

Figure 43. Interaction effect of PSU access to health services per capita and PSU percentage of Caucasians on child externalizing behavior problems.

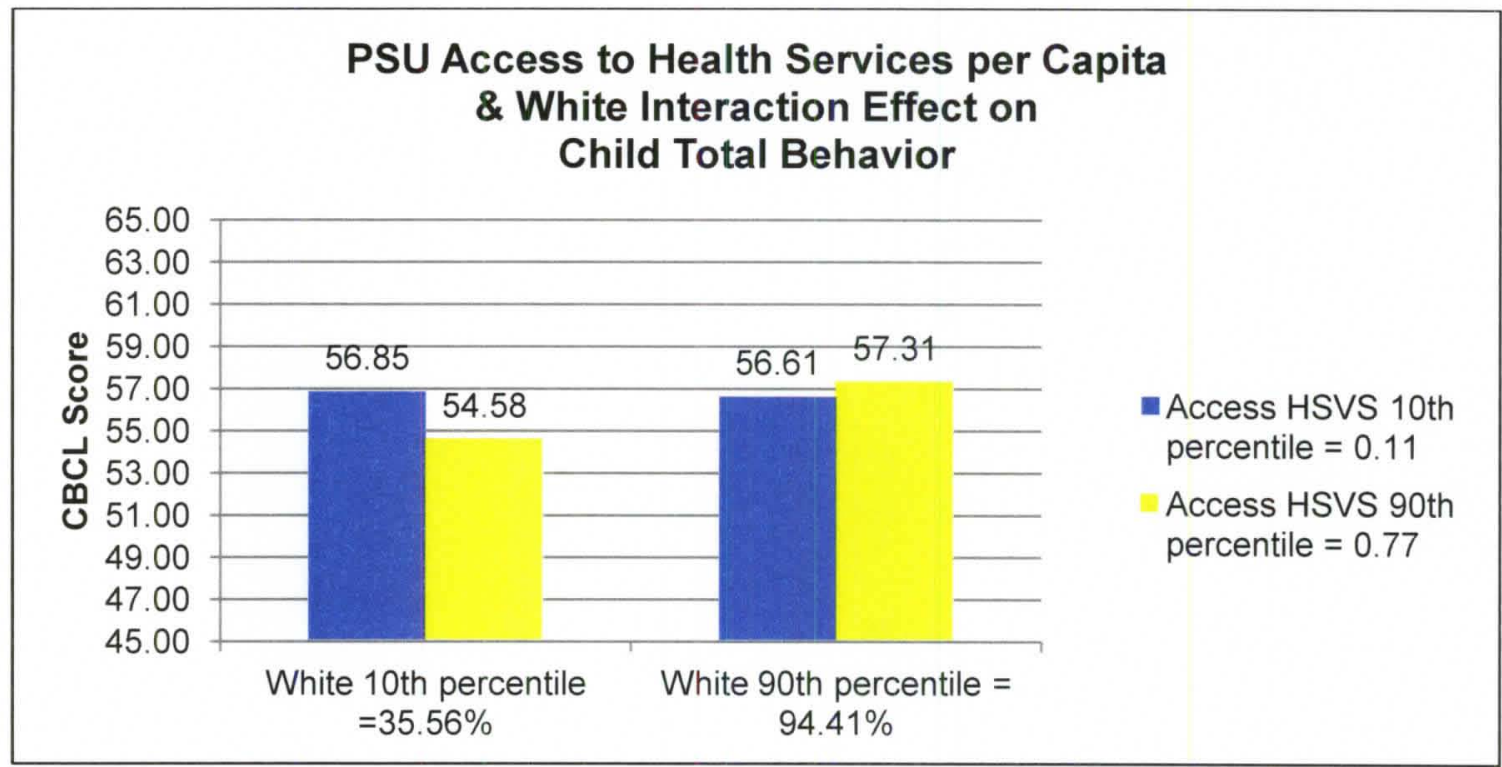

Figure 44. Interaction effect of PSU access to health services per capita and PSU percentage of Caucasians on child total behavior problems.

\section{Summary}

A multivariate longitudinal multilevel model was estimated using MCMC estimation. Through the building of six (6) models, the DIC statistic consistently decreased with the exception of increasing 8.16 points from Model D to Model $E$. 
However, the final model demonstrated the lowest DIC of all indicating good model fit. Additionally, the variance components consistently decreased with each model. Lower variance components and decreased DIC statistic ensured that the most parsimonious model was utilized to examine the effect of child, caregiver, and environmental main effects as well as interaction effects on child behavior problems over time.

Overall, there were several child, caregiver, and environmental main effects that were found to be statistically significant predictors of having higher levels of child internalizing behavior problems as reported by the caregiver. There were also a few interaction effects that proved to be statistically significant predictors of child behavior problems. Table 28 is a summary table of the significant predictors as it relates to higher internalizing, externalizing, and total behavior problems. As the table below demonstrates, there are both similarities and differences in predictors of internalizing, externalizing, and total behavior problems. These similarities and differences will be discussed in more detail in the next chapter.

Table 28

Summary Table of Significant Predictors of Child Behavior Problems

\begin{tabular}{|c|c|c|}
\hline $\begin{array}{c}\text { Internalizing Behavior } \\
\text { Problems }\end{array}$ & $\begin{array}{c}\text { Externalizing Behavior } \\
\text { Problems }\end{array}$ & $\begin{array}{l}\text { Total Behavior } \\
\text { Problems }\end{array}$ \\
\hline & Child-level Predictors & \\
\hline $\begin{array}{ll}\text { - } & \text { Male } \\
\text { - } & \text { Hispanic/Native } \\
\text { Indian/Alaskan/Other } \\
\text { (compared to Black) }\end{array}$ & $\begin{array}{ll}\text { - } & \text { Male } \\
\text { Black (compared to } \\
\text { Hispanic/Native Indian/ } \\
\text { Alaskan/Other) } \\
\text { White (compared to } \\
\text { Hispanic/Native } \\
\text { Indian/Alaskan/Other) }\end{array}$ & $\begin{array}{ll}\text { - } & \text { Male } \\
\text { White (compared to } \\
\text { Hispanic/Native } \\
\text { Indian/Alaskan/Other) }\end{array}$ \\
\hline - Older & - Older & - Older \\
\hline - Low social skills & - Low social skills & - Low social skills \\
\hline
\end{tabular}


- Sexual Maltreatment (compared to Neglect and Not Substantiated)

- Exposure to violence

- Low physical health status

- Not having a cognitive disability

- High cognitive health Internalizing Behavior Problems
- Sexual Maltreatment (compared to Neglect and Other)

- Exposure to violence

- Low physical health status

- Not having a cognitive disability

- Sexual Maltreatment (compared to Neglect, Other, and Not Substantiated)

- Exposure to violence

- Having a physical disability

- Low physical health status

- Not having a cognitive disability

- High cognitive health

Externalizing Behavior

Total Behavior Problems

\section{Caregiver-level Predictors}

- Younger

- Some college (compared to having a high school diploma/equivalent and having less than 12 years)

- Married (compared to separated/divorced/widow ed)

- Less children

- Higher number of changes in caregiver

- Out-of-home placement (compared to permanent placement)

- Low physical health status

- Domestic violence

- Low social support

- Negative perception of neighborhood

Internalizing Behavior Problems
- Younger

- Some college (compared to having a high school diploma/equivalent and having less than 12 years and "don't know")

- Married (compared to never married)

- Higher number of changes in caregiver

- Out-of-home placement (compared to permanent placement)

- Low physical health status

- Domestic violence

- Low social support

- Negative perception of neighborhood Externalizing Behavior Problems

- Younger

- Some college (compared to having a high school diploma/equivalent and having less than 12 years and "don't know")

- Married (compared to separated/divorced/widow ed and never married)

- Less children

- Higher number of changes in caregiver

- Out-of-home placement (compared to permanent placement)

- Low physical health status

- Domestic violence

- Low social support

- Negative perception of neighborhood

\section{Total Behavior} Problems

Environmental-level Predictors

- Higher percentage of single parents in PSU

- More access to social services per capita in PSU

- Higher percentage of Caucasians in PSU and more access to health services per capita in PSU
- Higher percentage of Caucasians in PSU

\begin{tabular}{l}
$\begin{array}{c}\text { Internalizing Behavior } \\
\text { Problems }\end{array}$ \\
\hline \\
\hline \\
- Higher percentage of \\
Caucasians in PSU and \\
more access to health \\
services per capita in PSU
\end{tabular}
Interaction Effects

- Percentage of single parents in PSU and sexual maltreatment (compared to not substantiated)

- Higher percentage of Caucasians in PSU and more access to health services per capita in PSU
- More access to social services per capita in PSU

- Higher percentage of Caucasians in PSU otal Behavio
Problems

- Higher percentage of Caucasians in PSU and more access to health services per capita in PSU 
- Access to health services per capita in PSU and sexual maltreatment (compared to physical maltreatment)

The next and final chapter will discuss how these results answer both of the hypotheses proposed in this study as well as discuss how these findings related to what has been previously established in the literature. Additionally, the final chapter will discuss the relevance of these findings as it relates to social work practice and policy decisions. Lastly, it will close with a discussion of strengths and weaknesses of this study and offer recommendations for future research. 


\title{
CHAPTER V: DISCUSSION
}

\author{
You may never know what results come of your action, \\ but if you do nothing there will be no result. Mahatma Gandhi
}

This final chapter will discuss the findings reported in the previous chapter. Additionally, a discussion of both the practice and policy implications will also be included. This chapter will conclude with a discussion of the strengths, limitations, and recommendations for future research. The analyses and results presented in the previous chapter sought to answer two (2) specific research questions: (a) Do the behavioral trajectories for children reported to child protective services (CPS) as a result of child maltreatment change differently over time? and (b) What are the most important child factors, caregiver factors, and environmental factors that predict the level of internalizing, externalizing, and total behavioral problems experienced by children reported to CPS as a result of child maltreatment over a period of six (6) years? This chapter will seek to explain how the accompanying aims and hypotheses were answered based on the analyses conducted in this dissertation.

\section{Research Question 1}

The corresponding specific aim of question 1 was to determine if behavioral trajectories for children reported to child protective services (CPS) as a result of child maltreatment change differently over time. The hypothesis was 
that behavioral trajectories for children reported to CPS as a result of child maltreatment will change differently over time. Based on the results presented in the previous chapter, hypothesis 1 was supported. This is best seen in the variability of the slope for internalizing, externalizing, and total behavioral problems over time. Both the decreased DIC as well as the statistically significant variance terms for the time predictor on the child/caregiver level indicate that children change differently. While a majority of children tend to decrease over the four (4) time periods, individually they decrease differently over time. Further, the slope is steeper for internalizing behavior problems $\left(\beta_{3 \mathrm{jk}}=\right.$ $-0.88, p<.01)$ than it is for either externalizing behavior problems $\left(\beta_{5 j \mathrm{kl}}=-0.52, \mathrm{p}\right.$ $<.01)$ or total behavior problems $\left(\beta_{4 \mathrm{jkl}}=-0.65, p<.01\right)$. This indicates that holding everything else constant at the grand mean or reference category, internalizing behavior problems decrease more over time than either externalizing or total behavioral problems. Therefore, while internalizing behavior problems ranks second at time 0 , by the end of time 3 internalizing behavior problems are lower than either externalizing or total behavior problems.

\section{Research Question 2}

The corresponding specific aim of the second research question proposed in this study was to determine if differences and changes in certain child factors, caregiver factors, and environmental factors will have a differential effect on six (6) year internalizing, externalizing, and total behavioral problems change trajectories of children reported to CPS. The hypothesis was that differences and changes in certain child factors, caregiver factors, and environmental factors 
within and between children reported to CPS will have a differential effect on six (6) year internalizing, externalizing, and total behavioral problems change trajectories. In order to answer this question, first remember that there were three (3) main theoretical frameworks that guided this study: (a) Psychosocial Development Theory; (b) Attachment Theory; and (c) Ecological Systems Theory. As this discussion will show, the findings from this study partially support the second hypothesis. Psychosocial Development Theory was utilized in the determination of child-level predictors. Attachment Theory was mainly related to caregiver-level predictors while Ecological Systems Theory was utilized to determine environmental-level predictors. Each of the significant predictors will now be discussed as it relates to the literature presented in chapter 2 .

\section{Child-level Significant Predictors}

Significant child-level predictors included child sex, child race/ethnicity, child age, social skills, type of maltreatment, exposure to violence, physical and cognitive disability, and physical and cognitive health. There was one (1) predictor that was removed from the model due to it not being a statistically significant predictor (risk factor index). Many of these child-related predictors were statistically significant across all behavioral problems (e.g., child age, social skills, physical health and cognitive disability), while other child-related predictors (e.g., physical disability and K-BIT scores) were only statistically significant on one (1) of the three (3) types of behavioral problems. It is important to note that child social skills explained a great deal of the variance in the model and more attention will be given to this later in the implications section. 
Child gender and child race/ethnicity were the two (2) statistically significant predictors of child behavior problems related to child demographics. The results with regard to child gender were surprising given that Achenbach (1991) reported that males scored higher on the externalizing behavior problems scale while females scored higher on the internalizing problems scale. However, the results presented in chapter 4 suggest that males (reference category) scored higher on both scales. This may have been the result of temporary caregivers not really knowing the child well before being asked to complete the $\mathrm{CBCL}$ on the child. Consistent with the literature is that females did score significantly lower on the total behavior problems scale (Rosenthal \& Curiel, 2006). Child race/ethnicity was found to be a statistically significant predictor of child behavior problems. With regard to internalizing behavior problems, Hispanic/Native Indian/Alaskan/Other (reference category) were significantly higher than African Americans and similar to Caucasians. With regard to externalizing behavior problems, Hispanic/Native Indian/Alaskan/Other (reference category) scored significantly lower than both African Americans and Caucasians. With regard to total behavior problems, Hispanic/Native Indian/Alaskan/Other scored significantly lower than Caucasians. This is consistent with previous research that indicated that being Hispanic resulted in lower behavior problems (Stahmer et al, 2009). However, other research indicates that there were no significant effects for Native Americans, Hispanics, or African Americans (Rosenthal \& Curiel, 2006). Stahmer and colleagues (2009) also reported that with the exception of Hispanics, there were no other 
significant effects for race. The significance found in this study may have been the result of combining Hispanics, Native Indians, Alaskans, and all other races/ethnicities in order to form a larger group whereas the other studies examined them individually.

There were two (2) statistically significant predictors of child behavior problems as it relates to child development: (a) child age and (b) child social skills. Rosenthal and Curiel (2006) stated that older children were reported as having lower behavior problems. This is inconsistent with findings shown in chapter 4 that demonstrated that older children were consistently reported as exhibiting higher internalizing, externalizing and total behavior problems. Therefore, while child age was a statistically significant predictor of behavior problems, there is some inconsistency with current research. Child social skills proved to be one of the most important predictors of child behavior problems. This is partially consistent with current literature that suggests that early social competence predicted membership to an increasing adjustment group for internalizing behavior problems and to a stable maladjustment group for externalizing behavior problems (Proctor, Skriner, Roesch, \& Litrownik, 2010). The results in the current literature suggests that early social competence leads to improved internalizing behavior problems and stable externalizing behavior problems, while the results presented in this dissertation suggest that improved social skills results in fewer behavior problems across the board.

Two (2) of the three (3) child maltreatment predictors were statistically significant predictors of child behavior problems: (a) type of maltreatment and 
(b) exposure to violence. There were both consistencies and inconsistencies with regard to the findings related to type of maltreatment. However, it is clear that including the type of maltreatment is important rather than simply combining maltreatment into a substantiated/not substantiated predictor. Results indicated that sexual maltreatment exhibited the highest internalizing, externalizing and total behavior problems, which is consistent with some literature (Litrownik et al., 2005). However, Litrownik and colleagues (2005) also reported that physical abuse was a statistically significant predictor of child externalizing behavior only whereas this study found that physical maltreatment was not statistically different from sexual maltreatment. They also found that neither neglect (e.g., failure to provide, lack of supervision) nor emotional abuse were predictive of child behavior problems (Litrownik et al., 2005) while this study found that children who experienced neglect exhibited fewer internalizing, externalizing, and total behavior problems than those children who experienced sexual abuse. This study combined emotional maltreatment with other types of maltreatment so it is difficult to make a comparison with the literature with respect to emotional maltreatment. However, the results reported in chapter 4 indicated that children who experienced "other" types of maltreatment demonstrated fewer externalizing and total behavioral problems than those who experienced sexual abuse. With regard to exposure to violence, the results reported in this dissertation are consistent with findings reported in current literature. Johnson and colleagues (2002) reported that children who were exposed to violence exhibited higher levels of aggression and depression while 
English and colleagues (2009) reported that exposure to violence resulted in higher internalizing, externalizing, and total behavior problems.

All four (4) child health predictors were significant: (a) child physical health; (b) child physical disability; (c) child cognitive health; and (d) child cognitive disability. However, not all of these predictors were in the direction expected. For example, child who did not have a cognitive disability were reported as having a higher level of internalizing, externalizing, ant total behavior problems. This may be due to the caregivers rating the child's behavior more favorably due to the cognitive impairment. They may have, perhaps, viewed the behaviors as "normal" and discounted the fact that they were still behavior problems. It could also be due to the children having less ability to process events that occurred in their environment or do not have the cognitive capacity to understand or perceive negative events as such, which results in them reacting differently than children with no cognitive disability. Children with higher levels of cognitive health, as measured by the K-BIT, were reported as having significantly higher levels of internalizing and total behavior problems. This may relate to the previous discussion regarding cognitive disability. Children with higher levels of cognitive health are better able to internally process and internalize negative events that happen around them, either in their home or neighborhood, resulting in higher levels of depression or anxiety which are two (2) of the subscales on the internalizing behavior problems scale. Physical health and physical disability were consistent with what would be expected and with the literature. Children with a physical disability were reported as 
having higher levels of total behavior problems. Since the CBCL is based on parent or caregiver report, it is expected that the extraordinary work involved in caring for a child with a physical disability would result in a perceived increase in total behavior problems. Additionally, as Kring and colleagues (2010) reported, children with more physical health problems exhibited higher levels of behavior problems. This is consistent with the results reported in chapter 4 .

\section{Caregiver-level Significant Predictors}

Significant caregiver-related predictors included caregiver age, education, marital status, number of children in the household, number of changes in caregiver, out-of-home placement, physical health status, domestic violence, social support, and perception of neighborhood. There were three (3) predictors (caregiver income, whether caregiver was biological caregiver, and number of days child was in out-of-home placement) removed from the model due to them not being statistically significant and four (4) predictors removed due to there not being sufficient data to include it in the analysis (depression, substance abuse, attachment, and emotional/cognitive stimulation). These predictors are largely supported in the literature and it is important that future studies include these predictors in the analysis.

Caregiver demographic predictors that were statistically significant included caregiver age and education. There was some ambiguity with regard to the impact caregiver age has on child behavior problems with some research suggesting that younger caregivers report higher levels of child behavior problems (Kalil \& Dunifon, 2007). This is consistent with the findings reported in 
this dissertation that showed that younger caregivers consistently reported higher levels of behavior problems across the board. However, there is inconsistency with respect to caregiver education. Current research indicates that caregivers with lower levels of education have children with higher levels of externalizing behavior problems (Rosenthal \& Curiel, 2006). This study reported that caregivers with some college (i.e., higher level of education) stated that children in their care had higher internalizing behavior problems than caregivers with less than 12 years of education and those having a high school diploma or equivalent. Additionally, caregivers with some college (i.e., higher level of education) reported that children in their care had higher externalizing and behavior problems than caregivers with less than 12 years of education and those having a high school diploma or equivalent and those caregivers who did not report their education level. This inconsistency may be the result of the cited study utilizing a teacher report of behavior problems whereas this study utilized the caregiver report. It may also be due to the fact that the caregiver potentially changed if the child was removed from the home as a result of maltreatment. Therefore, a caregiver with a higher level of education may have more honestly or overreported behavioral problems exhibited by the child in his or her care.

There were four (4) caregiver-level factors related to family structure that were significant predictors of child behavior problems: (a) marital status; (b) number of children in the household; (c) number of changes in caregiver; and (d) being a permanent caregiver. There were surprising results with regard to marital status. Shaw and colleagues (1999) examined four (4) groups of 
caregivers: (a) always 2-parent; (b) to be divorced; (c) already divorced; and (d) always single. They found that the always single group reported significantly higher internalizing and externalizing behavior problems than the always married group. However, this study reported that married caregivers reported significantly higher levels of internalizing behavior problems than the separated/divorced/widowed caregivers, significantly higher externalizing behavior problems than the never married caregivers, and significantly higher total behavior problems than both the separated/divorced/widowed and never married caregivers. This inconsistency may have been related to the change in caregiver as a result of the child being removed from the home. Runyan and colleagues (1998) reported that children with fewer siblings in the home had delayed behavioral development. This suggests that more siblings in the home is related to improved behavioral development and less behavioral problems. This is consistent with the finding reported in chapter 4 that shows that as the number of children in the household increased, behavioral problems as perceived by the caregiver decreased. This may be due to the caregiver being overwhelmed with other children to notice any internalizing behaviors (e.g., depression, withdrawn) or the caregiver may perceive that the child has better behavior than other children in the home resulting in the caregiver minimizing any negative behaviors exhibited by the child included in this study. There was no surprise with regard to the number of changes in caregiver or being a permanent caregiver. The results in this study that reported that the more a child experiences a change in caregiver as well as being in a non-permanent 
setting, the more behavior problems he or she will exhibit speaks to placement stability and is consistent with the literature (Lewis et al., 2007; Proctor, Skriner, Roesch, \& Litrownik, 2010).

All of the other caregiver factors (i.e., physical health, domestic violence, social support, and perception of neighborhood) were statistically significant predictors of child internalizing, externalizing, and total behavior problems. There was a negative relationship between caregiver physical health and child behavior problems. This suggests that caregivers with poorer selfreported physical health reported higher levels of child behavior problems. Physical health problems take a toll on caregivers both physically and emotionally. This may result in an increased level of stress and the caregiver may feel overwhelmed, potentially resulting in a more negative perception of the child's behavior. The results also indicated that domestic violence in the home increased reported behavior problems, which is consistent with the literature (English et al., 2009). With regard to social support, Runyan and colleagues (1998) reported that social support was one of the most important factors for distinguishing between children who were "doing well" from those who were "not doing well." This study confirms this claim, as caregivers who reported lower levels of social support also reported higher levels of behavior problems for the children in their care. The results presented in chapter 4 also suggest that caregivers with a more negative perception of their neighborhood reported higher levels of behavior problems for the children in their care. This is consistent with the literature that states that caregivers who had a negative 
perception of their neighborhood reported a higher level of depression and violence (Stevenson, 1998; Johnson, 1999).

\section{Environmental-level Significant Predictors}

Significant environmental-level predictors included percentage of single parents in a PSU, access to social services per capita in a PSU, and the percentage of Caucasians in a PSU. There were four (4) predictors that were removed from the model due to them being non-significant. These included income, crime, access to health services, and civic engagement. However, the way in which the PSUs were defined may have been the reason why more environmental predictors were not statistically significant. The PSUs included in this study were relatively large areas where the "real" neighborhood effect may not have been captured. Therefore, it is also recommended that future studies include neighborhoods defined as Census blocks or individually-defined areas.

PSUs with a higher percentage of single parents had significantly higher levels of child externalizing behavior problems. This finding was consistent with current research that reports that a higher concentration of single parents, particularly single mothers, resulted in increased behavioral problems for children (Hoffman, 2006). PSUs with more access to social services per capita had significantly higher levels of child internalizing and total behavior problems. This is inconsistent with current research that indicated that lack of access or perceived barriers to services resulted in more behavior problems (Gutman, McLoyd, \& Tokoyawa, 2005). Access to social services per capita in a PSU was defined in this study as the number of civic organizations and number of 
social assistance establishments located in a PSU. Social assistance establishments, or welfare offices, are often located in poorer areas. Poorer areas are associated with higher levels of behavior problems (Hoffman, 2006). Therefore, this initially confusing finding may be explained indirectly by a concentration of poverty in a PSU, which was not a statistically significant predictor of child behavior problems directly. PSUs with a higher percentage of Caucasians had higher levels of externalizing and total behavior problems. This finding was also inconsistent with the literature that states that areas with a higher percentage of minorities reside in poverty stricken areas (Kasarda, 1993;

Quillian, 2003), which have been shown to result in higher levels of behavior problems (Hoffman, 2006). Therefore, this result may be due to the fact that families residing in more affluent neighborhoods generally have less violent crime and delinquent behavior. Therefore, if a child exhibits slightly negative behavior, this may be exacerbated by the caregiver if they are comparing the child with other children in the neighborhood.

\section{Significant Interaction Effects}

There were three (3) interactions that were statistically significant predictors of child behavior problems: (a) percentage of single parents and sexual maltreatment (compared to not substantiated); (b) access to health services per capita and sexual maltreatment (compared to physical maltreatment); (c) percentage of Caucasians and access to health services per capita. 
The percentage of single parents in a PSU had a differential effect on child externalizing behavior problems depending on the type of maltreatment. The difference was noted between children where the maltreatment was unsubstantiated and children who were sexually maltreated (reference category). Children with unsubstantiated cases of child maltreatment had significantly lower externalizing behavior problems than children who were sexually maltreated. All children in the other maltreatment groups showed similar patterns to the sexually maltreated group.

Access to health services per capita within a PSU had a differential effect on child externalizing behavior problems depending on the type of maltreatment. The difference was noted between children where the maltreatment type was physical and where the maltreatment type was sexual (reference category). Children who had experienced physical maltreatment exhibited significantly lower externalizing behavior problems than children who experienced sexual abuse. All children in the other maltreatment groups showed similar patterns to the sexually maltreated group. This indicates that the other types of maltreatment (i.e., sexually maltreated, neglect, "other", and not substantiated) living in PSUs with greater access to health services per capita are more at risk for experiencing externalizing behavior problems than children who are physically maltreated. This may be due to the fact that access to health services included access to social workers, psychiatrists, and community health centers among others. Assuming more utilization of these services as a result of increased access, children are more likely to be diagnosed with one of the commonly diagnosed 
child behavior diagnoses (e.g., oppositional defiant, conduct disorder, ADHD). Caregivers who have children with one of these commonly diagnosed behavior disorders may be more sensitive to behaviors exhibited by their children and consequently more likely to report higher levels of externalizing behavior problems.

Access to health services per capita within a PSU had a differential effect on child internalizing, externalizing, and total behavior problems depending on the percentage of Caucasians in a PSU. Living in areas where there is a low percentage of Caucasians and lower access to health services puts a child more at risk of having behavior problems than living in higher access areas.

Additionally, living in areas with higher access to health services combined with a high percentage of Caucasians puts a child more at risk of having behavior problems. This indicates that caregivers reported higher levels of behavior problems for children residing in PSUs with more access to health services per capita and a higher concentration of Caucasians. This may be the result of living within a privileged environment (e.g., higher percentage of Caucasians) with a lot of access to professional health services (e.g. psychiatrists, psychologists) resulting in behaviors being rated by caregivers as more severe.

\section{Implications}

There are many implications of the study presented in this dissertation. The implications are both micro and macro. Micro implications are those that are directly related to social work practice while macro implications are those related 
to both agency and federal policy. Both practice and policy implications will be discussed in this section.

\section{Practice Implications}

The most glaring practice implication that can be taken from the results presented here is that all children are different and respond differently to the circumstances that they face. Table 28 at the end of chapter 4 clearly shows that there are different predictors for different behavior problems. For example, having a physical disability was predictive of total behavior problems, but not internalizing or externalizing problems. Therefore, interventions must be targeted appropriately in order to effectively and efficiently reduce child behavior problems.

On a child level, the results indicate that social skills are one of the most important predictors of child behavior problems. Children with scores in the lowest $10 \%$ (social skills $=70$ ) were predicted to have externalizing and total behavior problems in the "borderline clinical" range, closely approaching a clinical level. Additionally, the predicted internalizing behavior problems for children with scores in the lowest $10 \%$ (social skills $=70$ ) were approaching the "borderline clinical" level. Therefore, these results suggest that social skills training may be an important factor to consider when developing intervention plans for children presenting with behavior problems. Social skills training can be integrated into therapeutic treatment in the form of modeling and feedback.

A second major finding with respect to the child-level predictors was the impact of exposure to violence on child behavior problems. Children who scored 
in the $90^{\text {th }}$ percentile (exposure to violence score $=11$ ) had scores approaching the "borderline clinical" range. This suggests that not only experiencing maltreatment as normally defined (e.g., physical, sexual, neglect) but simply being exposed to violence in his or her environment results in higher behavior problems. Therefore, this study showed that being exposed to violence (e.g., domestic violence) results in maladaptive child behavior which points to the damage of living in a violent home. Given the large number of predictors included in the model analyzed in this study, it is important to note that exposure to violence ended up being one of the most important predictors of child behavior problems. This suggests that focus on the family and interventions aimed at reducing family violence may prove to be an important intervention strategy to reduce child behavior problems.

The results also indicated that caregivers must be involved in any treatment modality, as evidenced by the number of caregiver-level predictors that proved to be statistically significant predictors of child behavior problems. However, it is important to note that the caregiver was the current caregiver and not necessarily the biological caregiver, which may impact these implications. With that being noted, caregivers who reported higher levels of domestic violence and lower levels of social support also reported a higher level of behavior problems across the board for the children in their care. Therefore, interventions aimed at assisting caregivers with getting out of domestic violence situations, whether in the form of education or resources, as well as improving social support may be 
an important consideration when looking to reduce child behavior problems.

\section{Policy Implications}

There are several policy implications related to the findings presented in this dissertation. The results indicated that having a permanent placement rather than being in an out-of-home setting was paramount. Children who were in a permanent placement had significantly lower behavior problems across the board when compared to children in an out-of-home placement. These results seem to support legislation aimed at reducing the amount of time a child remains in outof-home care without finding a permanent placement, such as the Fostering Connections initiative. The Fostering Connections Act of 2008 focused on finding relatives or other close connections that may increase the likelihood of permanency. The results presented here suggest that placement stability and permanency may help reduce child behavior problems.

The second major policy implication that will be presented focuses on President Obama's Strengthening Communities initiative discussed in chapter 1. This initiative ultimately aims to improve communities and reduce maltreatment and its consequences through five (5) mechanisms: (a) nurturing and attachment, (b) knowledge of parenting and of child and youth development, (c) parental resilience, (d) social connections, and (e) concrete supports for parents. There were two (2) caregiver-level predictors that speak to these mechanisms. Social support, as perceived by the caregiver, decreased child behavior problems. Therefore, building up communities to facilitate community attachment and responsiveness may improve perceived social support thereby reducing 
child behavior problems. Caregiver perception of neighborhood was also a predictor of child behavior. Caregivers with a more favorable perception of their neighborhood also rated the children in their care as having less behavior problems. This suggests that by reducing perceived crime and gang activity and improving perceived safety in a neighborhood may lead to reduced behavior problems for children residing in those areas. These finding support President Obama's initiative and should be examined more diligently.

\section{Conclusion}

\section{Strengths of the Study}

There were many strengths of the study. First, the data utilized in this analysis were panel data on over 5,000 children maltreated or at risk of maltreatment. Researchers followed these children over a period of six (6) years, which allowed for longitudinal analysis that allows researchers to measure change over time. This reduces the threat to internal validity discussed in chapter 3 of this dissertation.

Second, the type of analysis utilized in this dissertation allowed for examination of predictive variables on multiple levels. This allows practitioners, researchers, and policy makers to more accurately and precisely target interventions. The fact that multilevel analysis can account for variations at multiple levels, such as the environment, illuminates the importance of environmental factors on many social problems, including child maltreatment.

Lastly, the sample included in the NSCAW was a nationally representative data set. This increases the generalizability of the results demonstrated in the 
previous chapter. Also, NSCAW researchers took several steps to ensure that the sample was representative and that measurement errors, which are inevitably present in standardized instruments, were minimized.

\section{Limitations of the Study}

There were a few limitations of the study that warrant attention. The first limitation of this study is the fact that some key predictors (e.g., caregiver depression and substance abuse) could not be included in the estimated model due to missingness and distribution, respectively. The literature suggests that both of these variables are a major factor in determining child behavior (Lindsey, Browne, Thompson, Hawley, Graham, Weisbart, Harrington, \& Kotch, 2008; Jaffee et al., 2007; Thompson, 2007; Edwards, Eiden, Colder, \& Leonard, 2006; Black, Papas, Hussey, Dubowitz, Kotch, \& Starr, 2002; Dubowitz, Papas, Black, \& Starr, 2002); however, they had to be eliminated from this analysis.

Secondly, the use of secondary data proved to be a challenge in analyzing the data and interpreting the results. While a codebook was included, there were several variables in which it was difficult to determine actual meaning and certain assumptions had to be made. For example, there were a number of missing data points on marital status that were coded as "legitimate skips"; however, there was no description of what "legitimate skip" meant for that particular variable. Thus, this required assumptions to be made with regard to the meaning of "legitimate skip" that may or may not have been accurate. Also, with regard to the use of secondary data, there was much missingness, which had to be 
handled prior to running any analysis. While decisions were made prudently, up to $20 \%$ of missing values were replaced in a few cases.

There were also limitations with respect to interpretation. Given that caregiver data was collected from the current caregiver rather than the child's biological caregiver, it was difficult to interpret the results related to the caregiver predictors. This may be the reason why several of the caregiver predictors demonstrated results contrary to the current literature. Also, the outcome variables were measured utilizing the $\mathrm{CBCL}$, which was reported by the current caregiver. It was unknown whether that child had been in the care of that specific caregiver for one (1) day or one (1) year at the time of the administration of the CBCL. This would greatly impact the results because it is difficult to rate the behavior of a child after a short period of time.

\section{Future Research}

Future research should include the variables that had to be eliminated from this study due to missingness. As previously mentioned, caregiver depression and substance abuse are key variables in predicting child behavioral problems. Therefore, more diligence in the collection of data for these variables must be done. While the secondary data source utilized in this study was one of the most comprehensive data sets available to child welfare, it was evident that there is still room to grow with respect to secondary data sets for child welfare. Additionally, it may be beneficial to utilize the findings in this study as a springboard into a smaller, more targeted study to really determine the impact of the results presented in this study. 
A follow-up study will build off of the results presented here in order to conduct a more targeted analysis. Taking a smaller sample (e.g., just those with substantiated cases of maltreatment, or those that did not experience any changes in caregiver) and targeting some of those more important predictors of child behavior problems will help tease out the results presented here. Another follow-up study will include a closer examination of child social skills at one time point predicting child behavior problems at the next time period.

Future research should also include a more narrow definition of an individual's environment. While PSUs were utilized in this study to classify individuals living together is some geographic location, it is important that future research utilize zip codes or census tracks to define neighborhoods. Ideally, future research will include participant definition of neighborhoods rather than neighborhoods defined by outsiders. This presents a number of challenges and could potentially be costly, but it would give even a clearer picture of child maltreatment and its impact on child behavioral problems.

Future research should also include a triangulation process in order to get a more comprehensive view of child behavior problems. This study presented here utilized the $\mathrm{CBCL}$, which is a parent/caregiver report instrument. However, there is also the Youth Self Report (YSR) that is completed by the child and the Teacher Report Form (TRF) that is completed by the child's teacher. These have both been shown to be valid with the $\mathrm{CBCL}$. It would be interesting to see how these three (3) raters differ in terms of measuring behavior problems or by 
using an average of the three (3) scores in order to get a more holistic view of behavior problems from the three (3) different sources.

It is also important to now examine the interventions that are utilized to intervene with children who have been maltreated and exhibit behavioral problems. Future research can build upon the findings presented here and determine which services most help children with behavior problems. For example, it was illuminated above that social skills may be the most important factor to consider when intervening with children. Therefore, if interventions aimed at increasing social skills are implemented, what is the impact on behavior problems demonstrated by these children? While the NSCAW data set does include data related to services received, it may be beneficial to collect data via primary collection methods in order to determine which interventions are most effective.

\section{Summary}

As the quote by Mahatma Gandhi at the beginning of this chapter states, "you may never know what results come of your action, but if you do nothing there will be no result." This dissertation has presented one of the most comprehensive and holistic models on child maltreatment and its impact on child behavior problems. It has illuminated factors that have not gained much attention in the literature as strong predictors of child behavior problems (e.g., social skills, perception of neighborhood, and percentage of Caucasians within a PSU) and disenchanted others (e.g., biological caregiver). It is now up to caregivers, social workers, teachers, and politicians to respond to these findings. 
If there is no response, there will be no improvement. With no improvement, the future for these children is grim. As Nelson Mandela once said, "safety and security don't just happen, they are the result of collective consensus and public investment. We owe our children, the most vulnerable citizens in our society, a life free of violence and fear." 


\section{REFERENCES}

Aber, J. L., \& Allen, J. P. (1987). Effects of maltreatment on young children's socioemotional development: An attachment theory perspective. Developmental Psychology, 23(3), 406-414.

Achenbach, T. M. (1991). Manual for the Child Behavior Checklist/4-18 and 1991 Profile. Burlington, VT: University of Vermont Department of Psychiatry.

Adolphs, R. (2002). Neural systems for recognizing emotions. Current Opinion in Neurobiology, 12, 169-177.

Adoption and Safe Families Act (ASFA). P.L. 105-89.

Adoption Assistance and Child Welfare Act. P.L. 96-272.

Ainsworth, M. (1982). Attachment: Retrospect and prospect. In C. M. Parkes and J. Stevenson-Hinde (Eds.), The place of attachment in human behaviour. London: Tavistock.

Ainsworth, M., Blehar, M., Waters, E., \& Wall, S. (1978). Patterns of attachment: Assessed in the strange situation and at home. Hillsdale, NJ: Erlbaum.

Barry, T. D., Dunlap, S. T., Cotton, S. J., Lochman, J. E., \& Wells, K. C. (2005). The influence of maternal stress and distress on disruptive behavior problems in boys. Journal of the Academy of Child and Adolescent Psychiatry, 44(3), 265-273.

Barth, R. P., Wildfire, J., \& Green, R. L. (2006). Placement into foster care and the interplay of urbanicity, child behavior problems, and poverty. American Journal of Orthopsychiatry, 76(3), 358-366.

Baumrind, D. (1994). The social context of child maltreatment. Family Relations, 43(4), 360-368.

Bava, S., Thayer, R., Jacobus, J., Ward, M., Jernigan, T. L., \& Tapert, S. F. (2010). Longitudinal characterization of white matter maturation during adolescence. Brain Research, 1327, 38-46. 
Berger, L. M. (2004). Income, family structure, and child maltreatment risk. Children and Youth Services Review, 26, 725-748.

Beyers, W. \& Seiffge-Krenke, I. (2010). Does identity precede intimacy? Testing Erikson's theory on romantic development in emerging adults of the $21^{\text {st }}$ century. Journal of Adolescent Research, 25, 387-415.

Bowlby, J. (1940). The influence of early environment in the development of neurosis and neurotic character. International Journal of Psychoanalysis, $21,154-178$.

Bowlby, J. (1953). Child care and the growth of maternal love. London: Penguin Books.

Bowlby, J. (1973). Separation: Anxiety and anger (Attachment and loss, vol. 2). London: Hogarth Press.

Bowlby, J. (1988). A secure base: Clinical applications of attachment theory. London: Routledge.

Broadhead, W. E., Gehlbach, S. H., DeGruy, T. V., \& Kaplan, B. H. (1988). The Duke-UNC Functional Social Support Questionnaire: Measurement of social support in family medicine patients. Medical Care, 26(7), 709-723.

Bronfenbrenner, U. (1979). The ecology of human development: Experiments by nature and design. Cambridge, MA: Harvard University Press.

Bronfenbrenner, U. (1994). Ecological models of human development. In International Encyclopedia of Education, Vol. 3, $2^{\text {nd }} \mathrm{Ed}$. Oxford: Elsevier. Retrieved from http://www.psy.cmu.edu/ siegler/35bronfenbrenner94.pdf.

Buchholz, E. S., \& Korn-Bursztyn, C. (1993). Children of adolescent mothers: Are they at risk for abuse? Adolescence, 28, 362-382.

Budd, K. S., Holdsworth, M. J. A., \& HoganBruen, K. D. (2006). Antecedents and concomitants of parenting stress in adolescent mothers in foster care. Child Abuse \& Neglect, 30, 557-574.

Carpenter, L. L., Shattuck, T. T., Tyrka, A. R., Geracioti, T. D., \& Price, L. H. (2011). Effect of childhood physical abuse on cortisol stress response. Psychopharmacology, 214(1), 367-375.

Catalano, S. (2007). Intimate partner violence in the U.S. Bureau of Justice Statistics. Retrieved from http://bjs.ojp.usdoj.gov/content/intimate/ipv.cfm.

Child Abuse and Prevention Act (CAPTA). 42 U.S.C. § 5106g(2). 
Child Welfare Information Gateway (n.d.). Retrieved from http://www.childwelfare.gov/can/factors/contribute.cfm.

Cicchetti, D. (1996). Child maltreatment: Implications for developmental theory and research. Human Development, 39, 18-39.

Cicchetti, D., \& Carlson, V. (Eds.). (1989). Child maltreatment. Theory and research on the causes and consequences of child abuse and neglect. New York: Cambridge University Press.

Cohen, J., Cohen, P., West, S. G., \& Aiken, L. S. (2003). Applied multiple regression/correlation analysis for the behavioral sciences $\left(3^{\text {rd }}\right.$ ed.). Mahwah, NJ: Lawrence Erlbaum Associates.

Coleman, J. S., \& Hoffer, T. B. (1987). Public and private schools: The impact of communities. New York, NY: Basic Books.

Coohey, C., Renner, L. M., Hua, L., Zhang, Y. J., \& Whitney, S. D. (2011). Academic achievement despite child maltreatment: A longitudinal study. Child Abuse \& Neglect, 35(9), 688-699.

Coulton, C. J., Korbin, J. E., Su, M., \& Chow, J. (1995). Community level factors and child maltreatment rates. Child Development, 66, 1262-1276.

Cunningham, S. M. (2003). The joint contribution of experiencing and witnessing violence during childhood on child abuse in the parent role. Violence \& Victims, 18(6), 619-639.

Currenton, S. M., McWey, L. M., \& Bolen, M. G. (2009). Distinguishing maltreating versus nonmaltreating at-risk families: Implications for foster care and early child education interventions. Families in Society, 90(2), 176-182.

Daro, D. (1988). Confronting child abuse: Research for effective program design. New York: The Free Press.

DePaul, J., \& Guibert, M. (2008). Empathy and child neglect: A theoretical model. Child Abuse \& Neglect, 32, 1063-1071.

Dowd, K., Kinsey, S., Wheeless, S., Thissen, R., Richardson, J., Suresh, R., Mierzwa, F., Biemer, P., Johnson, I., Lytle, T., Dolan, M., Hendershott, A., Smith, K., Day, O. (2008). National Survey of Child and Adolescent WellBeing Data File User's Manual. National Data Archive on Child Abuse and Neglect. 
Drake, B., \& Pandey, S. (1996). Understanding the relationship between neighborhood poverty and specific types of child maltreatment. Child Abuse \& Neglect, 20(11), 1003-1018.

Drake, B., Johnson-Reid, M., \& Sapokaite, L. (2006). Rereporting of child maltreatment: Does participation in other public sector services moderate the likelihood of a second maltreatment report? Child Abuse \& Neglect, $30,1201-1226$.

Dubowitz, H., Papas, M. A., Black, M. M., \& Starr Jr., R. H. (2002). Child neglect: Outcomes in high-risk urban preschoolers. Pediatrics, 109(6), 1100-1107.

Dubowitz, H., Pitts, S. C., \& Black, M. M. (2004). Measurement of three major subtypes of child neglect. Child Maltreatment, 9(4), 344-356.

Edwards, E. P., Eiden, R. D., Colder, C., \& Leonard, K. E. (2006). The development of aggression in 18 to 48 month old children of alcoholic parents. Journal of Abnormal Child Psychiatry, 34(3), 409-423.

Éithier, L. S., Lacharité, C., \& Couture, G. (1995). Childhood adversity, parental stress, and depression of negligent mothers. Child Abuse \& Neglect, 19, 619-632.

English, D. J., Graham, J. C., Newton, R. R., Lewis, T. L., Thompson, R., Kotch, J. B., \& Weisbart, C. (2009). At-risk and maltreated children exposed to intimate partner aggression/violence: What the conflict looks like and its relationship to child outcomes. Child Maltreatment, 14(2), 157-171.

English, D. J., Marshall, D. B., \& Stewart, A. J. (2003). Effects of family violence on child behavior and health during early childhood. Journal of Family Violence, 18(1), 43-57.

Erikson, E. H. (1993). Childhood and society. New York, NY: W. W. Norton \& Company, Inc.

Fantuzzo, J. W., Perlman, S. M., \& Dobbins, E. K. (2011). Types and timing of child maltreatment and early school success: A population-based investigation. Children and Youth Services Review, 33(8), 1404-1411.

Farruggia, S. P., Greenberger, E., Chen, C., \& Heckhausen, J. (2006).

Perceived social environment and adolescents' well-being and adjustment: Comparing a foster care sample with a matched sample. Journal of Youth \& Adolescence, 35(3), 330-339. 
Fergusson, D. M., Boden, J. M., \& Horwood, L. J. (2008). Exposure to childhood sexual and physical abuse and adjustment in early adulthood. Child Abuse \& Neglect, 32, 607-619.

Finkelhor, D. \& Jones, L. M. (2004). Explanations for the decline in child sexual abuse cases. Washington, DC: Department of Justice, Office of Justice Programs, Office of Juvenile Justice and Delinquency Prevention.

Flanagan, P., Coll, C. G., Andreozzi, L., \& Riggs, S. (1995). Predicting maltreatment of children of teenage mothers. Archives of Pediatrics and Adolescent Medicine, 149, 451-455.

Fostering Connections to Success and Increasing Adoptions Act. P.L. 110-351.

Francis, K. J., \& Wolfe, D. A. (2008). Cognitive and emotional differences between abusive and non-abusive fathers. Child Abuse \& Neglect, 32, $1127-1137$.

Freisthler, B. (2004). A spatial analysis of social disorganization, alcohol access, and rates of child maltreatment in neighborhoods. Children and Youth Services Review, 26(9), 803-819.

Furstenberg, F. F. \& Hughes, M. E. (1995). Social capital and successful development among at-risk youth. Journal of Marriage and the Family, $57,580-592$.

Garbarino, J. (2005). The consequences of child maltreatment: Biosocial and ecological issues. In R. J. Gelles \& J. B. Lancaster (Eds.). Child abuse and neglect: Biosocial dimensions (pp. 299-315). Brunswick, NJ: Aldine Transactions.

Garbarino, J., \& Sherman, D. (1980). High-risk neighborhoods and high-risk families: The human ecology of child maltreatment. Child Development, $51,188-198$.

Gelles, R. J. (2005). What to learn from cross-cultural and historical research on child abuse and neglect: An overview. In R. J. Gelles \& J. B. Lancaster (Eds.), Child Abuse and Neglect: Biosocial Dimensions (pp. 15-30). New Brunswick: Aldine Transaction.

Goldman, J., Salus, M. K., Wolcott, D., \& Kennedy, K. Y. (2003). A coordinated response to child abuse and neglect: The foundations for practice. Washington, D.C.: U.S. Department of Health and Human Services. Retrieved from, http://www.childwelfare.gov/pubs/usermanuals/foundation/foundatione.cfm 
Graham, J. C., English, D. J., Litrownik, A. J., Thompson, R., Briggs, E. C., \& Bangdiwala, S. I. (2010). Maltreatment chronicity defined with reference to development: Extension of the social adaptation outcomes findings to peer relations. Journal of Family Violence, 25, 311-324.

Gresham, F. M., \& Elliot, S. N. (1990). The Social Skills Rating System. Circle Pines, MN: American Guidance Systems.

Gutman, L. M., McLoyd, V. C., \& Tokoyawa, T. (2005). Financial strain, neighborhood stress, parenting behaviors, and adolescent adjustment in urban African American families. Journal of Research on Adolescence, 15(4), 425-449.

Hartley, C. C. (2004). Severe domestic violence and child maltreatment: Considering child physical abuse, neglect, and failure to protect. Children and Youth Services Review, 26, 373-392.

Hedges, L. V., \& Hedberg, E. C. (2007). Intraclass correlation values for planning group randomized trials in education. Educational Evaluation and Policy Analysis, 29, 60-87.

Hickey, K. S., \& Lyckholm, L. (2004). Child welfare versus parental autonomy: Medical ethics, the law, and faith-based healing. Theoretical Medicine, $25,265-276$.

Hilton, J. M., \& Desrochers, S. (2002). Children's behavior problems in singleparent and married-parent families. Journal of Divorce \& Remarriage, 37(1), 13-36.

Hoffman, J. P. (2006). Family structure, community context, and adolescent problem behaviors. Journal of Youth and Adolescence, 35, 867-880.

Holmes, J. (1993). John Bowlby and attachment theory. New York, NY: Routledge.

Hutchison, E. D. (1990). Child maltreatment: Can it be defined? Social Service Review, 64(1), 60-78.

Jaffee, S. R., Caspi, A., Moffitt, T. E., Polo-Tomás, M., \& Taylor, A. (2007). Individual, family, and neighborhood factors distinguish resilient and nonresilient maltreated children: A cumulative stressors model. Child Abuse \& Neglect, 31, 231-253.

Jaudes, P. K., Ekwo, E., \& VanVoorhis, J. (1995). Association of drug abuse and child abuse. Child Abuse \& Neglect, 19, 1065-1075. 
Johnson, R. M., Kotch, J. B., Catellier, D. J., Winsor, J. R., Dufort, V., Hunter, W., \& Amaya-Jackson, L. (2002). Adverse behavioral and emotional outcomes from child abuse and witnessed violence. Child Maltreatment, $7(5), 179-186$.

Johnson, S. D. (1999). The social context of youth violence: A study of African American youth. International Journal of Adolescent Medicine and Health, 11(3-4), 159-175.

Jones, K. (2012). MCMC training manual. Bristol, UK: Center of Multilevel Modeling.

Jones, L. M., \& Finkelhor, D. (2001). The decline in sexual abuse cases. Washington, DC: Department of Justice, Office of Justice Programs, Office of Juvenile Justice and Delinquency Prevention.

Jones, L. M., Finkelhor, D., \& Kopiec, K. (2001). Why is sexual abuse declining? A survey of state child protection administrators. Child Abuse \& Neglect, 25(9), 1139-1158.

Kalil, A., \& Dunifon, R. (2007). Maternal work and welfare use and child wellbeing: Evidence from 6 years of data from the Women's Employment Study. Children \& Youth Services Review, 29, 742-761.

Kasarda, J. D. (1993). Inner-city concentrated poverty and neighborhood distress: 1970 to 1990. Housing Policy Debate, 4(3), 253-302.

Kaslow, N. J., \& Thompson, M. P. (2008). Associations of child maltreatment and intimate partner violence with psychological adjustment among low SES, African American children. Child Abuse \& Neglect, 32, 888-896.

Kaufman, A. S., \& Kaufman, N. L. (1990). Kaufman Brief Intelligence Test manual $(K-B / T)$. Circle Pines, MN: American Guidance Service.

Kelleher, K., Chaffin, M., Hollenberg, J., \& Fischer, E. (1994). Alcohol and drug disorders among physically abusive and neglectful parents in a community based sample. American Journal of Public Health, 84, 1586-1590.

Kempe, C. H., Silverman, F. N., Steele, B. F., Droegemueller, W., \& Silver, H. K. (1962). The battered-child syndrome. Journal of the American Medical Association, 181(1), 17-24.

Koeske, G. F., \& Koeske, R. D. (1990). The buffering effects of social support on parenting stress. American Journal of Orthopsychiatry, 60(3), 440-451. 
Kreft, I., \& de Leeuw, J. (1998). Introducing multilevel modeling. Thousand Oaks, CA: Sage Publications.

Kring, S. R., Greenberg, J. S., \& Seltzer, M. M. (2010). The impact of health problems on behavior problems in adolescents and adults with autism spectrum disorders: Implications for maternal burden. Social Work in Mental Health, 8(1), 54-71.

Lau, A. S., Leeb, R. T., English, D., Graham, J. C., Briggs, E. C., Brody, K. E., \& Marshall, J. M. (2005). What's in a name? A comparison of methods for classifying predominant type of maltreatment. Child Abuse \& Neglect, 29, 533-551.

Lee, M. R. (2008). Civic community in the hinterland: Toward a theory of rural social structure and violence. Criminology, 46(2), 447-478.

Lewis, E. E., Dozier, M., Ackerman, J., \& Sepulveda-Kozakowski, S. (2007). The effect of placement instability on adopted children's inhibitory control abilities and oppositional behavior. Developmental Psychology, 43(6), $1415-1427$.

Lindsey, M. A., Browne, D. C., Thompson, R., Hawley, K. M., Graham, J. C., Weisbart, C., Harrington, D., \& Kotch, J. B. (2008). Caregiver mental health, neighborhood, and social network influences on mental health needs among African American children. Social Work Research, 32(2), 79-88.

Litrownik, A. J., Lau, A., English, D. J., Briggs, E., Newton, R. R., Romney, S., \& Dubowitz, H. (2005). Measuring the severity of child maltreatment. Child Abuse \& Neglect, 29, 553-573.

Luke, D. A. (2004). Multilevel modeling. Thousand Oaks, CA: Sage Publications, Inc.

Main, M., \& Solomon, J. (1986). Discovery of an insecure disorganized / disoriented attachment pattern: Procedures, findings, and implications for the classification of behavior. In T. B. Brazelton \& M. W. Yogman (Eds.), Affective development in infancy (pp. 95-124). Norwood, NJ: Ablex Publishing.

Manly, J. T., Kim, J. E., Rogosch, F. A., \& Cicchetti, D. (2001). Dimensions of child maltreatment and children's adjustment: Contributions of developmental timing and subtype. Development \& Psychopathology, 13, 759-782. 
Manns, J. R., \& Eichenbaum, H. (2006). Evolution of declarative memory. Hippocampus, 16, 795-808.

McCormick, C. M., \& Matthews, I. Z. (2010). Adolescent development, hypothalamic-pituitary-adrenal function, and programming of adult learning and memory. Progress in Neuro-Psychopharmacology \& Biological Psychiatry, 34, 756-765.

McGuigan, W. M., \& Pratt, C. C. (2001). The predictive impact of domestic violence on three types of child maltreatment. Child Abuse \& Neglect, 25, 869-883.

McLeod, J. D., \& Nonnemaker, J. M. (2000). Poverty and child emotional and behavioral problems: Racial/ethnic differences in processes and effects. Journal of Health and Social Behavior, 41, 137-161.

Merritt, D. H. (2009). Child abuse potential: Correlates with child maltreatment rates and structural measures of neighborhoods. Children and Youth Services Review, 31, 927-934.

Meyers, J. E. B. (2006). Child protection in America: Past, present, and future. New York, NY: Oxford University Press, Inc.

Meyers, L. S., Gamst, G., \& Guarino, A. J. (2006). Applied multivariate research: Design and interpretation. Thousand Oaks, CA: Sage Publications, Inc.

Miller, G. E., Chen, E., \& Zhou, E. S. (2007). If it goes up, must it come down? Chronic stress and the hypothalamic-pituitary-adrenocortical axis in humans. Psychological Bulletin, 133(1), 25-45.

Moerbeek, M. (2004). The consequences of ignoring a level of nesting in multilevel analysis. Multivariate Behavioral Research, 39, 129-149.

Narang, D. S., \& Contreras, J. M. (2005). The relationships of dissociation and affective family environment with the intergenerational cycle of child abuse. Child Abuse \& Neglect, 29, 683-699.

Payne, M. (1997). Modern social work theory $\left(2^{\text {nd }}\right.$ ed.). Chicago, IL: Lyceum Books, Inc.

Payne-Sturges, D. Sanders, W., Zenick, H., \& Wells, C. (2006). We cannot do it alone: Building a multi-systems approach for assessing and eliminating environmental health disparities. Environmental Research, 102, 141-145. 
Pears, K. C., Kim, H. K., \& Fisher, P. A. (2008). Psychosocial and cognitive functioning of children with specific profiles of maltreatment. Child Abuse \& Neglect, 32, 958-971.

Plybon, L. E., \& Kliewer, W. (2001). Neighborhood types and externalizing behavior in urban school-age children: Tests of direct, mediated, and moderated effects. Journal of Child and Family Studies, 10(4), 419-437.

Proctor, L. J., Skriner, L. C., Roesch, S., \& Litrownik, A. J. (2010). Trajectories of behavioral adjustment following early placement in foster care: Predicting stability and change over 8 years. Journal of the Academy of Child \& Adolescent Psychiatry, 49(5), 464-473.

Putnam, R. D. (2000). Bowling alone: The collapse and revival of American community. New York, NY: Simon \& Schuster.

Quillian, L. (2003). How long are exposures to poor neighborhoods? The longterm dynamics of entry and exit from poor neighborhoods. Population Research and Policy Review, 22(3), 221-249.

Rasbash, J., Browne, W., Healy, M., Cameron, B., \& Charlton, C. (2010). MLwiN (version 2.25) [Computer software].

Raudenbush, S. W., \& Bryk, A. S. (2002). Hierarchical linear models: Applications and data analysis methods $\left(2^{\text {nd }}\right.$ ed. $)$. Thousand Oaks, CA: Sage Publications, Inc.

Reinert, D. F., \& Edwards, C. E. (2009). Childhood physical and verbal mistreatment, psychological symptoms, and substance use: Sex differences and the moderating role of attachment. Journal of Family Violence, 24, 589-596.

Roazen, P. (1976). Erik H. Erikson: The power and limits of a vision. New York, NY: Free Press.

Root, C., MacKay, S., Henderson, J., DelBove, G., \& Warling, D. (2008). The link between maltreatment and juvenile fire setting: Correlates and underlying mechanisms. Child Abuse \& Neglect, 32, 161-176.

Rosenthal, J. A., \& Curiel, H. F. (2006). Modeling behavioral problems of children in the child welfare system: Caregiver, youth, and teacher perceptions. Children \& Youth Services Review, 28, 1391-1408.

Rubin, A., \& Babbie, E. R. (2008). Research methods for social work $\left(6^{\text {th }}\right.$ ed. $)$. Belmont, CA: Thompson Brooks/Cole. 
Runyan, D. K., Hunter, W. M., Socolar, R. R. S., Amaya-Jackson, L., English, D., Landsverk, J., Dubowitz, H., Browne, D. H., Bangdiwala, S. I., \& Matthew, R. M. (1998). Children who prosper in unfavorable environments: The relationship to social capital. Pediatrics, 101(1), 12-18.

Ryan, J. P., Hernandez, P. M., \& Herz, D. (2007). Developmental trajectories of offending for male adolescents leaving foster care. Social Work Research, 31(2), 83-93.

Saluja, G., Kotch, J., \& Lee, L-C (2003). Effects of child abuse and neglect: Does social capital really matter? Archives of Pediatrics and Adolescent Medicine, 157, 681-686.

Sampson, R. J., Morenoff, J. D., \& Earls, F. (1999). Beyond social capital: Spatial dynamics of collective efficacy for children. American Sociological Review, 64, 633-660.

Scannapieco, M., Connell-Carrick, K., \& Painter, K. (2007). In their own words: Challenges facing youth aging out of foster care. Child and Adolescent Social Work Journal, 24(5), 423-435.

Schlein, S. (Ed.) (1987). A way of looking at things: Selected papers of Erik H. Erikson 1930-1980. New York, NY: W. W. Norton \& Company, Inc.

Schneider, M. W., Ross, A., Graham, J. C., \& Zielinski, A. (2005). Do allegations of emotional maltreatment predict developmental outcomes beyond that of other forms of maltreatment? Child Abuse \& Neglect, 32, 682-692.

Shaffer, A., Huston, L., \& Egeland, B. (2008). Identification of child maltreatment using prospective and self-report methodologies: A comparison of maltreatment incidence and relation to later psychopathology. Child Abuse \& Neglect, 32, 682-692.

Shaffer, A., Yates, T. M., \& Egeland, B. R. (2009). The relation of emotional maltreatment to early adolescent competence: Developmental processes in a prospective study. Child Abuse \& Neglect, 33, 36-44.

Shahinfar, A., Fox, N. A., \& Leavitt, L. A. (2000). Preschool children's exposure to violence: Relation of behavior problems to parent and child reports. American Journal of Orthopsychiatry, 70, 115-125.

Shaw, D. S., Winslow, E. B., \& Flanagan, C. (1999). A prospective study of the effects of marital status and family relations on young children's adjustment among African American and European American families. Child Development, 70(3), 742-755. 
Shin, S. H., Edwards, E. M., \& Heeren, T. (2009). Child abuse and neglect: Relations to adolescent binge drinking in the national longitudinal study of Adolescent Health (AddHealth) Study. Addictive Behaviors, 34, 277-280.

Singer, J. D., \& Willett, J. B. (2003). Applied longitudinal data analysis: Modeling change and event occurrence. New York: Oxford University Press.

Snijders, T. A. (2005). Power and sample size in multilevel linear models. In B. S. Everett \& D. C. Howell (Eds.), Encyclopedia of Statistics in Behavioral Science (Vol. 3, pp. 1570-1573). Chichester, U.K.: Wiley.

Snijders, T., \& Bosker, R. (1999). Multilevel analysis: An introduction to basic and advanced multilevel modeling. Thousand Oaks, CA: Sage Publications.

Spybrook, J., Raudenbush, S. W., Liu, X., Congdon, R., \& Martinez, A. (2008). Optimal design for longitudinal and multilevel research: Documentation for the "Optimal Design" software. Ann Arbor: Survey Research Center of the Institute of Social Research, University of Michigan.

Stahmer, A., Hurlburt, M., Horwitz, S. M., Landsverk, J., Zhang, J., \& Leslie, L. K. (2009). Associations between intensity of child welfare involvement and child development among young children in child welfare. Child Abuse \& Neglect, 33, 598-611.

Straus, M. A., Hamby, S. L., Boney-McCoy, S., \& Sugarman, D. B. (1996). The Revised Conflict Tactics Scale (CTS2): Development and preliminary psychometric data. Journal of Family /ssues, 17(3), 283-316.

Stevenson, H. C. (1998). Raising safe villages: Cultural-ecological factors that influence the emotional adjustment of adolescents. Journal of Black Psychology, 24(1), 44-59.

Sullivan, P. M., \& Knutson, J. F. (2000). Maltreatment and disabilities: A population-based epidemiological study. Child Abuse \& Neglect, 24, $1257-1273$.

Tabachnick, B. G., \& Fidell, L. S. (2007). Using multivariate statistics ( $5^{\text {th }}$ ed.). Boston, MA: Pearson Education, Inc.

Thomaes, K., Dorrepaal, E., Draijer, N., de Ruiter, M. B., van Balkom, A. J., Smit, J. H., \& Veltman, D. J. (2010). Reduced anterior cingulate and orbitofrontal volumes in child abuse-related complex PTSD. Journal of Clinical Psychiatry, 71(12) 1636-1644. 
Thompson, R. (2007). Mothers' violence victimization and child behavior problems: Examining the link. American Journal of Orthopsychiatry, $77(2), 306-315$.

Thompson, R., \& May, M. A. (2006). Caregivers' perceptions of child mental health needs and service utilization: An urban 8-year old sample. Journal of Behavioral Health Services \& Research, 33(4), 474-482.

Tout, K., Zaslow, M. J., Mariner, C. L., \& Halle, T. (1998). Interviewer ratings of mother-child interaction and the home environment in the context of survey research: Contributions and concerns (Methods Working Paper No. 98.5). Washington, DC: Child Trends, Inc.

U.S. Department of Health and Human Services (1999). Blending perspectives on building common ground: $A$ report to Congress on substance abuse and child protection. Washington, D.C.: U.S. Government Printing Office.

U.S. Department of Health and Human Services, Administration for Children and Families, Administration on Children, Youth and Families, Children's Bureau (2009). Child Maltreatment 2007. Washington, DC: U.S. Government Printing Office.

U.S. Department of Health and Human Services, Administration for Children and Families, Administration on Children, Youth and Families, Children's Bureau (2010). Child Maltreatment 2009. Washington, DC: U.S. Government Printing Office.

U.S. Department of Health and Human Services, Administration for Children and Families, Administration on Children, Youth and Families, Children's Bureau (2011). Child Maltreatment 2010. Washington, DC: U.S. Government Printing Office.

U.S. Department of Health and Human Services, Administration for Children and Families, Administration on Children, Youth and Families, Children's Bureau (2011). Strengthening Families and Communities. Washington, DC: U.S. Government Printing Office.

van Harmelen, A-L, van Toi, M-J, van der Wee, N. J. A., Veltman, D. J., Aleman, A., Spinhoven, P., van Buchem, M. A., Zitman, F. G., Penninx, B. W. J. H., \& Elzinga, B. M. (2010). Reduced medial prefrontal cortex volume in adults reporting childhood emotional maltreatment. Biological Psychiatry, 68(9), 832-838. 
Walsh, C., MacMillan, H., \& Jamieson, E. (2002). The relationship between parental psychiatric disorder and child physical and sexual abuse:

Findings from the Ontario Health Supplement. Child Abuse \& Neglect, 26, $11-22$.

Wang, C-T, \& Holton, J. (2007). Total estimated cost of child abuse and neglect in the United States. Chicago, IL: Prevent Child Abuse America. Retrieved on October 16, 2010 from http://www.preventchildabuse.org/about us/media release/pcaa pew ec onomic impact study final.pdf.

Watkins, S. A. (1990). The Mary Ellen myth: Correcting child welfare history. Social Work, 35(6), 500-503.

Wells, S. J., Downing, J., \& Fluke, J. (1991). Responding to reports of child abuse and neglect. Child and Youth Services, 15(2), 63-72.

Weston, C. S. E. (2012). Another major function of the anterior cingulate cortex: The representation of requirements. Neuroscience and Biobehavioral Reviews, 36, 90-110.

Wilson, M., \& Daly, M. (2005). Risk of maltreatment of children living with stepparents. In R. J. Gelles \& J. B. Lancaster (Eds.), Child Abuse and Neglect: Biosocial Dimensions (pp. 215-232). New Brunswick: Aldine Transaction.

Zuravin, S., McMillen, C., DePanfilis, D., \& Risley-Curtiss, C. (1996). The intergenerational cycle of child maltreatment: Continuity versus discontinuity. Journal of Interpersonal Violence, 11(3), 315-334. 


\title{
CURRICULUM VITAE
}

\author{
April L. Murphy
}

\section{Education:}

\begin{abstract}
Graduate: $\quad$ University of Louisville
Specialization: Child Welfare

PhD in progress 2008-2012

Dissertation: A holistic examination of the impact of child maltreatment on child behavioral outcomes: $A$ longitudinal multilevel analysis
\end{abstract}

\section{Florida State University}

Specialization: Social Policy and Administration

MSW August 2007

Undergraduate: University of Louisville

Major: Economics

Minor: Finance

\section{B.S. December 2003}

\section{Academic Positions:}

University of Louisville

Kent School of Social Work

Fall 2010-present, Adjunct Instructor

Jefferson Community College

Spring 2008, Spring 2009-Fall 2011, Adjunct Instructor

University of Louisville 2009-present, Research Assistant for

Kent School of Social Work

Dr. Crystal Collins-Camargo

Florida State University

2005-2006, Research Assistant

School of Social Work

Florida State University

2004-2005, Teaching Assistant to Ross

Department of Economics

Fabricant in "Principles of Microeconomics" 
Undergraduate Courses Taught: The Family (SWK275)

Graduate Courses Taught:

Research Methodology \& Design (SW626)

Advanced Research Practice I (SW668)

Advanced Research Practice II (SW669)

\section{Post-Masters Social Work Experience:}

Signature Research Institute Research Methodologist

\author{
Maryhurst \\ Youth Counselor
}

02/2012 - present

Assist in the identification and writing of appropriate grants. Provide research services, including the development of research methodology and statistical analysis. Oversee the implementation of data collection to ensure consistency and accuracy of data. Create professional reports outlining the developed methodology, statistical analysis, findings, recommendations, and/or implications of results.

Seven Counties Services, Inc. 05/2011-12/2011 Senior Social Worker

Provided in-home therapy for children and their families. Primarily utilized $\mathrm{CBT}, \mathrm{MI}$, and play therapy techniques to improve child behavior and decrease family conflict. Developed individualized treatment goals that met medical necessity and completed all required paperwork in a timely manner.

10/2007-06/2009, 02/2010-10/2010 Provided support for adolescent girls in a secured treatment facility. Ensured that daily needs were met for the girls in the treatment facility. Completed paperwork, as assigned, in order to remain in compliance with state regulations. Assigned short-term goals for my assigned mentee. Mentored girls in my assigned dorm, going over weekly goals and providing them with the tools to achieve set goals. 
Senior II Youth Counselor

Senior I Youth Counselor

Center for Women \& Families Housing Advocate-Outreach
In addition to the above responsibilities, also provided support to staff and assisted in treatment decisions. Assigned staff tasks weekly and ensured those tasks were being completed. Responsible for completing all client discharge summaries as they were discharged from the facility in a timely manner.

In addition to the above mentioned responsibilities, also provided support to the supervisor and assisted with maintaining a safe dorm environment. Responsible for assisting staff in leading structured activities in a dorm setting. Completed all Utilization Reviews in order to maintain appropriate leveling of clients. Ensured that all staff were completing appropriate paperwork to remain in compliance with state regulations. Facilitated staff meetings in the absence of the supervisor. Maintained accurate records of client personal and clothing funds.

01/2008-06/2008

Provided case management to clients in the Outreach Leasing Program.

Developed monthly spending plans with clients and held clients accountable for following the developed budget.

Assisted client in setting monthly goals to reach a point of self-sufficiency by the end of the program. Communicated with other agencies in the outreach counties in order to coordinate services for clients.

\section{Additional Social Work Experience}

DISC Village, Inc.

Juvenile Drug Court Counselor
01/2006-07/2007

Conducted biopsychosocial assessments of new clients and determined focus of treatment. Provided individual counseling using 
Civil Citation

appropriate theories, such as cognitivebehavioral therapy, strengths-based therapy, and task-oriented approaches. Facilitated group counseling sessions and educated clients about substance abuse and the effects substance abuse has on achieving their goals. Provided family counseling sessions on a biweekly basis and assisted families in obtaining necessary resources in the community. Reported to the Juvenile Drug Court Judge on client progress and collaboratively determined appropriate sanctions for noncompliance. Developed progress notes and maintained up-to-date case management of caseload.

Assisted with research and data regarding the Civil Citation Program. Completed monthly and quarterly reports utilizing Microsoft Word and Excel. Assisted with personnel procedures and documentation. Assumed a lead role in communitybased projects.

\section{Grant Experience:}

United States Department of Health and Human Services, Administration for Children and Families, Administration for Children, Youth, and Families, Children's Bureau. Kentucky Diligent Recruitment of Families for Children in the Foster Care System. Crystal Collins-Camargo (PI). Responsible for evaluation of Project MATCH (Making Appropriate and Timely Connections for Children). Partnership with Kentucky Department for Community-Based Services, Murray State University, University of Kentucky and University of Louisville. Funding Cycle: October 2008-September 2013.

April 2009 - present, Graduate Assistant, University of Louisville, Kent School of Social Work: Work with project team includes assistance with evaluation team; responsible for data entry, assisting with instrument development, data analysis, report writing and dissemination. 


\section{Publications}

Collins-Camargo, C., Sullivan, D. \& Murphy, A., Use of data to assess performance and promote outcome achievement by public and private child welfare agency staff, Children and Youth Services Review (2010), doi: 10.1016/j.childyouth.2010.09.016

Collins-Camargo, C. E., Sullivan, D. J., \& Murphy, A. L. (2010). Promoting supervisory development in child welfare: Utilization of 360-degree evaluation. Professional Development, 13(2), 15-32.

\section{Technical Reports}

Grimes, M., Collins-Camargo, C.E., Sullivan, D.J., Murphy, A.L., Hall, J.G., Morris, J.L., Crump, C.A. \& Kilby, P. (2009, June). Project MATCH Phase II Plan: A collaboration between Kentucky Cabinet for Health and Family Services, University of Kentucky, University of Louisville, and Murray State University. Prepared for Department for Health and Human Services, Administration for Children and Families, Children's Bureau. Washington, DC.

\section{Book Reviews}

Murphy, A. L. (2010). Gisela Hauss and Dagmar Schulte (eds): Amid Social Contradictions: Towards a History of Social Work in Europe. Voluntas, 21, 135-136. DOI 10.1007/s11266-009-9115-y

\section{Articles Under Review:}

Murphy, A. L., Sar, B. K., \& Faul, A. C. Ethical principles role in predicting social work students' attitudes toward poverty. Journal of Teaching in Social Work.

Murphy, A., van Zyl, R., Collins-Camargo, C., \& Sullivan, D. Assessing systemic barriers to permanency achievement for children in out-of-home care: Validation of the Child Permanency Barriers Scale. Child Welfare.

\section{Presentations}

Murphy, A. L., Sar, B.K., \& Faul, A.C. (2011). The role of ethical principles in predicting social work students' attitude toward poverty. $57^{\text {th }}$ CSWE Annual Program Meeting, Atlanta, Georgia, Oct 27-30. 
Conferences Attended (selected)

Social Welfare Action Alliance, Poor People's Economic Human Rights Campaign \& Women in Transition. Building the Unsettling Force: A National Conference to End Poverty. Spalding University, Louisville, KY. (07/2009)

Seventh International Amsterdam Conference on "Multilevel Analysis." Utrecht University, Department of Methodology and Statistics. The Netherlands. (04/2009)

\section{Professional Organizations}

Gerontological Society of America

Society for Social Work and Research

Social Welfare Action Alliance

Council on Social Work Education

International Association of Schools of Social Work

National Association of Social Workers 2012-present

2011-present 2009-present 2008-present 2008-present

2011-2012 